\title{
FUNCTIONAL ROLE OF BETALAINS IN DISPHYMA AUSTRALE UNDER SALINITY STRESS
}

\author{
BY \\ GAGANDEEP JAIN
}

A thesis submitted to the Victoria University of Wellington

In fulfillment of the requirements for the degree of Doctor of Philosophy

Victoria University of Wellington 
"An understanding of the natural world and what's in it is a source of not only a great curiosity but great fulfillment"

-- David Attenborough 


\section{Abstract}

Foliar betalainic plants are commonly found in dry and exposed environments such as deserts and sandbanks. This marginal habitat has led many researchers to hypothesise that foliar betalains provide tolerance to abiotic stressors such as strong light, drought, salinity and low temperatures. Among these abiotic stressors, soil salinity is a major problem for agriculture affecting approximately $20 \%$ of the irrigated lands worldwide. Betacyanins may provide functional significance to plants under salt stress although this has not been unequivocally demonstrated. The purpose of this thesis is to add knowledge of the various roles of foliar betacyanins in plants under salt stress. For that, a series of experiments were performed on Disphyma australe, which is a betacyanic halophyte with two distinct colour morphs in vegetative shoots.

In chapter two, I aimed to find the effect of salinity stress on betacyanin pigmentation in $D$. australe and it was hypothesised that betacyanic morphs are physiologically more tolerant to salinity stress than acyanic morphs. Within a coastal population of red and green morphs of $D$. australe, betacyanin pigmentation in red morphs was a direct result of high salt and high light exposure. Betacyanic morphs were physiologically more tolerant to salt stress as they showed greater maximum $\mathrm{CO}_{2}$ assimilation rates, water use efficiencies, photochemical quantum yields and photochemical quenching than acyanic morphs. Contrary to this, the green morphs, although possessing the ability to synthesise betalains in flower petals, did not produce betalains in vegetative shoots in response to salt stress. Moreover, green morphs, in terms of leaf photosynthesis, performed poorly under salinity stress.

In chapter three I further investigated the physiological benefit of betacyanin accumulation in $D$. australe. I postulated that betacyanin in the leaves of $D$. australe can protect the salt stressed chloroplasts from harmful excessive light by absorbing significant amount of radiation. To test this, a novel experimental approach was used; the key biosynthetic step for betacyanin synthesis was identified, which was deficient in vegetative shoots of the green morphs. By supplying the product of this enzymatic reaction, L-DOPA, betacyanin synthesis could be induced in the leaves of green morphs. This model system was used to compare the photoprotective responses of red vs. green leaves. The L-DOPA induced betacyanic leaves showed similar responses (such as 
smaller reductions and faster recoveries of PSII and less $\mathrm{H}_{2} \mathrm{O}_{2}$ production than in the green leaves) to naturally betacyanic leaves when exposed to high light and salinity. The differences in photoinhibition between red and green leaves were attributed to the light absorbing properties of betacyanins. L-DOPA treated and naturally red leaves showed lower photoinactivation than green leaves when exposed to white or green light, although not when exposed to monochromatic (red) light.

In chapter four, I used a similar experimental model to that in the third chapter and showed that other than photoprotection, betacyanins in leaves may be involved in salt tolerance by enhancing toxic ion ( such as $\mathrm{Na}^{+}$) sequestration in betacyanic epidermal cells, storing $\mathrm{Na}^{+}$away from sensitive mesophyll tissue. The $\mathrm{Na}^{+}$localization between red and green leaves was compared after salinity treatment by using a sodium binding stain (SBFI-AM) and Cryo-SEM analysis. LDOPA treated and natural red leaves sequestered $\mathrm{Na}^{+}$ions to the epidermal cell layer. In contrast, green leaves retained $\mathrm{Na}^{+}$in the mesophyll tissue, which suggested that red leaves were better equipped to tolerate salt-specific effects. Therefore, betacyanic plants were more tolerant to applied salinity stress and showed relatively higher growth rates than green morphs.

The findings of this thesis provide a significant contribution to our understanding of the role of betacyanins in plants under salinity stress. My data suggest that the multi-faceted properties of betacyanins (such as their photoprotective function, and their involvement in sequestration of toxic ions) clearly provide a benefit to plants under salinity stress. 


\section{Format of the thesis}

This thesis is written as a collection of papers intended for publication. As such, there is inevitably some repetition in the introductions and discussions. Chapters 2 and 3 have already been published. Since English is not my primary language, these chapters benefited substantially from editorial assistance from my supervisors; however, the experimental design, analysis and interpretation are entirely my own work.

\section{Publications}

\section{Chapter 2}

Jain, G., Gould, K.S., 2015. Functional significance of betalain biosynthesis in leaves of Disphyma australe under salinity stress. Environ. Exp. Bot. 109, 131-140. doi:10.1016/j.envexpbot.2014.09.002

\section{Chapter 3}

Jain, G., Schwinn, K.E., Gould, K.S., 2015. Betalain induction by L -DOPA application confers photoprotection to saline-exposed leaves of Disphyma australe. New Phytol. Doi: 10.1111/nph.13409

\section{Appendix 1}

Jain, G., Gould, K.S., 2015. Are betalain pigments the functional homologues of anthocyanins in plants? Environ. Exp. Bot. doi: 10.1016/j.envexpbot.2015.06.002 


\section{Acknowledgements}

First of all, I would like to thank my primary supervisor, Kevin Gould, for his guidance, and support through-out my PhD. There were times when my research went a bit off-road, Kevin's constant encouragement and inspiration helped me to bring it back to the right path. I would also like to thank Kathy Schwinn, Kevin Davies, Ken Ryan and Stephen Hartley for the scientific advice they provided for my research. Also, thanks to Karl Yager, Luke Cooney, Ignatius Menzies, Marco Landi, Maheshini, Emma Gibbin and Shaun Wilkinson, who shared office and laboratory space with me and made this journey less-stressful.

During my research, I have received a great practical assistance from the technical staff of Victoria University of Wellington. In particular, I would like to thank, Lesley Milicich for assistance in glass house planting, Derek Heath for his help in HPLC, Sushila Pillai and Richard Crerar for assistance with Fluorescence-microscopy, David Flynn for assisting me in Cryo-SEM analysis and Chris Thorn for providing various lab equipments. I would also like to thank, Sandra Taylor, Marry Murray, Mark Stephen, Paul Marsden, Patricia Stein and Lesley Thompson for administrative assistance during my $\mathrm{PhD}$.

I thank Wellington Botanical Society and Victoria University of Wellington for the financial assistance during my $\mathrm{PhD}$.

Lastly, I would like to thank my family for their love and support. My father, Rashpal Jain, uncle Mahavir Jain, brothers, Vivek and Sushil for the financial help and inspiration to keep on working hard. I owe many thanks to my wife, Gunjan Gera, for her tolerance and patience. This thesis would not have been possible without her continuous support and encouragement during all the ups and downs of my $\mathrm{PhD}$. 


\section{Table of Contents}

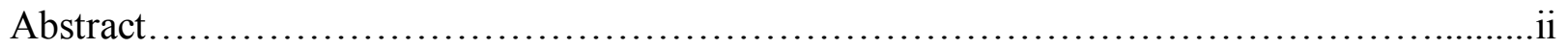

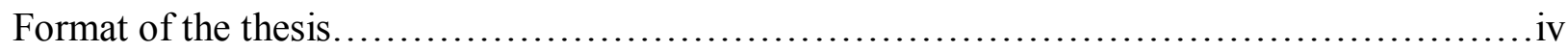

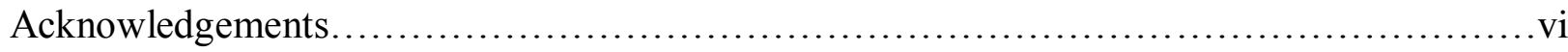

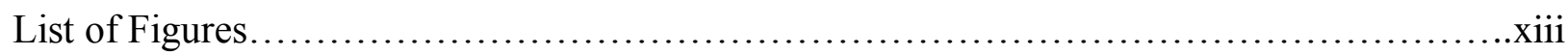

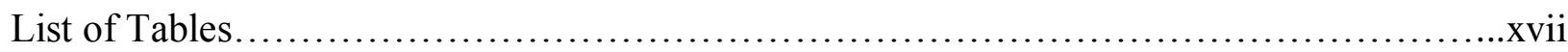

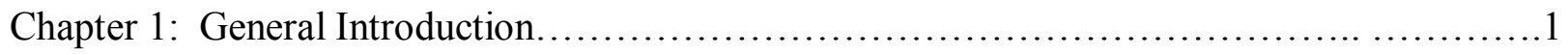

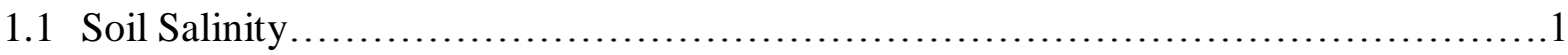

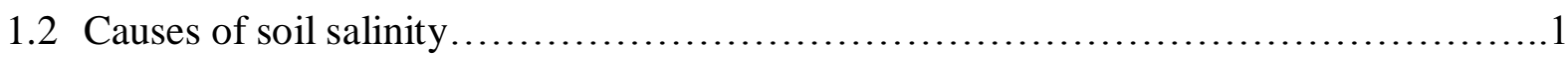

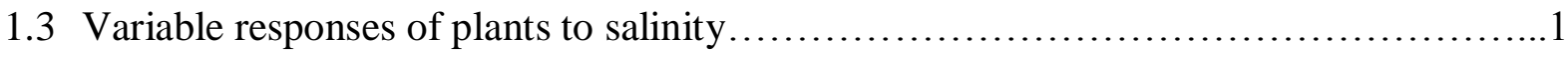

1.4 Physiological impact of salt stress in plants.......................................

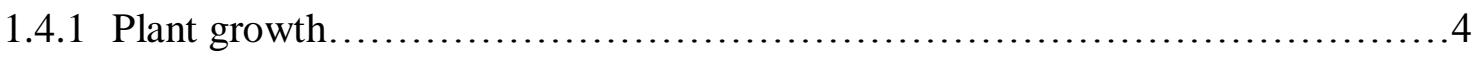

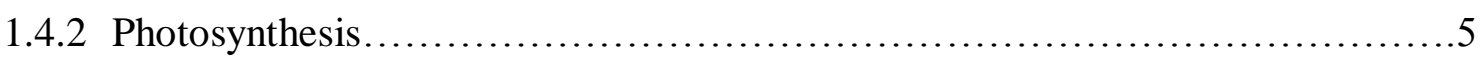

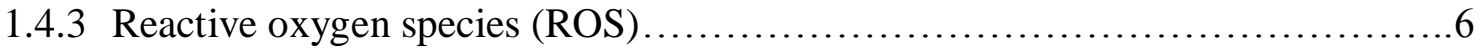

1.4.4 Nutritional imbalance......................................................

1.5 Halophytes: as substitute for crops of saline soil................................. 7

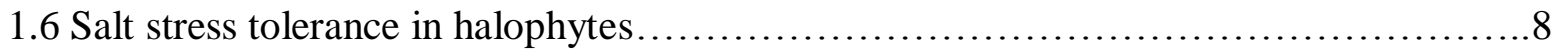

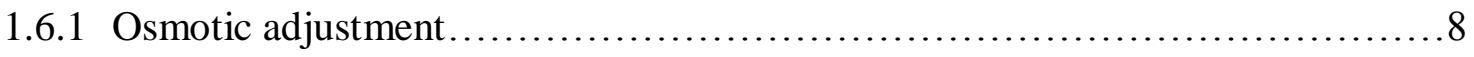

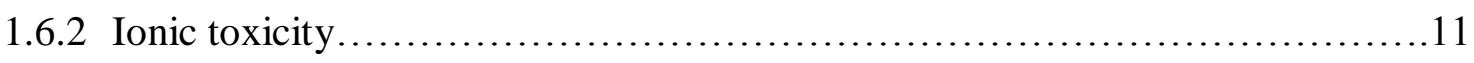

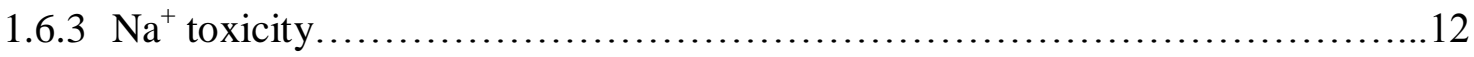

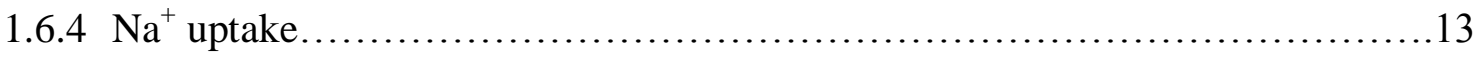

1.6.5 $\mathrm{Na}^{+}$homeostasis in the cytosol........................................... 17

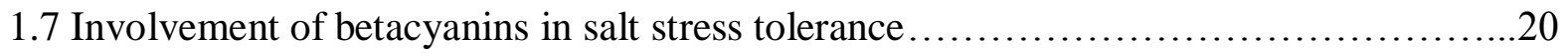

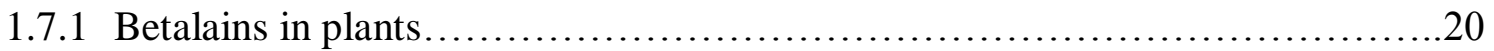

1.7.2 Biochemical structure and distribution in plants...........................20

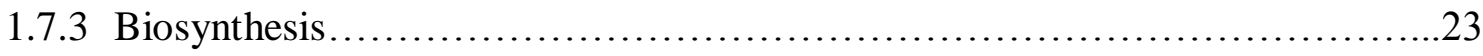

1.8 Addressing the functional significance of betacyanins under salinity stress.............25

1.8.1 Disphyma australe: an ideal system to test the functional significance of betacyanin synthesis under salt stress ...................................26 
1.8.2 Aims and objectives of the thesis....

Chapter 2: Functional significance of betalain biosynthesis in leaves of Disphyma australe under

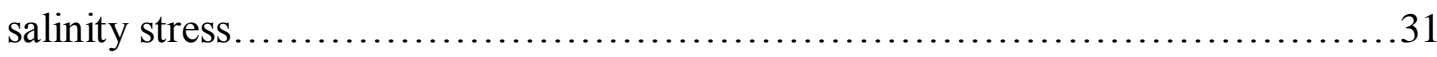

2.1 Abstract.....................................................................

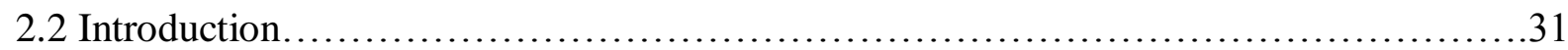

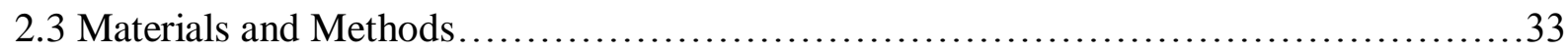

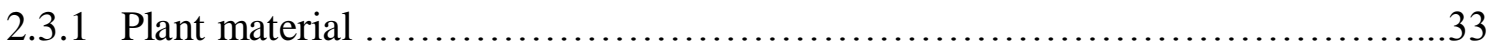

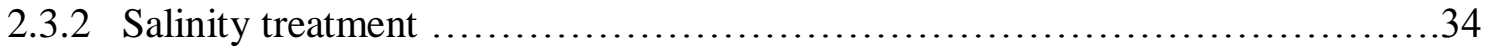

2.3.3 Pigment extraction and quantification..................................

2.3.4 Gas exchange.....................................................

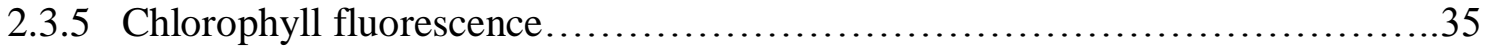

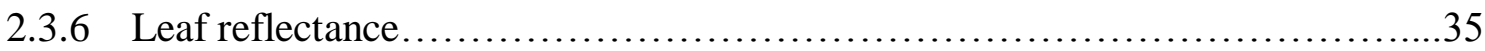

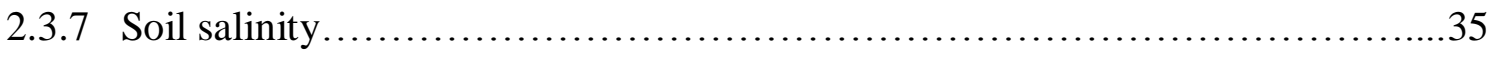

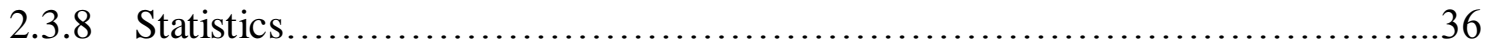

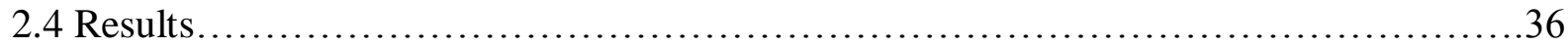

2.4.1 Betalain distribution............................................... 36

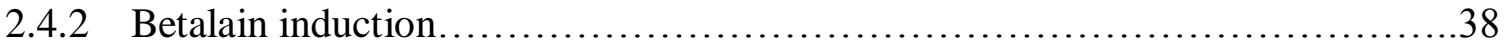

2.4.3 Betalain profile characterization....................................... 39

2.4.4 Chlorophyll and carotenoid contents..................................41

2.4.5 Gas exchange and water relations..................................... 43

2.4.6 Chlorophyll fluorescence.............................................. 45

2.4.7 Leaf reflectance................................................. 47

2.4.8 Substrate salinity ............................................... 48

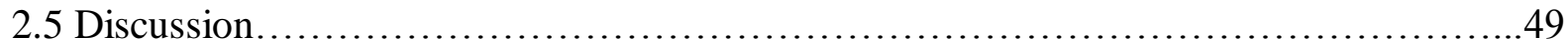

2.5.1 Up-regulation of betalain synthesis ................................50

2.5.2 Photoabatement by betalains..................................... 50

2.5.3 Avoidance of physiological drought by red plants ..........................

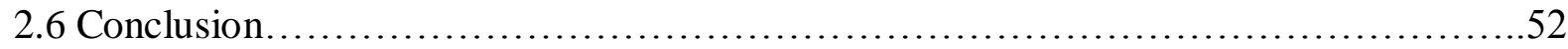

Chapter 3: Betalain induction by L-DOPA application confers photoprotection to saline-exposed leaves of Disphyma australe ............................................ 53

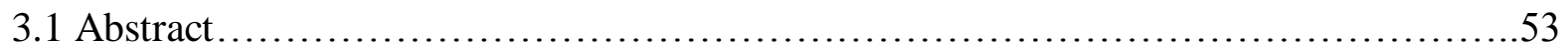




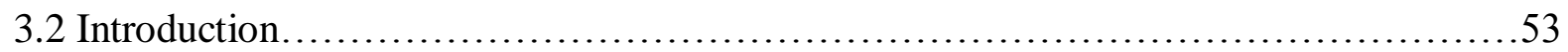

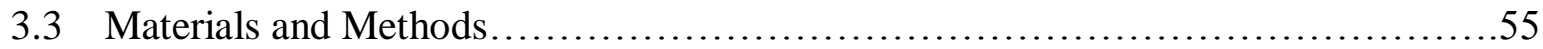

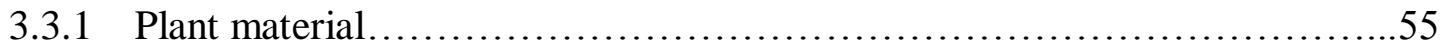

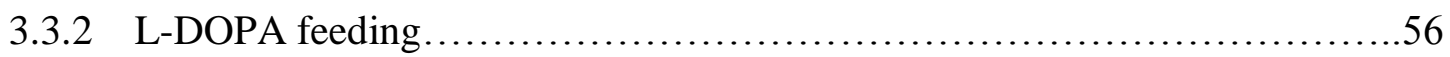

3.3.3 Betalain extraction and quantification...................................56

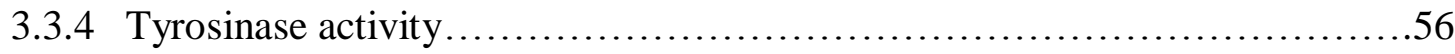

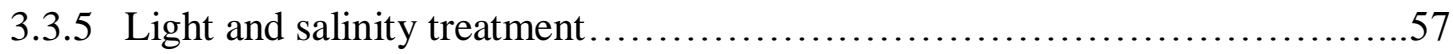

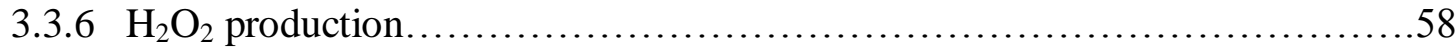

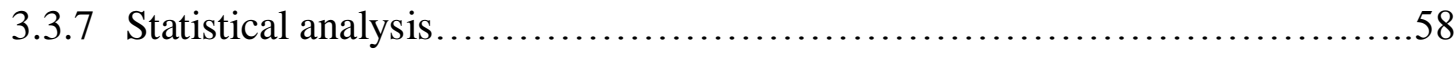

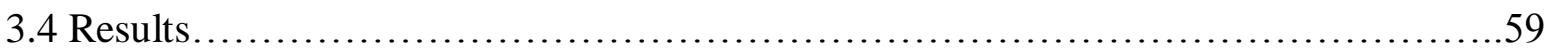

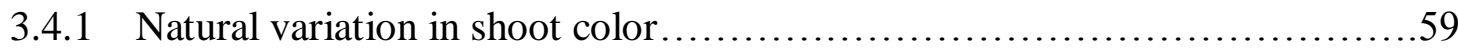

3.4.2 Betalain induction by L-DOPA......................................61

3.4.3 Betalain quantification and characterization.............................61

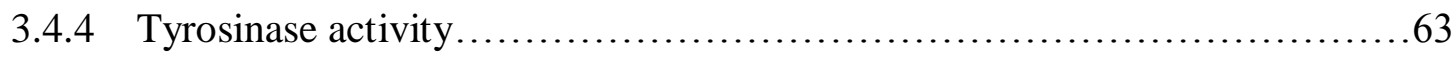

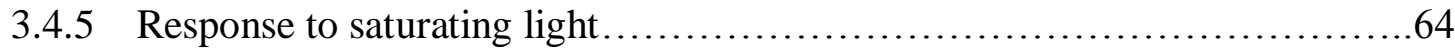

3.4.6 $\mathrm{H}_{2} \mathrm{O}_{2}$ production.....................................................68

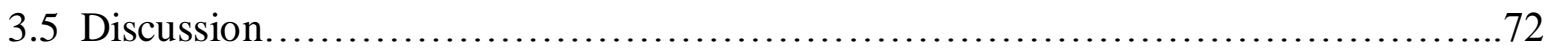

3.5.1 Spectral properties of betalains responsible for light screening..............72

3.5.2 Involvement of Tyrosinase in betalain biosynthesis.........................73

3.5.3 Unequivocal involvement of betalains in photoprotection ..................73

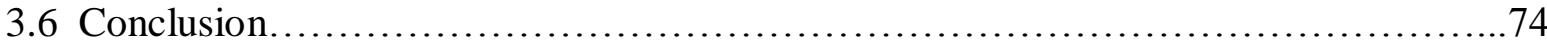

Chapter 4: Foliar betacyanins confer benefit to $D$. australe by $\mathrm{Na}^{+}$sequestration under applied

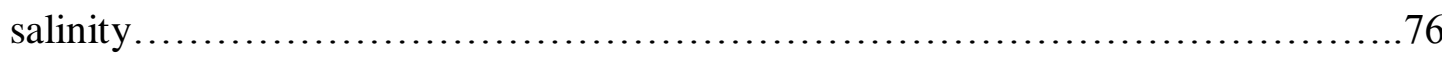

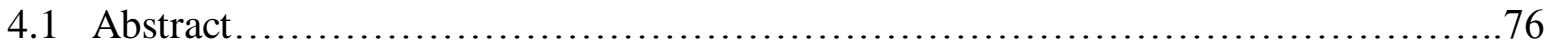

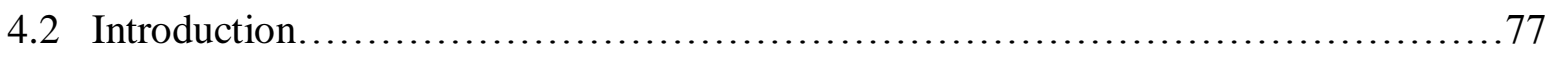

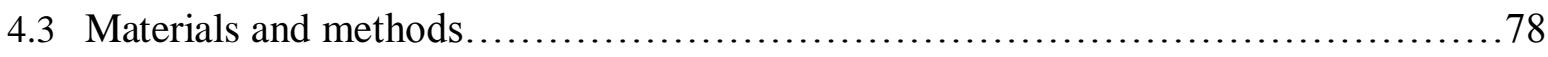

4.3.1 Experiment 1: Growth and physiological parameters..........................78

4.3.1.1 Plant Material............................................... 78

4.3.1.2 Salinity treatment............................................. 79

4.3.1.3 Growth Measurements.......................................79

4.3.1.4 Betalain quantification........................................79 
4.3.1.5 Water potential measurements..............................79

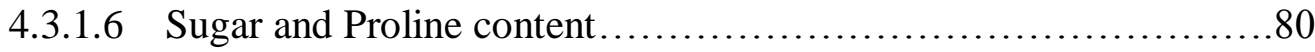

4.3.2 Experiment 2: $\mathrm{Na}^{+}$localisation by fluorescence imaging and cryo-SEM analysis. .80

4.3.2.1 Plant material...............................................80

4.3.2.2 Salinity treatment .......................................... 80

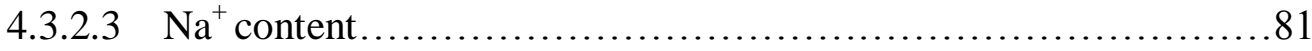

4.3.2.4 $\mathrm{Na}^{+}$Localisation..............................................81

4.3.2.5 Cryo-SEM analysis.........................................81

4.3.2.5 Statistical analysis.......................................... 82

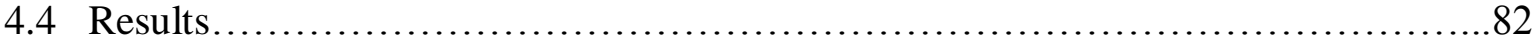

4.4.1 Effect of salinity on pigmentation..................................... 82

4.4.2 Growth rates...................................................... 85

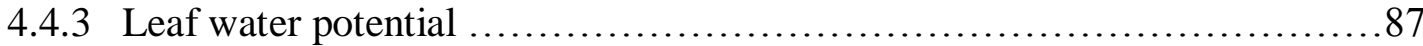

4.4.4 Sugar and Proline content ......................................... 87

$4.4 .5 \mathrm{Na}^{+}$content .................................................... 90

4.4.6 $\mathrm{Na}^{+}$localisation by fluorescence imaging...........................90

4.4.7 Cryo-SEM analysis.............................................92

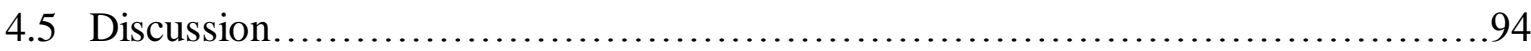

4.5.1 Involvement of betacyanin in avoiding $\mathrm{Na}^{+}$toxicity........................ 94

4.5.2 Physiological drought and osmotic adjustment..........................96

4.5.3 Salinity and plant growth...................................... 97

4.6 Conclusion

Chapter 5: General Discussion.................................................99

5.1 Novel discoveries from this thesis.......................................... 99

5.2 The significance of identifying a photoprotective function for foliar betacyanins in $D$. australe. 100

5.3 The significance of identifying an involvement of betacyanins in $\mathrm{Na}^{+}$homeostasis in Disphyma australe under salinity stress................................. 102

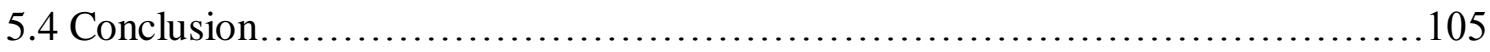

5.5 Future Prospects............................................................. 105 


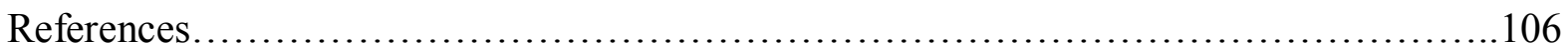

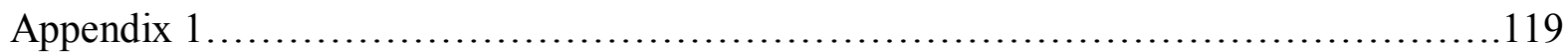




\section{List of figures}

Fig. 1.1 Salinity tolerance response of rice (Oryza sativa), durum wheat (Triticum turgidum ssp. durum), bread wheat (Triticum aestivum), barley (Hordeum vulgare), tall wheatgrass (Thinopyrum ponticum, syn. Agropyron elongatum), Arabidopsis (Arabidopsis thaliana), alfalfa (Medicago sativa), and saltbush (Atriplex amnicola), shown as increases in shoot dry matter following exposure to $\mathrm{NaCl}$ for 3 weeks, relative to plant

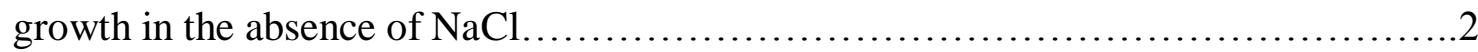

Fig 1.2. Salinity tolerance response of Suaeda maritima (diamonds) (35 d); Thellungiella halophila (squares) (14 d); Disphyma australe (triangles) (60 d); Puccinellia peisonis (stars) (42 d); Distichlis spicata (circles) (21 d) shown as increase in shoot drymatter following exposure to $\mathrm{NaCl}$, relative to plant growth in the absence of or very low

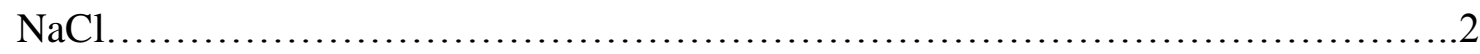

Fig 1.3. Illustration of a two-phase growth response to salinity for plants differing in salt sensitivity ...........................................................

Fig 1.4. Transport proteins and channels that are involved in $\mathrm{Na}^{+}$uptake, efflux and distribution. AKT1, inward rectifying $\mathrm{K}^{+}$channel; $\mathrm{CHX}$, cation: $\mathrm{H}^{+}$exchanger; HKT, high affinity $\mathrm{K}^{+}$transporter; NHX, vacuolar $\mathrm{Na}^{+}: \mathrm{H}^{+}$exchanger; NSCC, non-selective cation channel; ORC; outward rectifying $\mathrm{K}^{+}$channel; SOS1, plasma membrane $\mathrm{Na}^{+}: \mathrm{H}^{+}$antiport......16

Fig 1.5. The proposed model for SOS (salt overly sensitive pathway) for regulation of cytosolic $\mathrm{Na}^{+}$. 18

Fig 1.6. Chemical structure of (A) betanidin, a common betacyanin and (B) indicaxanthin, a betaxanthins....

Fig 1.7. Betacyanic plants (A) Disphyma australe shoot (source: Jain and Gould, 2015) (B) Tetragonia implexicoma leaves, (C) Bougainvillea glabra flower and bract, (D) Beta vulgaris root, (E) Hylocereus undatus fruit.

Fig 1.8. The betalain biosynthetic pathway. Enzyme abbreviations: CYT: cytochrome P450, DOD: 4,5-DOPA extradiol dioxygenase, TYR: tyrosine hydroxylating enzyme. ' $\mathrm{S}$ ' indicates spontaneous reaction .24

Fig 1.9. Vegetative shoots of $D$. australe showing contiguous red and green morphs (A) and red morphs (B) at Te Kopahou Reserve, Wellington.............................. 28

Fig 2.1 Vegetative shoots of Disphyma australe (A), showing contiguous red (R) and green (G) morphs at Te Kopahou Reserve, Wellington. Flowers of green (B) and red (C) D. australe morphs 
Fig 2.2. Transverse sections through shoots of Disphyma australe. Red leaf (A), green leaf (B), red stem (C) green stem (D). Key: $\mathrm{EP}=$ Epidermis, $\mathrm{M}=$ Mesophyll tissue, $\mathrm{VB}=$ Vascular Tissue, $\mathrm{CX}=$ Cortex ........................................... 37

Fig 2.3 Photographs of Disphyma australe, green and red morphs (A) control plants, (B) 200

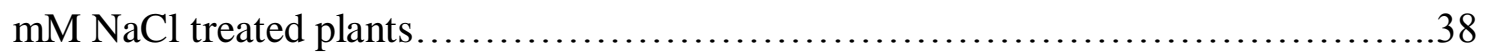

Fig 2.4 Betalain content in extracts from leaves of red and green morphs of Disphyma australe before (white bars) and $14 \mathrm{~d}$ after (black bars) $200 \mathrm{mM} \mathrm{NaCl}$ treatment. 39

Fig 2.5 HPLC chromatogram for leaf extracts of red morphs of Disphyma australe $14 \mathrm{~d}$ after (A) and before (B) $200 \mathrm{mM} \mathrm{NaCl}$ treatment at $538 \mathrm{~nm}$.

Fig 2.6 Pigment concentrations in the leaves of red and green morphs of Disphyma australe. Total chlorophyll (A), total carotenoids (B), chlorophyll $a: b$ (C) and carotenoid : chlorophyll ratios (D) before (white bars) and $14 \mathrm{~d}$ after (black bars) $200 \mathrm{mM} \mathrm{NaCl}$ treatment.

Fig 2.7 (A) Net maximum $\mathrm{CO}_{2}$ assimilation rate $\left(\mathrm{A}_{\max }\right)$, (B) stomatal conductance $\left(\mathrm{g}_{\mathrm{s}}\right)$, and $(\mathrm{C})$ water use efficiency in leaves of red and green morphs of Disphyma australe before (white bars) and $14 \mathrm{~d}$ after (black bars) treatment $200 \mathrm{mM} \mathrm{NaCl}$ or $\mathrm{H}_{2} \mathrm{O} \ldots \ldots \ldots \ldots . .44$

Fig 2.8 Light response curves for (A) photochemical quantum yield, (B) photochemical quenching and $(\mathrm{C})$ non-photochemical quenching for leaves of red $(\mathrm{O})$ and green $(\mathrm{O})$ morphs of Disphyma australe after $14 \mathrm{~d}$ with $200 \mathrm{mM} \mathrm{NaCl}$ (solid lines) or water controls (dashed lines)

Fig 2.9 Reflectance spectra for five randomly selected green leaves of green morphs $(\mathrm{G})$ and red leaves of red morphs (R) of Disphyma australe... .48

Fig. 3.1 Vegetative shoots of (a) green, (b) parti-coloured, (c) red morphs of Disphyma australe; control (d,f,h,j), and L-DOPA-treated (e,g,i,k) leaves and partial transverse sections of the green morph, showing betacyanin accumulation in epidermal cells (i) and vascular parenchyma (k); control (l) and L-DOPA-treated (m) leaves of parti-coloured morph; transverse sections through leaves of parti-coloured (n) and red (o) morphs

Fig. 3.2 Betalain content in extracts from green (open bars) and red (closed bars) leaves of Disphyma australe, taken from green (G), parti-coloured (PC), and red (R) morphs before and after L-DOPA treatment. .62

Fig. 3.3 HPLC chromatogram for L-DOPA fed leaf extracts of green morphs of Disphyma australe. Peaks tentatively identified as (1) betanin, (2) isobetanin, (3) betanidin, (4) lampranthin-II, (5) isolampranthin. 
Fig. 3.4 Temporal changes in photochemical quantum yield of PSII $\left(\Delta F / F m^{\prime}\right)$ for leaves of particoloured $(\square)$, red $(\mathbf{\square})$, green $(\bigcirc)$ and L-DOPA-treated green $(\mathbf{O})$ morphs of Disphyma australe. Leaves were exposed for $6 \mathrm{~h}$ to $1300 \mu \mathrm{mol} \mathrm{m}^{-2} \mathrm{~s}^{-1}$ white $(\mathrm{a}, \mathrm{b})$, green (c, d) or red $(\mathrm{e}, \mathrm{f})$ light. Shaded areas show recovery of $\Delta F / F m^{\prime}$ when plants were returned to darkness .66

Fig. 3.5 Light response curves for (a) photochemical quantum yield of PSII $\left(\Delta F / F m^{\prime}\right)$ and (b) non-photochemical quenching (NPQ) for leaves of green morphs of Disphyma australe before $(\bigcirc)$ and after $(\bigcirc)$ L-DOPA treatment................................67

Fig. 3.6 Transverse sections and their epifluorescence micrographs of DCFH-infiltrated leaves of control (a-h) and L-DOPA-fed (i-p) green morphs of Disphyma australe. Shoot tips were untreated in the dark $(a, b, i, j)$, or exposed to low light $+\mathrm{NaCl}(\mathrm{c}, \mathrm{d}, \mathrm{k}, \mathrm{l})$, high light $\mathrm{NaCl}(\mathrm{e}, \mathrm{f}, \mathrm{m}, \mathrm{n})$, or high light $+\mathrm{NaCl}(\mathrm{g}, \mathrm{h}, \mathrm{o}, \mathrm{p})$

Fig. 3.7 Transverse sections and their epifluorescence micrographs of DCFH-infiltrated leaves of parti-coloured (a-h) and red (i-p) morphs of Disphyma australe. Shoot tips were untreated in the dark $(a, b, i, j)$, or exposed to low light $+\mathrm{NaCl}(\mathrm{c}, \mathrm{d}, \mathrm{k}, \mathrm{l})$, high light $-\mathrm{NaCl}$

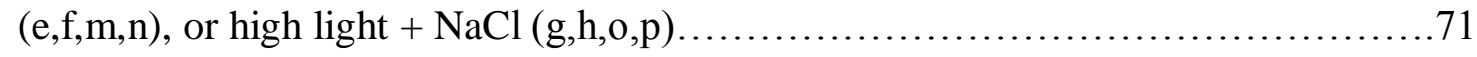

Fig 4.1 Photographs of Disphyma australe. Control red (A) and green (B) morphs, and saline treated red (C) and green (D) morphs .83

Fig 4.2 Betalain concontrations in extracts from the leaves of red (dark bars) and green (white bars) of Disphyma australe.... .84

Fig 4.3 Proportionate increase in dry biomass of red (dark bars) and green (white bars) morphs of Disphyma australe after $5 \mathrm{wk}$ of $\mathrm{NaCl}$ treatment..............................86

Fig 4.4 Water potential values for leaves of red (dark bars) and green (white bars) morphs of Disphyma australe after 5 wk of $\mathrm{NaCl}$ treatment.

Fig 4.5 Soluble sugar content for leaves of red (dark bars) and green (white bars) morphs of Disphyma australe after $5 \mathrm{wk}$ of $\mathrm{NaCl}$ treatment.... .88

Fig 4.6 Proline content for leaves of red (dark bars) and green (white bars) morphs of Disphyma australe after 5 wk of $\mathrm{NaCl}$ treatment. 
Fig 4.7 Photographs of red (A), green (B) and L-DOPA treated (C) leaves of Disphyma australe. Transverse sections (D-F) and their epifluorescence micrographs (G-I) of sodiumbinding benzofuran isophthalate-AM (SBFI-AM) infiltrated leaves of red $(\mathrm{D}, \mathrm{G})$ and green $(\mathrm{E}, \mathrm{H})$ morphs and L-DOPA treated $(\mathrm{F}, \mathrm{I}$,$) leaves of green morphs of Disphyma$ australe. Leaves were treated with $200 \mathrm{mM} \mathrm{NaCl}$ .91

Fig 4.8 Peak / background (P/BG) ratios for $\mathrm{Na}^{+}$in the epidermal cell vacuole (black bars) and mesophyll cell vacuole (white bars) of green, red and L-DOPA treated leaves of Disphyma australe

Fig. 4.9 Cryo-scanning electron microscopy micrograph of a frozen and lightly etched transverse face of a red leaf of $D$. australe treated with $200 \mathrm{mM} \mathrm{NaCl}$. E: epidermal cell; M:

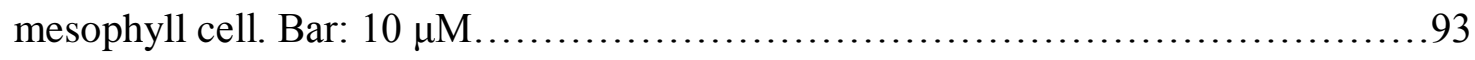

Fig 4.10 EDX spectra from leaf epidermal cell vacuoles (a-c) of green leaf (a, red leaf (b and LDOPA treated green leaf (c of Disphyma australe. Spectrum are representative of $\mathrm{n}=6$. Peaks: C: carbon; O: oxygen; Na: sodium...............................93

Fig 5.1. A proposed model for the transport of $\mathrm{Na}^{+}$in Disphyma australe. Within leaf, apoplastic (red arrows) and symplastic (black arrows) movement of $\mathrm{Na}^{+} \ldots$ .104 


\section{List of Tables}

Table 1.1 Distribution of compatible solutes among halophytic families of angiosperms.......10

Table 1.2 Major monovalent ion transporters in plants involved with $\mathrm{Na}^{+}, \mathrm{K}^{+}$and $\mathrm{Cl}^{-}$transport.14

Table 2.1: Betalain peaks detected in leaf extracts from red morphs of $D$. australe after salinity treatment. Tentative identities were assigned according to HPLC retention times as reported by, Kugler et al. (2007) and Svensson et al. (2008)......................41

Table 2.2 Electrical conductivities of substrate samples, and corresponding frequencies of red and green morphs of Disphyma australe, at increasing distances from the shoreline (Means \pm SE, $n=5$ )

Table 3.1 Tyrosinase activity (units $\mathrm{mg}^{-1}$ protein $\mathrm{h}^{-1}$ ) in extracts from leaves and petals of red (R), green (G) and parti-coloured (PC) morphs of Disphyma australe, as measured by dopachrome production using L-tyrosine or L-DOPA as the substrate. .64

Table 4.1 Effect of $\mathrm{NaCl}$ treatment for $5 \mathrm{wk}$ on production of leaf number, increase in leaf diameter and stem length of red and green morphs of Disphyma australe $(\mathrm{n}=8$, Means $\pm \mathrm{SE}$ ). Different letters represent significant differences between red and green morphs for each parameter across $\mathrm{NaCl}$ concentrations $(\mathrm{P}<0.05)$ . .86

Table 4.2 $\mathrm{Na}^{+}$concentrations ( $\mathrm{mM} / \mathrm{g} \mathrm{DW}$ ) of leaves, stem and roots of red and green morphs of Disphyma australe after $5 \mathrm{wk}$ of either distilled water (control) or $200 \mathrm{mM} \mathrm{NaCl}$ treatment. $(n=5$, Means \pm SE). .90 


\section{Chapter 1: General Introduction}

\subsection{Soil Salinity}

Soil salinity is a major problem for agriculture across the world. It affects crops, horticulture and forage production worldwide. More than six per cent of the world's total land area is affected by salinity (Munns \& Tester, 2008). High concentrations of mineral salts in soil make it saline. Saline soils usually have variable concentrations of different salts such as sodium chloride $(\mathrm{NaCl})$, sodium nitrate $\left(\mathrm{NaNO}_{3}\right)$, magnesium chloride $\left(\mathrm{MgCl}_{2}\right)$, sodium sulphate $\left(\mathrm{Na}_{2} \mathrm{SO}_{4}\right)$, magnesium sulphate $\left(\mathrm{MgSO}_{4}\right)$ and calcium carbonate $\left(\mathrm{CaCO}_{3}\right)$ (Kader, 2006). Of these, $\mathrm{NaCl}$ is the most dominant salt and is responsible for most salinity related problems in plants (Flowers $e t$ al., 2015). The salinity level of a soil is usually measured as the electrical conductivity (EC) of the soil solution and expressed as deciSiemens $/ \mathrm{m}$. Soil with an EC of $4 \mathrm{dS} / \mathrm{m}$ or more, which is equivalent to nearly $40 \mathrm{mM} \mathrm{NaCl}$ concentration, is considered as saline (Munns \& Tester, 2008).

\subsection{Causes of soil salinity}

Salt accumulation in the soils of a particular area can occur due to natural sources, like weathering of parental rocks releasing salts in the soils, and deposition of oceanic salts by wind and rain (Munns, 2005). In coastal areas, sea water is the major source of soil salinity. The rainwater in coastal areas contains $6-50 \mathrm{mg} / \mathrm{Kg}$ of $\mathrm{NaCl}$ and sea water can flood nearby areas during high tides (Munns \& Tester, 2008). In addition, much of the agricultural land is becoming saline rapidly due to irrigation. In arid and semi-arid regions, irrigation is used extensively for agriculture. This practice raises the water table of that particular area which also brings salts to the upper layers of soil (Shabala \& Cuin, 2008). High evaporation in these areas then worsens the situation. Moreover, poor agricultural practices like over-irrigation, inefficient water use and poor water drainage etc. also exacerbated the soil salinity (Kader, 2006).

\subsection{Variable responses of plants to salinity}

Different species of plants respond differently to soil salinity. They can be broadly classified into two categories, glycophytes and halophytes, based on their capacity to grow in saline environments (Sairam \& Tyagi, 2004). Glycophytes are salt sensitive plants, which cannot 
tolerate higher concentrations of salt. Agricultural crops are mostly glycophytes, and rice (Oryza sativa) is the most salt-sensitive crop. Hordeum vulgare (barley) in contrast is relatively salttolerant, although high concentrations of salt reduces its yield (Fig. 1.1) (Munns \& Tester, 2008).

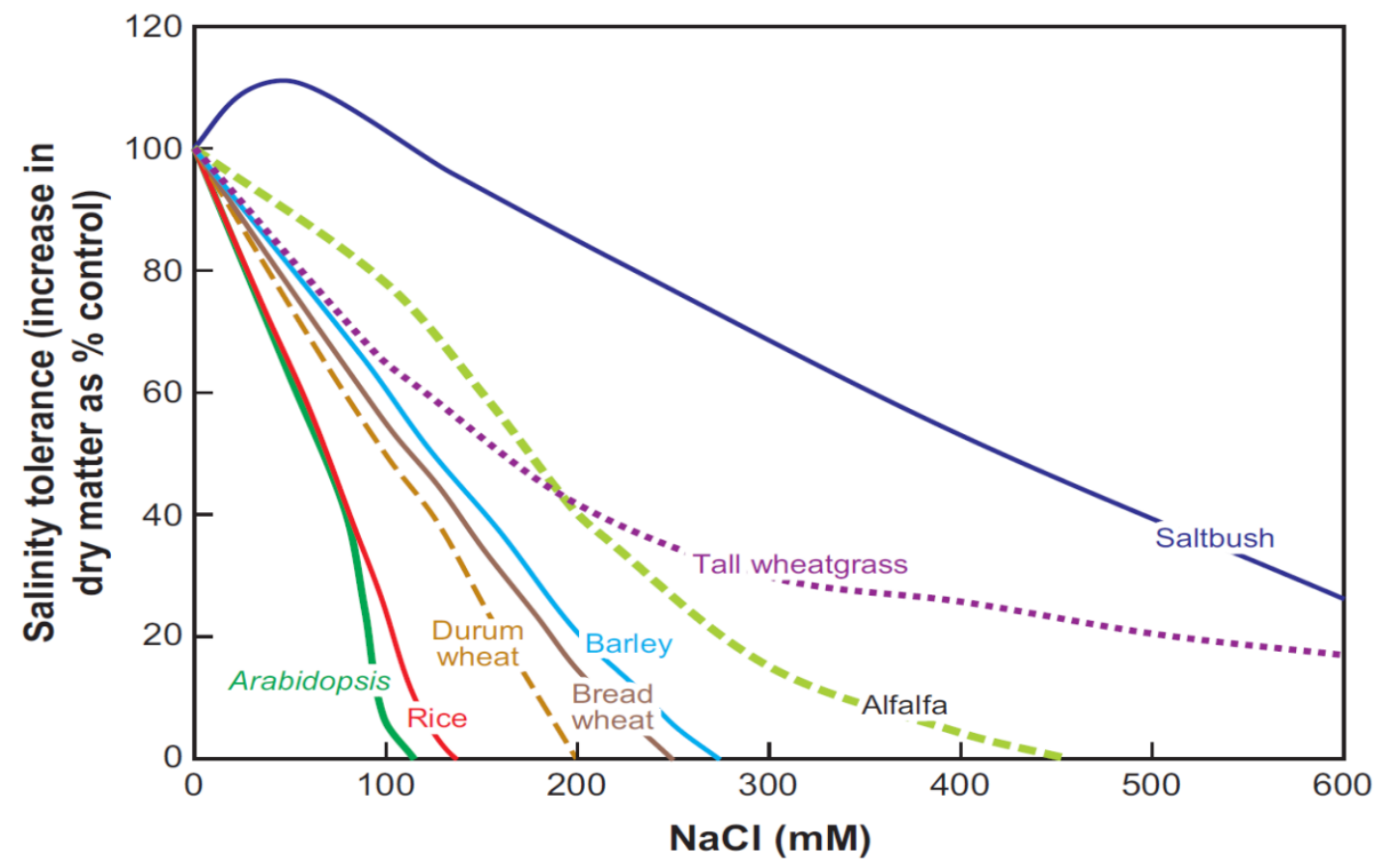

Fig 1.1. Salinity tolerance response of rice (Oryza sativa), durum wheat (Triticum turgidum ssp. durum), bread wheat (Triticum aestivum), barley (Hordeum vulgare), tall wheatgrass (Thinopyrum ponticum, syn. Agropyron elongatum), Arabidopsis (Arabidopsis thaliana), alfalfa (Medicago sativa), and saltbush (Atriplex amnicola), shown as increases in shoot dry matter following exposure to $\mathrm{NaCl}$ for 3 weeks, relative to plant growth in the absence of $\mathrm{NaCl}$. Source: Munns and Tester (2008). 
Halophytes on the other hand are salt tolerant plants that can complete their life cycle in salt concentrations of $200 \mathrm{mM} \mathrm{NaCl}$ (Flowers \& Colmer, 2008). They can grow at salt concentrations which would be lethal for the glycophytes (Flowers \& Colmer, 2015). However, growth responses to salinity vary across halophytic plant species; many halophytes can grow optimally on soils with salt concentrations of 50-250 mM NaCl (Fig. 1.2) (Flowers \& Colmer, 2008).

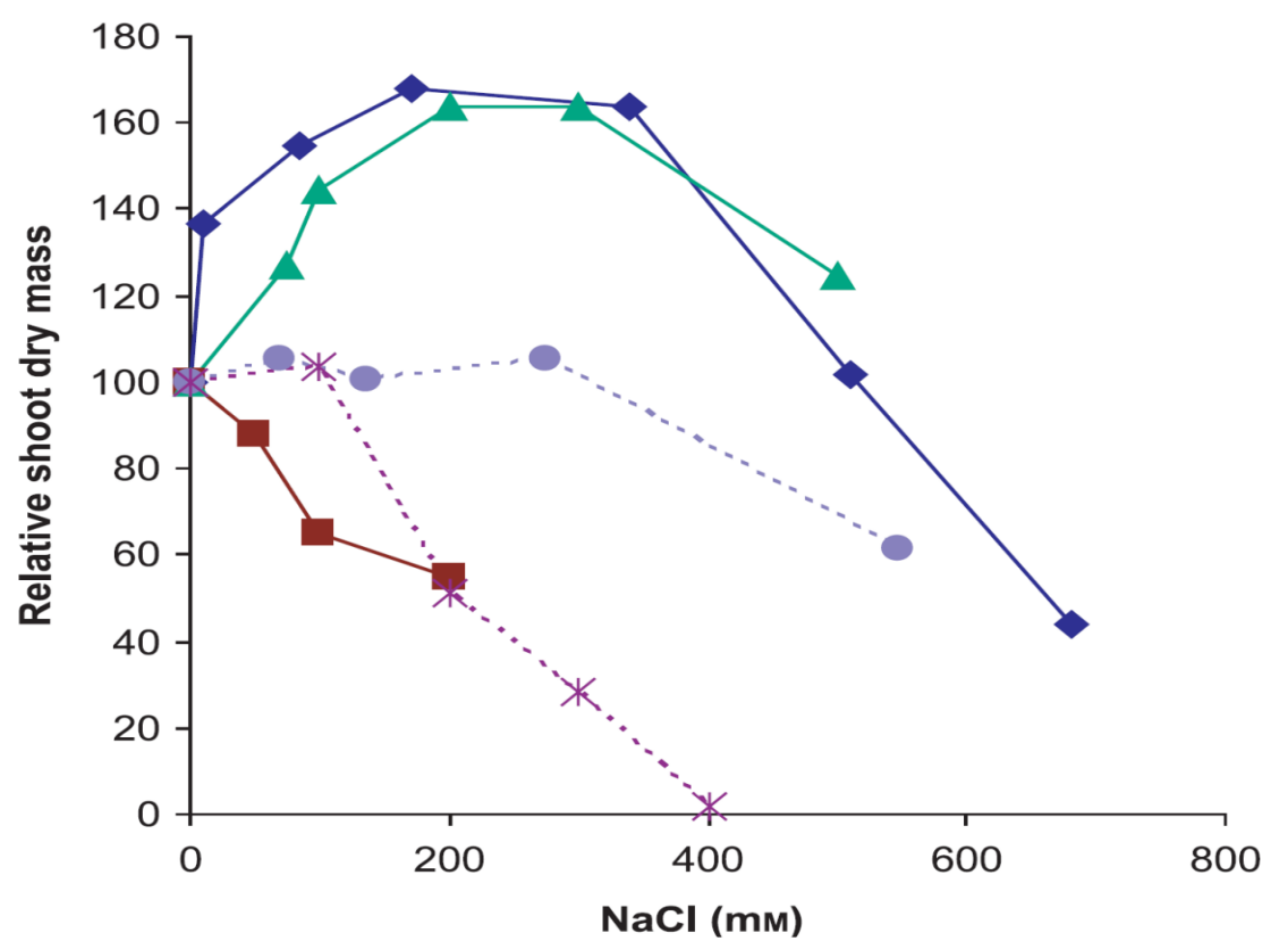

Fig 1.2. Salinity tolerance response of Suaeda maritima (diamonds) (35 d); Thellungiella halophila (squares) (14 d); Disphyma australe (triangles) (60 d); Puccinellia peisonis (stars) (42 d); Distichlis spicata (circles) (21 d) shown as increase in shoot drymatter following exposure to $\mathrm{NaCl}$, relative to plant growth in the absence of or very low $\mathrm{NaCl}$. Solid lines, dicotyledonous species; broken lines, monocotyledonous species. The length of exposure to salt is given in parentheses. Source: Flowers and Colmer (2008). 


\subsection{Physiological impact of salt stress in plants}

Plants growing at soils with excessive soluble mineral salts often experience salinity stress. During salinity stress, plants have to deal with osmotic imbalance and ionic toxicity (Flowers et al., 2015; Slama et al., 2015). Osmotic imbalance occurs when the salt concentration rises in the vicinity of the root zone, leading to inhibition of the uptake of water and essential minerals by roots. Secondly, excessive ions, such as $\mathrm{Na}^{+}$and $\mathrm{Cl}^{-}$, in the root zone can enter into the transpiration stream and cause cellular injury in plants. Over accumulation of these ions (ionic toxicity) can interrupt major metabolic processes, including photosynthesis, leading to chlorosis and cell death (Slama et al., 2015). These two effects of salt stress can be observed at the whole plant level. Below I discuss the effect of salt stress on major processes such as growth, photosynthesis, nutrient uptake and reactive oxygen production in plants.

\subsubsection{Plant Growth}

Reduced plant growth rate is among the primary effects of salinity stress, due to the unavailability of water to plants and excessive accumulation of ions within plants (Flowers \& Colmer, 2008). Exposure to salinity induces a two phase growth response (Fig 1.3) (Munns \& Tester, 2008). During first phase, growth is reduced by excessive salt near the root zone, which inhibits water uptake by plants. To achieve positive turgor pressure, plants divert energy towards osmolyte synthesis instead of biomass accumulation. This phase is termed the osmotic effect of salt stress (Munns \& Tester, 2008). During phase two, growth is further reduced in salt sensitive species. At this stage, very high ionic concentrations are accumulated within the cells and the inability of plant cells to exclude and/or compartmentalize excessive salt leads to cell death. This is the salt-specific effect (Munns, 2005; Munns \& Tester, 2008). However, halophytes are not as much affected as glycophytes, because they use various mechanisms to resist or tolerate saltspecific effects (see section 1.6).

Moreover, salinity-induced effects on growth vary from species to species across halophytes. Many eudicotyledonous halophytes grow optimally at 50-250 mM NaCl (Flowers, 1985; Flowers

\& Colmer, 2008; Shabala, 2013), whereas monocotyledonous halophytes show better growth under no salt or very low soil salt (50 mM or less) concentrations (Glenn et al., 1999). Even 
though halophytes can grow under saline conditions, higher concentrations still can severely reduce plant growth (Fig. 1.2). There are several reasons for reduced plant growth in halophytes

under higher salt concentrations, for example, reduced carbon fixation, change in cell wall elasticity, inability to adjust osmotically and inability to compartmentalize ions (Flowers \& Colmer, 2008, 2015; Munns \& Tester, 2008).

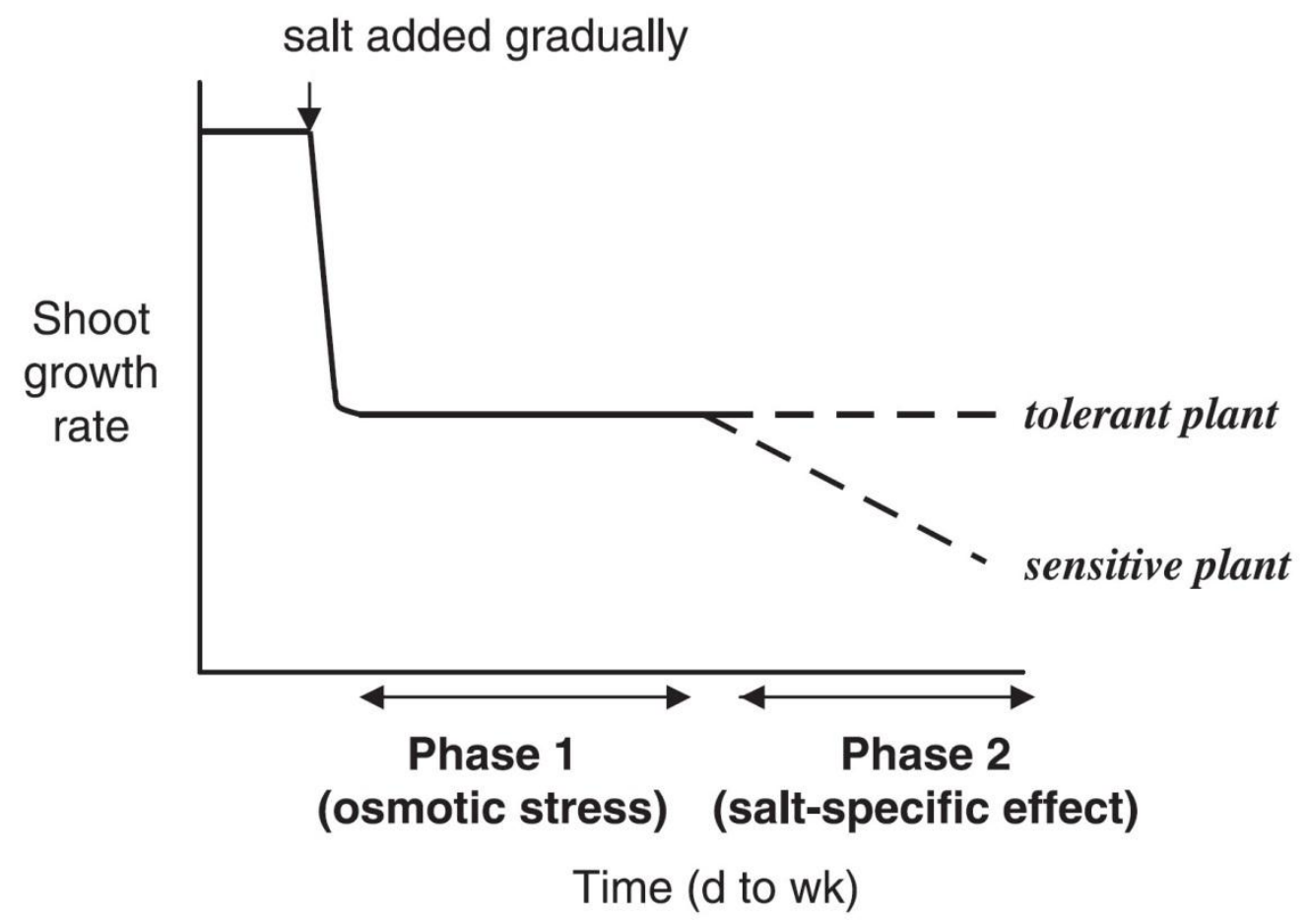

Fig 1.3. Illustration of a two-phase growth response to salinity for plants differing in salt sensitivity. Source: Munns (2005).

\subsubsection{Photosynthesis}

Photosynthesis is especially sensitive to salinity stress (Munns et al., 2006). Plants exposed to salinity stress often show reductions in the efficiency of PSII (photosystem II), photosynthetic electron transport chain (ETC) and $\mathrm{CO}_{2}$ assimilation rate (Chaves et al., 2009). The detailed mechanism for impaired photosynthesis under salinity stress is not known, but studies suggest that photosynthesis is largely affected by altered water potentials and ionic toxicity within cells. Reduction in the leaf water potential triggers stomatal closure and reduces 
the net $\mathrm{CO}_{2}$ uptake by stressed leaves, therefore limiting net photosynthesis (Chaves et al., 2009; Flexas et al., 2004). Also, toxic concentrations of ions within cells can impair photosynthetic metabolism. Additionally, there are secondary effects of salinity, such as the production of reactive oxygen species (ROS), which also adversely influence photosynthesis. Oxidative damage via ROS production is most severe when plants face multiple stress conditions such as drought/salinity accompanied by high light and low temperatures and these combinations of stressors can seriously damage the leaf photosynthetic machinery (Flexas et al., 2004; Ort, 2001).

There is an ongoing discussion as to whether drought/salinity stressors limit photosynthesis through stomatal closure or by metabolic impairment (Zhu, 2001; Flexas et al., 2004; Chaves et al., 2009). There is substantial evidence that stomatal closure under drought/salinity stress occurs before metabolism is affected (Flexas et al., 2004; Tang et. al., 2002; Tezara et al., 2003). However, under prolonged exposure to salinity, plants exhibit metabolic impairment through ionic toxicity (Flowers \& Colmer, 2008). Some plants prevent ionic toxicity by salt exclusion or by cellular ion compartmentation. But when these mechanisms are insufficient, ionic concentrations in the cells rise to toxic levels. Cytoplasmic $\mathrm{Na}^{+}$ concentrations (100 mM or above) inhibit photosynthetic enzymes (Munns et al., 2006; Chaves et al., 2009). Percey et al., (2014), suggested that the capability of chloroplasts to process light energy is impaired by the over accumulation of apoplastic $\mathrm{Na}^{+}$, which causes the efflux of $\mathrm{K}^{+}$ from mesophyll cells and an alteration in the cytosolic $\mathrm{Na}^{+} / \mathrm{K}^{+}$ratio.

\subsubsection{Reactive oxygen species}

ROS levels increase in plants following salinity exposure (Bose et al., 2014). Production of ROS impaired the ability of chloroplasts to process light energy. Therefore, chloroplasts exposed to excessive light energy generate excessive ROS, such as superoxide $\left(\mathrm{O}_{2}{ }^{\circ}\right)$, hydroxyl radical $\left(\mathrm{OH}^{\circ}\right)$, peroxyl radicals $(\mathrm{ROO})$, singlet oxygen $\left({ }^{1} \mathrm{O}_{2}\right)$ and hydrogen peroxide $\left(\mathrm{H}_{2} \mathrm{O}_{2}\right)$ (Mittler et al., 2004; Miller et al., 2010). Plants use ROS to activate signaling pathways in response to abiotic or biotic stressors (Mittler et al., 2004). However, excessive production of ROS can lead to oxidative stress which can damage DNA, denature proteins and destroy cell membranes. Production of ROS in response to environmental stresses such as salinity directly controls crop productivity (Bose et al., 2014; Parihar et al., 2015). In many crop plants, such as rice, pea, 
mustard and tomato, ROS mediated membrane damage is the major cause of the cellular toxicity by salinity (Mittova et al., 2004; Ahmad et al., 2009, 2010; Parihar et al., 2015). Therefore, regulation of ROS is a crucial process for plants to avoid cellular toxicity.

\subsubsection{Nutritional imbalance}

Soil salinity always interrupts nutrient uptake by plants, and plant growth is damaged by salinityinduced nutritional imbalance (Flowers and Colmer, 2008; Hu and Schmidhalter, 2005; Rogers et al., 2003). However, it is considered as a secondary effect of salinity stress in crops (Grattan \& Grieve, 1998). Plants absorb most of their required micro and macronutrients from the soil solution. The availability of micronutrients to plants depends on the solubility of micronutrients and the $\mathrm{pH}$ of the soil solution (Parihar et al., 2015). Micronutrient deficiency under salt stress can result from changes in $\mathrm{pH}$ of the soil solution (Parihar et al., 2015). Uptake of macronutrients such as nitrogen $(\mathrm{N})$ also decreases under salinity stress $(\mathrm{Hu} \&$ Schmidhalter, 2005). $\mathrm{N}$ deficiency under salinity stress is because of interaction between ions such as $\mathrm{Na}^{+}$and $\mathrm{NH}_{4}{ }^{+}$and/or $\mathrm{Cl}^{-}$and $\mathrm{NO}_{3}{ }^{-}$which reduces the availability of $\mathrm{N}$ to plants (Qadir \& Schubert, 2002; Britto \& Kronzucker, 2006; Parihar et al., 2015). Similarly, the availability of phosphorous, calcium and magnesium can be reduced due to high ionic concentrations in soil (Qadir \& Schubert, 2002; Britto \& Kronzucker, 2006; Hussin et al., 2013).

\subsection{Halophytes: as substitutes for crops of saline soil}

Halophytes have a number of physiological and morphological adaptations that help them grow in high saline soils. Therefore, halophytes can be a potential crop for saline soils (Rozema \& Flowers, 2008; Shabala et al., 2014; Ventura et al., 2015). Some halophytes under saline conditions can produce higher biomass than conventional crops e.g. Salicornia bigelovii (a potential oil seed crop) produced 2.0 tons of seeds/ha; by contrast, in 2007 the average sunflower seed production in the world was 1.2 tons/ha (Rozema \& Flowers, 2008). However, the domestication of halophytes as crop plants poses new challenges, with unknown plant diseases, and new methods of cultivating, processing and marketing required (Ventura et al., 2015).

On the other hand, halophytes, which use various mechanisms to tolerate salinity, can provide a gateway to make conventional crops more salt tolerant. For that, it is crucial to understand the physiological mechanism of salinity tolerance in halophytes. 


\subsection{Salt stress tolerance in halophytes}

Physiological adaptations such as osmoregulation and ionic homeostasis are the major mechanisms dealing with salinity induced stress in halophytes. For osmotic adjustment halophytes accumulate $\mathrm{Na}^{+}$and $\mathrm{Cl}^{-}$in the cell vacuoles, and a range of organic solutes (amino acids, sugars, sugar alcohols) in the cytosol. To avoid ionic toxicity at the cellular level, some halophytes sequester excessive ions into the apoplast or specialized structures, such as salt bladders. However, tolerances vary among species; for example, the halophyte Suaeda maritima can accumulate $500-600 \mathrm{mM}$ of $\mathrm{Na}^{+}$in the leaves when exposed to $\mathrm{NaCl}$ stress (Flowers et al., 2015), while Tecticornia spp. can accumulate up to $2 \mathrm{M} \mathrm{Na}^{+}$on exposure to extreme salt stress (English \& Colmer, 2013).

\section{$\underline{\text { 1.6.1 Osmotic adjustment }}$}

Plants growing under excessive soil salinity conditions may incur osmotic imbalance. These plants need to achieve positive turgor pressure to absorb water and other minerals from the soil. To achieve positive turgor pressure, cellular solute concentrations must be maintained higher than that of the soil solution. Halophytes can maintain positive turgor pressure by producing compatible solutes.

Low molecular weight osmolytes (compatible solutes) are highly soluble and non-toxic for plant cells even at high concentrations, and they do not adversely affect normal cellular metabolic activities (Yancey, 2005; Slama et al., 2015). A wide range of compatible solutes has been identified from halophytes which are synthesized during osmotic stress. According to Slama et al. (2015) and Yancey (2005), these solutes can be categorised into sugars, (glucose, fructose, sucrose, trehalose, raffinose and fructans); sugar alcohols or polyols (sorbitol, mannitol, glycerol, inositols etc.); amino acids, (proline, glycine, taurine, etc.), quaternary ammonium compounds, (glycine betaine, proline betaine, choline- $O$-sulphate, hydroxyproline betaine etc.) and tertiary sulphonium compounds (such as dimethylsulphoniopropionate, DMSP). All these compounds can be found in plants experiencing salt or drought stress, however, the distribution varies among families. The accumulation of these compounds may increase on exposure to osmotic stress but not all plants synthesise all types of solutes. For example, members of 
Aizoaceae generally accumulate proline, while the Amaranthaceae largely accumulate gycine betaine (Slama et al., 2015). Synthesising osmolytes is a costly process for plants as it requires a large number of ATP molecules (Yancey, 2005; Flowers \& Colmer, 2008). Known osmolytes within halophytic families are listed in Table 1.1. 
Table 1.1 Distribution of compatible solutes among halophytic families of angiosperms. Source:

Slama et al. (2015)

\begin{tabular}{|c|c|c|}
\hline Order & Family & Osmolytes \\
\hline \multicolumn{3}{|c|}{ Monocotyledoneae } \\
\hline \multirow[t]{3}{*}{ Poales } & Cyperaceae & Sucrose \\
\hline & Junaceae & Sucrose \\
\hline & Poaceae & Sucrose, proline \\
\hline \multicolumn{3}{|l|}{ Dicotyledoneae } \\
\hline \multirow[t]{5}{*}{ Alismatales } & Cymodoceaeceae & Proline, glycine, inositol \\
\hline & Juncaginaceae & Proline, pipecolate, fructose, maltose, sucrose \\
\hline & & Proline, glycine, sucrose \\
\hline & Posidoniaceae & Proline, sucrose \\
\hline & Zosteraceae & \\
\hline Asterales & Asteraceae & Proline, glycine betaine, myo-inositol, sucrose \\
\hline Brassicales & Brassicaseae & Proline, sucrose \\
\hline \multirow[t]{6}{*}{ Caryophyllales } & Aizoaceae & Proline, myo-inositol, ononitol, pinitol, glycine betaine \\
\hline & & Glycine betaine, proline, methylated onium compounds, sugars \\
\hline & Amaranthaceae & Glycine betaine \\
\hline & Frankeniaceae & $\begin{array}{l}\text { B-Alanine betaine, choline- } O \text {-sulphate, proline, pipecolate, } \\
\text { sucrose, }\end{array}$ \\
\hline & Plumbaginaceae & Proline \\
\hline & Portulacaceae & Proline \\
\hline Fagales & Casuarinaceae & Proline \\
\hline Lamiales & Acanthaceae & Glycine betaine \\
\hline Malpighiales & Rhizophoraceae & Proline, sucrose \\
\hline \multirow[t]{2}{*}{ Myrtales } & Combretaceae & Mannitol \\
\hline & Myrtaceae & Proline analogues, methylated proline \\
\hline Plantaginales & Plantaginaceae & Sorbitol, proline, rhamnose \\
\hline Rosales & Fabaceae & Proline, glycine betaine, pinitol, \\
\hline Solanales & Solanaceae & Glycine betaine \\
\hline
\end{tabular}


Accumulation of osmolytes under osmotic stress is a specific metabolic response that helps plants to withstand adverse conditions. Thermodynamically, the accumulation of osmolytes under osmotic stress reduces the water potential of cells. This phenomenon is important for plants specially under saline conditions (Sairam \& Tyagi, 2004). Among these wide range of osmolytes, proline is the most common in higher plants (Kishor et al., 2005). Increases in proline concentration have been recorded for number of plants under osmotic stress (Kishor et al., 2005; Lokhande et al., 2011; Sperdouli \& Moustakas, 2012; Llanes et al., 2013). Similarly, among various quaternary ammonium compounds, glycine betaine is most abundant in plants exposed to abiotic stress (Lokhande et al., 2011; Slama et al., 2015). However, from an energetic point of view, it is quite costly for stressed plants to synthesise these organic solutes, which would divert the supply of essential elements for growth processes (Flowers et al., 2015). Therefore, halophytes tend to achieve osmotic balance using inorganic ions rather than by accumulating solutes (Greenway \& Munns, 1980; Flowers \& Colmer, 2008; Flowers et al., 2015).

In addition to osmotic adjustment, these osmolytes may play other vital functions in plants (Szabados et al., 2011; Slama et al., 2015). For example, proline accumulation under salt stress has been associated with NADPH recycling (Llanes et al., 2013; Slama et al., 2015). Similarly, soluble sugars may stabilise cell membranes under water stress as well as act as a signalling molecule for various metabolic processes (Tognetti et al., 2013; Llanes et al., 2013). Some of the osmolytes can protect macromolecular structures by enhancing thermodynamic stability of proteins (Yancey, 2005), while others may be efficient scavengers of reactive oxygen species; for example, mannitol can scavenge hydroxyl radicals (Shen et al., 1997), and proline can scavenge singlet oxygen (Alia et al., 1997).

\subsubsection{Ionic toxicity}

With increase in soil salinity, ions i.e. $\mathrm{Na}^{+}$and $\mathrm{Cl}^{-}$, can enter into the plant cells and cause ionic toxicity (Flowers et al., 2015). Excessive concentrations of ions that inhibit the cell growth and metabolism are considered toxic (Flowers \& Colmer, 2015). Even though halophytes are naturally salt tolerant, higher concentrations of $\mathrm{NaCl}$ in the root zone can still kill them; for example, Tecticornia spp. dies with $2 \mathrm{M} \mathrm{NaCl}$ in the root zone (English \& Colmer, 2013). Moreover, non-lethal $\mathrm{NaCl}$ concentrations can inhibit growth in halophytes (Flowers \& Colmer, 2008). 


\section{$\underline{\text { 1.6.3 } \mathrm{Na}^{+} \text {toxicity }}$}

Plants maintain adequate concentrations of $\mathrm{K}^{+}$and $\mathrm{Na}^{+}$in the cytoplasm for various metabolic processes. Under salt stress however, these concentration can vary depending on the level of stress. Cytoplasmic $\mathrm{Na}^{+}$can be very harmful for plant cells when present in supra-optimal concentrations. During salt stress, growth inhibition by $\mathrm{Na}^{+}$is among the primary effects of salt stress. $\mathrm{K}^{+}$on the other hand, is an essential cation for cells and high concentrations of $\mathrm{K}^{+}(100-$ $200 \mathrm{mM}$ ) are necessary for various metabolic processes (Shabala \& Cuin, 2008). There are $>50$ enzymes in plant cells that need $\mathrm{K}^{+}$as a co-factor for functioning. These same enzymes are, however, susceptible to high cytosolic $\mathrm{Na}^{+}$and high $\mathrm{Na}^{+} / \mathrm{K}^{+}$ratios (Shabala \& Cuin, 2008; Flowers et al., 2015). For example, in halophytes, the mitochondrial enzyme malate dehydrogenase is salt-sensitive. Moreover, in Suaeda maritima, respiration in isolated mitochondria was inhibited by $50 \%$ following an exposure to $300 \mathrm{mM} \mathrm{NaCl}$ (Flowers, 1974). Under saline conditions, there is competition between $\mathrm{Na}^{+}$and $\mathrm{K}^{+}$for uptake through a common pathway as both are similar monovalent cations. Likewise, increased levels of cytosolic $\mathrm{Na}^{+}$ compete with $\mathrm{K}^{+}$for the binding sites of many enzymes and result in inhibition of metabolic processes. Cellular $\mathrm{Na}^{+}$can affect cell membrane permeability by displacing $\mathrm{Ca}^{+}$from plasma membranes (Munns \& Tester, 2008), and this can lead to the leakage of ions (such as $\mathrm{K}^{+}$) creating an imbalance in the $\mathrm{Na}^{+} / \mathrm{K}^{+}$ratios (Maathuis, 2014). Consequently, it is crucial for a plant cell to avoid $\mathrm{Na}^{+}$toxicity.

Like $\mathrm{Na}^{+}, \mathrm{Cl}^{-}$ions can be equally toxic for halophytes. Interestingly protein synthesis is inhibited by both $\mathrm{Cl}^{-}$and $\mathrm{Na}^{+}$(Flowers et al., 2015). However, $\mathrm{Cl}^{-}$toxicity has received far less attention than $\mathrm{Na}^{+}$. Flower and Colmer, (2008) estimated that $\mathrm{Na}^{+}$and $\mathrm{K}^{+}$concentrations are almost $35 \%$ higher than $\mathrm{Cl}^{-}$in eudicotyledonous halophytes. Even so, halophytes accumulate significant levels of $\mathrm{Cl}^{-}$in the shoots, so along with $\mathrm{Na}^{+}$, regulation of cytoplasmic $\mathrm{Cl}^{-}$is also important for salt tolerance. At low concentrations $\mathrm{Cl}^{-}$uptake is mediated via a $\mathrm{Cl}^{-}: 2 \mathrm{H}^{+}$symport and at high concentrations $\mathrm{Cl}^{-}$influx is mediated via an anion channel, but the literature lacks information on the possible $\mathrm{Cl}^{-}$transporters in halophytes (Flowers \& Colmer, 2008; Flowers et al., 2015).

\section{$\underline{1.6 .4 \mathrm{Na}^{+} \text {uptake }}$}


$\mathrm{Na}^{+}$can be toxic at high concentrations in plants; however, low concentrations can enable some metabolic functions, especially when $\mathrm{K}^{+}$is lacking (Munns \& Tester, 2008; Adams \& Shin, 2014). Moreover, $\mathrm{Na}^{+}$in some halophytes is needed for optimal growth, for example, Suaeda maritima and Salicornia species have enhanced growth in the presence of $\mathrm{NaCl}$ in the growth medium (Maathuis, 2014). During salt stress, however, the regulation of high $\mathrm{Na}^{+}$concentrations within plants is a primary requirement for plants. Halophytes have adapted a wide range of mechanisms to deal with high $\mathrm{Na}^{+}$concentrations (Flowers \& Colmer, 2008; Shabala \& Mackay, 2011; Flowers et al., 2015), and understanding the mechanism of $\mathrm{Na}^{+}$uptake and regulation is critical to developing salt tolerant crops.

In plants exposed to excessive soil salinity, roots are the first organ to experience high $\mathrm{Na}^{+}$ concentration in soil solutions. This $\mathrm{Na}^{+}$enters into root hair epidermal cells across the plasma membrane through passive transport. The lipid bilayer of the plasma membrane is impermeable to solutes. There are, however, many transport proteins in the plasma membrane that carry specific solutes across membranes (Adams and Shin, 2014; Flowers and Colmer, 2008; Maathuis, 2014; Zhang et al., 2009). A number of transporters (Table 1.2) might be involved in $\mathrm{Na}^{+}$uptake. However, these transporters vary widely among species. 
Table 1.2 Major monovalent ion transporters in plants involved with $\mathrm{Na}^{+}, \mathrm{K}^{+}$and $\mathrm{Cl}^{-}$transport. Source : Flowers \& Colmer, (2008); Zhang et al., (2009); Maathuis, (2014).

\begin{tabular}{|c|c|c|c|}
\hline Protein Family & Transporters & Role & References \\
\hline $\begin{array}{l}\text { Cation-chloride co- } \\
\text { transporters }\end{array}$ & $\mathrm{CCC}$ & $\begin{array}{l}\text { Mediate movement of } \mathrm{Cl}^{-} \text {which is } \\
\text { coupled with } \mathrm{Na}^{+} \text {and/or } \mathrm{K}^{+}\end{array}$ & $\begin{array}{l}\text { Colmenero-Flores et al., } \\
\text { 2007; Zhang et al., } 2009\end{array}$ \\
\hline \multirow[t]{3}{*}{ Cation proton antiporters } & $\mathrm{CHX}$ & $\begin{array}{l}\text { Cation } / \mathrm{H}^{+} \text {exchangers, play a role in } \\
\text { xylem loading of } \mathrm{Na}^{+}\end{array}$ & $\begin{array}{l}\text { Flowers and Colmer, 2008; } \\
\text { Gierth and Mäser, 2007; } \\
\text { Véry and Sentenac, } 2003\end{array}$ \\
\hline & NHX & $\begin{array}{l}\mathrm{Na}^{+} / \mathrm{H}^{+} \text {exchangers found in } \\
\text { plasmamembrane and tonoplast. }\end{array}$ & \\
\hline & SOS & Salt overly sensitive, $\mathrm{Na}^{+} / \mathrm{H}^{+}$exchangers. & \\
\hline High affinity $K$ transporter & HKT & $\begin{array}{l}\text { HKT have distinct subfamilies }\left(\mathrm{Na}^{+} / \mathrm{K}^{+}\right. \\
\text {symporters and } \mathrm{Na}^{+} \text {- selective } \\
\text { transporters) which are involved in } \\
\text { uptake of } \mathrm{Na}^{+} \text {and } \mathrm{K}^{+}\end{array}$ & $\begin{array}{l}\text { Adams and Shin, 2014; } \\
\text { Maathuis, 2014; Platten et } \\
\text { al., 2006; Zhang et al., } 2009\end{array}$ \\
\hline $\begin{array}{l}\mathrm{K}^{+} \text {uptake permeases/High } \\
\text { affinity } \mathrm{K}^{+} / \mathrm{K}^{+} \text {transporter }\end{array}$ & KUP/HAK/KT & $\begin{array}{l}\text { Cation symporters; responsible for high } \\
\text { affinity } \mathrm{K}^{+} \text {uptake }\end{array}$ & $\begin{array}{l}\text { Flowers and Colmer, 2008; } \\
\text { Gierth and Mäser, 2007; } \\
\text { Véry and Sentenac, 2003; } \\
\text { Zhang et al., 2009 }\end{array}$ \\
\hline $\begin{array}{l}\text { Low affinity cation } \\
\text { transporter }\end{array}$ & LCT1 & $\begin{array}{l}\text { Low affinity uptake of cations e.g. } \mathrm{Na}^{+} \text {, } \\
\mathrm{Ca}^{2+} \text { and } \mathrm{Rb}^{+}\end{array}$ & $\begin{array}{l}\text { Véry and Sentenac, 2003; } \\
\text { Zhang et al., } 2009\end{array}$ \\
\hline \multirow[t]{5}{*}{$\begin{array}{l}\text { Non-selective cation } \\
\text { channels }\end{array}$} & NSCCs & Responsible for passive fluxes of cations & $\begin{array}{l}\text { Adams and Shin, 2014; } \\
\text { Apse and Blumwald, 2007; }\end{array}$ \\
\hline & VI-NSCCs & $\begin{array}{l}\text { Voltage independent non-selective cation } \\
\text { channels }\end{array}$ & $\begin{array}{l}\text { Demidchik and Maathuis, } \\
\text { 2007; Flowers and Colmer, }\end{array}$ \\
\hline & VICs & Voltage independent channels & 2008; Zhang et al., 2009 \\
\hline & CNGCs & Cyclic nucleotide-gated channels & \\
\hline & GLRs & Glutamate like receptors & \\
\hline \multicolumn{4}{|l|}{$\mathrm{K}^{+}$transport channels } \\
\hline & AKT1 & $\begin{array}{l}\text { Arabidopsis } \mathrm{K}^{+} \text {transporter, mediate low } \\
\text { affinity } \mathrm{K}^{+} \text {transport }\end{array}$ & $\begin{array}{l}\text { Flowers and Colmer, 2008; } \\
\text { Maathuis, 2007; Véry and }\end{array}$ \\
\hline & KIRC & $\begin{array}{l}\mathrm{K}^{+} \text {inwardly rectifying channel, proposed } \\
\text { as major pathway for low affinity } \mathrm{K}^{+} \\
\text {transport }\end{array}$ & $\begin{array}{l}\text { Sentenac, 2003; Zhang et } \\
\text { al., } 2009\end{array}$ \\
\hline & KORC & $\mathrm{K}^{+}$outwardly rectifying channel & \\
\hline & SKOR & Stelar $\mathrm{K}^{+}$outward rectifier & \\
\hline
\end{tabular}


Once $\mathrm{Na}^{+}$enters epidermal cells, its transport to the xylem occurs through the apoplastic and/or the symplastic pathway (Maathuis, 2014). In the apoplast, $\mathrm{Na}^{+}$can move freely until it reaches to the Casparian strip of the endodermis, which is an effective physical barrier for $\mathrm{Na}^{+}$movement (Adams \& Shin, 2014). At this point, $\mathrm{Na}^{+}$moves symplastically towards the stele, however in some cases $\mathrm{Na}^{+}$can move through the Casparian strip via apoplastic bypass flow (Plett \& Møller, 2010). Symplastic movement of $\mathrm{Na}^{+}$toward the stele may be done by CHX transporters (Hall et al., 2006; Maathuis, 2014).

When $\mathrm{Na}^{+}$reaches the vascular bundles, it is loaded into the xylem, where it follows long distance transport to the shoot. Xylem loading of $\mathrm{Na}^{+}$can be active under low salinity and passive under high salinity (Apse \& Blumwald, 2007; Plett \& Møller, 2010). Active loading is a channel mediated process and passive loading is mediated by $\mathrm{Na}^{+} / \mathrm{H}^{+}$exchangers. Numerous studies have suggested the involvement of various membrane transporters such as SOS1, CHX21, HKT-type transporters in xylem loading of $\mathrm{Na}^{+}$(Table 1.2; Fig. 1.4). Finally, after longdistance travel, $\mathrm{Na}^{+}$reaches leaf cells, including mesophyll cells, where it is unloaded from the xylem. HKT type transporters may carry $\mathrm{Na}^{+}$unloading from xylem tissue (Zhang et al., 2009). In halophytes, however, a large amount of $\mathrm{Na}^{+}$recirculates through the phloem back to the roots, as a salinity tolerance mechanism (Adams \& Shin, 2014; Maathuis, 2014) . 


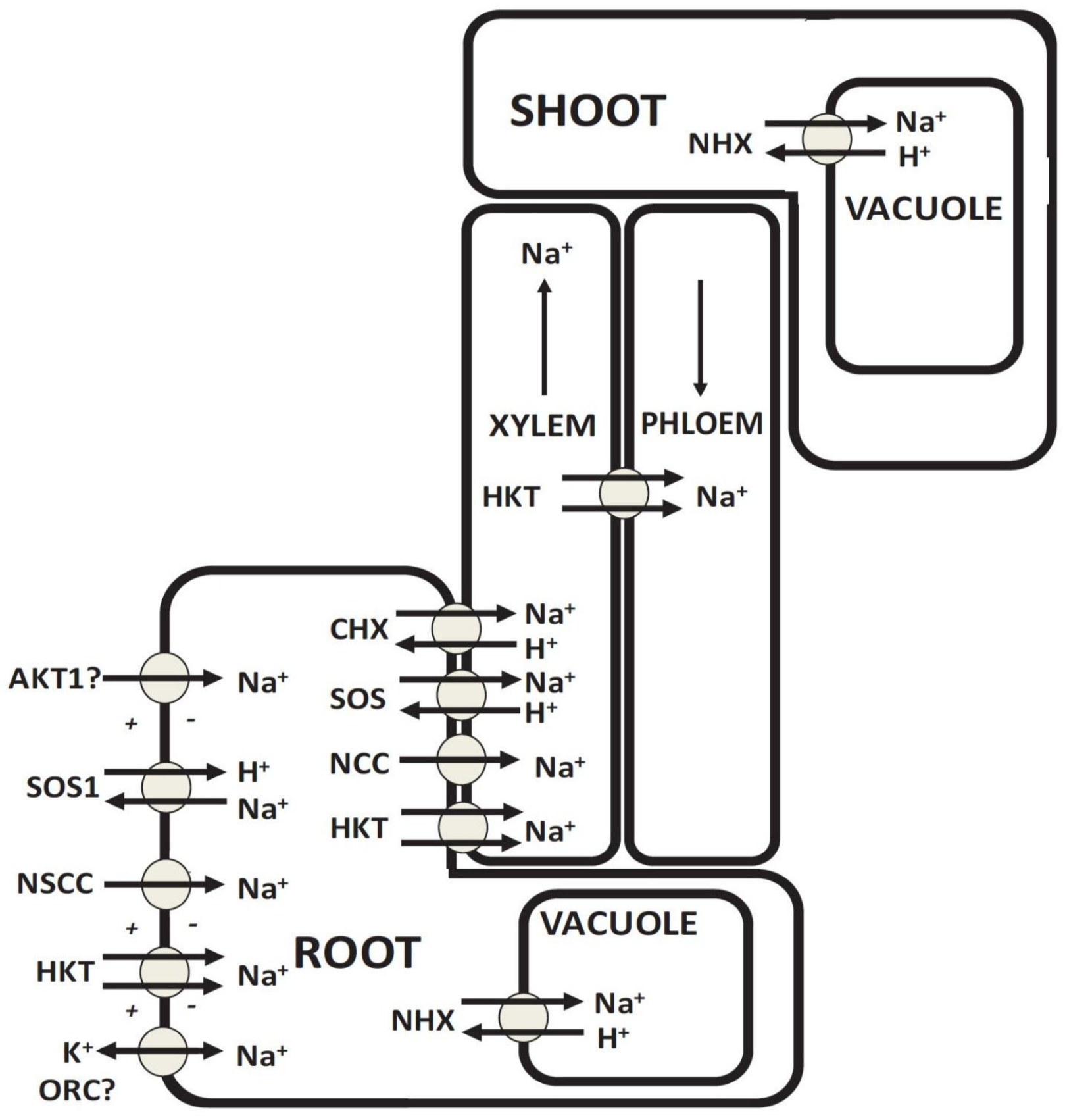

Fig 1.4. Transport proteins and channels that are involved in $\mathrm{Na}^{+}$uptake, efflux and distribution. AKT1, inward rectifying $\mathrm{K}^{+}$channel; $\mathrm{CHX}$, cation: $\mathrm{H}^{+}$exchanger; HKT, high affinity $\mathrm{K}^{+}$ transporter; NHX, vacuolar $\mathrm{Na}^{+}: \mathrm{H}^{+}$exchanger; NSCC, non-selective cation channel; ORC; outward rectifying $\mathrm{K}^{+}$channel; SOS1, plasma membrane $\mathrm{Na}^{+}: \mathrm{H}^{+}$antiport. Source: Maathuis (2014). 


\subsection{5 $\mathrm{Na}^{+}$Homeostasis in the cytosol}

Maintenance of low cytoplasmic $\mathrm{Na}^{+}$concentrations is one of the key steps to tolerate salinity stress. This helps to avoid $\mathrm{Na}^{+}$toxicity and also to maintain osmotic balance (Munns \& Tester, 2008). Along with low $\mathrm{Na}^{+}$concentrations, it is important to maintain adequate $\mathrm{Na}^{+} / \mathrm{K}^{+}$ratios in the cytosol for many metabolic reactions. The best way to keep low $\mathrm{Na}^{+}$levels in the cytoplasm is to minimise $\mathrm{Na}^{+}$influx, and plants can inactivate transporters to restrict $\mathrm{Na}^{+}$entry (Maathuis, 2014). However, once $\mathrm{Na}^{+}$has accumulated at toxic levels into the cytoplasm, plants must sequester this extra $\mathrm{Na}^{+}$either into the apoplast and/or into the vacuoles to avoid toxicity. Small amounts of $\mathrm{Na}^{+}$can be stored into other organelles such as the ER and Golgi bodies (Jou et al., 2006).

\section{Apoplastic sequestration of $\mathrm{Na}^{+}$(salt exclusion)}

Most plants exposed to high saline conditions exclude $98 \%$ of the $\mathrm{Na}^{+}$ions in the soil solution (Munns, 2005). Plants can transport excess $\mathrm{Na}^{+}$from the cytoplasm through the plasma membrane to the apoplast and to the soil. A substantial amount of work has revealed the SOS (salt overly sensitive) pathway in plants, which plays a key role in $\mathrm{Na}^{+}$efflux from cytosol through the plasma membrane (Shi et al., 2002; Zhu, 2003). Several SOS loci have been identified; SOS1 in Arabidopsis, encodes $\mathrm{Na}^{+} / \mathrm{H}^{+}$antiporters in the plasma membrane, which is involved in $\mathrm{Na}^{+}$exclusion from cytoplasm. SOS1 is mainly located in root tissues; in the plasma membrane of the epidermal cells in to root tip as well as in the root stele. In halophytes, SOS1 from membrane vesicles was highly expressed in the shoot and root of T. halophila (VeraEstrella et al., 2005) even in non-stressed plants (Taji et al., 2004). SOS1 is activated under high salt stress by SOS2 (a member of calcium induced protein kinases, CIPK, family). CIPK24 is a serine protein kinase that is autophosphorylated, and this phosphorylation activates SOS1. However, CIPK24 is associated with SOS3 (or CBL4, calcineurin-B like) which escorts it to the

plasma membrane bound SOS1, for activation. CBL4 (SOS3) is a $\mathrm{Ca}^{2+}$ binder; under salt stress $\mathrm{Ca}^{2+}$ binds to the CBL4 and allows its interactions with CIPK24. CIPK-CBL mediated phosphorylation then activates plasma membrane bound SOS1, which activates $\mathrm{Na}^{+} / \mathrm{H}^{+}$ antiporters (Maathuis, 2014). This works as a linear pathway which starts with a transient salt 
induced $\mathrm{Ca}^{2+}$ increase in the cytoplasm and turns off when antiporters are activated and cytoplasmic $\mathrm{Na}^{+}$is limited (Adams \& Shin, 2014; Maathuis, 2014).

Moreover, CIPK24 may inhibit the activity of transporters like HKT1, which is involved in $\mathrm{Na}^{+}$ uptake (Kader, 2006; Maathuis, 2014). It can also enhance NHX1 activity, which is responsible for $\mathrm{Na}^{+}$influx into the vacuole.

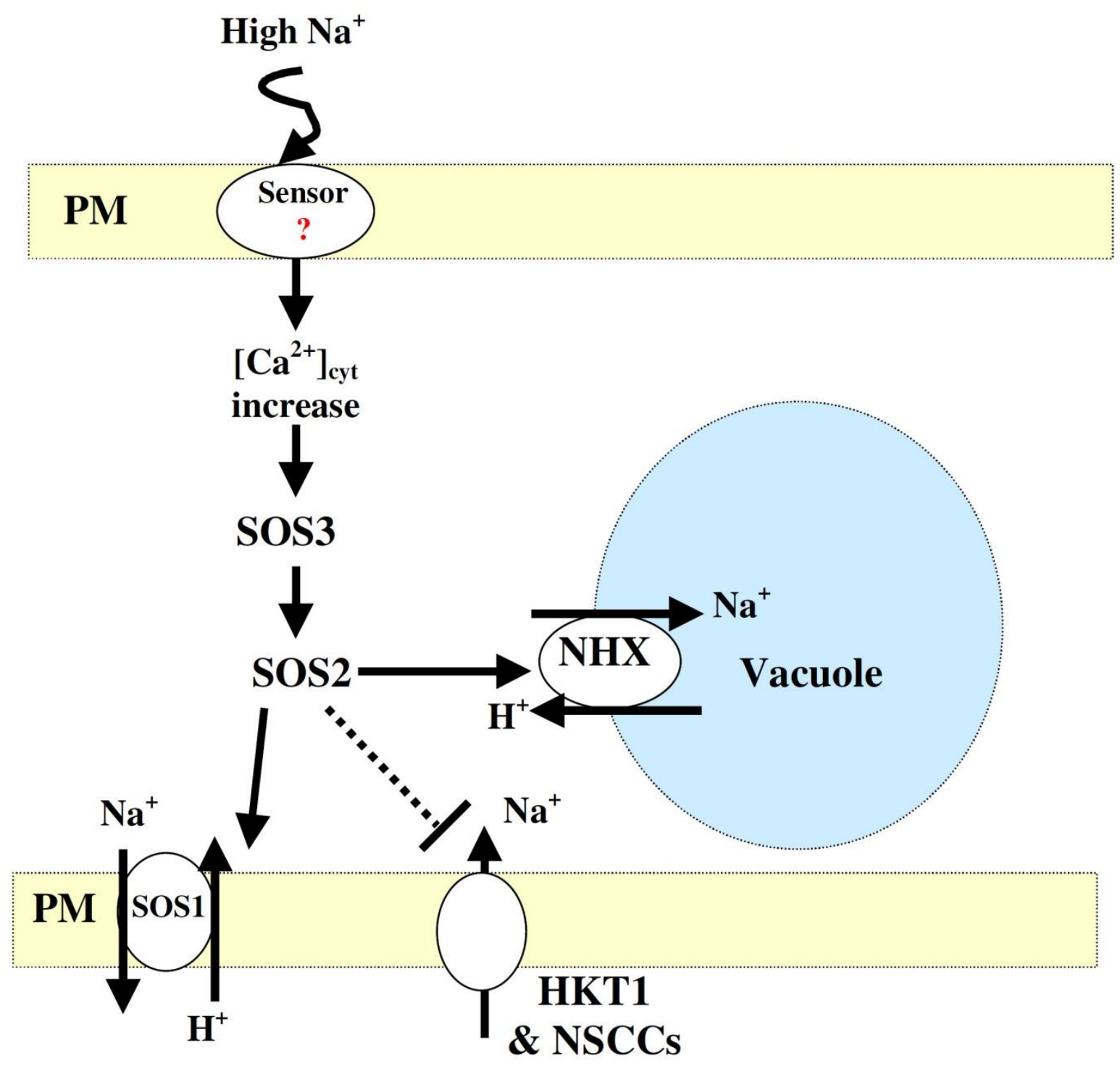

Fig 1.5. The proposed model for SOS (salt overly sensitive pathway) for regulation of cytosolic $\mathrm{Na}^{+}$. Source: Kader (2006) 


\section{$\underline{\mathrm{Na}^{+} \text {sequestration into the vacuole }}$}

Vacuoles occupy the largest portion of most plant cells. Sequestration of $\mathrm{Na}^{+}$into the vacuole is an important strategy to avoid cytoplasmic $\mathrm{Na}^{+}$toxicity. However, halophytes retain higher concentrations of $\mathrm{Na}^{+}$in the cytoplasm to use them as a cheap osmolytes for osmotic adjustment, but the majority of $\mathrm{Na}^{+}$is transported and stored in vacuoles. Excessive $\mathrm{Na}^{+}$is transported to the vacuole via a $\mathrm{Na}^{+} / \mathrm{H}^{+}$antiporter, which is energized by the vacuolar $\mathrm{H}^{+}$-ATPase (VATPase) and $\mathrm{H}^{+}$-pyrophosphatase (V-PPase) (Bartels \& Sunkar, 2005; Gaxiola et al., 2007; Flowers \& Colmer, 2008). VATPases generate proton motive force by hydrolyzing ATP, this force then energizes vacuolar transporters such as the $\mathrm{Na}^{+} / \mathrm{H}^{+}$antiporter. The activity of vacuolar transporters has been recorded to be up-regulated in many plants such as M. crystallinum (Ratajczak et al., 1994), S. bigelovii (Ayala et al., 1996; Parks et al., 2002), S. salsa (Qiu et al., 2007; Wang et al., 2007b).

Vacuolar $\mathrm{Na}^{+} / \mathrm{H}^{+}$antiport is mediated by NHX antiporters in plant cells (Fig 1.5) and were first identified in Arabidopsis under stress (Apse et al., 1999). Over expression of NHX in mutant Arabidopsis (AtNHX1) and in mutant rice (OsNHX1) significantly reduced the salt stress (Apse et al., 1999; Fukuda et al., 2004). Similar results were observed for other species such as wheat (Xue et al., 2004) and tomato (Zhang \& Blumwald, 2001) following manipulation of the expression of NHX. However, contradictory results were reported by (Yang et al., 2009). NHXs have dual selectivity for ions, for example under low $\mathrm{Na}^{+}$, NHX exchangers mediate $\mathrm{K}^{+} / \mathrm{H}^{+}$ exchange instead of $\mathrm{Na}^{+} / \mathrm{H}^{+}$exchange (Barragan et al., 2012). This property can help plants to maintain adequate $\mathrm{Na}^{+} / \mathrm{K}^{+}$ratios (Xue et al., 2004). In halophytes , NHX was only found in the roots of T. halophile (Vera-estrella et al., 2005). However, $\mathrm{Na}^{+} / \mathrm{H}^{+}$antiporter genes have been identified from $M$ crystallinum (Chauhan et al., 2000) and cloned in S. salsa (Ma et al., 2004) and A. gmelini (Hamada et al., 2001).

Besides NHX, cation/ $/ \mathrm{Ca}^{2+}$ exchangers (CCXs), a class of cation transporters, may also be involved in vacuolar $\mathrm{Na}^{+}$sequestration; these compounds have been found in Arabidopsis to exhibit $\mathrm{Na}^{+} / \mathrm{K}^{+}$transport in the vacuole (Morris et al., 2008). 


\subsection{Involvement of betacyanins in salt stress tolerance}

\section{$\underline{\text { 1.7.1 Betalains in plants }}$}

Plants have a biochemically diverse group of pigments including the chlorophylls, carotenoids, anthocyanins and betalains. These pigments have vast structural diversity and impart a range of colours in plants. These pigments may also perform vital functions; for example, chlorophyll converts light energy into chemical energy by photosynthesis. Similarly, carotenoids which provide yellow-orange colour to the plants, converts excess light energy to heat and protects foliage from excessive light (Demmig et al., 1987). Anthocyanins have a wide range of functional benefits in plants. The functional roles of chlorophylls and carotenoids are well established; for anthocyanins, too, extensive research has been conducted over the recent decades. However, betalains are much smaller and less common group of pigments for which their physiological functions have been largely overlooked.

Betalains are tyrosine-derived, nitrogenous compounds and are only found in one order of vascular plants (Caryophyllales) and certain fungi (Jain \& Gould, 2015a). Betalains in plants can produce similar colours to anthocyanins and share similar optical properties with them. However,

both pigments are mutually exclusive; they have never been recorded in the same species (Stafford, 1994). Because of their similarities, it has been suggested betalains might perform similar functions to anthocyanins in plants.

\subsubsection{Biochemical structure and distribution in plants}

Unlike other pigments, the chemical structure of betalains is not very well studied. Initially, betalains were called 'nitrogenous anthocyanins' which falsely implied structural similarities between anthocyanin and betalain (Lawrence et al., 1939). The detailed structures of betalain compounds were unknown until the mid-20 ${ }^{\text {th }}$ century (Steglich \& Strack, 1990). Later, Mabry and Dreiding, (1967) coined the term 'betalain' from their derivative betalamic acid, which was originally identified from red beet (Beta vulgaris). Now we know that betalains have two structural groups (i) betaxanthins $\left(\lambda_{\max }=470 \mathrm{~nm}\right)$ and (ii) betacyanins $\left(\lambda_{\max }=536 \mathrm{~nm}\right)$ (Fig. 1.6) (Stintzing \& Carle, 2004). 
(A)

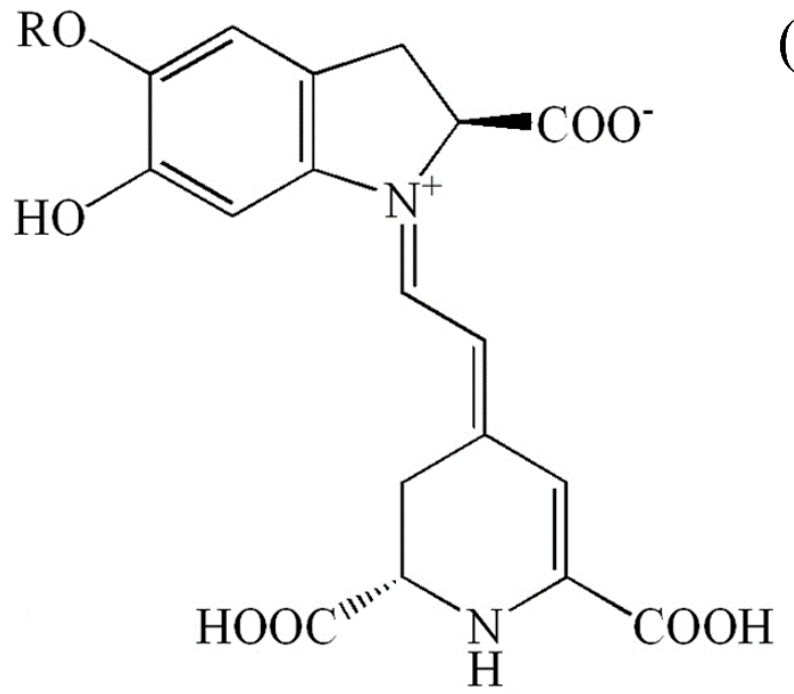

(B)

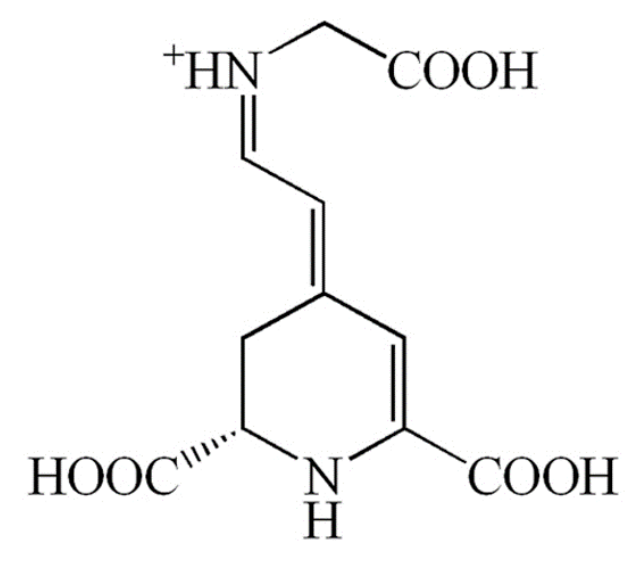

Fig 1.6. Chemical structure of (A) betanidin, a common betacyanin and (B) indicaxanthin, a betaxanthin

Betalain pigments are present in the fruits, flowers, leaves, stems, and/or roots of plants from a wide range of natural environments (Stintzing \& Carle, 2004; Grotewold, 2006; Tanaka et al., 2008; Gandía-Herrero \& García-Carmona, 2013; Sakuta, 2014) (Fig 1.7). Betalain production can be observed at different stages of plant growth, they may be present only in immature organs, only in senescing organs, or else persist for the life of the organ (Lee \& Collins, 2001; Hortensteiner \& Lee, 2007). Very few studies have looked at the histological locations of betalains and the information is very limited. However, studies show that betalains may be localized in dermal, ground, and vascular tissues of vegetative organs (Lee \& Collins, 2001; Nakashima et al., 2011; Mosco, 2012; Calcott, 2014). 


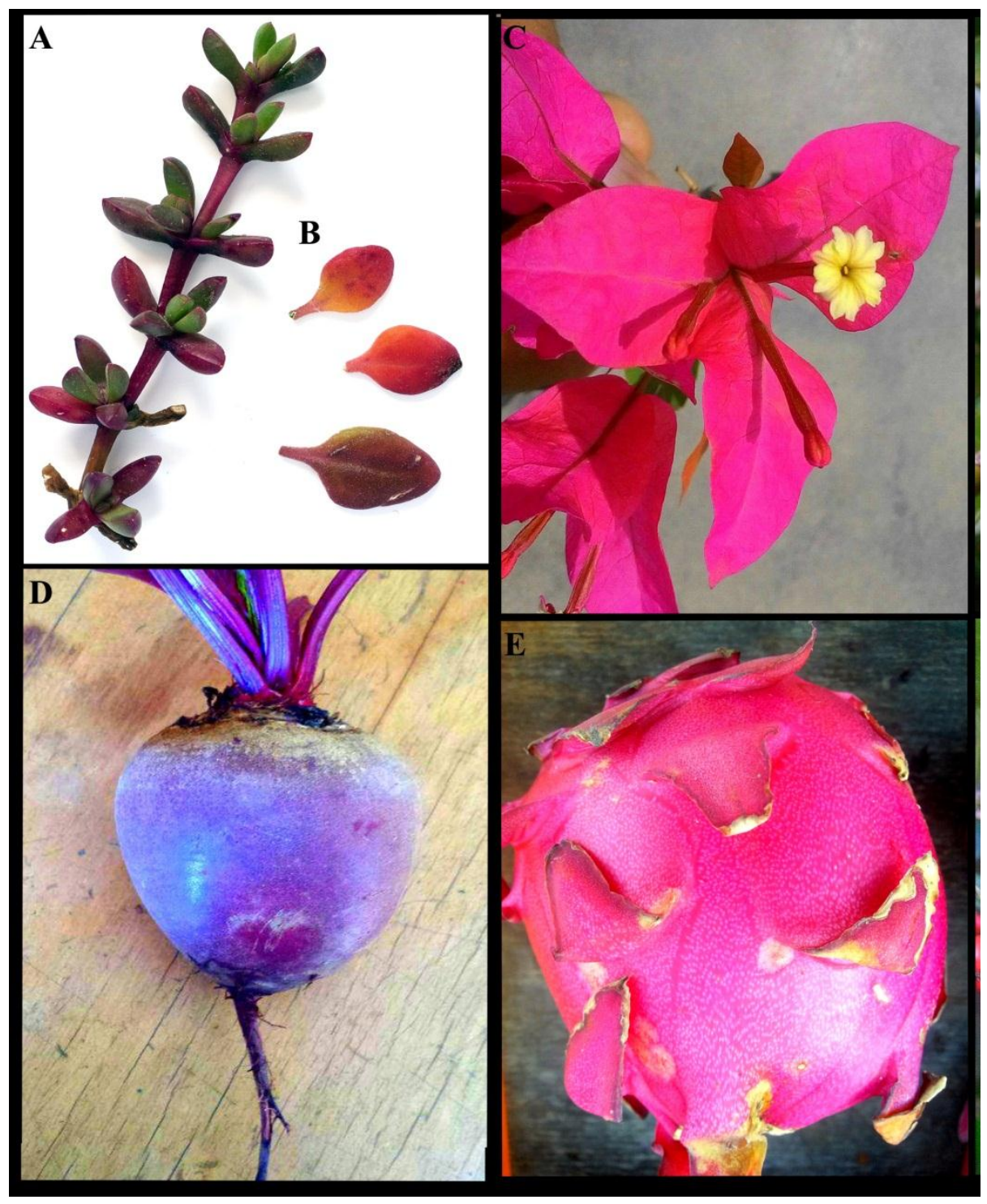

Fig 1.7. Betacyanic plants (A) Disphyma australe shoot (source: Jain and Gould, 2015) (B) Tetragonia implexicoma leaves, (C) Bougainvillea glabra flower and bract, (D) Beta vulgaris root, (E) Hylocereus undatus fruit. 


\section{$\underline{1.7 .3 \text { Biosynthesis }}$}

The biosynthetic steps involved in betalain biosynthesis are summarized in Fig 1.8. This biosynthetic pathway begins with the hydroxylation of L-tyrosine to L-3,4dihydroxyphenylalanine (L-DOPA) through the hydroxylase activity of tyrosinase. There may be a correlation between betalain accumulation and increases in transcription and activity of tyrosinase (Fukuda et al., 1995; Steiner et al., 1999; Wang et al., 2007b) but a betalain related tyrosinase gene has not yet been identified. Furthermore, Hatlestad et al., (2012) suggested that instead of tyrosinase, cytochrome P450 might catalyze the conversion of tyrosine to L-DOPA in Beta vulgaris. Thus, the involvement of tyrosinase in first step of betalain biosynthesis is a question of debate (Gandía-Herrero \& García-Carmona, 2013).

Following the hydroxylation of tyrosine, L-DOPA undergoes an extradiol cleavage by DOPA4,5-dioxygenase and forms betalamic acid via 4,5-seco DOPA. Now this betalamic acid reacts with various amines and amino acids to form betaxanthins (Pavoković \& Krsnik-Rasol, 2011; Gandía-Herrero \& García-Carmona, 2013).

Betacyanin synthesis involves the condensation of betalamic acid with cyclo-DOPA, assumed to occur spontaneously (Strack et al., 2003; Grotewold, 2006). The oxidation of L-DOPA by cytochrome P450 produces dopaquinone (Hatlestad et al., 2012); which spontaneously forms cyclo-DOPA. Structural variations of the final betacyanin molecules come from the glycosylation and/or acylation of cyclo-DOPA (Tanaka et al., 2008; Azeredo, 2009). 


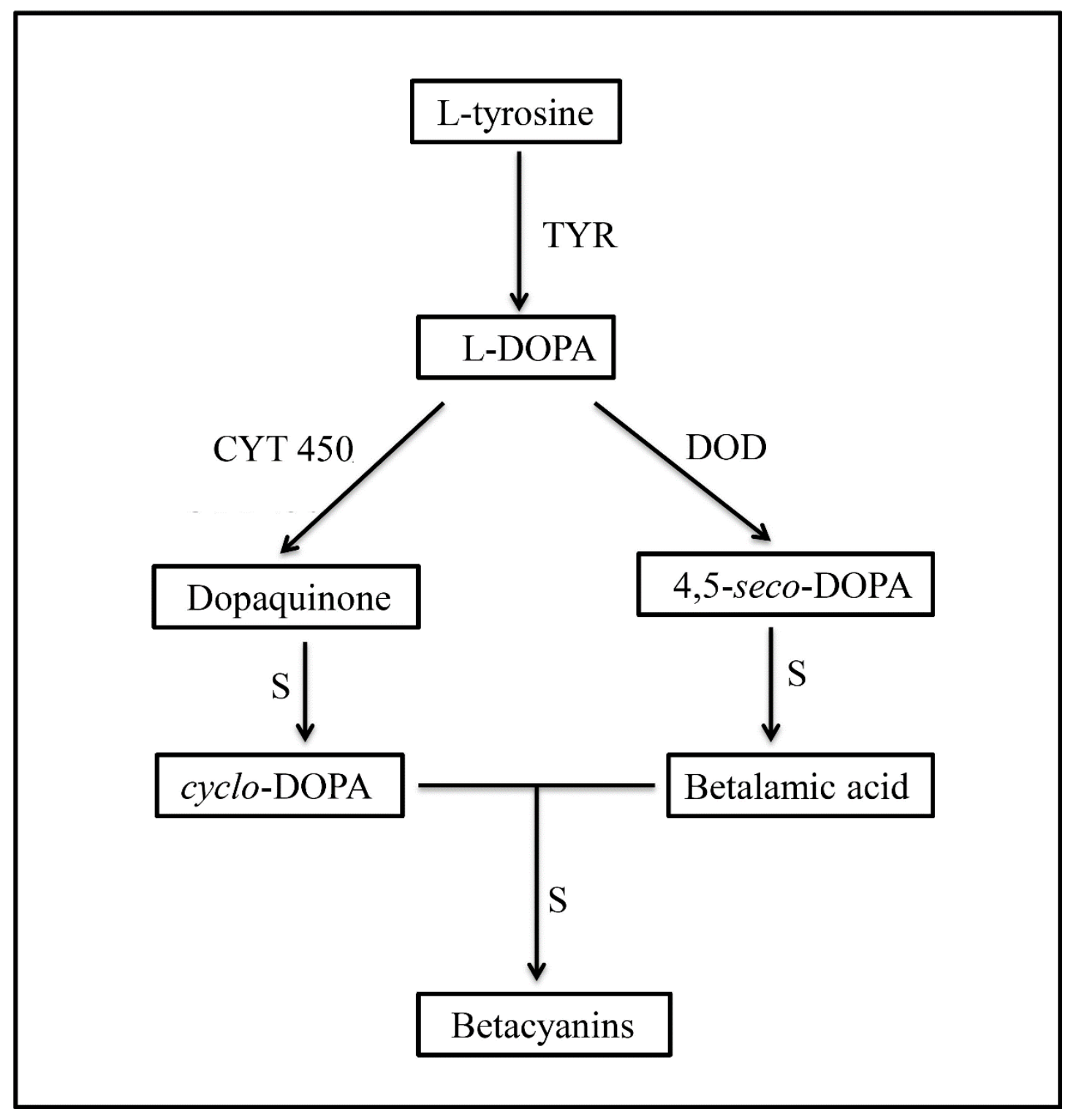

Fig 1.8. The betalain biosynthetic pathway. Enzyme abbreviations: CYT: cytochrome P450, DOD: 4,5-DOPA extradiol dioxygenase, TYR: tyrosine hydroxylating enzyme. ' $\mathrm{S}$ ' indicates spontaneous reaction. Adapted from: Harris et al., 2012; Hatlestad et al., 2012; Sakuta, 2014; Strack et al., 2003. 


\subsection{Addressing the functional significance of betacyanins under salinity stress}

Betalainic plants, specifically members of the Portulacaceae, Aizoaceae and Phytolaccoideae families, are commonly found in arid and/or saline habitats such as sandy dunes, deserts and salt marshes. Moreover, betacyanin concentration may be up-regulated under drought and salinity stress (Bothe, 1976; Wang et al., 2007b; Hayakawa \& Agarie, 2010; Nakashima et al., 2011). Therefore, betacyanin accumulation has been associated with salt stress tolerance in plants and various hypotheses have been proposed for their functional role.

Stintzing and Carle, 2004 suggested that betacyanins may function as compatible solutes to counter osmotic stress. However, Wang et al. (2007c) found no difference in cell sap osmolarity between betacyanic and acyanic cells either before or after salinity treatment. Similarly, Hughes et al. (2013) concluded that anthocyanin (another class of red pigments) concentrations in winter reddened leaves of Galax urceolata and Gaultheria procumbens, are too low to participate in osmotic adjustment.

Wang et al. (2007c) presented an intriguing new possibility for the involvement of betalains in salt tolerance. They found in Suaeda salsa that there was greater increase in vacuolar $\mathrm{H}^{+}$-ATPase (V-ATPase) activity in betacyanic than in green leaves when exposed to $400 \mathrm{mM}$ $\mathrm{NaCl}$. Therefore, betacyanic plants had a greater ability to compartmentalise $\mathrm{Na}^{+}$. To explain the link between V-ATPase activity and betacyanin accumulation, the authors suggested that plants use a similar mechanism to transport betacyanin and $\mathrm{Na}^{+}$into the cell vacuole. Therefore, betacyanin synthesis would stimulate V-ATPase activity for vacuolar transport of betacyanins, which would subsequently afford more efficient sequestration of $\mathrm{NaCl}$ into vacuoles.

Betalains may also photoprotect chloroplasts, since their capacity to process light energy is compromised by salinity. However, evidence for a photoprotective functions for betalains is lacking, although betalains share similar optical properties to anthocyanins (Neill \& Gould, 1999; Nakashima et al., 2011) for which there are abundant examples of photoprotective function (Gould, 2004; Hatier \& Gould, 2009; Gould et al., 2010). So, it would be interesting to test the photoprotective functions of betalains under salinity stress. Moreover, betalains have a strong antioxidant activity (Sepúlveda-Jiménez et al., 2004; Stintzing et al., 2005; Hilou et al., 2013; Taira et al., 2015) and it is possible therefore, that betalains may prevent oxidative stress 
in plants, caused by osmotic imbalance or ionic toxicity. However, no study to date has evaluated the antioxidant benefit of betacyanins in plants under salinity stress.

The multifaceted properties of betalains present the potential for a completely new strategy to develop salt tolerant crops. Betalain synthesis might be induced in conventional crops by transferring a single gene for betalain biosynthesis, which has already been achieved in cell cultures of potato and Antirrhinum majus (Harris et al., 2012). However, first it is crucial to understand the functional role of betacyanins in plants under salinity stress.

\subsubsection{Disphyma australe: an ideal system to test the functional significance of betacyanin synthesis under salt stress}

Disphyma australe is a succulent plant native to New Zealand (Fig 1.9). It belongs to the family Aizoaceae within the order Caryophyllales. In New Zealand, Aiton (1789) first described this plant as Mesembryanthemum australe. However, in 1927 it was transferred into the genus Disphyma, followed shortly afterwards by D. australe. Subsequently, three species were recognised: i) D. australe found on the mainland of New Zealand and on the Kermadec and Chatham islands; ii) D. papillatum, found exclusively in the Chatham islands; and iii) D. blackii found in Tasmania and southern Australia (Chinnock, 1971). More recently, Disphyma was reclassified as monotypic genus on the basis of multivariate analysis and examination of South African herbarium specimens (George, 1984). In 1986, Australian and New Zealand plants were classified as a subspecies (D. crassifolium subsp. clavellatum) distinct from the South African population (Baker \& De Salas, 2013). Despite the reclassification, New Zealand Plant Conservation Network (NZPCN) continues to use D. australe to refer to the populations of New

Zealand mainland and D. australe subsp. papillatum for the populations found on the Chatham Islands. D. australe in New Zealand has been recorded to hybridise with introduced Carpobrotus spp. (Chinnock, 1972). These triploid hybrids are sterile and were later classified as xCarpophyma mutabilis (hybrid of $D$. australe $x$ Carpobrotus edulis) and xCarpophyma pallida (hybrid of D. australe $x$ C. chilensis) (Heenan \& Sykes, 2010). 
Disphyma australe is a betacyanic halophyte which commonly grows on coastal areas and sand dunes throughout New Zealand. The species shows colour dimorphism in vegetative shoots; there are sympatric populations of red (betacyanic) and green (acyanic) leafed $D$. australe growing along the Wellington coastline. This colour dimorphism provides a good system to test the effects of salt stress between betacyanic and acyanic leaves without external factors such as previous acclimation differences between two morphs. 


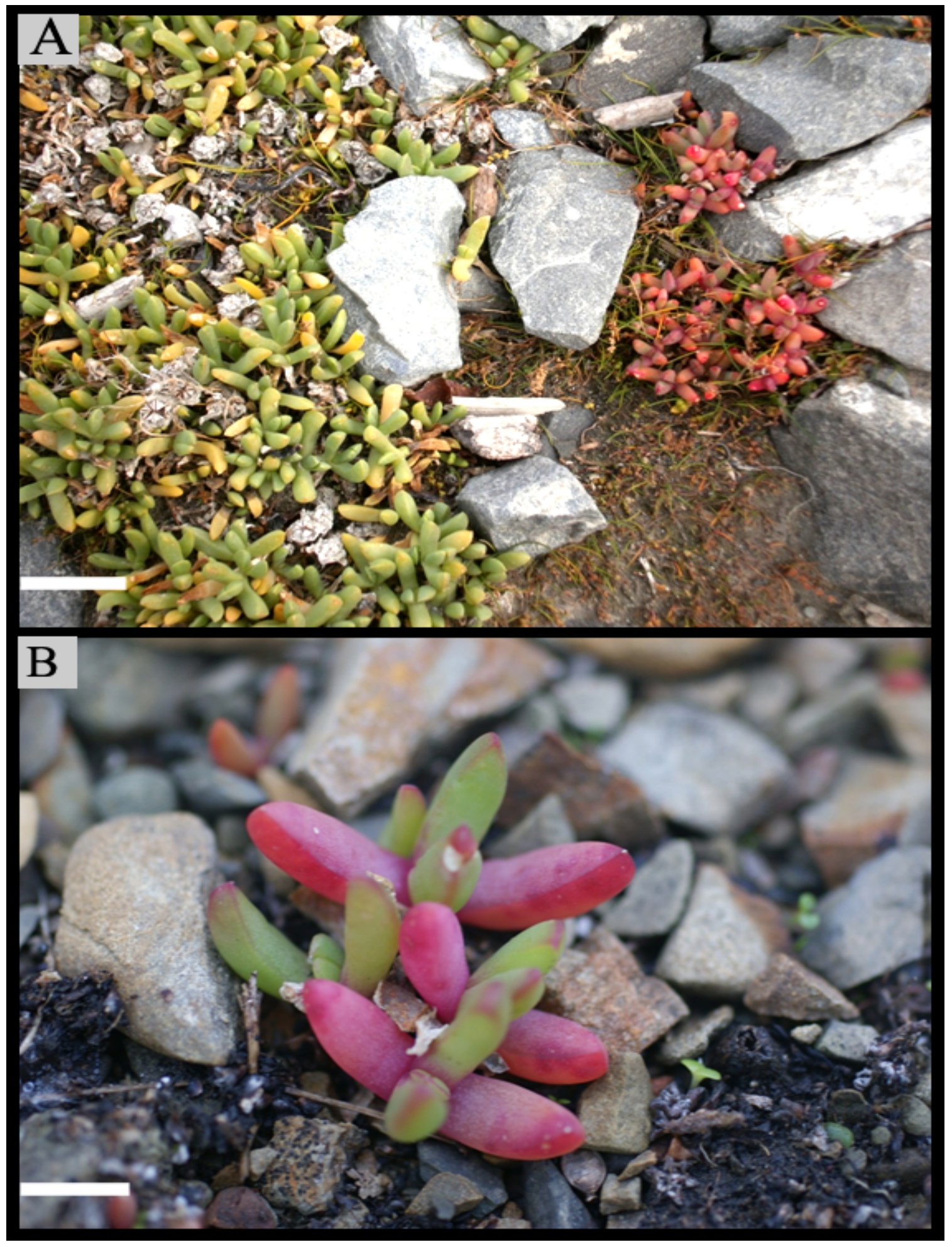

Fig 1.9. Vegetative shoots of $D$. australe showing contiguous red and green morphs (A) and red morphs (B) at Te Kopahou Reserve, Wellington. Bars: (A) $5 \mathrm{~cm}$ (B) $0.5 \mathrm{~cm}$. 


\subsubsection{Aims and objectives of the thesis}

The overall aim for this thesis was to examine the functional significance of betacyanins in plants under salt stress. During this project, several experiments with different hypotheses were performed to establish the relation between betacyanin accumulation and salinity tolerance mechanism in plants.

This thesis pursued the following objectives:

Chapter 2. Objectives: Investigate the impact of salt stress on betacyanin pigmentation in $D$. australe and identify the different betacyanins synthesised upon exposure to salt stress. Compare the physiological responses, for example photosynthetic yield of PSII, $\mathrm{CO}_{2}$ assimilation rate and stomatal conductance, of red and green morphs of $D$. australe under salt stress.

Hypotheses: (a) Betacyanin accumulation in shoots of $D$. australe is a direct response to salt stress. (b) Red (betacyanic) plants will have higher photosynthetic yield of PSII under salt stress compared to green (acyanic) plants. (c) Red plants will be physiologically more tolerant of salinity stress compared to green plants.

Chapter 3. Objectives: Identify the betacyanin biosynthetic step that is deficient in vegetative shoots of green morphs of $D$. australe and then test the possibility of betacyanin synthesis in green morphs upon substrate feeding. Identify the synthesised betacyanins using HPLC and compare them with that of red morphs. Examine the photoprotective roles of betacyanin in leaves of $D$. australe under various light and salinity treatments.

Hypotheses: (a) Green morphs lack the key biosynthetic enzyme tyrosinase which catalyses the formation of L-DOPA from tyrosine. (b) Vacuum infiltration of substrate (L-DOPA) to green leaves will produce betacyanins. (c) L-DOPA induced betacyanic leaves will have higher quantum yield of PSII compared to green leaves under the combination of light and salinity stress. (c) Hydrogen peroxide $\left(\mathrm{H}_{2} \mathrm{O}_{2}\right)$ production will be lower in L-DOPA induced red leaves as compared to green under combination of light and salinity stress 
Chapter 4. Objectives: Examine the effect of salt stress on relative growth (biomass accumulation) of red and green plants of $D$. australe. Also, study the osmotic stress tolerance ability (accumulation of osmoregulators, $\mathrm{Na}^{+}$sequestration) of red and green plants.

Hypotheses: (a) Red morphs of $D$. australe will have similar biomass accumulation to green morphs under control conditions, but higher biomass accumulation under salt stress. (b) The water potential of green leaves will be more negative than red leaves under salt stress. (c) Red leaves will be better able to sequester extra $\mathrm{Na}^{+}$away from mesophyll tissue than green leaves. 


\section{Chapter 2: Functional significance of betalain biosynthesis in leaves of Disphyma australe under salinity stress}

\subsection{Abstract}

Shoots of Disphyma australe, a coastal succulent plant native to New Zealand, vary in colour from entirely red to entirely green. We hypothesised that the red pigmentation develops in response to salinity stress, and that these betalain pigments contribute to salt tolerance. Effects of salinity on betalain content, $\mathrm{CO}_{2}$ assimilation, stomatal conductance, chlorophyll content and chlorophyll fluorescence were measured in leaves from red and green-leafed morphs. Newly formed leaves of both morphs were entirely green when grown under control conditions in a glasshouse. $\mathrm{NaCl}$ treatment increased betalain concentration 10-fold in leaves of the red, but not of the green morphs. The red leaves held six betacyanins (betanin, isobetanin, betanidin, isobetanidin, lampranthin-II, isolampranthin) but no betaxanthins; in the green morphs, neither betacyanin nor betaxanthin was present. In contrast, betalains were present in the petals of both morphs. Photosynthetic $\mathrm{CO}_{2}$ assimilation and water use efficiency were greater, and stomatal conductance was lower, in leaves of the red than of the green morphs following $\mathrm{NaCl}$ treatment. Photosystem II quantum yields and photochemical quenching were both greater in red than in green $\mathrm{NaCl}$ treated leaves under white actinic light. The data indicate that betalain accumulation in red morphs is a direct response to salinity, but that the green morphs, although possessing the genetic potential to biosynthesise betalains, lack the mechanism for the induction of betalain in

response to salinity stress. Foliar betalains appear to ameliorate responses to salinity stress in Disphyma australe.

\subsection{Introduction}

Disphyma australe (W. T. Aiton), a succulent plant common on coastal cliffs and dunes throughout New Zealand, shows marked variation in shoot colour (Allan, 1961; Chinnock, 1971). The prostrate stems and erect, fleshy leaves are, in some plants, entirely green; in others, the vegetative shoot is partially or entirely red (Fig. 2.1). The red and green D. australe morphs 
often co-occur at coastal locations. However, nothing is known of the possible genetic or environmental basis for this colour polymorphism.
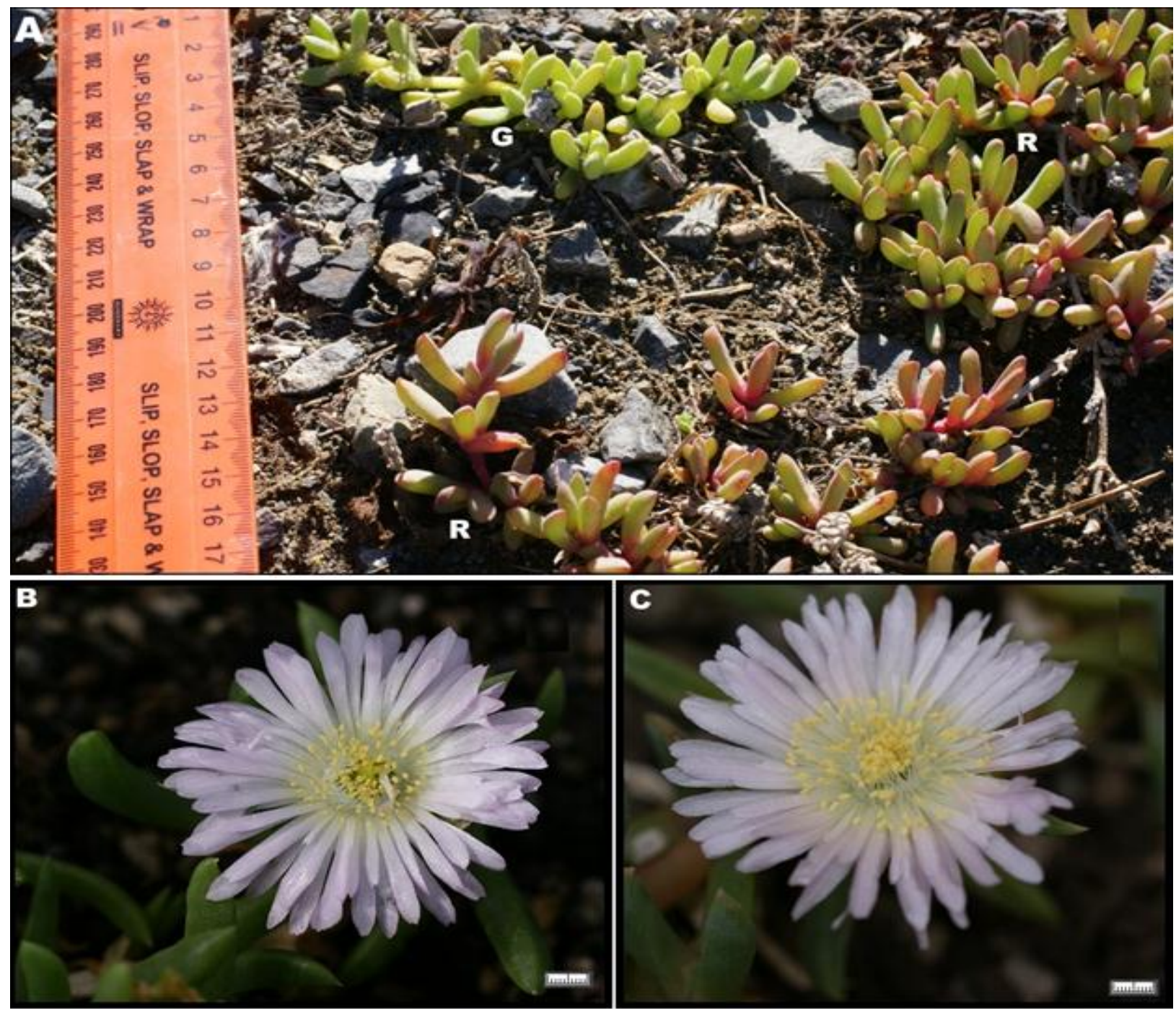

Fig 2.1 Vegetative shoots of Disphyma australe (A), showing contiguous red (R) and green (G) morphs at Te Kopahou Reserve, Wellington. Flowers of green (B) and red (C) D. australe morphs. Bar $=1 \mathrm{~cm}$.

As with other members of the Aizoaceae, the red colouration in D. australe results from the production of betalains (Chinnock, 1971). Betalains are water-soluble nitrogen-containing pigments synthesized from tyrosine, and there are two structural groups: the red/violet betacyanins, and the yellow/orange betaxanthins (Strack et al., 2003; Azeredo, 2009). Unlike the 
anthocyanins, which are by far the most common class of red pigment (Gould, 2004), the functional role of both groups of betalains remains poorly understood (Ibdah et al., 2002; Stintzing \& Carle, 2004). Anthocyanins and betalains do not co-occur naturally in the same plant (Stafford, 1994), although the simultaneous biosynthesis of both is theoretically possible as shown using transgenic Arabidopsis (Harris et al., 2012). As with the anthocyanins, it has been hypothesized that betalain accumulation in leaves may be an ameliorative response to abiotic stressors such as high UV irradiance, strong light, low temperature and salinity (Bothe, 1976; Ibdah et al., 2002; Wang et al., 2006; Wang \& Liu, 2007; Hayakawa \& Agarie, 2010). Indeed, in the halophyte Sueda salsa, red colouration in the vegetative shoot is more pronounced when plants are growing in the intertidal zone than on higher land, possibly indicating the involvement of salinity in betalain accumulation (Wang et al., 2006). Furthermore, those $S$. salsa plants that held the higher levels of betacyanin showed increased tonoplast $\mathrm{H}^{+}$-ATPase activity; the presence of betalains apparently correlated with an improved removal of $\mathrm{Na}^{+}$from cytoplasm to vacuole (Wang et al., 2007b).

It is possible therefore, that variation in shoot colour among D. australe individuals reflects spatial variation in the severity of salt stress they experience, and that the development of the red colour serves to mitigate the stress. Alternatively, the green morphs may simply lack the genetic capability to synthesise betalain pigments. Here, I compare the pigment composition and physiological responses to salinity of green and red D. australe. I hypothesise that $D$. australe accumulate betalain under saline conditions, and that betalainic plants are physiologically more tolerant of salinity stress. I report the effects of $\mathrm{NaCl}$ on betalain levels, $\mathrm{CO}_{2}$ assimilation rate and stomatal conductance in leaves from red and green-leafed morphs, and also quantify the effects of salinity on the photosynthetic yield of PSII in red and green leaves.

\subsection{Materials and Methods}

\subsubsection{Plant material}

A healthy shoot was taken from each of 10 red and 10 green D. australe plants, randomly collected from South-facing dunes and rocky outcrops along the coast at Te Kopahou reserve, Wellington, New Zealand ( $41^{\circ} 21^{\prime} 01^{\prime}$ S, 17443'55” E). Shoot cuttings with two leaves attached were rooted in trays containing a 2:1 mix of potting compost and sand for $5 \mathrm{wk}$, and then 
transferred one plant per pot to $800 \mathrm{~mL}$ pots with the same substrate and grown in an unheated glasshouse at Victoria University of Wellington.

\subsubsection{Salinity treatments}

Five individuals of each colour morph were watered with $15 \mathrm{~mL}$ of $200 \mathrm{mM} \mathrm{NaCl}$ every third day for 2 wk. Control plants were irrigated with distilled water. The youngest fully expanded leaves were harvested from each plant after 2 wk of treatment.

\subsubsection{Pigment extraction and quantification}

Exactly $1 \mathrm{~g}$ of fresh leaf was flash frozen in liquid nitrogen, ground to a powder and extracted in $10 \mathrm{~mL} 100 \%$ methanol for $1 \mathrm{~h}$ at $4{ }^{\circ} \mathrm{C}$. The extracts were centrifuged for $5 \mathrm{~min}$ at $10,000 \mathrm{~g}$, the supernatants discarded, and the pellets re-suspended in $10 \mathrm{~mL}$ distilled water at $\mathrm{pH} \mathrm{5}$, adjusted using $\mathrm{HCl}$ (Wang et al., 2006). Betalain content was estimated spectrophotometrically using a Shimadzu (Kyoto, Japan) 2550 UV-VIS spectrophotometer. Betalain content was estimated as $\mathrm{A}_{538,-0.33} \mathrm{~A}_{662}$, where $\mathrm{A}_{538}=\mathrm{A}_{\lambda \max }$. The subtraction of $0.33 \mathrm{~A}_{662}$ compensated for the small overlap in absorption by extracted chlorophyll. To estimate foliar chlorophyll and carotenoid content, frozen leaves were extracted in 80\% acetone, and absorbances at 470, 647 and $663 \mathrm{~nm}$ were measured in a Shimadzu spectrophotometer. Pigment concentrations were calculated using the equations by Lichtenthaler (1987).

Individual betalains were quantified using an Agilent 1100 Series HPLC (Waldbronn, Germany) with a Phenomenex $\mathrm{C}_{18}$ reversed phase column $(5 \mu \mathrm{M}, 250 \mathrm{X} 4.6 \mathrm{~mm})$. The injection volume was $50 \mu \mathrm{L}$ and column temperature was $25^{\circ} \mathrm{C}$. HPLC gradients were (A) formic acid: $\mathrm{H}_{2} \mathrm{O}$ (1:99, v:v), and (B) acetonitrile: $\mathrm{H}_{2} \mathrm{O}(80: 20$, v:v). Betaxanthins were separated isocratically with $100 \% \mathrm{~A}$, followed by a linear gradient from $0 \%$ to $20 \% \mathrm{~B}$ in $60 \mathrm{~min}$, and then $20 \%$ to $100 \% \mathrm{~B}$ in 5 min. Betacyanin separation was done beginning with $2 \% \mathrm{~B}$ in $\mathrm{A}$ and increasing to $33 \% \mathrm{~B}$ in A over $60 \mathrm{~min}$. Betacyanins were detected at $538 \mathrm{~nm}$ and betaxanthins at $470 \mathrm{~nm}$ (Kugler et al., 2007). Retention times of betalain peaks were compared to those from published records of authentic samples (Kugler et al., 2004, 2007; Svenson et al., 2008) and to previous work on D. australe (D. Lewis; pers. comm.). 


\subsubsection{Gas exchange}

An LI-6400 gas exchange system (LiCor, Lincoln, NE, USA) equipped with a red LED light source and leaf chamber LI-6400-08 was used to calculate maximum net $\mathrm{CO}_{2}$ assimilation rate $\left(\mathrm{A}_{\max }\right)$ and stomatal conductance $\left(\mathrm{g}_{\mathrm{s}}\right)$ for one leaf per plant. The chamber was modified such that the leaf was held in place using a polystyrene strip bearing a small hole, and was rendered airtight with blue-tack putty. All data were collected in the early morning. The air supply contained $400 \mu \mathrm{mol} \mathrm{CO}_{2} \mathrm{~mol}^{-1}$, the irradiance was $1500 \mu \mathrm{mol} \mathrm{m}^{-2} \mathrm{~s}^{-1}$, and leaf temperature was maintained at $25^{\circ} \mathrm{C}$. Water use efficiency (WUE) was calculated as the ratio of maximum net $\mathrm{CO}_{2}$ assimilation rate to stomatal conductance $\left(\mathrm{A}_{\max } / \mathrm{g}_{\mathrm{s}}\right.$ ). Stomatal densities (frequencies per $\mathrm{mm}^{2}$ ) were counted using nail varnish replicas of the leaves.

\subsubsection{Chlorophyll fluorescence}

Plants were dark adapted for two hours and then the ratio of variable to maximal chlorophyll fluorescence $(\mathrm{Fv} / \mathrm{Fm})$ measured using a Walz 2500 (Effeltrich, Germany) pulse amplitude modulated (PAM) chlorophyll fluorometer. Rapid light response curves for dark-adapted plants were generated using the light source supplied by the PAM, and quantum yield of PSII ( $\Phi_{\text {PSII }}$ ), photochemical quenching $(\mathrm{qP})$ and non-photochemical quenching (NPQ) were recorded as described by Maxwell and Johnson (2000).

\subsubsection{Leaf reflectance}

Reflectance spectra were recorded for five randomly selected green and red leaves, one leaf per plant, using an Ocean Optics (Dunedin, FL, USA) USB 2000 diode-array spectrometer, a QR 400-7-UV-VIS reflectance probe and a PX-2 pulsed xenon light source. Light was directed at $45^{\circ}$ to the leaf's adaxial surface and diffuse reflectance, measured at 0.4-nm intervals from 400 to $700 \mathrm{~nm}$, was referenced to an Ocean Optics WS-1 diffuse reflectance standard.

\subsubsection{Soil salinity}

To quantify variation in substrate salinity levels at the Te Kopahou Reserve, and to study how the distribution of red and green morphs might vary with edaphic $\mathrm{NaCl}$ levels, we ran five linear transects from the high tide line for $50 \mathrm{~m}$ towards the dunes. Substrate samples $5 \mathrm{~cm}$ deep were collected at 16,30, and $50 \mathrm{~m}$ from the high tide line, and their electrical conductivities (EC), 
used here as a proxy for $\mathrm{NaCl}$ concentrations, were measured for 1:5 (v/v) substrate: water mixes at $25^{\circ} \mathrm{C}$ using an IQ350 conductivity meter (IQ Scientific Instruments, San Diego, CA, USA), calibrated with $1000 \mu \mathrm{S} \mathrm{cm}^{-1} \mathrm{NaCl}$. At each location we counted the numbers of red and green morphs within $1 \mathrm{~m}$ on either side of the transects.

\subsubsection{Statistics}

Reported data represent the means of at least three replicates \pm standard errors. Normality of the data was confirmed using the Kolmogorov-Smirnov test in SPSS, and homogeneity of variance was confirmed using Levene's test $(\mathrm{P}>0.05)$. Differences in pigment levels and in gas exchange measurements between red and green morphs were tested using two-way ANOVA. Tukey's Post-hoc test $(\mathrm{P}<0.05)$ was performed for within-factor and between-treatment comparisons. Repeated measure ANOVA was used for comparisons of the rapid light response curves (Potvin et al., 1990). Paired $t$ tests were used to compare before and after measurements on the same plants. Frequencies of red and green morphs in field were compared using a Chi squared test.

\subsection{Results}

\subsubsection{Betalain distribution}

The leaves on $D$. australe were succulent and triquetrous, borne on multiple branches from prostrate stems. Shoot colour varied substantially among individuals of D. australe, even between adjacent plants at the same location (Fig. $2.1 \mathrm{~A}$ ). In general, red pigmentation was the more intense and expansive at the more sun-exposed sites; entire leaves and stems were red in plants that grew under full sunlight, whereas those found in partial shade were pigmented red only in the internodes and at the leaf bases. Nevertheless, shoots that were entirely green were to be found among the predominantly red patches. Irrespective of the colour of vegetative shoots, the petals of both morphs were commonly a pale violet (Fig. 2.1 B, C).

Microscopic observations of transverse sections revealed that the red leaves bore betalains exclusively in the epidermis and the outermost mesophyll layer; in the red stems, betalains were present in the innermost cortical cell layer as well as the epidermis, hypodermis, and outer cortex (Fig. 2.2 A, C). In contrast, betalains were not evident in any green leaf or stem 
(Fig. 2.2 B, D). There were not any other obvious anatomical differences between the leaves of two morphs.
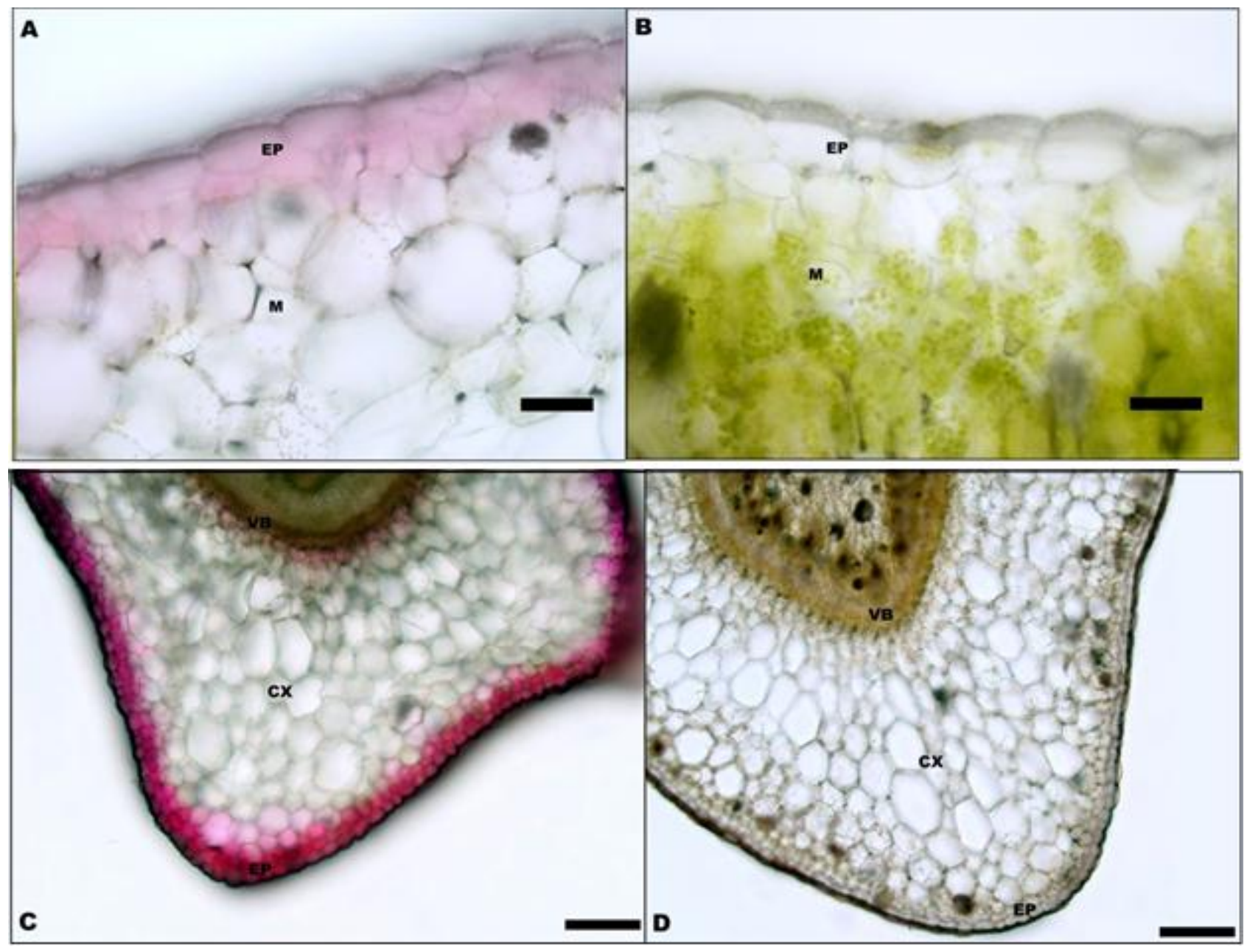

Fig 2.2. Transverse sections through shoots of Disphyma australe. Red leaf (A), green leaf (B), red stem $(\mathrm{C})$ green stem $(\mathrm{D})$. Key: $\mathrm{EP}=$ Epidermis, $\mathrm{M}=$ Mesophyll tissue, $\mathrm{VB}=$ Vascular Tissue, $\mathrm{CX}=$ Cortex. Bars: A, B $=20 \mu \mathrm{M} ; \mathrm{C}, \mathrm{D}=100 \mu \mathrm{M}$. 


\subsubsection{Betalain induction}

Newly formed leaves on red shoot cuttings of $D$. australe were entirely green when grown under control conditions in the glasshouse for $5 \mathrm{wk}$, although their internodes retained some red coloration (Fig. $2.3 \mathrm{~A})$.

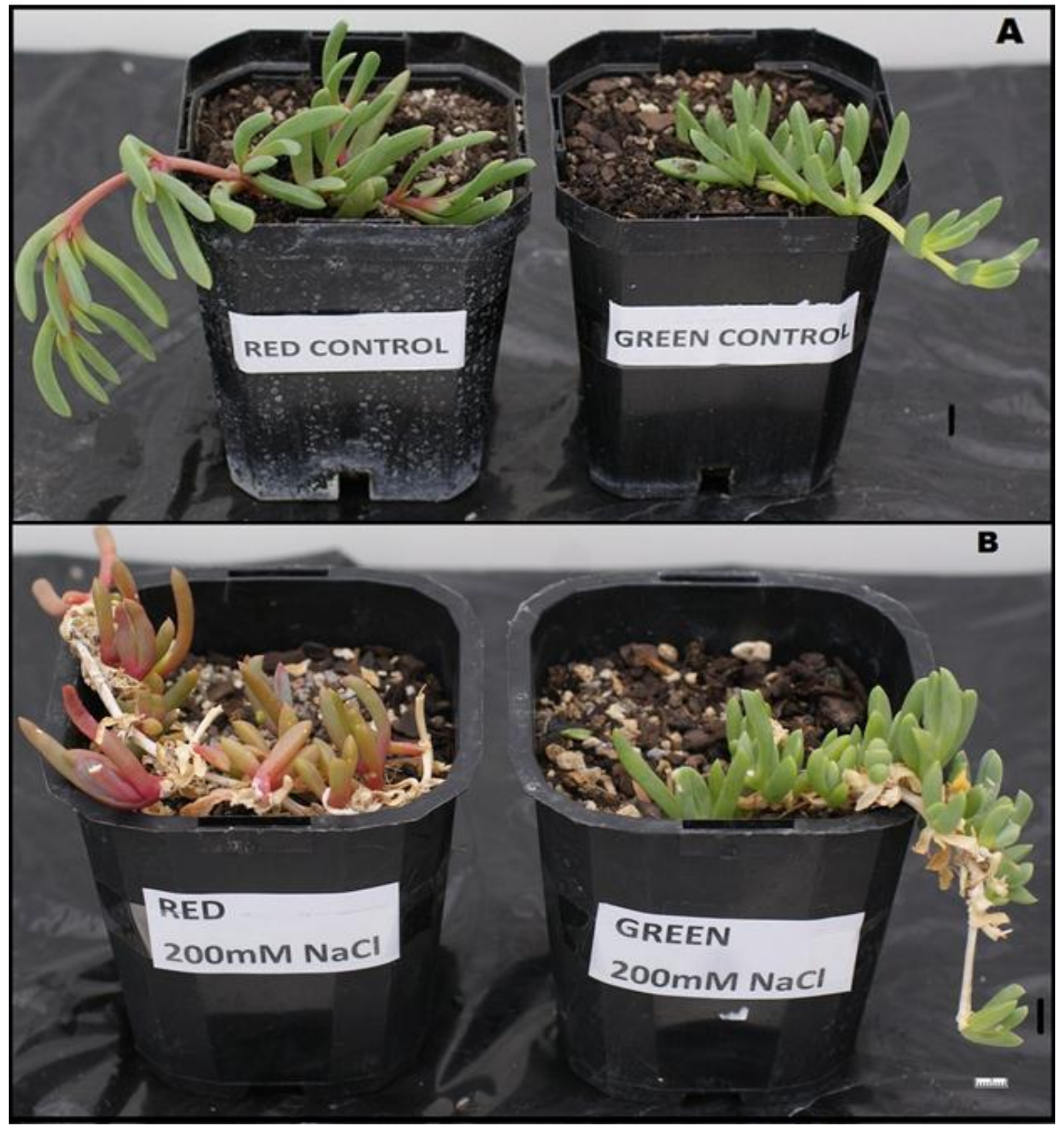

Fig 2.3 Photographs of Disphyma australe, green and red morphs (A) control plants, (B) 200 $\mathrm{mM} \mathrm{NaCl}$ treated plants. $\mathrm{Bar}=1 \mathrm{~cm}$. 
$\mathrm{A}_{538}$ values of methanolic extracts of leaves from red and green morphs before $\mathrm{NaCl}$ treatment confirmed that both morphs lacked betacyanin. However, betacyanin concentration increased up to 10 fold in leaves of the glasshouse-grown red morphs when exposed to $200 \mathrm{mM} \mathrm{NaCl}$ for $14 \mathrm{~d}$ ( $\mathrm{P}<0.001$; Figs. $2.3 \mathrm{~B}, 2.4$ ). In contrast, $\mathrm{A}_{538}$ values from green leaf extracts did not increase significantly after $\mathrm{NaCl}$ treatment $(\mathrm{P}>0.08)$. The $\mathrm{A}_{538}$ values for leaf extracts were on average 17-fold higher for the red than the green morphs after $\mathrm{NaCl}$ treatment. There was no significant change in $\mathrm{A}_{538}$ for extracts from control plants of both red and green morphs over the $14 \mathrm{~d}$ experimental period $(\mathrm{P}>0.05)$.

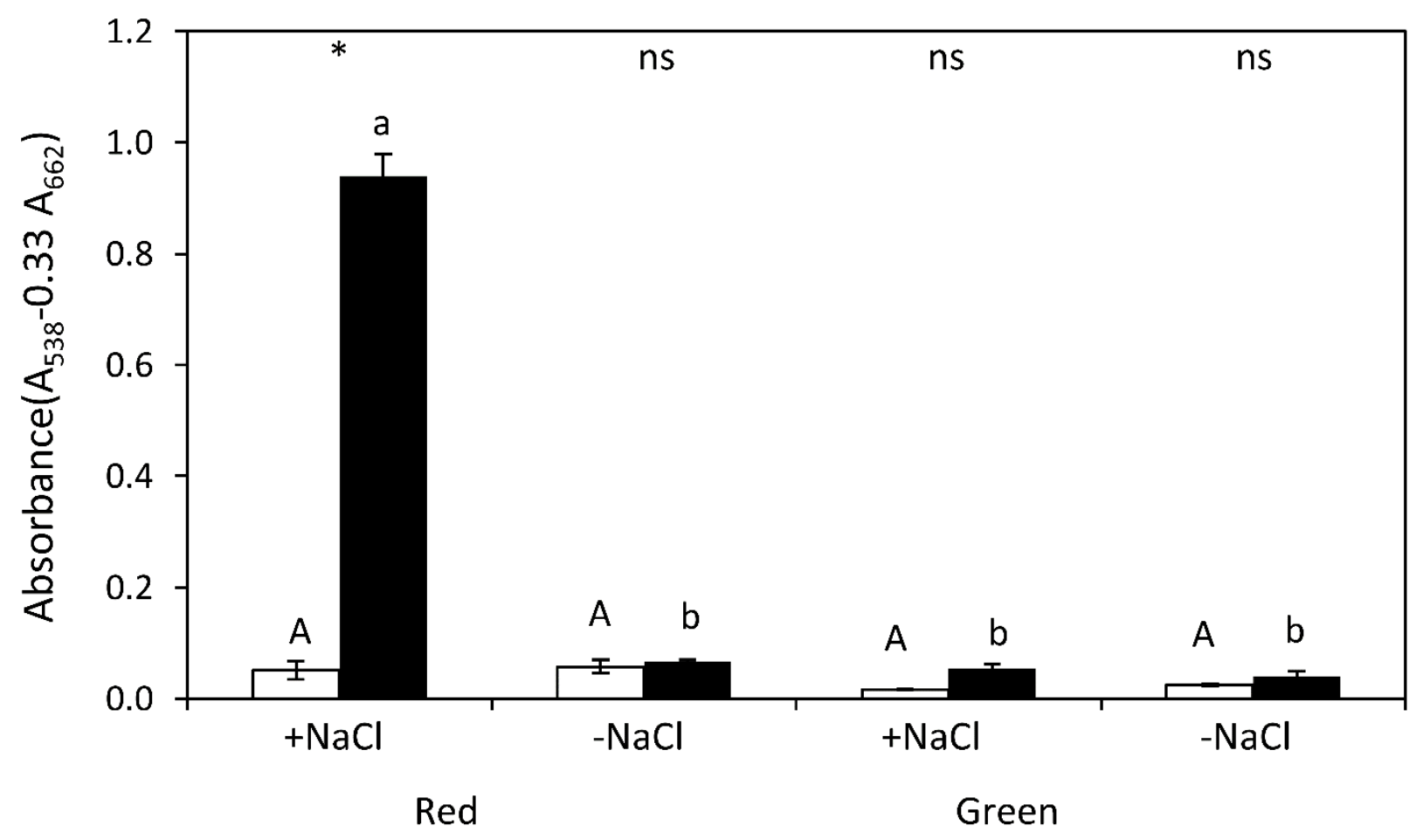

Fig 2.4 Betalain content in extracts from leaves of red and green morphs of Disphyma australe before (white bars) and $14 \mathrm{~d}$ after (black bars) $200 \mathrm{mM} \mathrm{NaCl}$ treatment $(\mathrm{n}=5$, means $\pm \mathrm{SE})$. Asterisks denote significant differences within treatments $(\mathrm{P}<0.05)$. Different letters above bars indicate significant differences across treatments $(\mathrm{P}<0.05)$.

\subsubsection{Betalain profile characterization}

The betalainic extracts of leaves from NaCl-treated red morphs generated six HPLC peaks at $538 \mathrm{~nm}$ (Fig. $2.5 \mathrm{~A}$ ), but none at $470 \mathrm{~nm}$. Based on their retention times, the peaks were 
tentatively identified as betanin, isobetanin, betanidin, isobetanidin, lampranthin-II and isolampranthin (Table 2.1). In contrast, no peak was detected in the extracts from $\mathrm{NaCl}$ - treated green morphs, or from untreated red and green morphs at 538nm or 470nm (Fig. $2.5 \mathrm{~B}$ ).
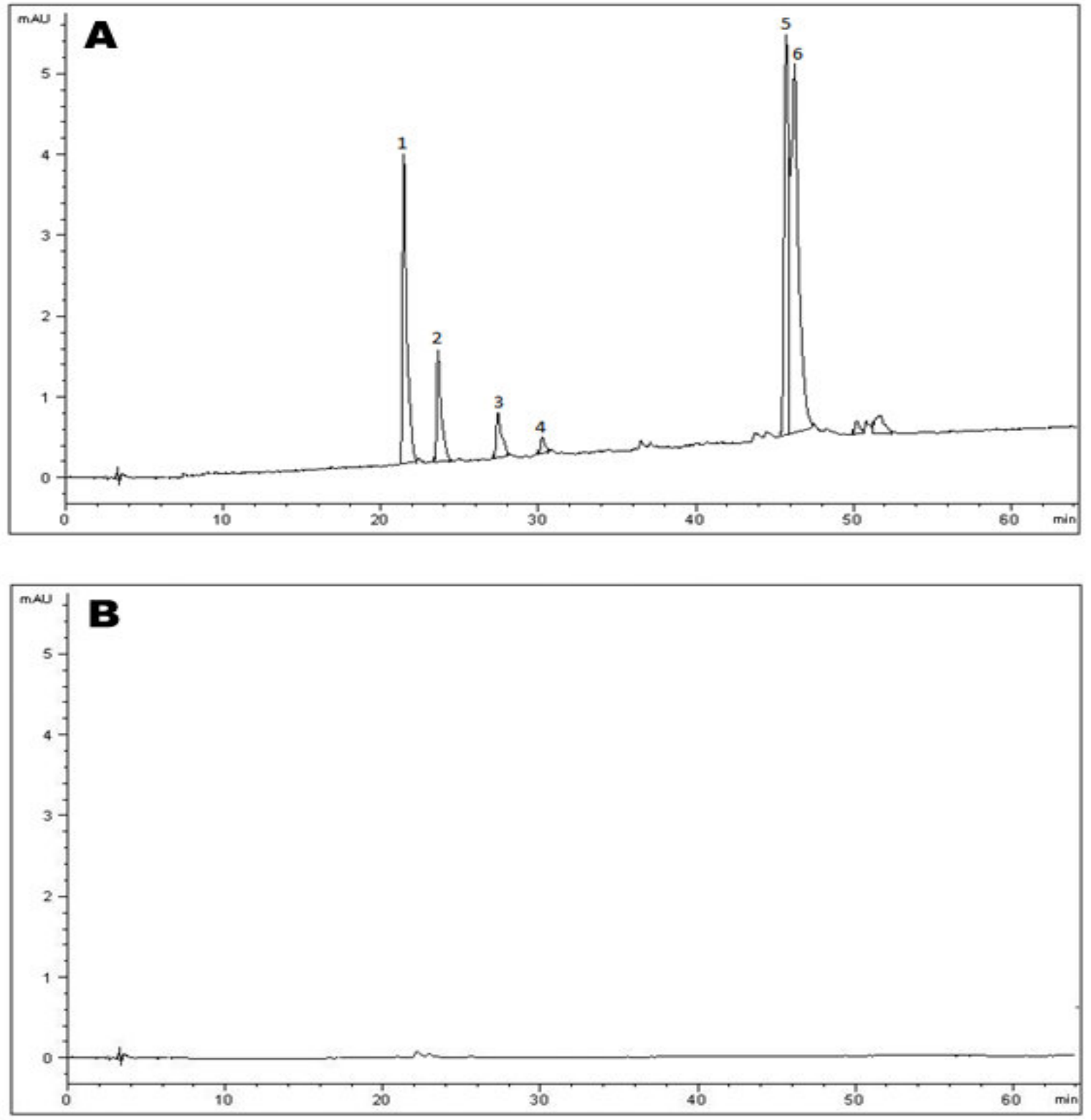

Fig 2.5 HPLC chromatogram for leaf extracts of red morphs of Disphyma australe $14 \mathrm{~d}$ after (A) and before (B) $200 \mathrm{mM} \mathrm{NaCl}$ treatment at $538 \mathrm{~nm}$ (for peak assignment see Table 2.1). 
Table 2.1: Betalain peaks detected in leaf extracts from red morphs of $D$. australe after salinity treatment. Tentative identities were assigned according to HPLC retention times as reported by, Kugler et al. (2007) and Svensson et al. (2008).

\begin{tabular}{|c|c|c|c|}
\hline & $\begin{array}{l}\text { Retention } \\
\text { Time (min) }\end{array}$ & Betalain & Common name \\
\hline 1 & 21.44 & Betanidin-5- $O$ - $\beta$-glucoside & betanin \\
\hline 2 & 23.62 & Isobetanidin-5-O- $\beta$-glucoside & Iso-betanin \\
\hline 3 & 27.41 & Betanidin & Betanidin \\
\hline 4 & 30.23 & Isobetanidin & Isobetanidin \\
\hline 5 & 45.72 & $\begin{array}{l}\text { Betanidin-5-O-[6'-O-(E)-feruloyl- } \\
\beta \text {-glucoside }]\end{array}$ & Lampranthin II \\
\hline 6 & 46.25 & $\begin{array}{l}\text { Isobetanidin-5-O-[6'-O-(E)- } \\
\text { feruloyl- } \beta \text {-glucoside }]\end{array}$ & Iso-lampranthin II \\
\hline
\end{tabular}

\subsubsection{Chlorophyll and carotenoid contents}

The green leaves which developed on glasshouse-grown cuttings from the red morphs had carotenoid and chlorophyll concentrations comparable to those from the green morphs $(\mathrm{P} \geq 0.05$; Fig. $2.6 \mathrm{~A}, \mathrm{~B})$. After $14 \mathrm{~d}$ with $\mathrm{NaCl}$, chlorophyll and carotenoid content declined, more so for the green (by 10\% and 28\%, respectively) than for the newly-reddened leaves on the red morphs (5\% and 23\%). Ratios of chlorophyll $a: b$ were initially similar for the two morphs, but after $\mathrm{NaCl}$ treatment, they fell sharply $(\mathrm{P}<0.001)$ in the red leaves, associated with an increase in chlorophyll $b$ and decrease in chlorophyll $a$ (Fig. $2.6 \mathrm{C}$ ). In contrast, the chlorophyll $a: b$ ratio in leaves of the green morph increased after $\mathrm{NaCl}$ treatment. Ratios of total carotenoids: total chlorophylls were similar $(\mathrm{P}>0.05)$ in both morphs (Fig. 2.6 D). 

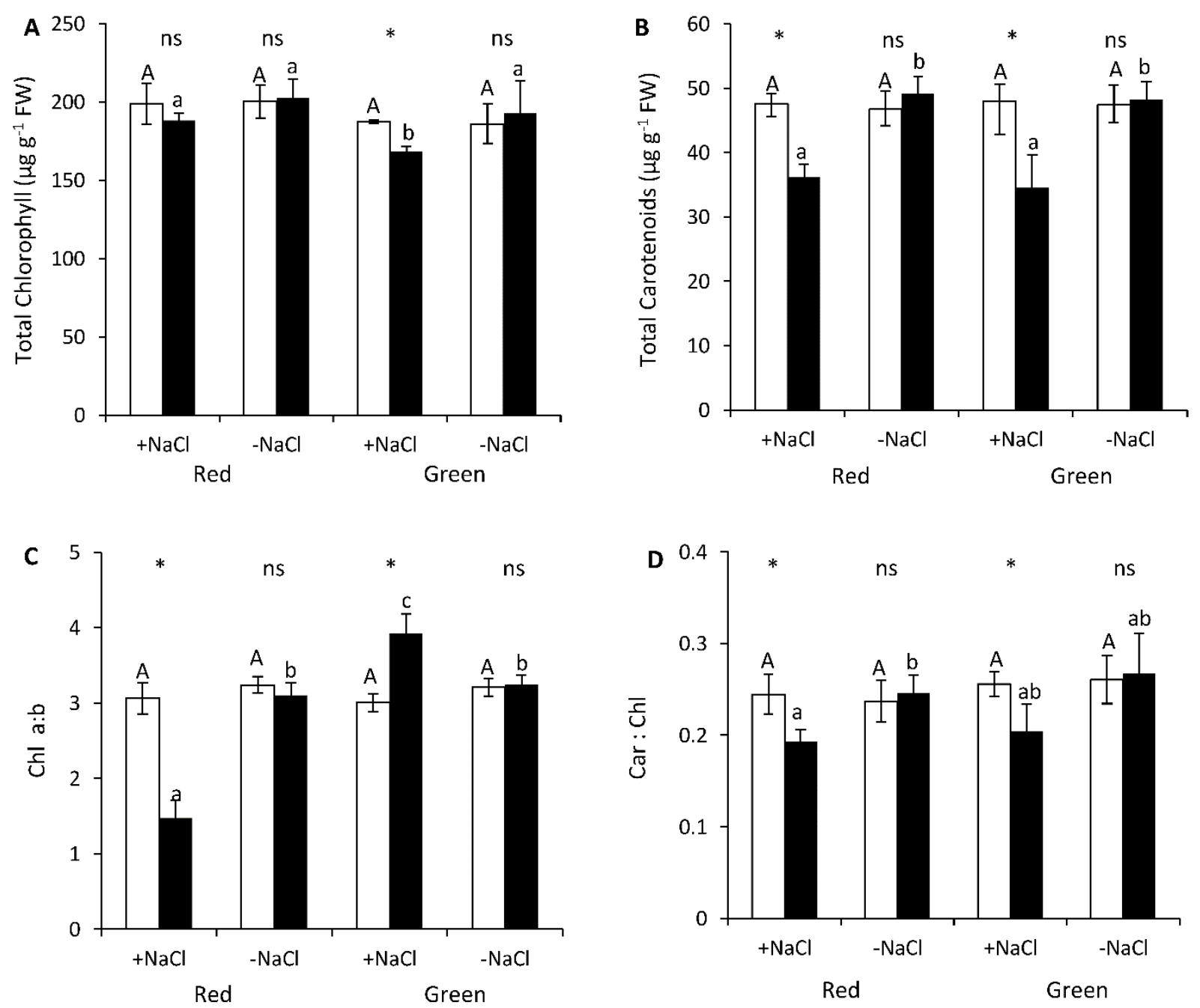

Fig 2.6 Pigment concentrations in the leaves of red and green morphs of Disphyma australe. Total chlorophyll (A), total carotenoids (B), chlorophyll $a: b(\mathrm{C})$ and carotenoid : chlorophyll ratios (D) before (white bars) and $14 \mathrm{~d}$ after (black bars) $200 \mathrm{mM} \mathrm{NaCl}$ treatment (means $\pm \mathrm{SE}$; $\mathrm{n}=5$ ). Asterisks denote significant differences within morphs over time $(\mathrm{P}<0.05)$. Different letters above bars show significant difference across treatments $(\mathrm{P}<0.05)$. 


\subsubsection{Gas exchange and water relations}

The stomatal frequency did not differ significantly $(\mathrm{P}>0.5)$ between the leaves of red $(59 \pm 3$ $\mathrm{mm}^{-2}$ ) and green morphs $\left(56 \pm 2 \mathrm{~mm}^{-2}\right)$. Maximum rates of $\mathrm{CO}_{2}$ assimilation $\left(\mathrm{A}_{\max }\right)$ were initially similar for the two sets of plants, but decreased on average by $50 \%$ in the red and by $65 \%$ in the green morphs after $\mathrm{NaCl}$ treatment (Fig. 2.7 A). Stomatal conductance $\left(\mathrm{g}_{\mathrm{s}}\right)$ also decreased significantly, more so in red than in the green morphs ( $\mathrm{P}<0.05$; Fig. $2.7 \mathrm{~B}$,). Water use efficiency (WUE), estimated as $\mathrm{A}_{\max } / \mathrm{g}_{\mathrm{s}}$, was greater for the red than the green morphs prior to treatment ( $\mathrm{P}<0.02$; Fig. $2.7 \mathrm{C}$ ). After $14 \mathrm{~d}$ with $\mathrm{NaCl}$, WUE increased further, by $40 \%$ in the red and $13 \%$ in the green morphs. 

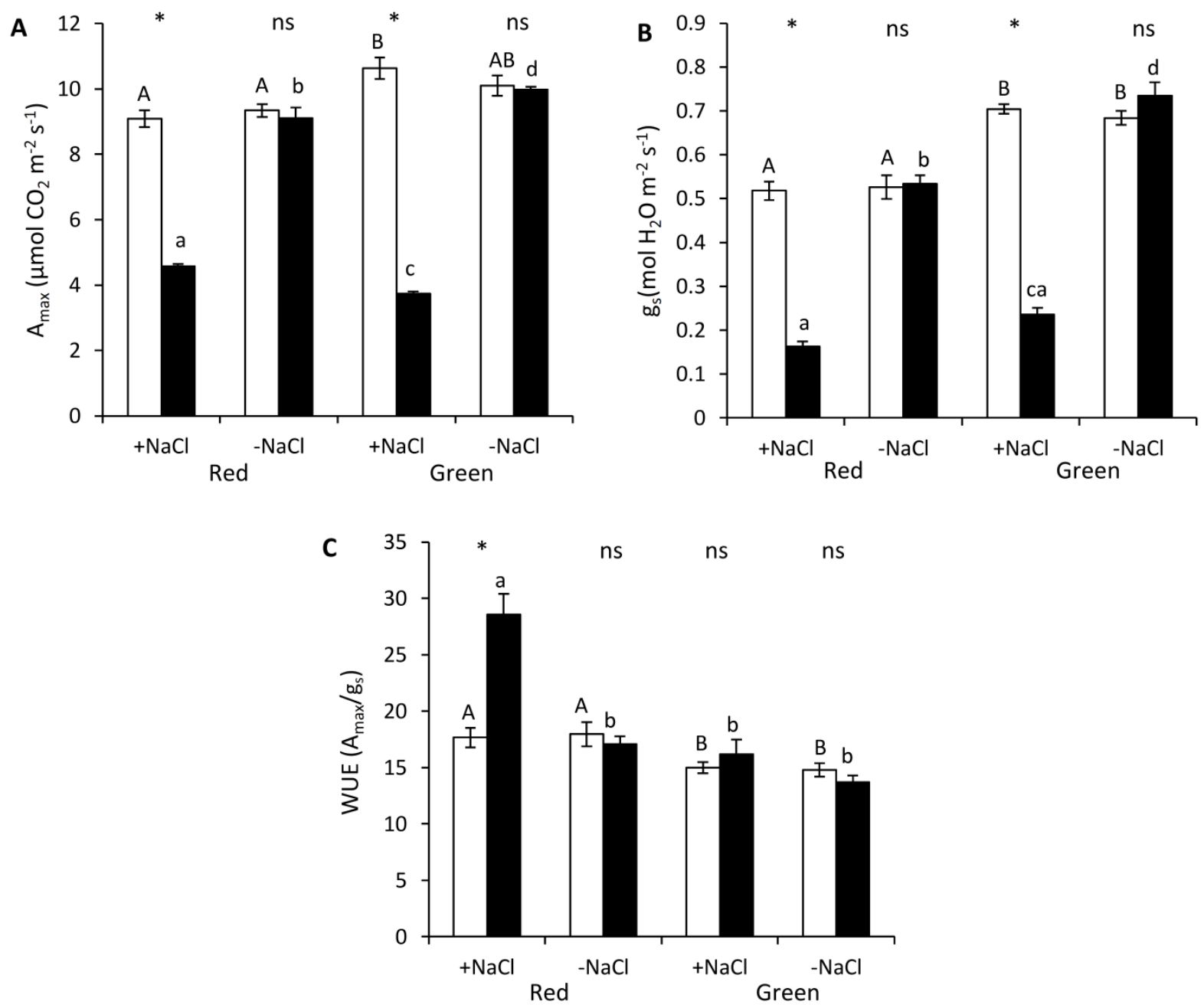

Fig 2.7 (A) Net maximum $\mathrm{CO}_{2}$ assimilation rate $\left(\mathrm{A}_{\max }\right)$, (B) stomatal conductance $\left(\mathrm{g}_{\mathrm{s}}\right)$, and $(\mathrm{C})$ water use efficiency in leaves of red and green morphs of Disphyma australe before (white bars) and $14 \mathrm{~d}$ after (black bars) treatment $200 \mathrm{mM} \mathrm{NaCl}$ or $\mathrm{H}_{2} \mathrm{O}(\mathrm{n}=5$, means $\pm \mathrm{SE})$. Asterisks denote significant differences within morphs over time $(\mathrm{P}<0.05)$. Different letters above bars show significant difference across treatments $(\mathrm{P}<0.05)$. 


\subsubsection{Chlorophyll fluorescence}

The maximum quantum efficiencies for PSII (Fv/Fm) were initially comparable for dark-adapted green leaves from the glasshouse-grown red $(0.78 \pm 0.01)$ and green $(0.79 \pm 0.01)$ morphs. When subjected to a light ramp between 7 and $1855 \mu \mathrm{mol} \mathrm{m} \mathrm{m}^{-2} \mathrm{~s}^{-1}$, values of $\Phi_{\text {PSII }}$ declined at statistically comparable rates in the two sets of plants (Fig. $2.8 \mathrm{~A} ; \mathrm{P}>0.02$ ). After $14 \mathrm{~d}$ with $\mathrm{NaCl}, \mathrm{Fv} / \mathrm{Fm}$ values fell slightly in both morphs, the newly-reddened ones (Fv/Fm=0.76 \pm 0.003$)$ being marginally less affected than the green ones $(0.74 \pm 0.006)$. There were much larger differences between morphs in the responses to a light ramp following $\mathrm{NaCl}$ treatment; the decline in $\Phi_{\text {PSII }}$ was far greater in the green than in the red (Fig. $2.8 \mathrm{~A} ; \mathrm{P}<0.001$ ). For the green morph, the decline in $\Phi_{\text {PSII }}$ was more rapid for NaCl-treated than control leaves $(\mathrm{P}>0.01)$. Interestingly, for the red morph, $\Phi_{\mathrm{PSII}}$ was consistently higher in the newly-reddened NaCltreated leaves than in untreated leaves during the light treatment $(\mathrm{P}>0.05)$. 

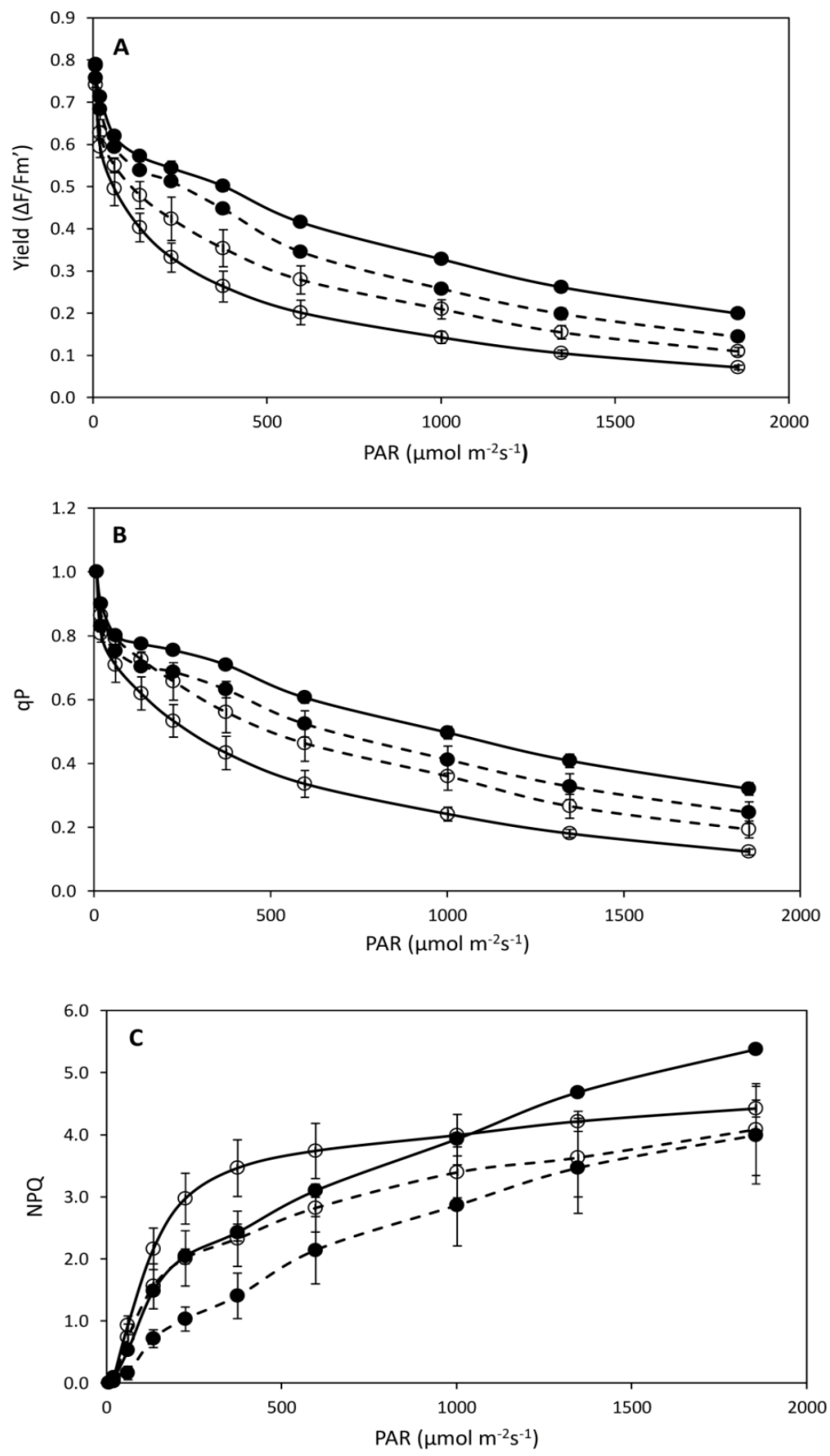

Fig 2.8 Light response curves for (A) photochemical quantum yield, (B) photochemical quenching and $(\mathrm{C})$ non-photochemical quenching for leaves of red $(\mathbf{O})$ and green $(\mathrm{O})$ morphs of Disphyma australe after $14 \mathrm{~d}$ with $200 \mathrm{mM} \mathrm{NaCl}$ (solid lines) or water controls (dashed lines). Means $\pm S E ; n=3$. 
Photochemical quenching coefficients $(\mathrm{qP})$ were statistically similar for leaves from untreated red and green morphs under the light ramp (Fig. $2.8 \mathrm{~B}$; P >0.4), but after $\mathrm{NaCl}$ treatment the red leaves consistently had the higher $\mathrm{qP}$ values ( $\mathrm{P}<0.001$ ). Non photochemical quenching (NPQ) values were often higher for leaves from untreated green than the untreated red morphs, but the difference was not statistically significant (Fig. $2.8 \mathrm{C}$; P >0.05). After $\mathrm{NaCl}$ treatment NPQ values were greater in green than in red leaves with irradiances up to $600 \mu \mathrm{mol} \mathrm{m} \mathrm{m}^{-2} \mathrm{~s}^{-1}$; the trend reversed under stronger light, but the difference was insignificant $(\mathrm{P}>0.05)$.

\subsubsection{Leaf reflectance}

Leaves of the green morphs of D. australe reflected approximately 15\% more PAR (400-700 $\mathrm{nm}$ ) than did the betalainic leaves of the red morphs (Fig. 2.9). This increase was largely restricted to the green-yellow waveband; the green leaves reflected up to $67 \%$ more light than did the red between 500-600 nm (Fig. 2.9; P <0.001). In contrast, the integrated reflectances of blue light $(400-500 \mathrm{~nm})$ and of red light $(600-700 \mathrm{~nm})$ were statistically comparable for the leaves of both colours ( $\mathrm{P}>0.05$ in each instance). Thus, the ratio of reflectance of red to green wavebands was lower in the non-betalainic leaves of green morphs $(0.65 \pm 0.007)$ than in betalainic leaves of the red morphs $(2.1 \pm 0.06)$. 


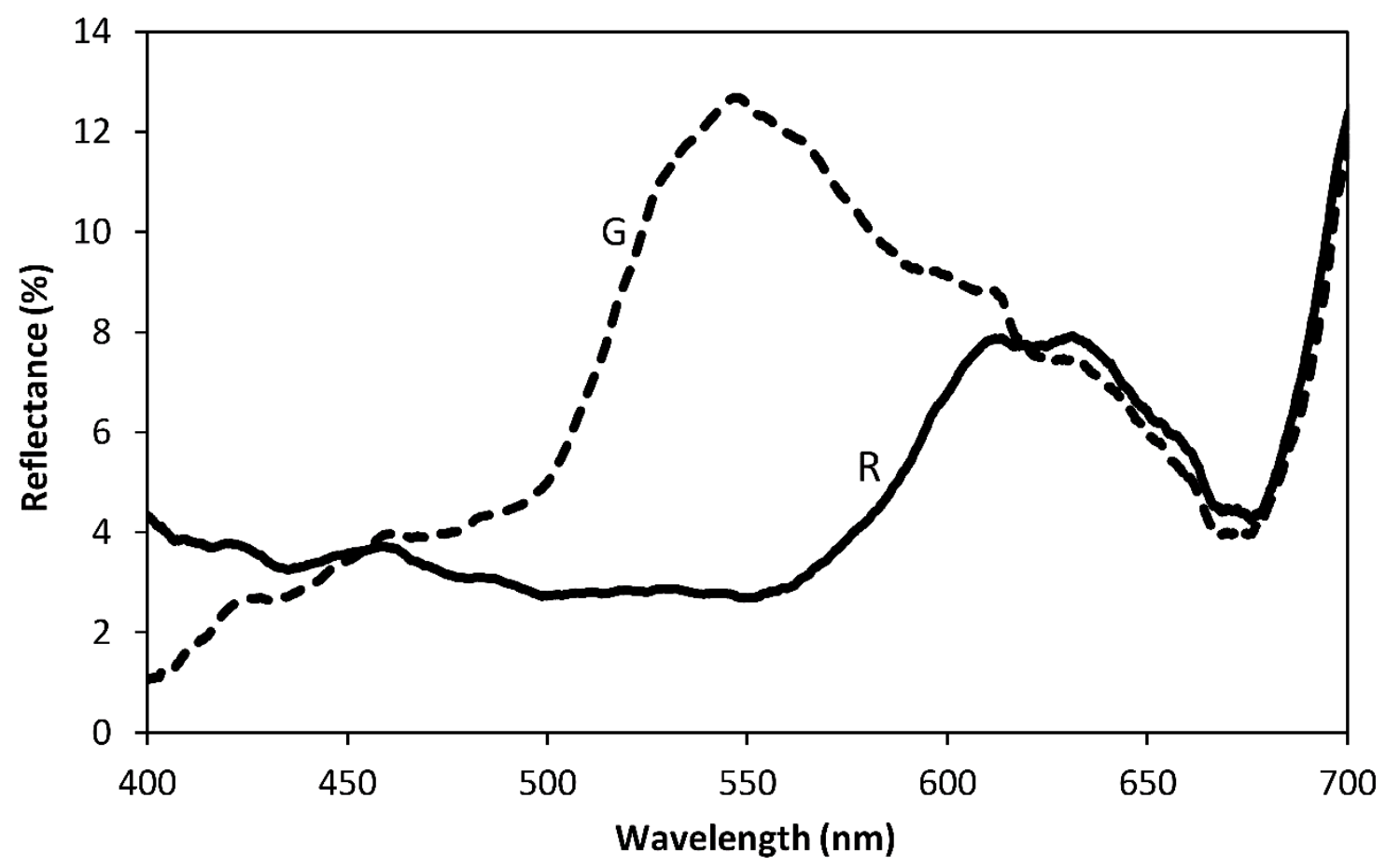

Fig 2.9 Reflectance spectra for five randomly selected green leaves of green morphs $(\mathrm{G})$ and red leaves of red morphs (R) of Disphyma australe.

\subsubsection{Substrate salinity}

Conductivity measurements (EC values) of substrate samples were greatest at locations closest to the ocean and declined significantly with increasing distance from the high tide line (Table 2.2). At any one location, the EC values of samples in the immediate vicinity of red $(0.168 \pm 0.003$ $\left.\mathrm{mS} \mathrm{cm}{ }^{-1}\right)$ and green morphs $\left(0.169 \pm 0.002 \mathrm{mS} \mathrm{cm}^{-1}\right)$ were statistically similar $(\mathrm{P}>0.05)$.

The proportions of red and green morphs varied predictably across the substrate salinity gradients. High salinity sites had proportionately more red morphs than green morphs $\left(\chi^{2}, \mathrm{P}\right.$ $<0.001$; Table 2.2). In contrast, green morphs were most abundant at the farthest location from the high tide line $\left(\chi^{2}, \mathrm{P}<0.001\right.$; Table 2.2). 
Table 2.2 Electrical conductivities of substrate samples, and corresponding frequencies of red and green morphs of Disphyma australe, at increasing distances from the shoreline (Means $\pm \mathrm{SE}$, $\mathrm{n}=5)$.

\begin{tabular}{cccc}
\hline $\begin{array}{c}\text { Distance from shoreline } \\
(\mathbf{m})\end{array}$ & $\begin{array}{c}\text { Electrical Conductivity } \\
\left(\mathbf{m S ~ c m}^{-\mathbf{1}}\right)\end{array}$ & \multicolumn{2}{c}{ Number (\%) } \\
\cline { 2 - 4 } $\mathbf{1 6}$ & $0.170 \pm 0.002$ & $36(81 \%) \pm 3$ & $8(19 \%) \pm 1$ \\
$\mathbf{3 0}$ & $0.093 \pm 0.005$ & $14(46 \%) \pm 2$ & $17(54 \%) \pm 3$ \\
$\mathbf{5 0}$ & $0.039 \pm 0.003$ & $12(23 \%) \pm 2$ & $41(77 \%) \pm 5$ \\
\hline
\end{tabular}

\subsection{Discussion}

To explain variation in colour of vegetative shoots within coastal populations of Disphyma australe (Fig. 2.1), we postulated that exposure of roots to $\mathrm{NaCl}$ leads to an accumulation of red betalain pigments, and that these, in turn, confer a measure of tolerance to salinity when also exposed to high light. Accordingly, the green-leafed individuals would have experienced less salinity stress, and would be less resilient to it. Our data from the red morph are entirely consistent with the hypothesis; in a salt-free substrate under the conditions of a glasshouse, the red leaves turned green, but they resumed their red colour when treated with saline solution. Moreover, red leaf morphs were more abundant in the field at sites with higher salinity levels (Table 2.2). The development of red pigmentation correlated to superior maximum $\mathrm{CO}_{2}$ assimilation rates (Fig. 2.7 A), water use efficiencies (Fig. 2.7 C) photochemical quantum yields (Fig. $2.8 \mathrm{~A}$ ) and photochemical quenching (Fig. $2.8 \mathrm{~B}$ ) under salinity stress. However, contrary to our hypothesis, those vegetative shoots that were originally green in their natural environments did not accumulate betalains upon $\mathrm{NaCl}$ treatment (Fig. 2.3). Although the green morphs were genetically equipped for betalain biosynthesis as evidenced by the presence of betalains in their petals (Fig. 2.1), they apparently lack the mechanism to respond to salinity by 
producing betalains in vegetative shoots. In terms of leaf photosynthesis, the green morphs performed relatively poorly under salinity stress (Fig. 2.3, 2.7A).

\subsubsection{Up-regulation of betalain synthesis}

The biosynthesis of six structurally distinct betacyanins was up-regulated in the red morphs following $14 \mathrm{~d}$ exposure to $200 \mathrm{mM} \mathrm{NaCl}$ (Fig. 2.5 B). The results indicate that high salinity levels encountered in their natural coastal environments may be an important factor governing betalain synthesis in $D$. australe shoots. Our data are consistent with other studies that have reported higher betalain content in plants following the imposition of a variety of abiotic stressors including salinity (Wang et al.,2006; Hayakawa and Agarie 2010; Wang et al. 2007). The functional significance of individual betacyanins, tentatively identified here as betanin, isobetanin, betanidin, isobetanidin, lampranthin II and isolampranthin-II (Table 2.1), remains unknown. However, collectively they serve to modify the light environment within a leaf, with the potential to affect photosynthetic performance.

\subsubsection{Photoabatement by betalains}

Photodamage of PSII in chloroplasts compromised by salinity stress has been reported for the leaves of many species (e.g., Duarte et al., 2013; Hertwig et al., 1992; Sharma and Hall, 1991). For D. australe, the rapid light response curves for $\Phi_{\mathrm{PSII}}$ in $\mathrm{NaCl}$-treated leaves indicated that the red leaves maintained higher quantum efficiency than treated green leaves under saturating light (Fig. 2.8 A). Of course, the presence of betalains in the leaves does not necessarily implicate a role for these pigments in photoprotection; the betalains may simply be a symptom of, rather than an ameliorative response to salinity stress. Nonetheless, such a role has been suggested for foliar betalains in the related species Mesembryanthemum crystallinum, for which the spectral properties of betalains were considered suitable to abate potentially damaging light and UV radiation that would otherwise fall incident on the chloroplasts (Vogt et al., 1999; Ibdah et al., 2002). Similarly, Wang and Liu (2007) showed that betacyanic leaves of the halophyte Sueda salsa were less photoinhibited than green leaves after a chilling stress. For D. australe, too, the complement of betacyanins apparently assists in photoprotection of the leaves through

photoabatement, as evidenced by higher $\Phi_{\mathrm{PSII}}$ and $\mathrm{qP}$ values (Fig. $2.8 \mathrm{~A}, \mathrm{~B}$ ). Indeed, the sharp decline in chlorophyll $a: b$ as leaves reddened after $\mathrm{NaCl}$ treatment (Fig. 2.6 C) is a typical 
response of chloroplasts acclimating to shade; this is entirely consistent with the development of chloroplasts under a photoprotective betalainic filter, and is comparable to the responses of chloroplasts that develop beneath foliar anthocyanins (Gould et al., 2002; Kyparissis et al., 2007). Moreover, the reflectance data revealed that the betalainic leaves appear red because they absorb more green and yellow light rather than reflecting more red light (Fig. 2.9). The spectral properties of these betalainic leaves are thus similar to many red anthocyanic leaves (Neill \& Gould, 1999), for which there is abundant evidence that these red pigments assist photoprotection directly by abating incident quantum fluxes.

In addition to their light-screening properties, the $\mathrm{NaCl}$-treated red leaves are evidently better equipped to deal with the surplus photons absorbed by chloroplasts. Of note, non-photochemical quenching, which correlates to the thermal dissipation of excess energy by xanthophyll cycle pigments (Demmig-Adams \& Adams, 1992; Maxwell \& Johnson, 2000), was higher for the red leaves under high irradiance. Thus, epidermal betacyanins seem to be important, but only one of the elements contributing to the suite of mechanisms for the photoprotection required under conditions of salinity stress. The putative photoprotective function of foliar betalains is analogous to that of foliar anthocyanins, which have been shown to reduce the propensity for and the severity of photoinhibition in many plant species (Steyn et al., 2002; Close \& Beadle, 2003; Gould, 2004).

\subsubsection{Avoidance of physiological drought by red plants}

Salinity stress typically induces reductions in stomatal conductance and net $\mathrm{CO}_{2}$ assimilation (Ramani et al., 2006; Chaves et al., 2009; Sucre \& Suárez, 2011). Both decreased in the red and the green leaves of NaCl-treated D. australe (Fig. 2.7 A, B). The average decrease in the net photosynthetic rate was greater for the green morphs (65\%) than red morphs (49\%) after salinity stress, indicating that the green plants had been the more adversely affected. A reduction in stomatal conductance enhances the water use efficiency (WUE) of leaves (Flexas et al., 2004; Sucre \& Suárez, 2011); in NaCl-treated D. australe, WUE increased significantly more in the red than in green leaves (Fig. $2.7 \mathrm{C}$ ), indicating that the red morphs may be better able to accommodate physiological drought in the short term. The mechanism through which betalains may confer tolerance to salinity- induced water stress is unknown. It may be that betalains serve to scavenge reactive oxygen species produced by chloroplasts for which photosynthetic electron 
transport has been compromised by salinity stress (Wang \& Liu, 2007). Alternatively, Wang et al. (2007) found that in Suaeda salsa, higher levels of betacyanin correlated with increased tonoplast $\mathrm{H}^{+}$-ATPase activity; the presence of betalains was apparently associated with an enhanced removal of $\mathrm{Na}^{+}$from the cytoplasm to vacuole. The applicability of their evidence to other plant systems remains unknown, but it is at least consistent with our hypothesis that betalainic plants are more tolerant to salinity stress.

\subsection{Conclusion}

In conclusion, our data indicate that salinity contributes to the induction of betalain biosynthesis in vegetative shoots of $D$. australe. Green morphs, which apparently lack the mechanism to induce foliar betalain biosynthesis in response to salinity, are evidently less tolerant to salinity, both in terms of water conservation and photoprotection. The comparison of the green and red morphs, as well as the ready manipulation by salinity of leaf colour in the red morph presents an elegant system to further study the possible involvement of betalain pigments in salinity. 


\section{Chapter 3: Betalain induction by L-DOPA application confers photoprotection to saline-exposed leaves of Disphyma australe}

\subsection{Abstract}

The capacity to synthesise betalains has arisen in diverse phylogenetic lineages across the Caryophyllales, and because betalainic plants often grow in deserts, sand dunes, or salt marshes, it is likely that these pigments confer adaptive advantages. However, possible functional roles of foliar betalains remain largely unexplored and are difficult to test experimentally. We took a novel approach to examine putative photoprotective roles of betalains in leaves for which chloroplast function has been compromised by salinity. Responses to high light and salinity of LDOPA (L-3,4-dihydroxyphenylalanine)-treated red shoots of Disphyma australe were compared with those of naturally red- and green-leafed morphs. Betalain content, and tyrosinase activity were measured, and chlorophyll fluorescence profiles and $\mathrm{H}_{2} \mathrm{O}_{2}$ production compared under white, red or green light. Green leaves lacked tyrosinase activity, but when supplied with exogenous L-DOPA they produced five betacyanins. Both the naturally red and L-DOPAinduced red leaves generated less $\mathrm{H}_{2} \mathrm{O}_{2}$ and showed smaller declines in PSII quantum efficiency than did green leaves when exposed to white or green light, though not to red light. Light screening by epidermal betalains effectively reduces the propensity for photoinhibition and photo-oxidative stress in subjacent chlorenchyma. This may assist plant survival in exposed and saline environments.

\subsection{Introduction}

The betalains are a small class of alkaloid pigments found exclusively in certain families of the Caryophyllales and in some Basidiomycetes (Stintzing \& Carle, 2004). Synthesized from tyrosine by as few as three enzymatic reactions, there are two structural groups: the red/violet betacyanins, and the yellow/orange betaxanthins (Strack et al., 2003; Azeredo, 2009). Betacyanins share many physical and chemical properties with the more abundant class of red pigments, the anthocyanins; they have similar absorption maxima in the visible spectrum, for example, and they are both potent antioxidants (Stintzing \& Carle, 2004; Wang et al., 2006; 
Gandía-Herrero et al., 2010). Accordingly, the two pigment classes are often considered to be functional homologues. There is evidence that, like the anthocyanins, the betalains in flowers and fruit serve to attract pollinators and frugivores (Piattelli, 1981). However, unlike those for the anthocyanins, possible functions of betalains in leaves and other vegetative organs have received scant scientific attention and remain poorly understood (Ibdah et al., 2002; Stintzing \& Carle, 2004).

There are good reasons to postulate that foliar betalains assist plant function. First, these pigments may have evolved more than once from phylogenetically diverse lineages in the core Caryophyllales (Brockington et al., 2011). Thus, there may be a strong selective pressure driving their evolution. Second, betalains and anthocyanins do not naturally co-occur (Mabry et al., 1963; Kimler et al., 1970) even though in the laboratory it is possible to induce betalain biosynthesis in the normally anthocyanic Arabidopsis (Harris et al., 2012). That would indicate that betalains do not serve to complement anthocyanin function, although they might well substitute for it; foliar anthocyanins have been implicated in a variety of stress responses, including protection from strong light, free-radical damage, and herbivory pressure (Gould, 2004; Hatier \& Gould, 2009; Boldt et al., 2014). Third, plants with betalainic leaves are often found in marginal environments such as deserts, sand dunes, and salt marshes (Ehrendorfer, 1976). This has led many workers to hypothesize roles for betalain accumulation in tolerance to the kinds of stressors shoots would experience at such locations: drought, high UV irradiance, strong light, low temperatures and salinity (Bothe, 1976; Ibdah et al., 2002; Wang et al., 2006; Wang \& Liu, 2007; Hayakawa \& Agarie, 2010).

The photoprotection hypothesis is an obvious starting point to study betalain function in leaves. Because the epidermal betacyanins are red, they, like anthocyanins, strongly absorb green/yellow wavebands of light (Nakashima et al., 2011; Jain \& Gould, 2015b). This potentially abates excitation pressure on subjacent chloroplasts, thereby reducing the propensity for photoinhibition and photo-oxidative damage when leaves are exposed to saturating light (Steyn et al., 2002; Gould, 2004). However, testing for a photoprotective role of betalains (or anthocyanins) is far from trivial. This is because plants employ a suite of mechanisms to mitigate the adverse effects of excess quanta (Takahashi \& Badger, 2011), and it is difficult, therefore, to disentangle from this pool the unique contributions of red pigments. Moreover, 
studies that compare the photoinhibitory responses of red versus green leaves inevitably face the problem of having to extricate effects of pigmentation from those of differences in age, genotype, and/or prior acclimation between the two morphs. For example, Wang and Liu (2007) found that betacyanic leaves of the halophyte Suaeda salsa were less photoinhibited than green leaves after a chilling stress. However, to facilitate the production of red- and green-leafed plants, the seedlings had to be given different light treatments prior to a photoinhibitory stress; possible effects of their different developmental histories therefore preclude evaluation of the specific contribution of the pigments per se to photoprotection.

To examine betalain function yet avoid these possible complications, I have taken a novel approach using shoots of the New Zealand ice plant, Disphyma australe (Aizoaceae). I previously described the presence of sympatric populations of red-and green-leafed $D$. australe along the Wellington coastline (Jain \& Gould, 2015b). Betacyanin production in the red morph was shown to depend on exposure to both salinity and high light, but the green morph was unable to produce betalains under inductive conditions. Furthermore, the red morph showed greater tolerance to the combination of high light and salinity, as measured by higher $\mathrm{CO}_{2}$ assimilation rates, lower depression of photosystem II quantum efficiencies, and greater wateruse efficiencies relative to the green morph. It was therefore tempting to postulate a protective role for betalains in this species. Interestingly, the green morphs produced purple flowers, indicating that they were genetically equipped to synthesise betalains but that the leaves were unable to respond to environmental cues for betalain production. Here, I identify the key biosynthetic step that is deficient in vegetative shoots of the green morphs. I show that by supplying the product of this enzymatic reaction, L-DOPA, to green shoots, betacyanins are formed in the leaves. I then use this experimental system to test for a possible photoprotective effect of betalains in shoots for which chloroplast function has been compromised by salinity and high light stress.

\subsection{Materials and Methods}

\subsubsection{Plant material}


Healthy red and green $D$. australe (Aiton) N.E.Br. shoot cuttings were randomly collected from 30 plants in a coastal dune population at Te Kopahau reserve, Wellington, New Zealand $\left(41^{\circ} 21^{\prime} 01^{\prime \prime} \mathrm{S}, 174^{\circ} 43^{\prime} 55^{\prime \prime} \mathrm{E}\right)$. Plants were sampled along four north-south transects, $8 \mathrm{~m}$ apart, running from the shoreline to the dunes. Three visibly-distinct plant types were taken, as described in the Results: green morphs, red morphs and parti-coloured morphs. Plants were selected if all three morphs were close to one another and within $1 \mathrm{~m}$ of either side of a transect. Ten cuttings per morph were held with the cut stems in water at room temperature until required.

\subsubsection{L-DOPA feeding}

Shoot tips bearing the two youngest fully-expanded leaves were submerged in an aqueous solution of 10 mM L-DOPA (L-3,4-dihydroxyphenylalanine; Sigma Aldrich, Auckland, NZ) and vacuum-infiltrated for $60 \mathrm{~s}$. The leaves were blotted dry, and the cut bases of the shoots inserted into $10 \mathrm{mM} \mathrm{L-DOPA}$ and held at $21^{\circ} \mathrm{C}$ under $300 \mu \mathrm{mol} \mathrm{m} \mathrm{m}^{-2} \mathrm{~s}^{-1}$ white light with a $10 \mathrm{~h}$ photoperiod. Control stem cuttings were treated in the same way but with sterile $\mathrm{ddH}_{2} \mathrm{O}$ substituting for L-DOPA. All cuttings were observed for betalain production after $48 \mathrm{~h}$.

\subsubsection{Betalain extraction and quantification}

After feeding L-DOPA, $0.1 \mathrm{~g}$ leaf tissue from each shoot tip was flash frozen in liquid nitrogen, ground to a powder and extracted in $5 \mathrm{~mL} 100 \%$ methanol for $1 \mathrm{~h}$ at $4{ }^{\circ} \mathrm{C}$. The extracts were centrifuged for $5 \mathrm{~min}$ at $10,000 \mathrm{~g}$, the supernatants discarded, and the pellets re-suspended in 5

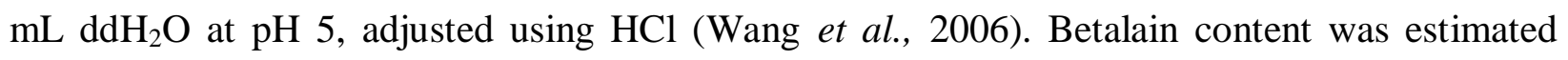
spectrophotometrically using a Shimadzu (Kyoto, Japan) 2550 UV-VIS spectrophotometer, as $\mathrm{A}_{538}-0.33 \mathrm{~A}_{662}$, where $\mathrm{A}_{538}=\mathrm{A}_{\lambda \max }$. The subtraction of $0.33 \mathrm{~A}_{662}$ compensated for the small overlap in absorption by extracted chlorophyll. This method was also used to quantify betalain in naturally red leaves. Absorbance values were converted to betanin equivalents using the molar extinction coefficient $\varepsilon=60,000 \mathrm{~L} \mathrm{~mol}^{-1} \mathrm{~cm}^{-1}$, and molecular weight $=550$ (Cai \& Corke, 1999).

Individual betalains were separated and quantified using an Agilent 1100 Series HPLC (Waldbronn, Germany) with a Phenomenex $\mathrm{C}_{18}$ reversed phase column (5 $\mu \mathrm{M}, 250$ X $\left.4.6 \mathrm{~mm}\right)$ using the solvents and methodology of Jain \& Gould (2015).

\subsubsection{Tyrosinase activity}


The youngest fully-expanded leaf on five plants per morph was randomly collected from the field site. Exactly $0.5 \mathrm{~g}$ of leaf tissue was flash-frozen in liquid nitrogen, ground to a powder and extracted in $2 \mathrm{~mL}$ extraction buffer comprising $100 \mathrm{mM}$ potassium phosphate buffer ( $\mathrm{pH}$ 7.5), $5 \%(\mathrm{w} / \mathrm{v})$ polyvinylpolyprrolidone PVPP and $2 \%(\mathrm{v} / \mathrm{v})$ Triton X-100 at $4^{\circ} \mathrm{C}$. The extract was centrifuged at $3000 \mathrm{~g}$ for $3 \mathrm{~min}$, and the supernatant added to an equal volume of saturated (4.1 M) ammonium sulfate, which produced a flocculent white precipitate. Extracts were then recentrifuged at 16,000 $\mathrm{g}$ for $5 \mathrm{~min}$, the supernatants discarded, and the pellets re-suspended in chilled $0.1 \mathrm{M}$ citrate buffer ( $\mathrm{pH}$ 4.8). The same method was used to extract the enzyme from 0.2 $\mathrm{g}$ of petals from five randomly selected flowers per morph.

Tyrosinase activity was quantified spectrophotometrically by following the oxidation of L-DOPA to dopachrome (Robb, 1984). To $1 \mathrm{~mL}$ of an assay mix comprising $50 \mathrm{mM}$ phosphate buffer (pH 7.0), $50 \mu \mathrm{L} \mathrm{CuSO}_{4}$, and either $5 \mathrm{mM}$ tyrosine (Sigma-Aldrich, Auckland, NZ) or 10 mM L-DOPA, was added $100 \mu \mathrm{L}$ of the processed plant extract. Solutions were incubated for 30 min at $21^{\circ} \mathrm{C}$, and dopachrome formation estimated by monitoring increasing absorbance at 475 nm using a Shimadzu 2550 UV-VIS spectrophotometer. Data were recorded every 30 s for 5 min. One unit of tyrosinase activity was defined as the concentration of enzyme that catalyses the appearance of $1 \mu \mathrm{mol}$ dopachrome per min. Dopachrome concentration was calculated using the molar extinction coefficient $\varepsilon=3700 \mathrm{~L} \mathrm{~mol}^{-1} \mathrm{~cm}^{-1}$. Enzyme activity was expressed as tyrosinase units $\mathrm{mg}^{-1}$ protein $\mathrm{h}^{-1}$. Protein content in leaves and petals was quantified as described by Bradford (1976), using bovine serum albumin as the standard.

To confirm that the changes in absorbance were indeed attributable to tyrosinase activity, the experiment was repeated with the addition of enzyme inhibitors $100 \mu \mathrm{M}$ 2mercaptobenzothiazole (Sigma-Aldrich, Auckland, NZ) and $10 \mu \mathrm{M}$ tropolone to the mix.

\subsubsection{Light and salinity treatments}

Chlorophyll $a$ fluorescence of red and green leaves, and of L-DOPA-treated leaves of green morphs, was monitored before, during and after a saturating light treatment. Harvested shoot tips, each bearing two fully-expanded leaves, were held with their bases in water for $48 \mathrm{~h}$ at room temperature. They were dark-acclimated for $1 \mathrm{~h}$ and then the maximum quantum efficiencies of photosystem II (PSII), estimated by the ratios of variable to maximum chlorophyll 
fluorescence $(F v / F m)$, were determined for one leaf per shoot using a Walz 2500 (Effeltrich, Germany) pulse amplitude modulated (PAM) chlorophyll fluorometer. Each shoot tip was then inserted into an Eppendorf tube containing $200 \mathrm{mM} \mathrm{NaCl}$ and irradiated with $1300 \mu_{\mathrm{mol} \mathrm{m}}^{-2} \mathrm{~s}^{-1}$ white, red or green light for $6 \mathrm{~h}$ at $21^{\circ} \mathrm{C}$. The light was supplied by a bank of $12 \times 1 \mathrm{~W}$ LEDs (model OS9151, ADEO Services, Lezenne, France), which emitted cool-white light with a 6500 K colour temperature; to produce red or green light we inserted red \#19 or green \#389 polycarbonate filters (Supergel Rosco, Sydenham, UK) between the light source and plants. At regular intervals during the light treatments, effective PSII quantum yields were recorded, estimated as $\Delta F / F m^{\prime}=\left(F m^{\prime}-F t\right) / F m^{\prime}$, where $F m^{\prime}$ is the maximum fluorescence in the lightadapted state, and Ft is the steady-state fluorescence. Leaves were then returned to darkness and $F v / F m$ values recorded each hour for $2 \mathrm{~h}$. Rapid light response curves for dark-adapted green morph plants were generated before and after L-DOPA treatment using the light source supplied by the PAM, and quantum yields of PSII ( $\left.\Phi_{\text {PSII }}\right)$ and non-photochemical quenching (NPQ) were recorded as described by Maxwell and Johnson, (2000).

\subsection{6 $\mathrm{H}_{2} \mathrm{O}_{2}$ Production}

To observe $\mathrm{H}_{2} \mathrm{O}_{2}$ production in leaves, the methods of Landi et al. (2014) were used with a slight modification. Shoot tips were washed, blotted dry, and then incubated for 30 min at $21^{\circ} \mathrm{C}$ in a loading buffer comprising $50 \mathrm{mM}$ Tris- $\mathrm{HCl}(\mathrm{pH}$ 7.0) and $20 \mu \mathrm{M}$ 2,7-dichlorofluoroscein diacetate (DCFH-DA). Individual leaves were detached, and held upright on either $\mathrm{ddH}_{2} \mathrm{O}$ or 200 $\mathrm{mM} \mathrm{NaCl}$ for $3 \mathrm{~h}$ at $21^{\circ} \mathrm{C}$ under cool-white light at either 400 or $1300 \mu \mathrm{mol} \mathrm{m} \mathrm{m}^{-2}$. After incubation, median transverse sections of the leaves were mounted in the loading buffer on a microscope slide and examined for green epifluorescence in an Olympus AX70 compound microscope (Olympus Optical Co., Hamburg, Germany) using 488 nm excitation and collecting emission above $515 \mathrm{~nm}$. Images were taken using an Olympus DP70 digital camera.

\subsubsection{Statistical analysis}

Reported data represent the means of at least five replicates \pm standard errors. DCFH-DA fluorescence images of TS of leaves are representative of at least 6 replicates per treatment. Normality of the data was confirmed using the Kolmogorov-Smirnov test in SPSS. Means were 
compared by one way ANOVA. Repeated measures ANOVA was used for comparisons of the rapid light response curves (Potvin et al., 1990).

\subsection{Results}

\subsubsection{Natural variation in shoot colour}

Three chromatically-distinct types of vegetative shoot of $D$. australe naturally co-occurred at our coastal field site: (i) 'green morphs' (G), for which the shoots entirely lacked red pigmentation (Fig. 3.1a); (ii) 'parti-coloured morphs' (PC), for which the nodes and internodes were pigmented red but the leaves were green (Fig. 3.1b); and (iii) 'red morphs' (R), for which the leaves and stem were entirely red (Fig. 3.1c). Purple (i.e., betalainic) petals were observed on flowering shoots of all three morphs. 

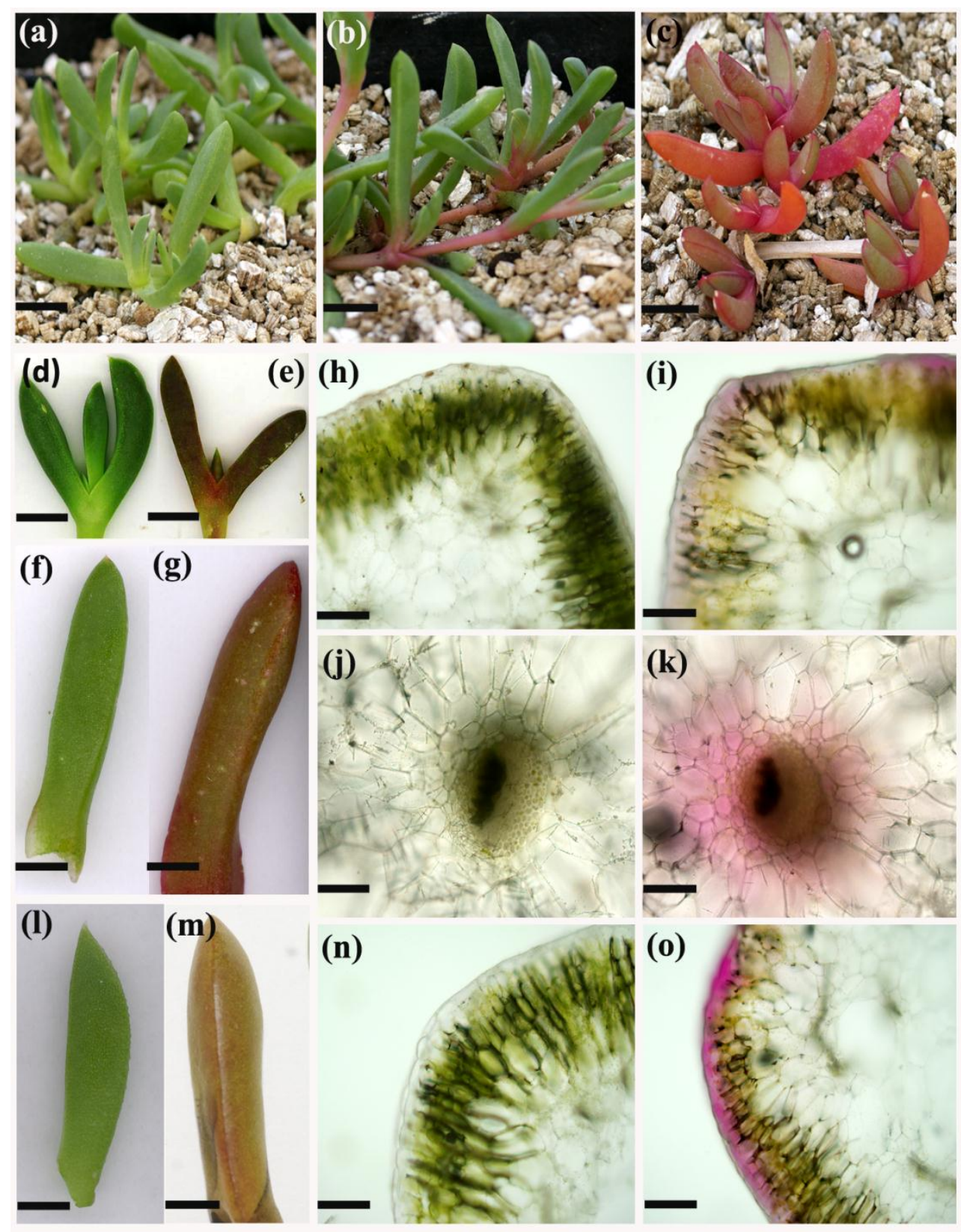

Fig. 3.1 Vegetative shoots of (a) green, (b) parti-coloured, (c) red morphs of Disphyma australe; control (d,f,h,j), and L-DOPA-treated (e,g,i,k) leaves and partial transverse sections of the green morph, showing betacyanin accumulation in epidermal cells (i) and vascular parenchyma (k); control (l) and L-DOPA-treated (m) leaves of parti-coloured morph; transverse sections through leaves of parti-coloured (n) and red (o) morphs. Bars: a-c $=1 \mathrm{~cm}$; d, e $=5 \mathrm{~mm}, \mathrm{f}, \mathrm{g}, 1, \mathrm{~m}=2 \mathrm{~mm}$, $\mathrm{h}, \mathrm{i}, \mathrm{n}, \mathrm{o}=100 \mu \mathrm{m} ; \mathrm{j}, \mathrm{k}=20 \mu \mathrm{m}$. 


\subsubsection{Betalain induction by L-DOPA}

To determine whether betalain production could be induced in the G and PC morphs, we fed LDOPA to the leaves. L-DOPA is formed from tyrosine in the first step of the betalain biosynthetic pathway. When shoot tips from the $\mathrm{G}$ and $\mathrm{PC}$ morphs were incubated in $\mathrm{ddH}_{2} \mathrm{O}$ their leaves remained entirely green, but when incubated in L-DOPA for $48 \mathrm{~h}$ an intense red pigmentation developed on the internodes and all sides of the triquetrous leaves (Fig. $3.1 \mathrm{~d}$-g). Microscopic observations of transverse sections through L-DOPA-fed leaves revealed that the red pigments, subsequently confirmed as betalains, were present as contiguous layers in the epidermis, the outermost mesophyll, and in parenchyma surrounding vascular bundles; the distribution was similar to that in naturally red leaves, except that the $\mathrm{R}$ morphs lacked betalains in vascular parenchyma (Fig. $3.1 \mathrm{~h}-\mathrm{o}$ ).

\subsubsection{Betalain quantification and characterization}

$\mathrm{A}_{538}$ values of methanolic extracts from green leaves of the $\mathrm{G}$ and PC morphs confirmed that both lacked betalains. However, $\mathrm{A}_{538}$ values for extracts of $\mathrm{G}$ and PC morphs increased 11-18 fold following L-DOPA treatment, although they remained marginally lower than those from $\mathrm{R}$ morphs $(P<0.001$; Fig. 3.2). 


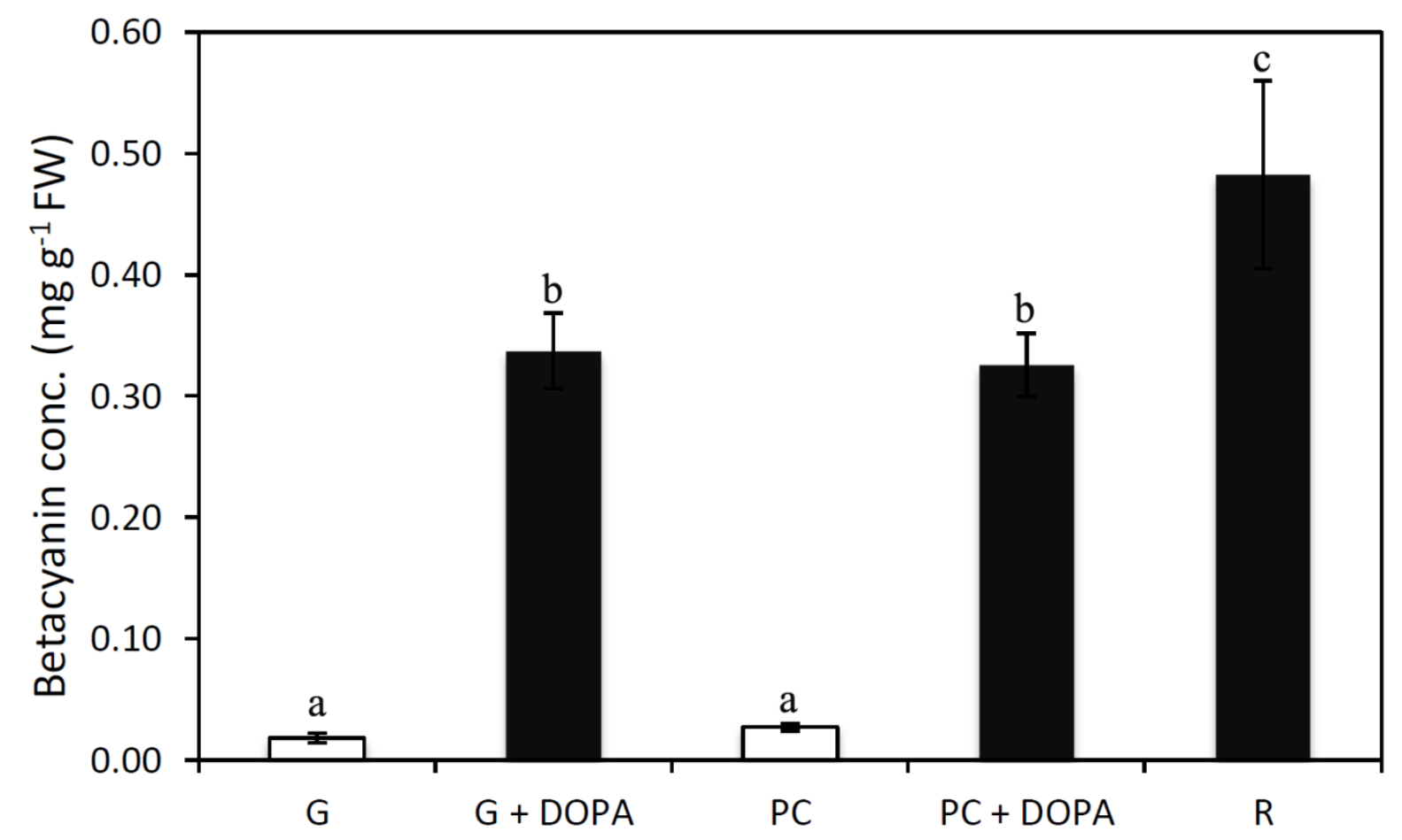

Fig. 3.2 Betalain content in extracts from green (open bars) and red (closed bars) leaves of Disphyma australe, taken from green (G), parti-coloured (PC), and red (R) morphs before and after L-DOPA treatment. Concentrations expressed as betanin equivalents. Means $\pm \mathrm{SE}, \mathrm{n}=5$. Different letters above bars indicate significant differences across treatments $(\mathrm{P}<0.05)$.

Extracts of L-DOPA-treated leaves from the G morphs generated five HPLC peaks at 538 $\mathrm{nm}$ (Fig. 3.3), but no peak at $470 \mathrm{~nm}$, indicating the presence of betacyanins but not of betaxanthins. Based on their retention times in reference to those published in previous studies (Kugler et al., 2007; Svenson et al., 2008; Jain \& Gould, 2015b), the peaks were tentatively identified as being the same as those previously identified in the R morph (Jain \& Gould, 2015): betanin, isobetanin, betanidin, lampranthin-II and isolampranthin. 


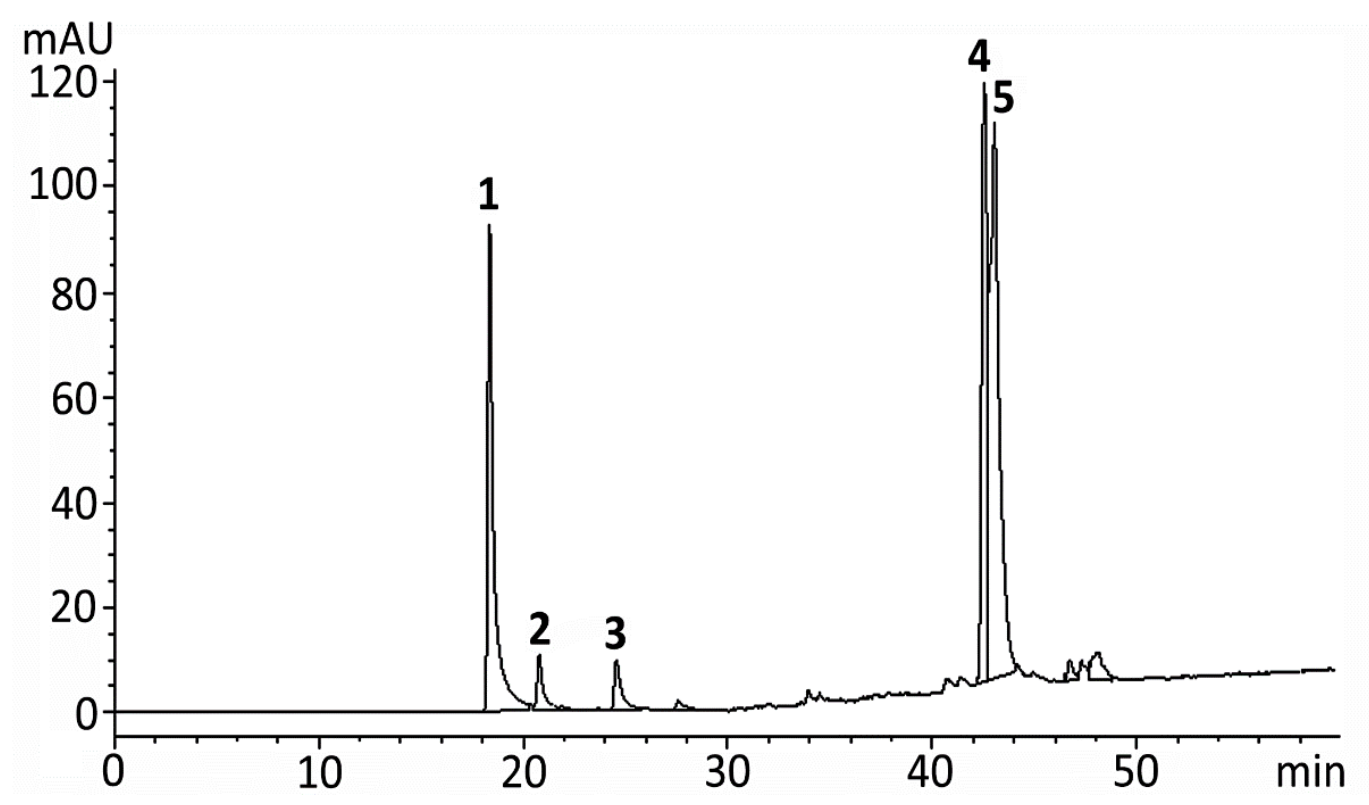

Fig. 3.3 HPLC chromatogram for L-DOPA fed leaf extracts of green morphs of Disphyma australe. Peaks tentatively identified as (1) betanin, (2) isobetanin, (3) betanidin, (4) lampranthin-II, (5) isolampranthin.

\subsubsection{Tyrosinase activity}

To understand why betacyanins are not normally synthesised in leaves of the G and PC morphs, we tested leaf extracts for tyrosinase activity, the enzyme most commonly reported to be involved in two key steps in the betalain pathway. A tyrosinase has been proposed to catalyse both the hydroxylation of tyrosine to L-DOPA, and the subsequent oxidation of L-DOPA to dopaquinone, which spontaneously cyclizes to form the cyclo-DOPA that is needed for betacyanin formation (reviewed by Strack et al., 2003). Tyrosinase-like activity was quantified by measuring dopachrome (which forms spontaneously from dopaquinone via a cyclo-DOPA intermediate) using either tyrosine or L-DOPA as the substrate. There was no measurable tyrosinase activity using either substrate with the leaf extracts of $\mathrm{G}$ morphs, either before or after L-DOPA treatment (Table 3.1). In contrast, extracts from red leaves of the $\mathrm{R}$ morphs showed the highest tyrosinase activities, which were on average 4.8-fold greater with L-DOPA than with Ltyrosine as the substrate. Tyrosinase activities in green PC leaves were lower than those of the $\mathrm{R}$ morph, on average by $38 \%$ (with L-tyrosine) and $61 \%$ (with L-DOPA). The validity of the 
protocol for comparisons across morphs was confirmed using the purple petals, for which tyrosinase activities were comparable in the $\mathrm{R}$ and $\mathrm{G}$ morphs (Table 3.1). As a further check of the methodology, the inclusion of tyrosinase inhibitors tropolene or 2-MBT completely prevented dopachrome production in all leaf and petal extracts.

Table 3.1. Tyrosinase activity (units $\mathrm{mg}^{-1}$ protein $\mathrm{h}^{-1}$ ) in extracts from leaves and petals of red (R), green (G) and parti-coloured (PC) morphs of Disphyma australe, as measured by dopachrome production using L-tyrosine or L-DOPA as the substrate. Values followed by different letters differ significantly $(\mathrm{P}<$ $0.05)$ within a column. Means \pm S.E., $n=5$.

\begin{tabular}{llll}
\hline Morph & Organ extracted & \multicolumn{2}{l}{ Substrate } \\
\cline { 3 - 4 } & & L-Tyrosine & L-DOPA \\
\hline R & Red leaf & $2.9 \pm 0.20 \mathrm{a}$ & $13.9 \pm 2.79 \mathrm{a}$ \\
R & Petal & $3.3 \pm 0.07 \mathrm{a}$ & $7.5 \pm 0.15 \mathrm{~b}$ \\
PC & Green leaf & $1.8 \pm 0.04 \mathrm{~b}$ & $5.4 \pm 0.47 \mathrm{c}$ \\
G & Green leaf & $0.0 \pm 0.00 \mathrm{c}$ & $0.0 \pm 0.00 \mathrm{~d}$ \\
G & Red (L-DOPA fed) leaf & $0.0 \pm 0.00 \mathrm{c}$ & $0.0 \pm 0.00 \mathrm{~d}$ \\
G & Petal & $3.5 \pm 0.06 \mathrm{a}$ & $7.33 \pm 0.29 \mathrm{~b}$ \\
\hline
\end{tabular}

\subsubsection{Responses to saturating light}

Shoot tips that had been incubated in $\mathrm{ddH}_{2} \mathrm{O}$ or L-DOPA for $48 \mathrm{~h}$ had similar maximum quantum yields of photosystem II $(F v / F m=0.72 \pm 0.002)$ irrespective of morph type or leaf colour. When exposed to $1300 \mu \mathrm{mol} \mathrm{m} \mathrm{s}^{-2}$ white light and $200 \mathrm{mM} \mathrm{NaCl}$, quantum yields ( $\left.\Phi_{\mathrm{PSII}}\right)$ decreased progressively. After $6 \mathrm{~h}, \Phi_{\mathrm{PSII}}$ had declined by $75 \%$ in the PC morph, but by only $46 \%$ in the R morph (Fig. 3.4 a). Similarly, for the $\mathrm{G}$ morphs $\Phi_{\mathrm{PSII}}$ had declined by $74 \%$ in green leaves and by $48 \%$ in the red (L-DOPA fed) leaves (Fig. 3.4 b). The depression of $\Phi_{\text {PSII }}$ was significantly greater $(\mathrm{P}<0.03)$ for green leaves subjected for $6 \mathrm{~h}$ to the combination of light and salinity 
$\left(\Delta F / F m^{\prime}=0.19 \pm 0.001\right)$ than to high light alone $\left(\Delta F / F m^{\prime}=0.27 \pm 0.001\right)$, confirming that salinity stress had contributed to this response. When returned to darkness, quantum yields recovered to $80-94 \%$ of their original values over a $10 \mathrm{~h}$ period. Recovery was swifter in the red than in the green leaves.

Using green light rather than white light did not appreciably alter the decline in $\Phi_{\mathrm{PSII}}$ in green leaves of the PC and $\mathrm{G}$ morphs. In contrast, for the red leaves under green light, $\Phi_{\text {PSII }}$ decreased by only $26 \%$ in the R morph, and by $31 \%$ in the L-DOPA-fed G morph (Fig. 3.4 c,d). Again, recovery was swifter and more extensive in the red than in the green leaves. Under red light, differences between the responses of red and green leaves were far smaller; $\Phi_{\mathrm{PSII}}$ declined by $60 \%$ in $\mathrm{R}$ and $73 \%$ in PC (Fig. 3.4 e). For the $\mathrm{G}$ morph, the decline in $\Phi_{\text {PSII }}$ was almost identical for control (70\%) and L-DOPA-fed (72\%) leaves (Fig.3.4 f). 

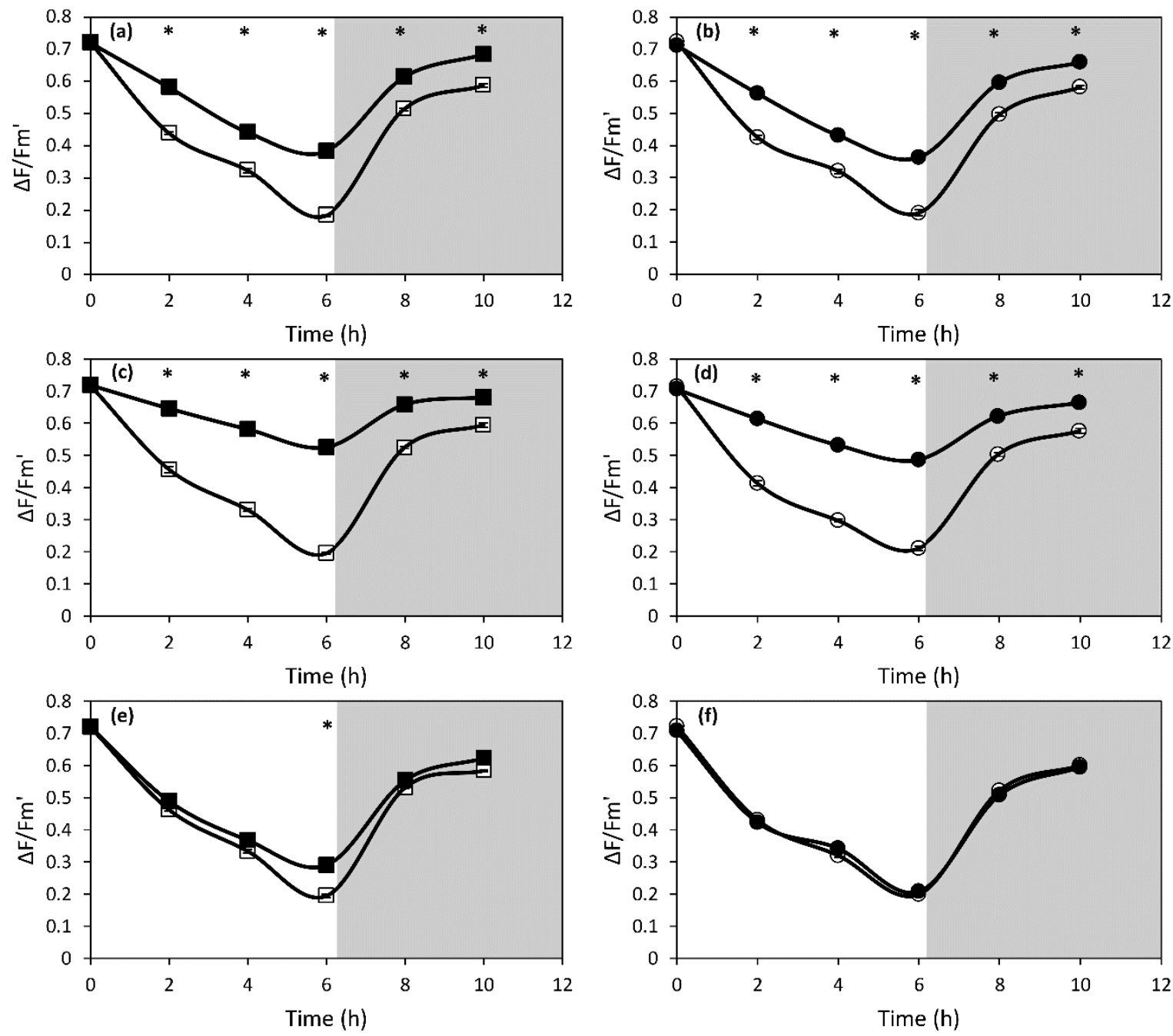

Fig. 3.4 Temporal changes in photochemical quantum yield of PSII $\left(\Delta F / F m^{\prime}\right)$ for leaves of particoloured ( $\square$ ), red ( $\square$ ), green $(\bigcirc)$ and L-DOPA-treated green $(\bullet)$ morphs of Disphyma australe. Leaves were exposed for $6 \mathrm{~h}$ to $1300 \mu \mathrm{mol} \mathrm{m} \mathrm{m}^{-2} \mathrm{~s}^{-1}$ white (a, b), green (c, d) or red (e, f) light. Shaded areas show recovery of $\triangle F / F m^{\prime}$ when plants were returned to darkness. Means $\pm \mathrm{SE}$; $\mathrm{n}=5$. Asterisks indicate significant differences between morphs at each time point $(\mathrm{P}<0.05)$.

When subjected to an ascending light ramp, $\Phi_{\mathrm{PSII}}$ declined more rapidly in control than in L-DOPA-treated leaves of the G morph (Fig. 3.5 a; P < 0.01). Non-photochemical quenching (NPQ) values were statistically higher in the control than in L-DOPA-treated leaves (Fig. 3.5 b; $\mathrm{P}<0.01)$. 

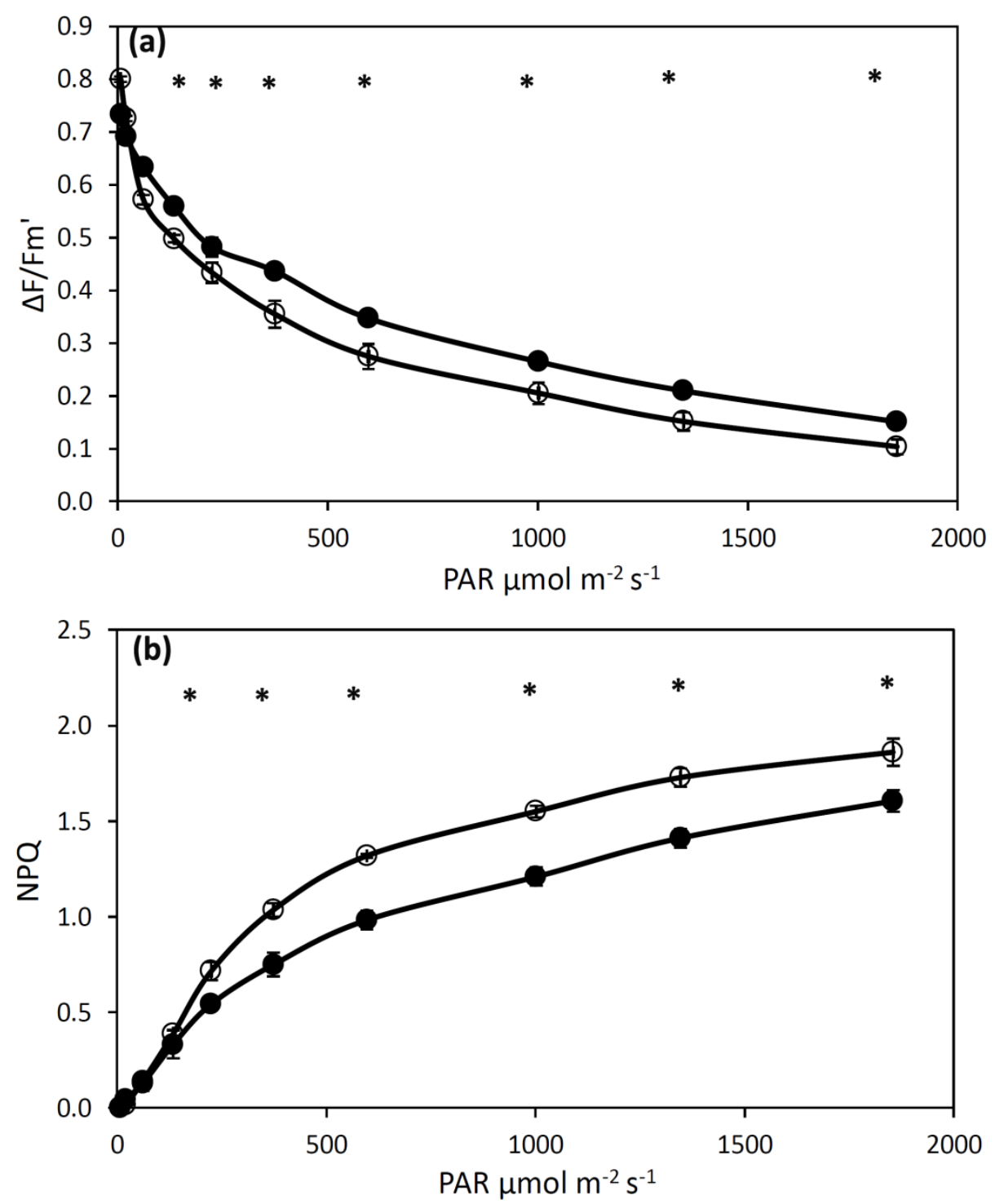

Fig. 3.5 Light response curves for (a) photochemical quantum yield of PSII $\left(\Delta F / F m^{\prime}\right)$ and (b) non-photochemical quenching (NPQ) for leaves of green morphs of Disphyma australe before $(O) / *+$ and after $(\bullet)$ L-DOPA treatment. Means \pm SE; $n=5$. Asterisks indicate significant differences at each time point $(\mathrm{P}<0.05)$. 


\subsection{6 $\mathrm{H}_{2} \mathrm{O}_{2}$ Production}

Green epifluorescence indicating the presence of $\mathrm{H}_{2} \mathrm{O}_{2}$ was recorded from sections of DCFHDA-infiltrated leaves following an exposure to low or high light with or without a salinity treatment (Figs. 3.6 \& 3.7). Sections from control leaves (dark-acclimated, without salinity) did not fluoresce green irrespective of leaf colour or morph. For the green leaves of G morphs, the intensity and distribution of fluorescence increased in accordance with the severity of the applied stressors (Fig. 3.6 a-h). Thus, with salinity and low light, fluorescence was relatively weak and largely confined to epidermal cells and the centrally-located water storage parenchyma (Fig. 3.6 d); under high light minus salinity all tissues fluoresced to some degree (Fig. 3.6 f); and under high light with salinity all tissues fluoresced intensely (Fig. $3.6 \mathrm{~h}$ ). In contrast, the red L-DOPA treated leaves showed a very different pattern of responses to the stressors (Fig. 3.6 i-p). Fluorescence was substantially weaker than that in the green leaves, and was confined to isolated epidermal cells and, under high light, the water storage parenchyma. The absence of green fluorescence from palisade mesophyll tissue, which in these red leaves did not hold betalains, served to confirm that the fluorescence pattern could not simply be ascribed to the extinction of any green emission by the red pigments. 

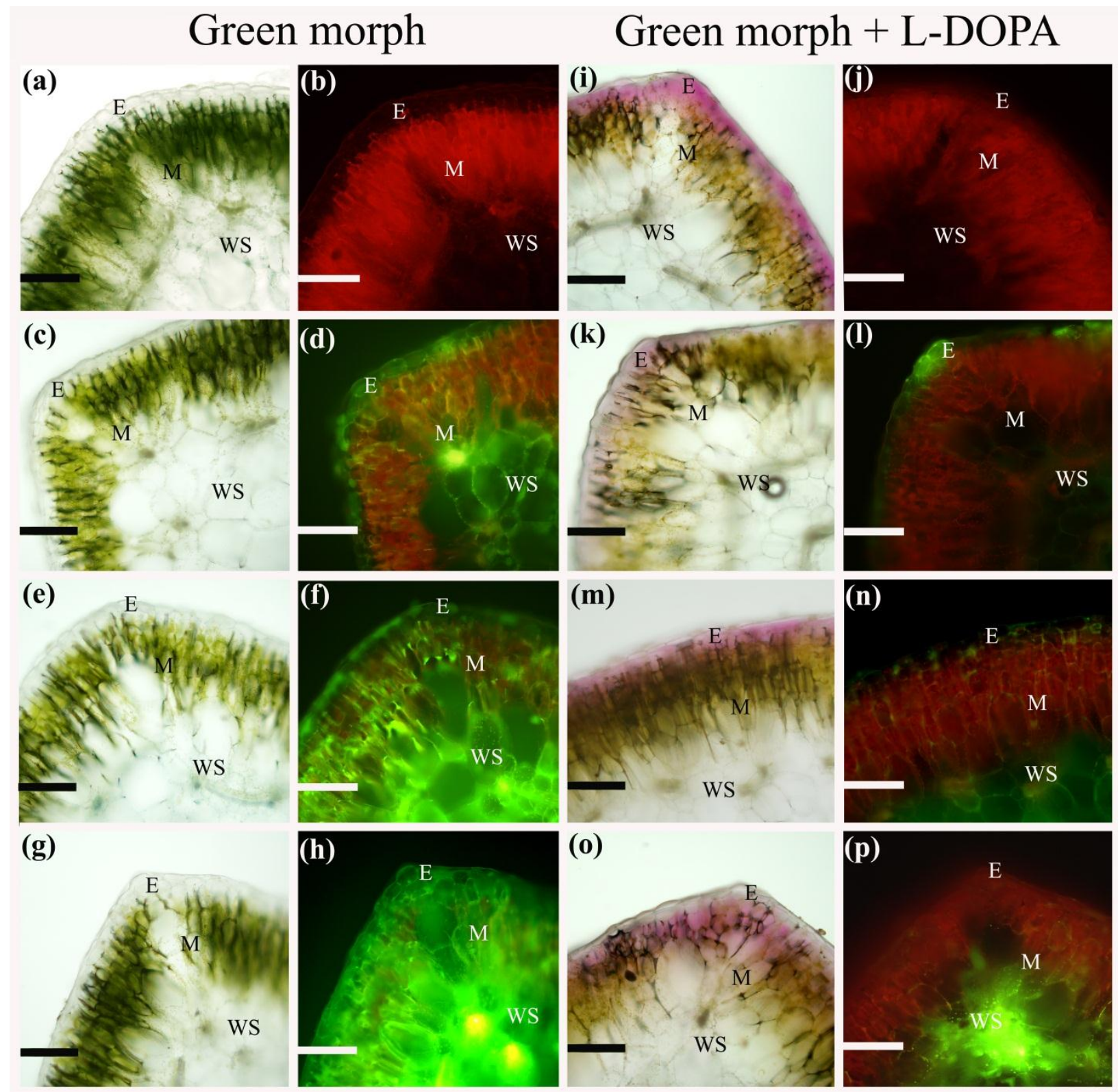

Fig. 3.6 Transverse sections and their epifluorescence micrographs of DCFH-infiltrated leaves of control (a-h) and L-DOPA-fed (i-p) green morphs of Disphyma australe. Shoot tips were untreated in the dark $(\mathrm{a}, \mathrm{b}, \mathrm{i}, \mathrm{j})$, or exposed to low light $+\mathrm{NaCl}(\mathrm{c}, \mathrm{d}, \mathrm{k}, \mathrm{l})$, high light $-\mathrm{NaCl}$ (e,f,m,n), or high light $+\mathrm{NaCl}(\mathrm{g}, \mathrm{h}, \mathrm{o}, \mathrm{p})$. Low light $=400 \mu \mathrm{mol} \mathrm{m}^{-2} \mathrm{~s}^{-1}$; high light $=1300 \mu \mathrm{mol} \mathrm{m}$ ${ }^{2} \mathrm{~s}^{-1} ; \mathrm{NaCl}=200 \mathrm{mM}$. Sections are representative of $\mathrm{n}=6$. $\mathrm{E}=$ epidermis, $\mathrm{M}=$ mesophyll, WS = water storage parenchyma. Bars $=100 \mu \mathrm{m}$. 
Fluorescence signals in leaves of the PC morph (Fig. 3.7 a-h) were almost identical to those of the green G-morphs. For the R morphs, fluorescence was entirely limited to the water storage parenchyma under conditions of high light plus salinity (Fig. 3.7 i-p). Collectively, the data indicate that $\mathrm{H}_{2} \mathrm{O}_{2}$ production is greatly reduced, both in concentration and in distribution, in the betacyanin-containing leaves facing salinity and/or high light stress. 


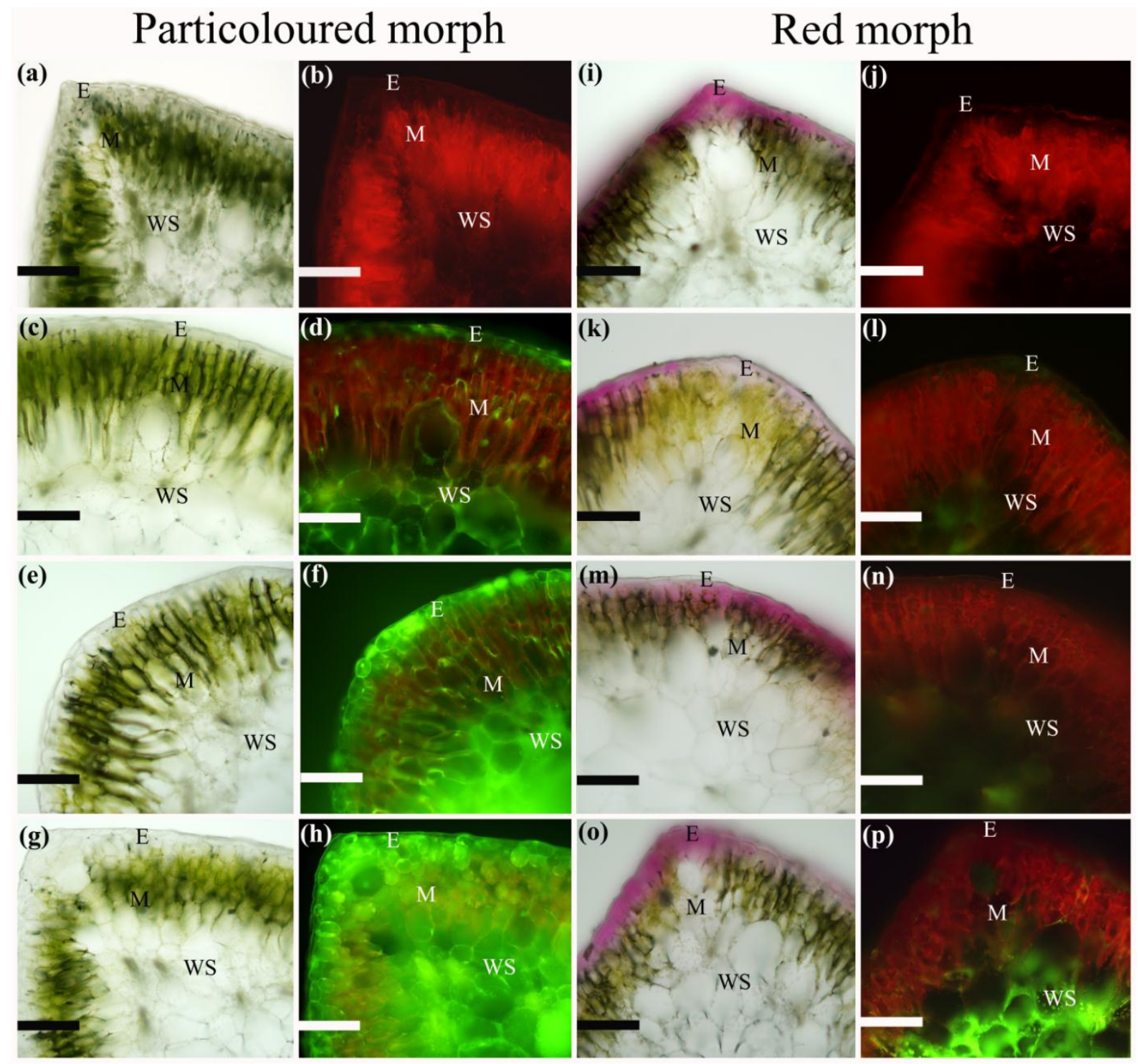

Fig. 3.7 Transverse sections and their epifluorescence micrographs of DCFH-infiltrated leaves of parti-coloured (a-h) and red (i-p) morphs of Disphyma australe. Shoot tips were untreated in the dark (a,b,i,j), or exposed to low light $+\mathrm{NaCl}(\mathrm{c}, \mathrm{d}, \mathrm{k}, \mathrm{l})$, high light $-\mathrm{NaCl}(\mathrm{e}, \mathrm{f}, \mathrm{m}, \mathrm{n})$, or high light $+\mathrm{NaCl}(\mathrm{g}, \mathrm{h}, \mathrm{o}, \mathrm{p})$. Low light $=400 \mu \mathrm{mol} \mathrm{m} \mathrm{s}^{-1} ;$ high light $=1300 \mu \mathrm{mol} \mathrm{m}^{-2} \mathrm{~s}^{-1} ; \mathrm{NaCl}=200$ $\mathrm{mM}$. Sections are representative of $\mathrm{n}=6 . \mathrm{E}=$ epidermis, $\mathrm{M}=$ mesophyll, $\mathrm{WS}=$ water storage parenchyma. Bars $=100 \mu \mathrm{m}$. 


\subsection{Discussion}

When green shoots of $D$. australe were fed with L-DOPA, they synthesised five betacyanin pigments (Fig. 3.3) which were structurally identical to the betalain complement in naturally-red leaves (Jain and Gould, 2015). Like their natural counterparts, the L-DOPA-induced red leaves showed smaller depressions and swifter recoveries of $\Phi_{\text {PSII }}$ (Fig. 3.4), and produced less $\mathrm{H}_{2} \mathrm{O}_{2}$ (Fig. 3.6) when exposed to high light and salinity than did the green leaves. There were no differences in leaf structure, age, genotype, or developmental history between green and LDOPA-fed red leaves of the $\mathrm{G}$ morph that could potentially explain these results. Furthermore, non-photochemical quenching via the xanthophyll cycle, which is often considered to be the primary mechanism for dissipating excess quantum energy (Goss \& Lepetit, 2015) was actually lower in the L-DOPA treated than in untreated leaves (Fig. 3.5), and so that, too, cannot explain the data. Taken together, my results provide strong support for a photoprotective role of foliar betalains in this species.

\subsubsection{Spectral properties of betalains responsible for light screening}

L-DOPA per se is unlikely to have affected the photo-oxidative responses of leaves to high light and salinity. It is a colourless compound which, at low concentrations, can exert mild pro-oxidant rather than antioxidant effects in cells (Spencer et al., 1996). Rather, the differential responses of red and green leaves to different wavebands (Fig.3.4) indicate that the betacyanins that formed in epidermal cells from the applied L-DOPA were the compounds that exerted the primary effect. Betacyanic leaves of $D$. australe absorb more green-yellow light than do the green leaves, though the presence of betacyanin affects neither the absorbance nor reflectance of red light (Jain and Gould, 2015; Chapter 2). A light-screening function of betacyanins explains why $\Phi_{\text {PSII }}$ declined less in red than in green leaves under white or green light, but not under red light (Fig. 3.4). A similar light-screening role has been postulated for foliar betalains in Mesembryanthemum crystallinum, for which the spectral properties of betalains were considered suitable to abate potentially damaging light and UV radiation that would otherwise fall incident on the chloroplasts (Vogt et al., 1999; Ibdah et al., 2002). 


\subsubsection{Involvement of Tyrosinase in betalain biosynthesis}

The induction of betacyanin production by L-DOPA feeding (Fig. 3.2) demonstrated that the leaves of the $G$ morph have a block in the conversion of tyrosine to L-DOPA, the first biosynthetic step of the betalain pathway. Genes that control this step have not yet been reported, although it has been a prevalent view in the literature that a tyrosinase is involved (reviewed by Strack et al., 2003). Tyrosinases are copper-containing, bifunctional enzymes that hydroxylate phenols to form $o$-diphenols and then oxidize these products to $o$-quinones. Thus, tyrosinase activity is proposed to catalyse both the formation of L-DOPA from tyrosine and the oxidation of L-DOPA to dopaquinone, which spontaneously converts to cyclo-DOPA and then combines with betalamic acid to form betacyanin. On that basis, I investigated tyrosinase activity in the different morphs. Intriguingly, there was an absence of tyrosinase activity in the $\mathrm{G}$ morph and significantly lower activity in the leaves of PC than in those of the R morph (Table 3.1). Similar correlations between betacyanin content and tyrosinase activity have been shown for other species (Steiner et al., 1999; Wang et al., 2007a). But how, in the absence of tyrosinase, might the L-DOPA-fed green leaves of $D$. australe synthesise betacyanins from L-DOPA? Recently, an alternative step in the pathway for betacyanin biosynthesis has been discovered in beet, involving a novel cytochrome P450 that catalyses the formation of cyclo-DOPA from L-DOPA (Hatlestad et al., 2012). Cytochrome P450 activity could explain the production of betacyanin in our focal species following L-DOPA application, circumventing the requirement for tyrosinase in cyclo-DOPA production. The naturally red leaves of the $\mathrm{R}$ morph might also employ cytochrome P450, though they evidently retain the potential to oxidise L-DOPA using tyrosinase (Table 3.1). Interestingly, Hatlestad et al. (2012) postulated that cytochrome P450 might also be involved in the hydroxylation of tyrosine to L-DOPA. Future studies involving molecular genetics are needed to resolve unequivocally the enzymes that are involved in this initial step in the pathway.

\subsubsection{Unequivocal involvement of betalains in photoprotection}

A reduction in the quantum yield of PSII is a typical response of glycophytes to high salt concentrations. The precise mechanism remains incompletely understood, but recent evidence suggests that the build-up of apoplastic $\mathrm{Na}^{+}$causes the efflux of cytosolic $\mathrm{K}^{+}$from mesophyll cells, thereby impairing the abilities of chloroplasts to process light energy (Percey et al., 2014). 
This leads to the production of supernumerary free radicals, which are rapidly converted to potentially damaging concentrations of $\mathrm{H}_{2} \mathrm{O}_{2}$ (Miller et al., 2010). The green leaves of $D$. australe appear to be the more adversely affected by salinity, as evidenced by sharper declines in $\Phi_{\text {PSII }}$ and substantially greater production of $\mathrm{H}_{2} \mathrm{O}_{2}$ than the red leaves when treated with $200 \mathrm{mM}$ $\mathrm{NaCl}$ and exposed to high light. The green leaves also show lower $\mathrm{CO}_{2}$ assimilation rates than those in the red leaves (Jain and Gould, 2015; Chapter 2). The production of betacyanins through L-DOPA application apparently ameliorates this photo-oxidative assault; higher values of $\Phi_{\text {PSII }}$ were retained (Figs. $3.4 \& 3.5$ ), and patterns of $\mathrm{H}_{2} \mathrm{O}_{2}$ production, which were remarkably similar in the naturally red and the L-DOPA treated red leaves, contrasted sharply with those for green leaves in the PC and $\mathrm{G}$ morphs (Figs. $3.6 \& 3.7$ ). There are at least three possible explanations for these effects of betacyanins: (i) betalains may facilitate the efflux of $\mathrm{Na}^{+}$from the cytosol into the vacuole (Wang et al., 2007b); (ii) betalains are strong antioxidants, and may directly scavenge a variety of ROS (Stintzing \& Carle, 2004; Wang \& Liu, 2007); and (iii) photoabatement by betalains reduces excitation pressure on chloroplasts. However, explanation (i) is highly unlikely because betacyanins predominantly reside within epidermal cells and vascular parenchyma (Fig. $3.1 \mathrm{i}, \mathrm{k}, \mathrm{o}$ ), and are not, therefore, optimally located to sequester $\mathrm{Na}^{+}$in the mesophyll chlorenchyma. Explanation (ii) is also unlikely for the same reason, although $\mathrm{H}_{2} \mathrm{O}_{2}$ is a relatively long-lived ROS that can eventually be transported from cell to cell as well as into cell vacuoles (Mittler et al., 2004), and so it is conceivable that epidermal betalains might neutralize $\mathrm{H}_{2} \mathrm{O}_{2}$ originating from adjacent tissues. Nevertheless, the differential responses of the red leaves to differently coloured light, in addition to the spatial separation between betacyanins and photosynthetic tissue, suggest that a light screening role for betacyanins best explains my data in D. australe.

\subsection{Conclusion}

In conclusion, light screening by epidermal betalains appears to effectively reduce the propensity for photoinhibition and photo-oxidative stress in subjacent chlorenchyma. This may assist the survival of $D$. australe at locations where plants are exposed to high light and/or salinity. Accordingly, at our coastal field site ratios of $\mathrm{R}$ to $\mathrm{G}$ morphs were found to increase towards the shoreline where edaphic sodicity was greatest (Jain \& Gould, 2015b). Thus, the presence of foliar betacyanins seems to expand the colonisable range for this species. A photoprotective role 
potentially explains the relative abundance of other betalainic species in marginal environments such as salt marshes and deserts (Ehrendorfer, 1976) and is analogous to the reported functions of anthocyanins in the leaves of many species (Hatier \& Gould, 2009). Nevertheless, the persistence of green-leafed morphs within natural populations of $D$. australe suggests that the production of betalains entails a cost, especially under conditions of low stress. 


\section{Chapter 4: Foliar betacyanins confer benefit to $D$. australe by $\mathrm{Na}^{+}$sequestration under applied salinity}

\subsection{Abstract}

Soil salinity can inhibit plant growth, and affects crop productivity worldwide. However, halophytes are naturally salt-tolerant plants which can provide a gateway to develop salt tolerant crops that grow on highly saline soils. For that it is crucial to study and understand the physiological mechanisms of salinity tolerance in these plants. In New Zealand, Disphyma australe, a succulent halophyte uses a novel mechanism to tolerate salinity stress. My previous work showed that exposure to salinity and high light causes betalain production in the leaves of D. australe. Moreover, red pigmentation in the leaves photoprotect the subjacent chloroplasts from high light when the roots are subjected to saline solution. In the present work, I further investigated the involvement of betacyanin in salinity tolerance in D. australe. I hypothesised that epidermal betacyanins in red morphs would assist the sequestration of excessive $\mathrm{Na}^{+}$into epidermal cells to avoid $\mathrm{Na}^{+}$toxicity in mesophyll tissue. I also studied growth rate, leaf water potential and compatible solute accumulation in red and green morphs of D. australe under salinity stress. Epifluorescence images of cytoplasmic $\mathrm{Na}^{+}$revealed that both naturally red and L-DOPA induced red leaves stored most of the $\mathrm{Na}^{+}$in epidermal cells, thereby avoiding excess $\mathrm{Na}^{+}$in mesophyll tissues. By contrast, in green morphs $\mathrm{Na}^{+}$concentrations were uniformly distributed throughout all the leaf tissues. Moreover, red morphs showed higher growth rate and accumulated more compatible solutes than green morphs under salinity stress. This study provides good evidence that betacyanins may enhance salt tolerance in $D$. australe by drawing $\mathrm{Na}^{+}$away from sensitive photosynthetic cells. 


\subsection{Introduction}

Plants are often exposed to various environmental factors such as chilling, high light, drought and salinity which adversely affect their physiological functioning. Among all these environmental stressors, soil salinity is particularly important, affecting almost $20 \%$ of the irrigated lands worldwide (Slama et al., 2015). Munns and Tester (2008) suggested that 0.5-1\% of world's total irrigated area is lost every year due to soil salinity. Therefore, developing salinity tolerant crops is an important strategy to satisfy increasing food demand. Halophytes, which are natural salt tolerant plants that use various mechanisms to exclude or tolerate the effects of salinity, can provide a gateway to make conventional crops more salt tolerant (Rozema \& Flowers, 2008; Shabala et al., 2014; Ventura et al., 2015). However, to implement this strategy, it is crucial to understand the detailed physiological mechanisms of salt tolerance.

In, New Zealand, a common succulent halophyte Disphyma australe apparently uses a novel mechanism to tolerate salinity stress. In my previous work (Jain and Gould, 2015; Chapter 2), I found that $D$. australe shows a dimorphism in shoot colour within a population, caused by the presence of betacyanins, a class of nitrogenous red pigments. Further, I showed that exposure to high light and salinity induces the production of betacyanins in red morphs; green morphs, however, lacked the full enzyme complement for betacyanin biosynthesis in vegetative shoots in response to salinity. Moreover the red morphs were the more tolerant to salinity stress; they showed higher photosynthetic $\mathrm{CO}_{2}$ assimilation rates, and greater water use efficiency, photosystem II quantum yield and photochemical quenching than green morphs when exposed to salt. In subsequent work (Jain et al., 2015; Chapter 3), I showed that foliar betacyanins in D. australe provide photoprotection to chloroplasts in subjacent chlorenchyma cells, for which the photosynthetic ability had been compromised by salinity.

Salinity stress is primarily associated with osmotic imbalance and ionic toxicity in plants (Sairam \& Tyagi, 2004; Munns \& Tester, 2008). Therefore, to associate foliar betacyanin with salinity stress tolerance, it is important to study the possible involvement of betacyanins in these primary effects. Wang et al. (2007a) suggested that for Suaeda salsa, higher levels of $\mathrm{Na}^{+}$might be sequestered into the vacuoles of betacyanic cells than of acyanic cells, implicating a role for betacyanins in $\mathrm{Na}^{+}$movement. However, this possibility was not explored experimentally. 
A similar function could be proposed for betacyanins in $D$. australe, where betacyanic epidermal cells could draw $\mathrm{Na}^{+}$ions away from the underlying mesophyll and avoid cytotoxicity in photosynthetic cells. Photosynthesis in plants is particularly sensitive to salinity stress; cytoplasmic $\mathrm{Na}^{+}$concentrations $(100 \mathrm{mM}$ or above) can inhibit photosynthetic enzymes (Munns et al., 2006; Chaves et al., 2009). Moreover, toxic concentrations of ions within cells can impair the capacity of chloroplasts to process light energy and can lead to the production of reactive oxygen species (ROS) (Sairam \& Tyagi, 2004; Flexas et al., 2004; Chaves et al., 2009). Therefore, it is important for a photosynthetic cell to maintain a low cytoplasmic $\mathrm{Na}^{+}$ concentration. On the other hand, the epidermal cells, which are metabolically less active and have larger vacuolar space than mesophyll cells, are good sites for the storage of toxic ions (Conn \& Gilliham, 2010).

Here, I aim to investigate the possible involvement of betacyanins in salinity tolerance. $D$. australe provides an excellent system for this study. Previously, I described that green morphs of D. australe can be induced to turn red by substrate (L-DOPA) feeding (Jain et al., 2015; Chapter 3). I use this system here to test the possible role of betacyanins in $\mathrm{Na}^{+}$sequestration. I also study and compare the relative growth and accumulation of compatible solutes between red and green morphs under salt stress.

\subsection{Materials and methods:}

\subsubsection{Experiment 1: Growth and physiological parameters}

\subsubsection{Plant Material}

Fifty healthy shoot cuttings each of red and green morph of $D$. australe were collected randomly from south facing dunes near the coast at Te Kopahau reserve, Wellington, New Zealand ( $\left.41^{\circ} 21^{\prime} 01^{\prime \prime S}, 174^{\circ} 43^{\prime} 55^{\prime \prime E}\right)$. Collected shoot cuttings with the two youngest fully expanded leaves

attached were then planted in trays containing 2:1 potting compost and sand for $5 \mathrm{wk}$. These rooted plants were then transferred to $800 \mathrm{~mL}$ pots (one plant per pot) containing the same substrate and were grown in an unheated glasshouse at Victoria University of Wellington. 


\subsubsection{Salinity treatment}

Ten potted plants of each morph were watered with $20 \mathrm{ml}$ of $50 \mathrm{mM}, 100 \mathrm{mM}, 200 \mathrm{mM}$ and 400 $\mathrm{mM}$ of $\mathrm{NaCl}$ solution every third day for $5 \mathrm{wk}$. Control plants were watered with laboratory prepared distilled water.

\subsubsection{Growth Measurements}

Shoot length, leaf number and leaf diameter was measured for all the plants after 5 wk of salt treatment and then all plants were destructively harvested for analysis. Roots and shoots were separated, washed, blotted dry, weighed and oven dried at $65^{\circ} \mathrm{C}$ for $48 \mathrm{~h}$. Relative growth rates were expressed as proportionate increase in dry mass, calculated relative to the dry mass of subsamples taken prior to the salinity treatment.

\subsubsection{Betalain quantification}

The youngest fully expanded leaves were harvested at the end of salinity treatment and were flash frozen in liquid nitrogen. These were ground to powder and extracted in $100 \%$ methanol and betalain content quantified spectrophotometrically following the methods described previously in (Jain and Gould, 2015; Chapter 2). Betacyanin contents were expressed as betanin equivalents and calculated from the molar extinction co-efficient $\varepsilon=600001 \mathrm{~mol}^{-1} \mathrm{~cm}^{-1}$ and molecular weight $=550($ Cai \& Corke, 1999) .

\subsubsection{Water potential measurements}

Leaf water potential $(\Psi)$ of five individuals per salt treatment and control plants was measured prior to destructive harvesting. The leaves of $D$. australe are sessile, so stems with four leaves attached were cut and wrapped in a plastic bag for 10 minutes and then $\Psi$ was measured at midday at room temperature using a pressure chamber (PMS 615 pressure chamber; PMS instrument company, USA).

\subsubsection{Sugar and Proline content}


Five leaf samples for each treatment were harvested, cut into small pieces, weighed and heated at $60^{\circ} \mathrm{C}$ in $10 \mathrm{ml} 80 \%$ ethanol for 30 minutes. These extracts were then filtered and used for quantifying proline and soluble sugar content following the acid ninhydrin reagent and anthrone reagent methods (Bates et al., 1973; Giannakoula et al., 2010).

For proline quantification, $2 \mathrm{ml}$ of ethanolic extracts and $1 \mathrm{ml}$ ninhydrin reagent were mixed and kept in a boiling water bath for 10 minutes. Then samples were cooled to room temperature and diluted with $2 \mathrm{ml}$ of $95 \%$ ethanol. Absorbance was recorded at $570 \mathrm{~nm}\left(\mathrm{~A}_{570}\right)$ using a Shimadzu (Kyoto, Japan) $2550 \mathrm{UV}$-vis spectrophotometer. Final concentrations were calculated from a proline standard (Sigma-Aldrich) (Bates et al., 1973).

Soluble sugars were quantified by mixing $1 \mathrm{ml}$ ethanolic extract to $2 \mathrm{ml}$ ice cold anthrone. Fully mixed samples were then kept in a water bath at $90^{\circ} \mathrm{C}$ for $20 \mathrm{~min}$. Absorbance of chilled samples was recorded at $625 \mathrm{~nm}$ using a Shimadzu (Kyoto, Japan) 2550 UV-vis spectrophotometer. Soluble sugar concentrations were calculated using a glucose standard (Sigma-Aldrich) (Giannakoula et al., 2010).

\subsubsection{Experiment 2: $\mathrm{Na}^{+}$localisation by fluorescence imaging and cryo-SEM analysis}

\subsubsection{Plant material}

For the $\mathrm{Na}^{+}$localisation experiment, 10 individuals for each red and green morph were collected from the same location as described above. Five shoot tips of green morphs were induced to synthesise betacyanins by L-DOPA feeding following the previously described method (Jain $e t$ al., 2015; Chapter 3). These cuttings were kept in the water at room temperature until required.

For $\mathrm{Na}^{+}$content measurements, plants were collected and grown as described in 4.3.1.1. These plants were then watered with either distilled water or $200 \mathrm{mM} \mathrm{NaCl}$ every third day for $5 \mathrm{wk}$ and then whole plants were harvested for $\mathrm{Na}^{+}$content measurements.

\subsubsection{Salinity treatment}

To localise $\mathrm{Na}^{+}, 5$ red, green and L-DOPA fed individual leaves were held upright in either distilled water or $200 \mathrm{mM} \mathrm{NaCl}$ for $48 \mathrm{~h}$ under white light $\left(400 \mu \mathrm{mol} \mathrm{m}^{-2} \mathrm{~s}^{-2}\right.$; supplied by $12 \mathrm{x}$ 
1W LEDs, model OS9151; ADEO Services, France, with color temperature of 6500K) at room temperature. These leaves were then used for stain loading and fluorescent imaging and also for cryo-SEM analysis.

\subsubsection{3 $\mathrm{Na}^{+}$content}

Harvested plants were oven dried at $65^{\circ} \mathrm{C}$ for $48 \mathrm{~h}$, weighed, and then inserted in $5 \mathrm{ml}$ distilled water and held in a boiling water bath for $1 \mathrm{hr}$. Extracts were then filtered and diluted with distilled water to $5 \mathrm{ml}$ final volume. These extracts were then used to measure $\mathrm{Na}^{+}$content using atomic absorption spectrometery (Thermo Scientific iCE 3500 AAS, USA) (Ramani et al., 2006).

\subsubsection{4 $\mathrm{Na}^{+}$Localisation}

Salt treated leaves were held upright in $1 \mathrm{ml}$ of $10 \mu \mathrm{M}$ sodium-binding benzofuran isophthalateacetoxymethyl ester (SBFI-AM) fluorophore in the dark for $4 \mathrm{~h}$ at room temperature. SBFI-AM is a UV excited fluorophore and most commonly used for cytosolic sodium measurements (Schreiner \& Rose, 2012). After incubation, median transverse sections of the leaves were examined for green epifluorescence in an Olympus AX70 compound microscope (Olympus Optical Co., Hamburg, Germany) using $380 \mathrm{~nm}$ excitation and collecting emission above 530 nm. Images were taken using an Olympus DP70 digital camera (Kader \& Lindberg, 2005).

\subsubsection{Cryo-SEM analysis}

A $0.5 \mathrm{~cm}$ long segment was cut from the apex of the salt treated leaves (one leaf from each of two red, green and L-DOPA treated plants), attached to copper stubs, and plunged into liquid $\mathrm{N}_{2}$. Frozen leaf segments were then placed in a cryo-transfer unit and transferred to the vacuum chamber of a cryo-SEM (JEOL 6400; JEOL Ltd. Tokyo, Japan). The leaf segment was then fractured in the transverse plane to expose internal leaf tissue, carefully etched at $-100{ }^{\circ} \mathrm{C}$ for $1-3$ minutes to remove frost, and cooled to between -120 and $-130{ }^{\circ} \mathrm{C}$. The fractured surface was then sputter coated with gold/palladium, and examined in secondary electron mode in the SEM. An area within a tissue was selected that maximised the area covered while avoiding X-ray signals from adjacent tissues. Energy dispersive X-ray analysis (EDX) was performed on these selected 
areas of tissues using a Gatan 666 EDX spectrometer (Japan) with a $\mathrm{Si} / \mathrm{Li}$ detector. $\mathrm{Na}^{+}$ concentrations were calculated from spectral data as peak height/background (P/BG) counts and expressed as $\mathrm{P} / \mathrm{BG}$ ratio. $\mathrm{P} / \mathrm{BG}$ ratio is linearly related to element concentration (Ryan \& Drysdale, 1988). The net "peak height" was calculated by subtracting the bremsstrahlung immediately under the peak. The "background" was a region of the bremsstrahlung from 6-8 Kev devoid of peaks.

\subsubsection{Statistical analysis}

Reported data represent the means of at least five replicates \pm standard errors. Fluorescence images of transverse sections of leaves are representative of at least five replicates per treatment. Normality of the data was confirmed using the Kolmogorov-Smirnov test in SPSS (SPSS Inc., Chicago, IL, USA). Means were compared by one-way ANOVA. Differences in proportionate increase in biomass, pigment levels, water potential values, proline and soluble sugar contents between red and green morphs were tested using two-way ANOVA. Tukey's Post-hoc test (P $<0.05)$ was performed for within-factor and between-treatment comparisons.

\subsection{Results}

\subsubsection{Effect of salinity on pigmentation}

As showed in previous work (Chapters 2 and 3), the saline treated red morphs accumulated betacyanins in the shoots (Fig. 4.1 A and C). However, the green morphs did not produce any red pigmentation on salt exposure (Fig. 4.1 B and D). 


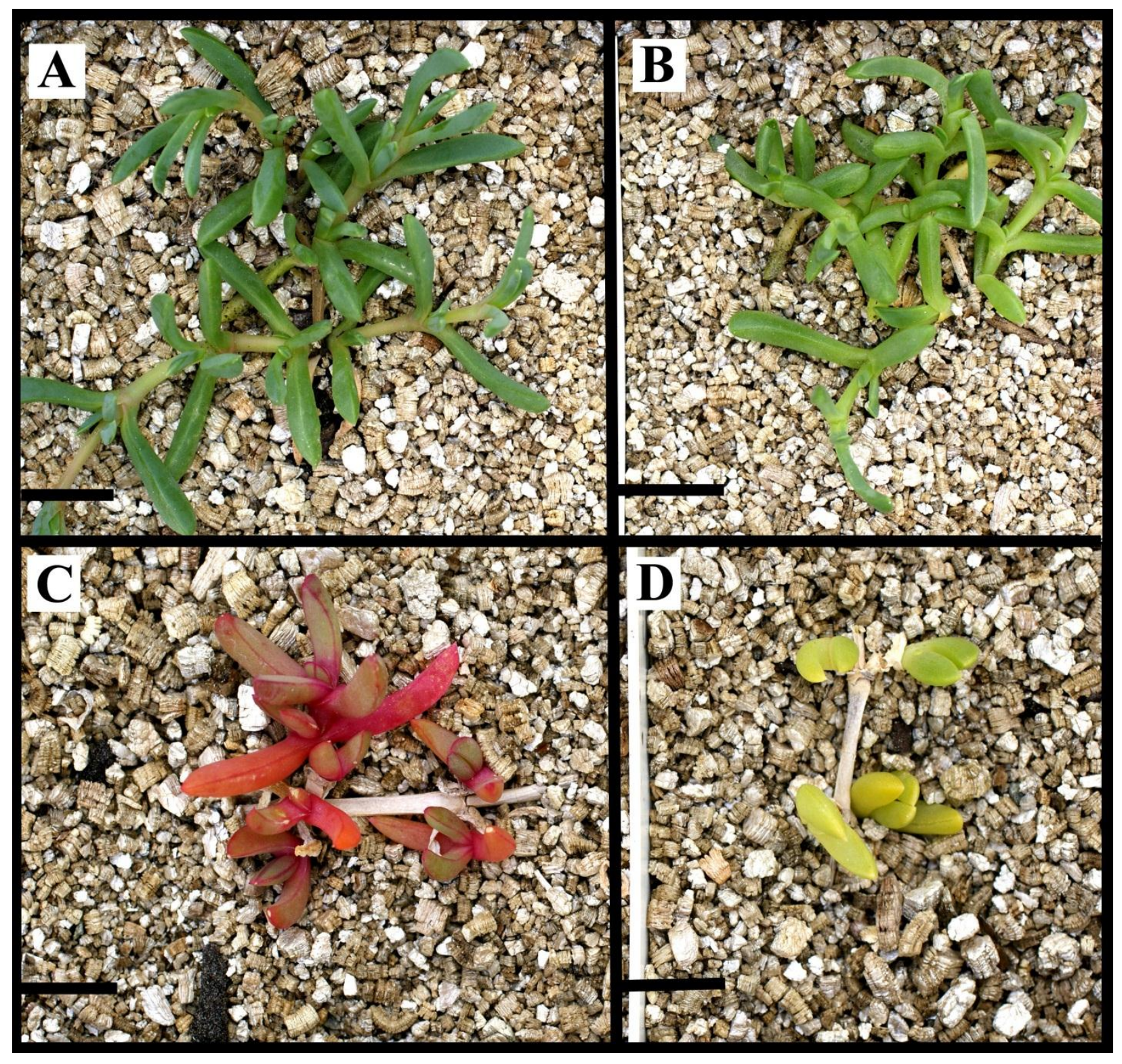

Fig 4.1 Photographs of Disphyma australe. Control red (A) and green (B) morphs, and saline treated red (C) and green (D) morphs. Scale bars: $1 \mathrm{~cm}$ 
Spectrophotometric quantification of betacyanins revealed that there is a direct correlation between red pigmentation and salt stress. Pigmentation was progressively higher in the leaves from red morphs treated with higher salt concentrations (Fig 4.2). In control plants however, betacyanin concentrations were negligible. Red morphs treated with $400 \mathrm{mM} \mathrm{NaCl}$ had the highest foliar betalain concentrations, which were approximately 31-fold higher than untreated red and green controls. Green morphs did not synthesise betacyanins even after exposure to varied $\mathrm{NaCl}$ treatments (Fig 4.2).

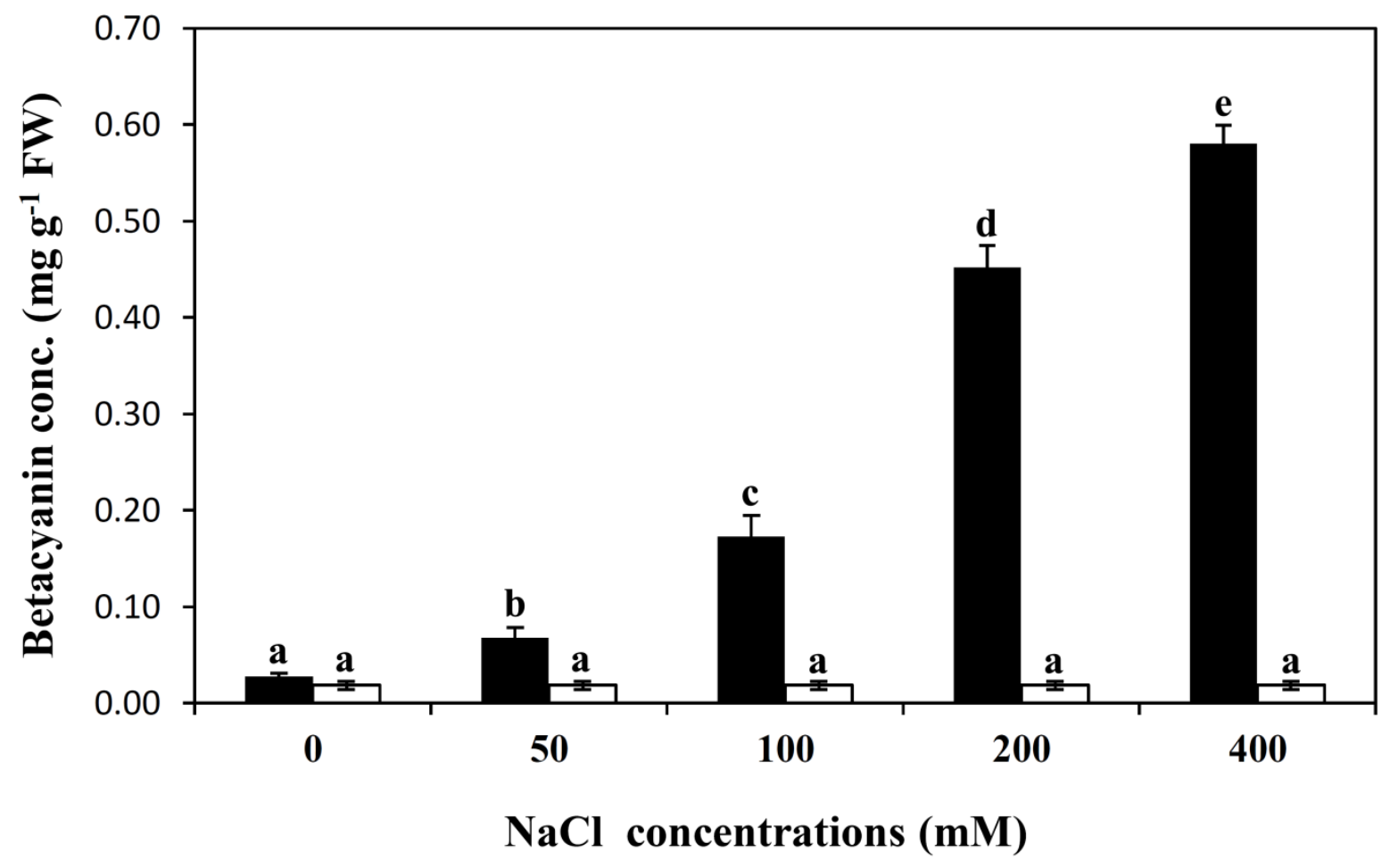

Fig 4.2 Betalain concontrations in extracts from the leaves of red (dark bars) and green (white bars) of Disphyma australe $(\mathrm{n}=5$, Means $\pm \mathrm{SE})$. Concentrations are expressed as betanin equivalents. Different letters above bars indicate significant differences across treatments $(P<$ $0.05)$. 


\subsubsection{Growth rates}

Exposure to $50 \mathrm{mM} \mathrm{NaCl}$ promoted biomass increase in red morphs, on average $15 \%$ higher than the control red and green plants after 5 weeks (Fig 4.3). In contrast, there was no evidence of a promotive effect of low $\mathrm{NaCl}$ concentration on the green morph.

At higher levels of salinity $(100 \mathrm{mM}, 200 \mathrm{mM}$ and $400 \mathrm{mM} \mathrm{NaCl})$ proportionate increase in dry mass declined with increasing $\mathrm{NaCl}$ concentrations in both morphs (Fig 4.3). However, red morphs were evidently less affected by higher salinity. For example, the proportionate increase in biomass of red morphs treated with $400 \mathrm{mM} \mathrm{NaCl}$ was $30 \%$ as compared to $20 \%$ in green morphs.

Final leaf numbers and stem lengths of red and green morphs decreased consistently with progressively higher $\mathrm{NaCl}$ concentrations (Table 4.1). The decrease in leaf number and stem length was more prominent for green than red morphs. Interestingly, leaf diameter of both morphs was greater under increasing concentrations of $\mathrm{NaCl}$, although the girth increment was higher for red than for green morphs (Table 4.1). 


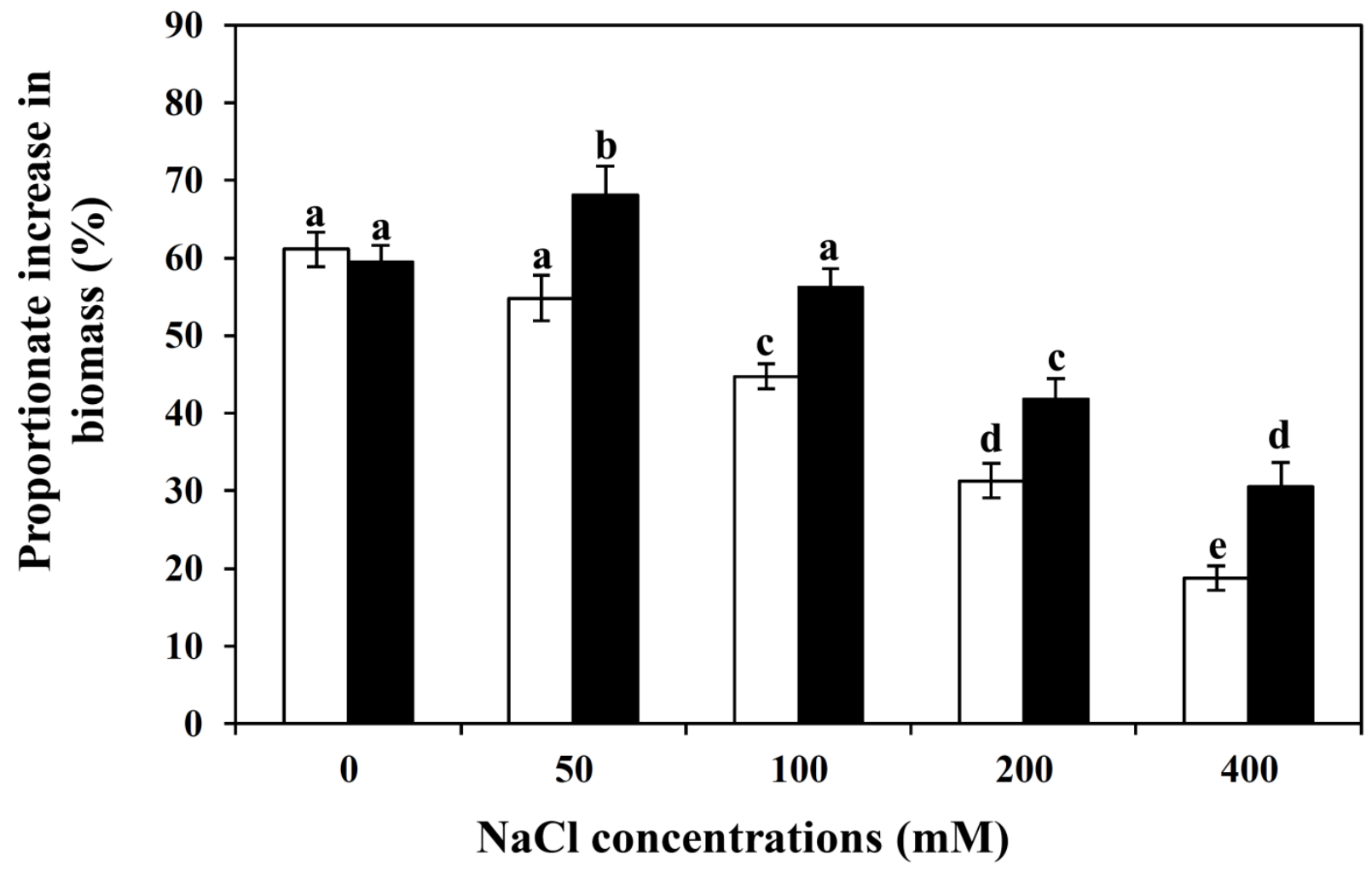

Fig 4.3 Proportionate increase in dry biomass of red (dark bars) and green (white bars) morphs of Disphyma australe after 5 wk of $\mathrm{NaCl}$ treatment $(\mathrm{n}=8$, Means $\pm \mathrm{SE})$. Different letters above bars indicate significant differences across treatments $(P<0.05)$.

Table 4.1 Effect of $\mathrm{NaCl}$ treatment for 5 wk on production of leaf number, increase in leaf diameter and stem length of red and green morphs of Disphyma australe $(\mathrm{n}=8$, Means $\pm \mathrm{SE})$. Different letters represent significant differences between red and green morphs for each parameter across $\mathrm{NaCl}$ concentrations $(\mathrm{P}<0.05)$.

\begin{tabular}{ccccccc}
\hline NaCl conc. & \multicolumn{2}{c}{ Leaf Number } & \multicolumn{2}{c}{ Leaf diameter(mm) } & \multicolumn{2}{c}{ Stem length (cm) } \\
& Red & Green & Red & Green & Red & Green \\
\hline $\mathbf{0 ~} \mathbf{~ m M}$ & $34 \pm 6 \mathrm{a}$ & $33 \pm 4 \mathrm{a}$ & $3.0 \pm 0.09 \mathrm{a}$ & $3.0 \pm 0.19 \mathrm{a}$ & $10.3 \pm 0.43 \mathrm{a}$ & $09.8 \pm 0.48 \mathrm{a}$ \\
$\mathbf{5 0} \mathbf{~ m M}$ & $33 \pm 2 \mathrm{a}$ & $28 \pm 1 \mathrm{~b}$ & $3.8 \pm 0.20 \mathrm{~b}$ & $3.4 \pm 0.18 \mathrm{a}$ & $11.6 \pm 0.51 \mathrm{~b}$ & $08.8 \pm 0.51 \mathrm{c}$ \\
$\mathbf{1 0 0} \mathbf{~ m M}$ & $28 \pm 1 \mathrm{~b}$ & $19 \pm 3 \mathrm{c}$ & $4.3 \pm 0.10 \mathrm{c}$ & $4.0 \pm 0.20 \mathrm{bc}$ & $07.1 \pm 0.56 \mathrm{c}$ & $05.7 \pm 0.36 \mathrm{~d}$ \\
$\mathbf{2 0 0} \mathbf{~ m M}$ & $17 \pm 3 \mathrm{c}$ & $10 \pm 1 \mathrm{~d}$ & $5.0 \pm 0.23 \mathrm{~d}$ & $4.7 \pm 0.10 \mathrm{~d}$ & $05.1 \pm 0.27 \mathrm{~d} 03.0 \pm 0.40 \mathrm{e}$ \\
$\mathbf{4 0 0} \mathbf{~ m M}$ & $12 \pm 1 \mathrm{~d}$ & $09 \pm 2 \mathrm{~d}$ & $5.4 \pm 0.20 \mathrm{~d}$ & $4.8 \pm 0.20 \mathrm{~d}$ & $04.3 \pm 0.20 \mathrm{f}$ & $02.3 \pm 0.50 \mathrm{e}$ \\
\hline
\end{tabular}




\subsubsection{Leaf water potential}

Leaf water potential $(\Psi)$ values from leaves of control red and green morphs were comparable (Fig 4.4). Exposure to salinity lowered $\Psi$ in both morphs. $\Psi$ was progressively more negative in red and green morphs under increasing concentrations of $\mathrm{NaCl}$. The decline in leaf water potential with increasing $\mathrm{NaCl}$ concentrations was steeper for red than for green and the difference was significant (Fig 4.4; $\mathrm{P}<0.05$ ).

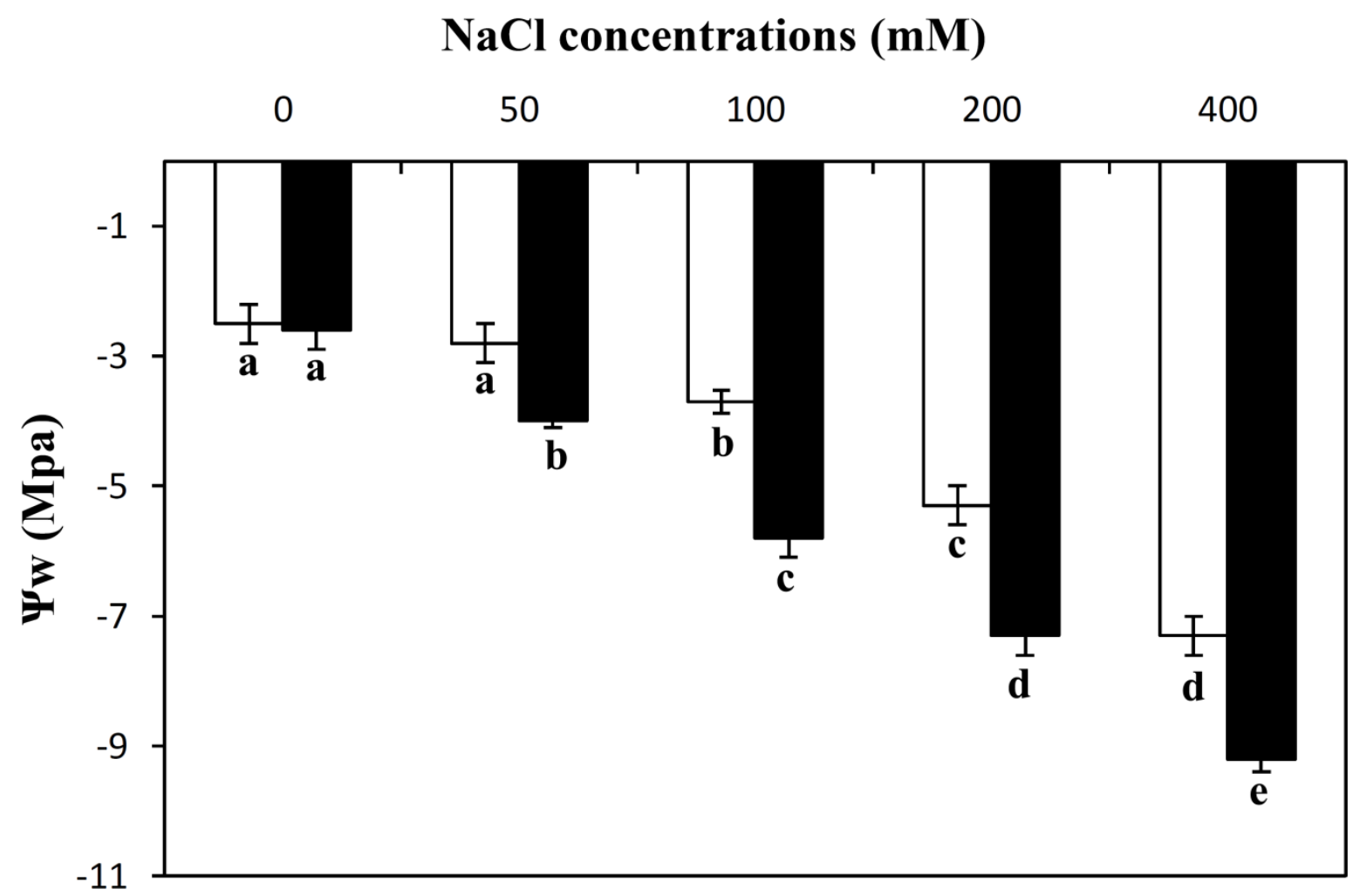

Fig 4.4 Water potential values for leaves of red (dark bars) and green (white bars) morphs of Disphyma australe after 5 wk of $\mathrm{NaCl}$ treatment. $(\mathrm{n}=5$, Means $\pm \mathrm{SE})$. Different letters above bars indicate significant differences across treatments $(P<0.05)$.

\subsubsection{Sugar and Proline content}

Total soluble sugar content in the leaves from red and green morphs increased on exposure to $\mathrm{NaCl}$ concentrations (Fig 4.5). Total soluble sugar was progressively higher in both morphs 
under increasing $\mathrm{NaCl}$ concentrations but red morphs had significant higher values than green morphs (Fig 4.5). The maximum increase was observed in red leaves with $400 \mathrm{mM} \mathrm{NaCl}$, which was approximately 4 fold higher than control red and green leaves.

Proline content was comparable in the leaves from untreated red and green morphs. It increased gradually in both morphs on exposure to increasing concentrations of $\mathrm{NaCl}$ for 5 wk. The difference at $50 \mathrm{mM}$ and $100 \mathrm{mM} \mathrm{NaCl}$ treatments was not significant between morphs. At higher concentrations (200 $\mathrm{mM}$ and $400 \mathrm{mM} \mathrm{NaCl}$ ), however, proline content was significantly higher in leaves of red than the green morphs (Fig. 4.6; P < 0.05).

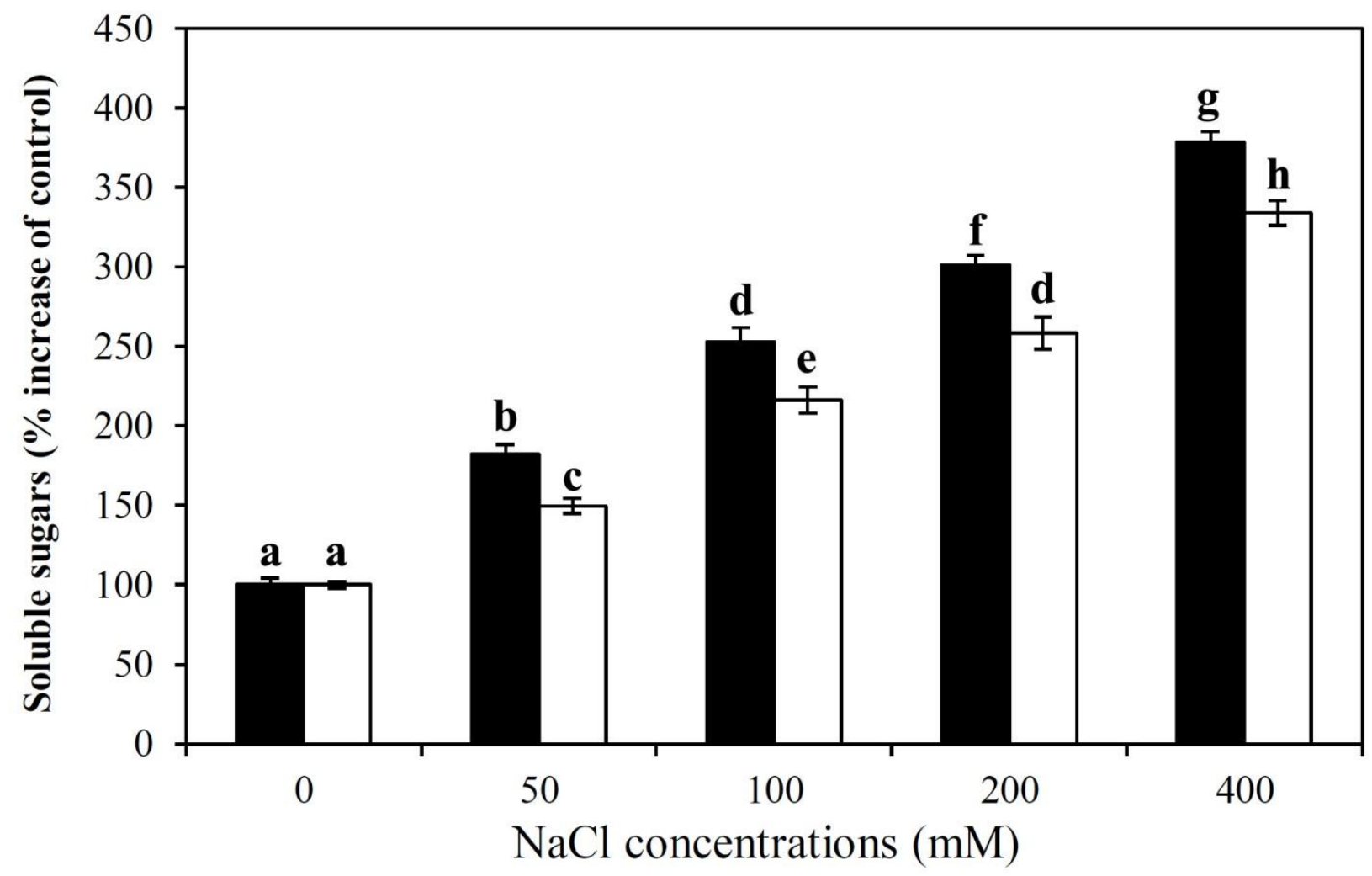

Fig 4.5 Soluble sugar content for leaves of red (dark bars) and green (white bars) morphs of Disphyma australe after $5 \mathrm{wk}$ of $\mathrm{NaCl}$ treatment. $(\mathrm{n}=5$, Means $\pm \mathrm{SE})$. Different letters above bars indicate significant differences across treatments $(P<0.05)$. 


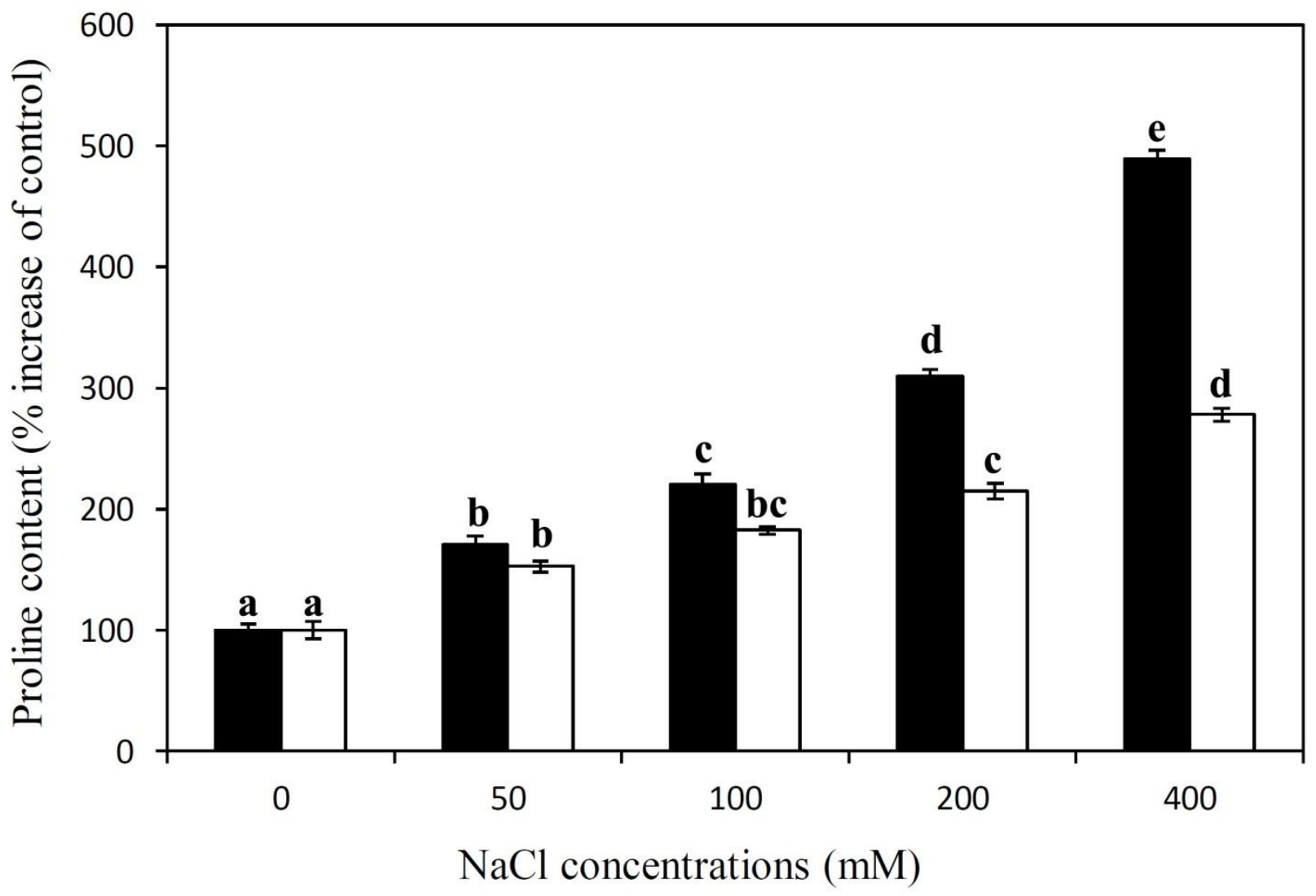

Fig 4.6 Proline content for leaves of red (dark bars) and green (white bars) morphs of Disphyma australe after $5 \mathrm{wk}$ of $\mathrm{NaCl}$ treatment. $(\mathrm{n}=5$, Means $\pm \mathrm{SE})$. Different letters above bars indicate significant differences across treatments $(P<0.05)$. 


\subsection{5 $\mathrm{Na}^{+}$content}

$\mathrm{Na}^{+}$concentrations were measured in the root, stem and leaves of red and green morphs after 5 wk exposure to $200 \mathrm{mM} \mathrm{NaCl}$ treatment. Both morphs accumulated higher $\mathrm{Na}^{+}$concentration in the shoots as compared to roots. The red morphs had higher $\mathrm{Na}^{+}$concentration in their leaves as compared to the green morphs (Table 4.2). In contrast, green morphs had highest $\mathrm{Na}^{+}$ concentration in the stem as compared to the red stem (Table 4.2). However, $\mathrm{Na}^{+}$concentrations in the roots of both morphs were not significantly different from one another $(\mathrm{P}=0.2)$.

Table 4.2 $\mathrm{Na}^{+}$concentrations ( $\mathrm{mM} / \mathrm{g} \mathrm{DW}$ ) of leaves, stem and roots of red and green morphs of Disphyma australe after $5 \mathrm{wk}$ of either distilled water (control) or $200 \mathrm{mM} \mathrm{NaCl}$ treatment. $(\mathrm{n}=$ 5 , Means \pm SE). Different letters represent significant differences between red and green morphs for each parameter across $\mathrm{NaCl}$ treatments $(\mathrm{P}<0.05)$.

\begin{tabular}{|c|c|c|c|c|}
\hline & \multicolumn{2}{|c|}{ Red } & \multicolumn{2}{|c|}{ Green } \\
\hline & Control & $200 \mathrm{mM} \mathrm{NaCl}$ & Control & $200 \mathrm{mM} \mathrm{NaCl}$ \\
\hline Leaf & $26.6 \pm 2.2 \mathrm{a}$ & $165.9 \pm 13.2 \mathrm{~b}$ & $24.8 \pm 3.9 \mathrm{a}$ & $117.03 \pm 14.2 \mathrm{c}$ \\
\hline Stem & $10.9 \pm 1.2 \mathrm{a}$ & $96.9 \pm 11.8 b$ & $13.4 \pm 1.2 \mathrm{a}$ & $130.1 \pm 14.1 \mathrm{c}$ \\
\hline Root & $5.13 \pm 0.9 \mathrm{a}$ & $50.65 \pm 6.5 b$ & $4.7 \pm 1.1 \mathrm{a}$ & $47.16 \pm 7.2 \mathrm{~b}$ \\
\hline
\end{tabular}

\subsection{6 $\mathrm{Na}^{+}$localisation by fluorescence imaging}

SBFI-AM binds with cytosolic $\mathrm{Na}^{+}$and produces green epifluorescence. Transverse sections of leaves treated with either distilled water or $200 \mathrm{mM} \mathrm{NaCl}$ were observed for this green epifluorescence (Fig 4.7). Transverse sections from the control leaves did not produce any green fluorescence irrespective of the leaf colour or morph (Fig 4.7 G-I). Green fluorescence was observable from the leaves exposed to $200 \mathrm{mM} \mathrm{NaCl}$ (Fig $4.7 \mathrm{~J}$-L). Fluorescence from the $\mathrm{NaCl}$ exposed green leaves was visible in all foliar tissues viz. epidermal layer, mesophyll, water storage parenchyma and vascular bundles (Fig $4.7 \mathrm{~K}$ ). By contrast, in $\mathrm{NaCl}$ treated red leaves, fluorescence was largely restricted to the epidermal cells and vascular bundles (Fig $4.7 \mathrm{~J}$ ). Similar observations were recorded for $\mathrm{NaCl}$ treated L-DOPA leaves; only their epidermal cells and vascular bundles fluoresced green (Fig $4.7 \mathrm{~L}$ ). Collectively, these data indicate that $\mathrm{Na}^{+}$was more widely distributed throughout the tissues in green (acyanic) leaves, but was confined to epidermal and central vascular tissues in red (natural and L-DOPA fed; betacyanic) leaves. 

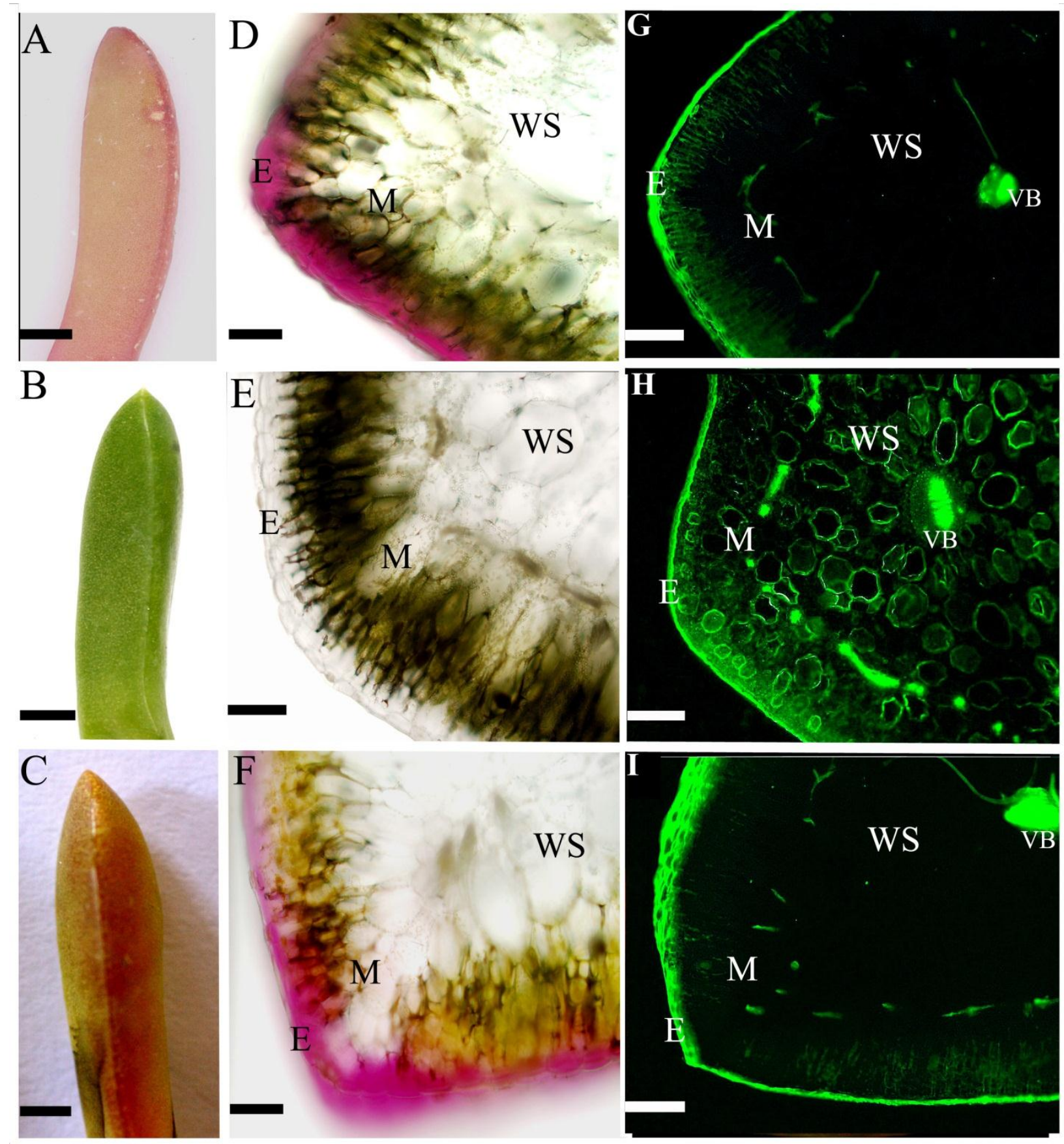

Fig 4.7 Photographs of red (A), green (B) and L-DOPA treated (C) leaves of Disphyma australe. Transverse sections (D-F) and their epifluorescence micrographs (G-I) of sodium-binding benzofuran isophthalate-AM (SBFI-AM) infiltrated leaves of red $(\mathrm{D}, \mathrm{G})$ and green $(\mathrm{E}, \mathrm{H})$ morphs and L-DOPA treated (F,I,) leaves of green morphs of Disphyma australe. Leaves were treated with $200 \mathrm{mM} \mathrm{NaCl}$. Sections are representative of $\mathrm{n}=5$. E, epidermis; M, mesophyll; WS, water storage parenchyma; VB, vascular bundles. Bars, $5 \mathrm{~mm}(\mathrm{~A}-\mathrm{C}) ; 100 \mu \mathrm{M}(\mathrm{D}-\mathrm{L})$. 


\subsubsection{Cryo-SEM analysis}

In the vacuole of epidermal cells, $\mathrm{Na}^{+}$concentrations (measured as $\mathrm{P} / \mathrm{BG}$ ratios) were greater for red than for green leaves (Fig 4.8). $\mathrm{Na}^{+}$concentrations were similar in epidermal cell vacuoles of the L-DOPA treated red leaves and naturally red leaves, but significantly higher $(1.83 \mathrm{x})$ than in green leaves (Fig 4.8). $\mathrm{Na}^{+}$concentrations in the vacuoles of epidermal cells of naturally red and L-DOPA treated leaves were $3 \mathrm{x}$ higher than those in the vacuoles of neighbouring mesophyll cells $(\mathrm{P}=0.02)$. By contrast, in the green leaves, the vacuolar $\mathrm{Na}^{+}$concentrations of epidermal cells were only $1.2 x$ higher than nearby mesophyll cells $(P=0.12)$. In addition, $\mathrm{Na}^{+}$ concentrations in the vacuoles of mesophyll cells of green leaves were significantly higher than those of red leaves. However, $\mathrm{Na}^{+}$concentrations in the vacuole of mesophyll cell of L-DOPA treated leaves were not different from those in either the red or green leaves.

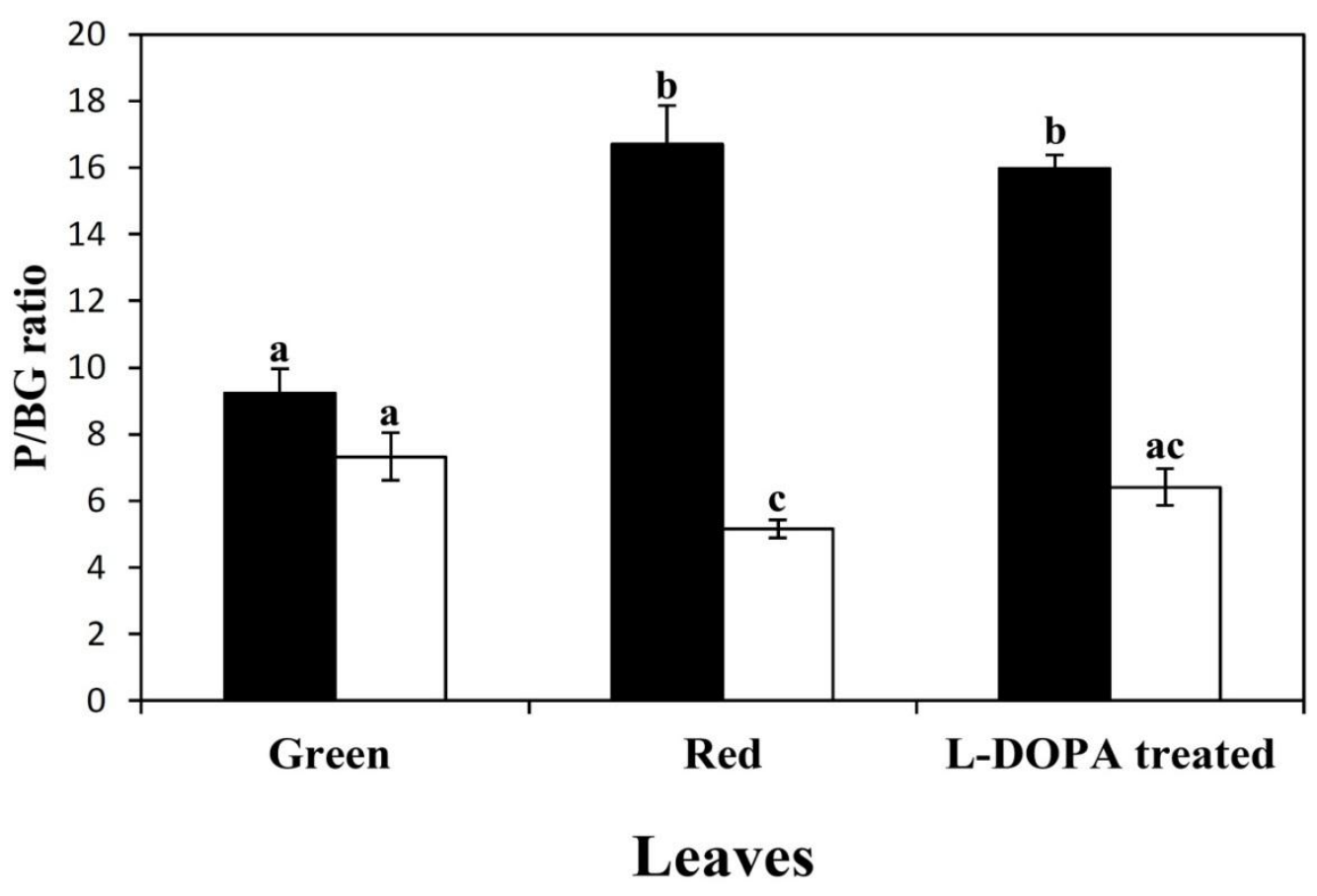

Fig 4.8 Peak / background (P/BG) ratios for $\mathrm{Na}^{+}$in the epidermal cell vacuole (black bars) and mesophyll cell vacuole (white bars) of green, red and L-DOPA treated leaves of Disphyma australe. Different letters represent significant differences between each leaf for each cellular vacuole $(P<0.05)$. Means: $n=6 \pm$ SE. 


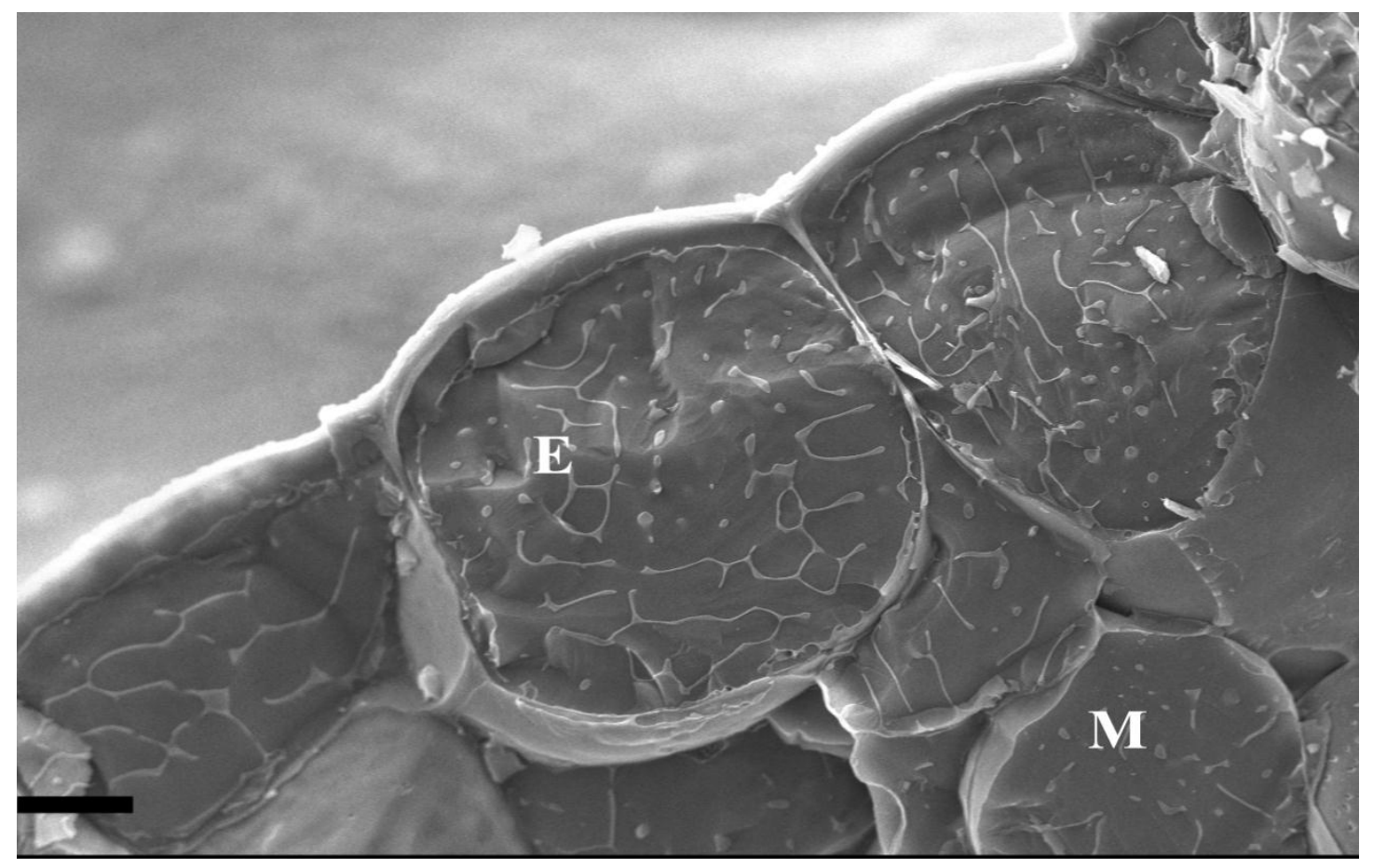

Fig. 4.9 Cryo-scanning electron microscopy micrograph of a frozen and lightly etched transverse face of a red leaf of $D$. australe treated with $200 \mathrm{mM} \mathrm{NaCl}$. E: epidermal cell; M: mesophyll cell. Bar: $10 \mu \mathrm{M}$.
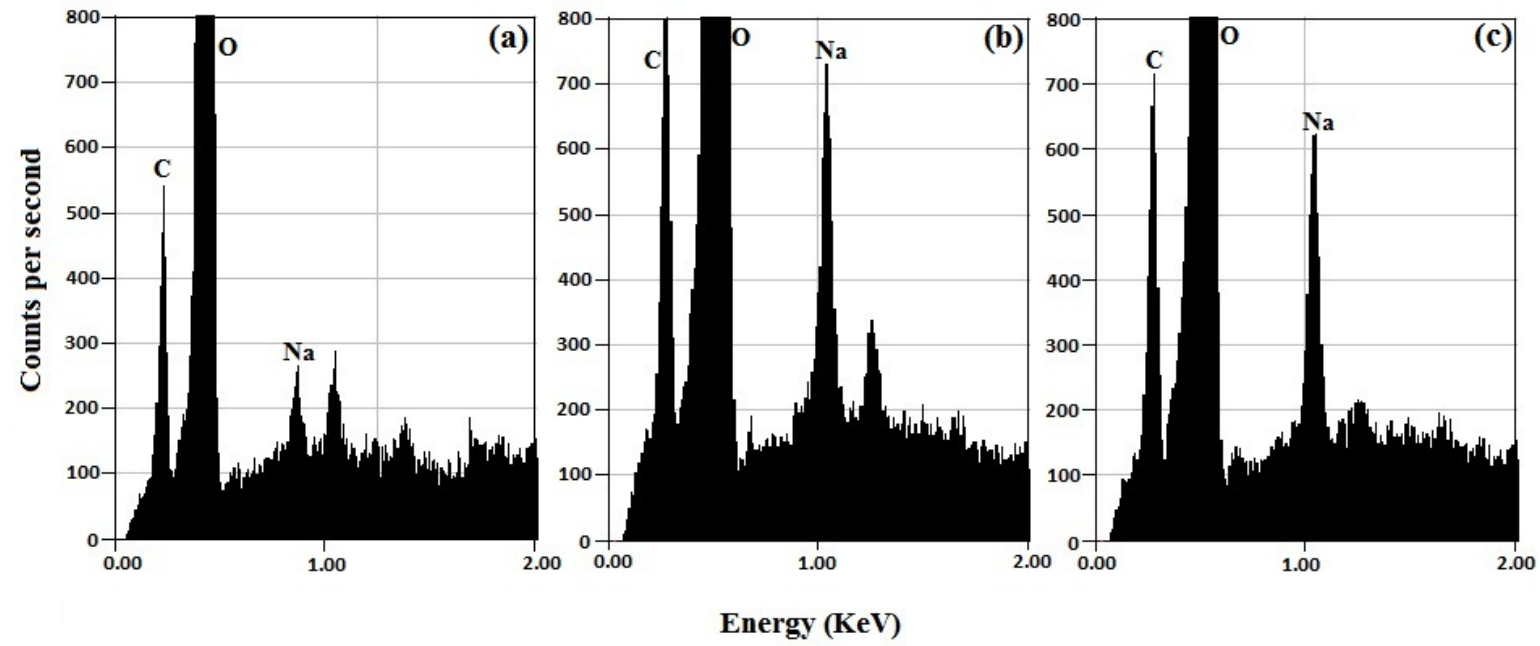

Fig 4.10 EDX spectra from leaf epidermal cell vacuoles (a-c) of green leaf (a), red leaf (b) and LDOPA treated green leaf (c) of Disphyma australe. Spectrum are representative of $n=6$. Peaks: C: carbon; O: oxygen; Na: sodium. 


\subsection{Discussion}

My previous work (Chapters 2 and 3) showed that the red morphs of D. australe appeared to better tolerate soil salinity than did the green morphs. In this study, I further investigated the possible mechanism of salinity tolerance by red morphs. I hypothesised that red morphs would show higher growth rate under saline conditions and would be more tolerant to salinity induced physiological drought by accumulating compatible solutes. My data were consistent with this hypothesis; when $D$. australe was subjected to various salinity treatments, proportionate biomass accumulation was greater in the red than in the green morphs (Fig 4.3). In addition, red morphs accumulated higher proline and soluble sugar contents in their leaves as compared to green morphs when exposed to salinity (Fig $4.5 \& 4.6$ ). Moreover, leaf water potential was more negative for red than green leaves under salt stress, which indicates their greater capacity for osmotic adjustment (Fig 4.4). To explain the association between betacyanin accumulation and salinity tolerance in red morphs, I postulated that epidermal location of betacyanins would enhance $\mathrm{Na}^{+}$accumulation specifically in the epidermal cells, which would help red morphs avoid toxic $\mathrm{Na}^{+}$concentrations in the mesophyll tissue. SBFI-AM fluorophore loaded images of red, green and L-DOPA fed leaves revealed that cytosolic $\mathrm{Na}^{+}$was more abundant in mesophyll tissues of green morphs, but in red and L-DOPA fed leaves it was confined to the epidermal cell layer and the vascular bundles (Fig 4.7). The cryo-SEM analysis for red and green leaves also revealed that betacyanic cells had higher $\mathrm{Na}^{+}$concentrations in the vacuole of epidermal cells than acyanic cells (Fig 4.8). These results provide strong evidence that betacyanins may enhance salt tolerance in $D$. australe by drawing $\mathrm{Na}^{+}$away from sensitive photosynthetic cells.

\subsubsection{Involvement of betacyanin in avoiding $\mathrm{Na}^{+}$toxicity}

Plants exposed to high soil $\mathrm{NaCl}$ concentrations are often prone to cytoplasmic $\mathrm{Na}^{+}$toxicity. Excessive cytoplasmic $\mathrm{Na}^{+}$concentrations can inhibit physiological processes in the cell (Flowers et al., 2015). To avoid toxic cytoplasmic $\mathrm{Na}^{+}$concentrations, halophytes use a variety of mechanisms, such as exclusion of $\mathrm{Na}^{+}$, sequestration of $\mathrm{Na}^{+}$into the cell vacuole and exclusion of excessive $\mathrm{Na}^{+}$through leaf glands or bladder cells (Flowers \& Colmer, 2008; Shabala \& Mackay, 2011; Adams \& Shin, 2014). In the present study, the differences in $\mathrm{Na}^{+}$ localisation in the leaves of D. australe, as revealed by epifluorescence microscopy (Fig 4.7) 
indicate that the $\mathrm{Na}^{+}$ions appear to be effectively drawn to the betacyanin containing cells, thereby avoiding cytotoxic effects in the photosynthetic tissues.

An interesting study by (Wang et al., 2007b) might explain why $\mathrm{Na}^{+}$would be drawn towards betacyanic cells. Wang et al., (2007b) found in Suaeda salsa that betacyanic plants had a greater ability to compartmentalise $\mathrm{Na}^{+}$because of their higher vacuolar $\mathrm{H}^{+}$-ATPase (V-ATPase) activity relative to that in green leaves when exposed to $400 \mathrm{mM} \mathrm{NaCl} . \mathrm{H}^{+}$-ATPase (V-ATPase) enregise the tonoplast $\mathrm{Na}^{+} / \mathrm{H}^{+}$antiporter in plants for transport of cytosolic $\mathrm{Na}^{+}$into the vacuole (Flowers \& Colmer, 2008). Further, the authors postulated that the proton gradients generated by VATPase could provide the motive force for the movement of both $\mathrm{Na}^{+}$and betacyanin into the cell vacuole. Therefore, betacyanin synthesis would stimulate V-ATPase activity for vacuolar transport of betacyanins, which would subsequently afford more efficient sequestration of $\mathrm{NaCl}$ into vacuoles. However, this hypothesis has never been tested experimentally.

The same could hold true for $D$. australe, where betacyanic epidermal cells might more efficiently sequester $\mathrm{Na}^{+}$than acyanic cells. In my experiment, L-DOPA fed leaves showed the same pattern of localisation of $\mathrm{Na}^{+}$as in the naturally red leaves, which adds considerable weight to the possible involvement of betacyanins in $\mathrm{Na}^{+}$sequestration. There are, however, limitations in the technique used to observe this; the SBFI-AM is a cytosolic fluorophore, and does not detect $\mathrm{Na}^{+}$within cell vacuoles. Therefore, cryo-SEM analysis was done to confirm the above data.

Cryo-SEM analysis revealed that there was more $\mathrm{Na}^{+}(1.83 \mathrm{x})$ in the vacuole of an epidermal cell of a red leaf than in that of green leaf (Fig 4.8). Similarly, in L-DOPA treated leaves, the vacuolar level of $\mathrm{Na}^{+}$in epidermal cells was similar to that of a naturally red leaf (Fig 4.8). These results are consistent with the hypothesis that betacyanic cells can sequester higher level of $\mathrm{Na}^{+}$into the vacuole than acyanic cells. Furthermore, in mesophyll cells, vacuolar $\mathrm{Na}^{+}$ concentrations were significantly lower for red than green leaves (Fig 4.8); it is possible, therefore, that red morphs are transporting excess sodium to the epidermal tissue and avoiding cytotoxicity in the photosynthetic cells. However, more detailed work on the cellular mechanism needs to be studied to understand the involvement of betacyanins in $\mathrm{Na}^{+}$sequestration. 
The $\mathrm{Na}^{+}$localisation data from this study indicate that red morphs are better adapted to avoid cellular $\mathrm{Na}^{+}$toxicity than green morphs. However, the persistence of green-leafed morphs within populations of $D$. australe suggests that green morphs could be using a different mechanism to

tolerate salinity stress. My data showed that $\mathrm{Na}^{+}$levels were significantly higher in the stem, but lower in the leaves of the green morphs relative to those of the red morphs (Table 4.2). This suggests that green morphs could be excluding extra salt from leaves by re-circulating it through phloem, which is an important strategy for salt tolerance in many halophytes (Plett \& Møller, 2010; Adams \& Shin, 2014).

\subsubsection{Physiological drought and osmotic adjustment}

Soil salinity limits water availability for plants by creating an osmotic imbalance (Slama et al., 2015). This water scarcity directly impacts plant growth and metabolism. Osmotic adjustment through the accumulation of compatible solutes such as amino acids, soluble sugars, sugar alcohols and inorganic ions, is a common mechanism that allows plants to tolerate this. My data indicate that red morphs of $D$. australe are comparatively more adapted to tolerate salinity induced physiological drought than green morphs. There are two observations that support this statement. First, under salt stress, red morphs maintained their osmotic balance by solute accumulation; they had higher concentrations of proline and soluble sugars than green morphs (Fig 4.5 and 4.6). Similar results have been recorded previously for D. australe (Bieleski, 1994) as well as for other members of the family Aizoaceae (Lokhande et al., 2011; Slama et al., 2015). Moreover, red morphs showed more negative water potential values than green morphs (Fig 4.4), which is an indication of osmotic adjustment (Hughes et al., 2010). It should be noted, however, that the values for leaf water potential are extremely negative, far more so than have been reported for most other species, although Khan et al. (2000) and Ahmad \& Malik (2013) reported similarly negative values for leaf water potential in the succulent halophytes Atriplex griffithii and Salicornia rubra.. It is possible that these very negative values indicate apoplasmic pressure potential rather than actual leaf water potential. They may be indicative of a hydraulic disconnection between the xylem in the stems, which is being measured with the chamber, and the leaves and their elastic water storing tissue. Nonetheless, there was still a significant difference between the measurements for the red and green leaves. The second observation consistent with an improved salt tolerance of red morphs is that they showed a lower stomatal 
conductance and a higher water use efficiency than did the green morphs (Jain and Gould, 2015; Chapter 2).

In addition, it is possible that the red morphs might benefit from the presence of betalains themselves, as the accumulation of betalains has been suggested to be involved in osmotic adjustment under salinity/drought stress (Stintzing \& Carle, 2004). However, Wang et al. (2007b), found no difference in cell sap osmolarity between betacyanic and acyanic cells either before or after salinity treatment. Similarly, Hughes et al. (2013) concluded that anthocyanin (another class of red pigments) concentrations, in winter reddened leaves of Galax urceolata and Gaultheria procumbens, are too low to participate in osmotic adjustment. Similarly, from my data, it seems that D. australe accumulates other solutes for osmotic adjustment. Moreover, foliar betacyanins in $D$. australe are confined to epidermal cells and are not optimally located to participate in osmotic adjustment.

\subsubsection{Salinity and plant growth}

Reduced plant growth is one of the primary impacts of soil salinity (Parihar et al., 2015). There are several reasons for declining plant growth under salinity, for example, reduced carbon fixation, change in cell wall elasticity and inability to adjust osmotically (Flowers \& Colmer, 2008; Munns \& Tester, 2008). Some halophytes, however, show enhanced growth at optimal saline conditions i.e. 50-250 mM NaCl (Flowers \& Colmer, 2008) but higher concentrations than that can have adverse impacts. My data suggest that growth in green morphs of $D$. australe was more affected by salinity than red morphs; for example, on exposure to gradually increasing concentrations of $\mathrm{NaCl}$, the proportionate increase in biomass declined more for green than red morphs (Fig. 4.3). Moreover, My previous study (Jain and Gould, 2015; Chapter 2), showed that $\mathrm{CO}_{2}$ assimilation rate decreased more in the green morphs than red morphs following $200 \mathrm{mM}$

$\mathrm{NaCl}$ treatment. This inability to utilise available $\mathrm{CO}_{2}$ could explain the reduced biomass accumulation in green morphs under salt stress. Also, red morphs exposed to salt benefitted from the presence of epidermal betalains in terms of photoprotection from high light (Jain et al., 2015; Chapter 2). Further, red morphs have comparatively better ability to adjust osmotically (by accumulating compatible solutes; Fig 4.5 and 4.6) which altogether suggests that red morphs are more tolerant to applied salinity stress. 


\subsection{Conclusion}

In conclusion, my data suggest that in addition to photoprotective function, involvement of betacyanins in sequestration of toxic ions provide a benefit to red morphs of $D$. australe under salinity stress, which is evident by their higher biomass accumulation than green morphs. On the other hand, it appears that the green morphs may be tolerating soil salinity by re-circulating extra salt from the leaves through phloem, which could explain the persistence of green morph within D. australe population at coastal areas. This study presents an elegant system to further test the possible involvement of betacyanins in salinity tolerance. 


\section{Chapter 5: General Discussion}

\subsection{Novel discoveries from this thesis}

This study advances our understanding of the physiological functions of betacyanins in salt stressed plants in two ways. It is the first study to demonstrate that betacyanins can photoprotect leaf chloroplasts from high light when the functional ability to process photons has been compromised by salinity stress. Secondly, this study is the first to show that betacyanic leaves apparently alter the transport of toxic ions (such as $\mathrm{Na}^{+}$) away from sensitive photosynthetic tissue to epidermal cells.

Chapter two showed that within a coastal population of red and green morphs of $D$. australe, betacyanin pigmentation in red morphs is a direct result of salt and high light exposure. In addition, the red morphs showed greater maximum $\mathrm{CO}_{2}$ assimilation rates, water use efficiencies, photochemical quantum yields and photochemical quenching under salinity stress. Contrary to this, the green morphs, although possessing the genetic ability to synthesise betalains in reproductive organs, did not produce betalains in vegetative shoots in response to salt stress. Moreover, green morphs, in terms of leaf photosynthesis, performed poorly under salinity stress.

Chapter three demonstrated that betacyanin in the leaves of $D$. australe provide a photoprotective function to salt stressed plants by screening photosynthetic tissues from harmful excessive light. I used a novel experimental approach to demonstrate betacyanin's photoprotective function. I identified the key biosynthetic step for betacyanin synthesis which was deficient in vegetative shoots of the green morphs. I showed that by supplying the product of this enzymatic reaction, LDOPA, betacyanin synthesis could be induced in the leaves of green morphs. This ready manipulation of betacyanin synthesis by substrate feeding provided a useful model system to compare the photoprotective responses of red $v s$. green leaves, while avoiding the problems such as differences in developmental history, genotype and previous acclimation between two morphs. As hypothesised, the L-DOPA induced betacyanic leaves showed similar responses (such as smaller depressions and faster recoveries of PSII and less $\mathrm{H}_{2} \mathrm{O}_{2}$ production than in the green leaves) to naturally betacyanic leaves when exposed to high light and salinity. The differences in photoinhibition between red and green leaves were attributable to the light absorbing properties of betacyanins. L-DOPA treated and naturally red leaves showed lower 
photoinactivation than green leaves when exposed to white or green light, although not when exposed to monochromatic (red) light.

In chapter four I used a similar experimental model to that in the third chapter and showed that other than photoprotection, betacyanins in leaves may be involved in salt tolerance by enhancing sequestration of toxic ions ( $\mathrm{such}$ as $\mathrm{Na}^{+}$) into the epidermal cells, away from sensitive mesophyll tissue. By using sodium binding stain (SBFI-AM) and cryo-SEM analysis, I compared the $\mathrm{Na}^{+}$ localization between red and green leaves after salinity stress treatment. Data showed that LDOPA treated and natural red leaves sequestered $\mathrm{Na}^{+}$ions to the epidermal cell layer. By contrast, green leaves retained $\mathrm{Na}^{+}$in the mesophyll tissue, which suggested that red leaves were better equipped to tolerate salt-specific effects. Therefore, betacyanic plants were more tolerant to applied salinity stress and showed relatively higher growth rates than green morphs. Moreover, red plants had up-regulated other salinity tolerance mechanisms, such as osmolyte accumulation, showed higher proline and soluble sugar content as compared to the green morphs under salinity stress. Taken together, my data showed that betacyanic plants were more tolerant to salinity stress than were acyanic plants.

\subsection{The significance of identifying a photoprotective function for foliar betacyanins in $D$. australe}

There are numerous studies which provide evidence for a photoprotective role of anthocyanins (another class of red pigments); however, until now, this evidence has been lacking for foliar betacyanins. My study is the first to show unequivocally that foliar betacyanins provide photoprotective function under salinity stress. Only two previous studies (Nakashima et al., 2011 and Wang and Liu, 2007) implicate a functional role for foliar betacyanins from photoinhibitory damage.

Nakashima et al. (2011) showed that in Amaranthus cruentus, photoinhibition was proportionately lower in betacyanic than acyanic plants following a water stress and high light treatment. That study suggested that the photoprotective function of betacyanins is attributable to the light-absorption properties of betacyanins. The authors found that betacyanins effectively absorb the light between 500-600 nm wavelengths (green light), as was also shown in my study for the leaves of D. australe (Jain and Gould, 2015b; chapter 2). These optical properties of 
betacyanins are comparable to that of foliar anthocyanins (Neill \& Gould, 1999), and are consistent with a light screening role.

Nakashima et al., (2011) however, failed to relate photoinhibitory damage unequivocally to betacyanins because (i) photoinhibitory damage between red and green leaves was not tested under monochromatic light, and (ii) the study compared the red and green leaves of two different genotypes, which means both plants could have different mechanisms to alleviate effects of excess light because plants employ a number of strategies to avoid adverse effects of excessive light (Takahashi \& Badger, 2011). In contrast, my study (Jain et al., 2015; Chapter 3) compared the level of photoinactivation under monochromatic green and red light on naturally red and LDOPA-induced red leaves with naturally green leaves of $D$. australe. The results showed that under green light, quantum efficiency of photosystem II $\left(\Phi_{\mathrm{PSII}}\right)$ decreased more in green than in either set of red leaves; on exposure to red light (which is not absorbed by betacyanins), red and green leaves showed similar reductions in $\Phi_{\text {PSII }}$. Moreover, non-photochemical quenching, a measure of energy dissipation via xanthophyll cycle, was lower for red leaves than green leaves under white light, which indicates that there may be greater need to raise energy dissipation when betacyanins are absent. Altogether my study provided strong support for photoprotective role of betacyanins.

In another study, Wang and Liu (2007) subjected red and green plants of S. salsa to a combination of strong light and chilling temperature and showed that betacyanic leaves had higher resistance to photoinhibitory damage than acyanic leaves. The authors also reported that $\mathrm{H}_{2} \mathrm{O}_{2}$ production following exposure to high light and low temperatures was greater in green than red leaves. Furthermore, higher resistance to photoinhibtion in betacyanic leaves was attributed to the antioxidant capacity of betacyanins. Similar results were found in my chapter three, where $\mathrm{H}_{2} \mathrm{O}_{2}$ production was higher in acyanic than betacyanic leaves following an exposure to high light and salinity. Although betacyanins are stored inside the vacuoles of a plant cell, and so are not optimally located to scavenge reactive oxygen species, oxidative species such as $\mathrm{H}_{2} \mathrm{O}_{2}$ are very stable and highly mobile, and can move within cell compartments and across adjacent cells (Mittler et al., 2004). Therefore, it is highly likely that betacyanins neutralize vacuolar $\mathrm{H}_{2} \mathrm{O}_{2}$. On the other hand, betacyanins may diminish the oxidative load in a leaf simply by filtering out 
yellow-green light, since the transfer of excitation energy to molecular oxygen in chloroplasts is a major source of ROS (Jain \& Gould, 2015a).

\subsection{The significance of identifying an involvement of betacyanins in $\mathrm{Na}^{+}$ homeostasis in Disphyma australe under salinity stress}

Several studies have reported the up-regulation of betacyanin synthesis under salt stress (Bothe, 1976; Hayakawa and Agarie, 2010; Wang et al., 2007b). However, the adaptive significance of foliar betacyanin accumulation under salt stress has, until now, been a matter of discussion.

My study (Jain et al., 2015; Jain \& Gould, 2015b) provides insight into the functional benefit of foliar betacyanins; in addition to their photoprotective function, foliar betacyanins may regulate $\mathrm{Na}^{+}$compartmentation to avoid ionic toxicity in Disphyma australe under salinity stress. When foliar betacyanins are present in epidermal tissues, the $\mathrm{Na}^{+}$ions appear to be effectively drawn to the betacyanin containing cells, thereby avoiding cytotoxic effects in the photosynthetic tissues. In mesophyll cells, which are photosynthetically active, maintaining low cytosolic $\mathrm{Na}^{+}$is considered essential for plants under salt stress (Shabala \& Mackay, 2011). On the other hand, epidermal cells, which are metabolically less active and have larger vacuolar space than mesophyll cells, are good sites for the storage of toxic ions (Conn \& Gilliham, 2010). Moreover, my results can exclusively be attributed to foliar betacyanins because L-DOPA induced betacyanic leaves showed similar outcomes as those of natural red leaves (Chapter 4). However, why $\mathrm{Na}^{+}$is attracted to betacyanic cells is unknown.

Wang et al., (2007), suggested a possibility for the involvement of betacyanins in vacuolar sequestration of $\mathrm{Na}^{+}$, which might explain why $\mathrm{Na}^{+}$is attracted to betacyanic cells. They found in Suaeda salsa that betacyanic plants had a greater ability to compartmentalise $\mathrm{Na}^{+}$because betacyanic leaves showed higher vacuolar $\mathrm{H}^{+}$-ATPase (V-ATPase) activity than green leaves when exposed to $400 \mathrm{mM} \mathrm{NaCl}$. The authors postulated that plants use similar mechanisms to transport betacyanin and $\mathrm{Na}^{+}$into the cell vacuole, therefore, betacyanin synthesis would stimulate V-ATPase activity for vacuolar transport of betacyanins, which would subsequently afford more efficient sequestration of $\mathrm{Na}^{+}$into vacuoles. 
However, the mechanism of transport of $\mathrm{Na}^{+}$from mesophyll tissue to betacyanic epidermal cells in $D$. australe is unknown. I propose a model to explain the possible mechanism, which is outlined in Fig. 5.1.

Accordingly, in $D$. australe the uptake of $\mathrm{Na}^{+}$from the soil solution might be carried by SOS1, NSCC or HKT type transporters of plasma membrane in the root epidermal cells. In Mesembryanthemum, it is shown that up-regulation of membrane channels such as SOS1 leads to the translocation of $\mathrm{Na}^{+}$from root to shoot vascular tissue (Chauhan et al., 2000; Su et al., 2003); It is possible that there is a similar pathway, which transport $\mathrm{Na}^{+}$from root to shoot in $D$. australe. Once $\mathrm{Na}^{+}$enters the shoot vascular tissue, it reaches to the leaf via long distance transport through the xylem. From xylem, $\mathrm{Na}^{+}$could be recirculated to the roots via phloem, as a salinity tolerance mechanism (Plett \& Møller, 2010; Adams \& Shin, 2014). After long-distance travel in xylem, $\mathrm{Na}^{+}$reaches leaf cells, where it is unloaded from the xylem, possibly via HKT type transporters (Zhang et al., 2009).

Once $\mathrm{Na}^{+}$is unloaded from the xylem to vascular associated cells, it reaches betacyanic epidermal cells either via the apoplast and/or symplast pathway. It is possible that vascular associated cells pump excess $\mathrm{Na}^{+}$to the apoplast via SOS1 transporters and this $\mathrm{Na}^{+}$then travels to the epidermis through apoplast. Vera-Estrella et al. (2005) showed in the halophyte Thellungiella halophile, SOS1 proteins from plasma membrane vesicles were highly expressed in the shoot and root of salt stressed plants. Also, in Mesembryanthemum leaves expression of membrane $\mathrm{Na}^{+} / \mathrm{H}^{+}$transporters was enhanced when plants were grown in $\mathrm{NaCl}$ (Barkla et al., 2002). Moreover, Tester and Davenport (2003) suggested that halophytes can accumulate ions in the apoplast and produce an osmotic gradient, which generates enough pressure to pump ionic solution through glands or into epidermal bladders. Alternatively, $\mathrm{Na}^{+}$, when unloaded from xylem to the vascular associated cells, can take a symplastic route and reach epidermal cells. Shabala and Mackay (2011) suggested that in halophytic leaves, ions can move from xylem to epidermal bladder cells symplastically through plasmodesmata.

In the epidermal cells, it is possible that $\mathrm{Na}^{+}$in the apoplast is taken in via HKT and/or SOS1 type transporters; McHKT1 transporters have been found in leaves of Mesembryanthemum (Su et al., 2003). Within epidermal cells, the tonoplast membrane transporters NHX would facilitate $\mathrm{Na}^{+}$influx into the vacuole; involvement of $\mathrm{NHX}$ in vacuolar $\mathrm{Na}^{+}$sequestration has 
been suggested in other plants (Flowers \& Colmer, 2008; Shabala \& Mackay, 2011; Maathuis, 2014). Moreover, in D. australe, it is possible that betacyanic epidermal cells have higher $\mathrm{H}^{+}$antiport activity, similar to the findings of (Wang et al., 2007b).

Thus, my results hint at a possible mechanism by which betacyanic morphs of $D$. australe regulate $\mathrm{Na}^{+}$within leaves. However, regulation and multiplicity of $\mathrm{Na}^{+}$channels needs to be analysed. Moreover, transport mechanism of betacyanins from cytosol to vacuole is not completely known, it is possible that there is an as yet unknown betacyanin transport pathway that could facilitate both betacyanin and $\mathrm{Na}^{+}$sequestration into the vacuole, which further needs to be analysed.

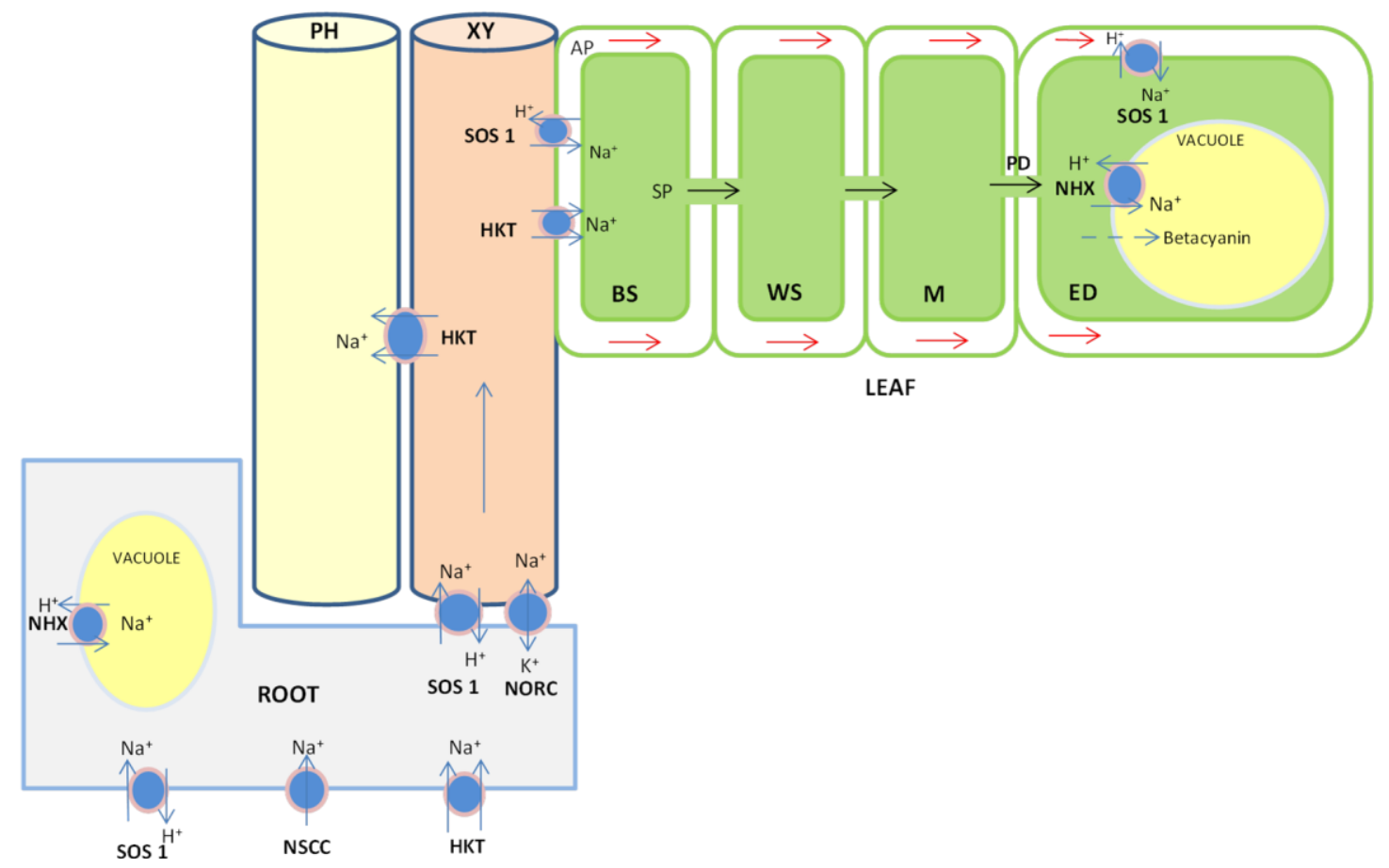

Fig 5.1. A proposed model for the transport of $\mathrm{Na}^{+}$in Disphyma australe. Within leaf, apoplastic (red arrows) and symplastic (black arrows) movement of $\mathrm{Na}^{+}$. Abbreviations: $\mathrm{PH}$, Phloem; XY, Xylem; AP, Apoplast; SP, Symplast; BS, Bundle sheath cell; WS, Water storage cell; M, Mesophyll cell; PD, Plasmodesmata; ED, Epidermal cell. HKT, High affinity $\mathrm{K}^{+}$ transporters; NHX, Vacuolar $\mathrm{Na}^{+}: \mathrm{H}^{+}$exchanger; NORC, Outward rectifying $\mathrm{Na}^{+}$channels; NSCC, non-selective cation channels; SOS1, Plasma membrane $\mathrm{Na}^{+}: \mathrm{H}^{+}$antiport. 


\subsection{Conclusion}

This study resolved a distinct gap in our understanding of betacyanin functions in plants, both providing a photoprotective advantage under salinity stress, and also regulating $\mathrm{Na}^{+}$homeostasis as a salt tolerance mechanism. Moreover, this study provided a novel experimental system where betacyanin synthesis can be controlled by substrate feeding, which might be used for further investigation of betacyanin functions. By identifying functional roles of betacyanins we begin to understand the adaptive significance of betacyanins in plants.

\subsection{Future Prospects}

My experiments have opened up many new avenues for betacyanin research, especially in relation to salinity tolerance. For future studies, I recommend that:

- The applicability of these results be tested on other betalainic species.

- To understand the mechanism of $\mathrm{Na}^{+}$compartmentation in betacyanic morphs of $D$. australe, it is very important to identify and study the effect of salt stress on expression of $\mathrm{Na}^{+}$transporters in betacyanic and acyanic plants.

- Along with $\mathrm{Na}^{+}$, the regulation and movement of other ions such as, $\mathrm{K}^{+}, \mathrm{Cl}^{-}$and $\mathrm{Ca}^{2+}$, which play important role in plants under salt stress, should be studied.

- Other than that, it is important to identify the unknown pathway for betacyanin transport from the cytosol to vacuole, further it would be interesting to test the vacuolar sequestration of $\mathrm{Na}^{+}$in betacyanic cells with blocked pathway for vacuolar betacyanin transport. 


\section{References}

Adams E, Shin R. 2014. Transport, signaling, and homeostasis of potassium and sodium in plants. Journal of Integrative Plant Biology 56: 231-249.

Ahmad P, Jaleel CA, Sharma S. 2010. Antioxidant defense system, lipid peroxidation, prolinemetabolizing enzymes, and biochemical activities in two Morus alba genotypes subjected to $\mathrm{NaCl}$ stress. Russian Journal of Plant Physiology 57: 509-517.

Ahmad P, Jeleel CA, Azooz MM, Nabi G. 2009. Generation of ROS and non-enzymatic antioxidants during abiotic stress in plants. Botanical Research International 2: 11-20.

Ahmad R, Malik KA. 2013. Prospects for Saline Agriculture (R Ahmad and KA Malik, Eds.). Springer Science \& Business Media.

Aiton, W. 1789. Hortus Kewensis. 2: 187

Alia, Saradhi PP, Mohanty P. 1997. Involvement of proline in protecting thylakoid membranes against free radical-induced photodamage. Journal of Photochemistry and Photobiology B:

Biology 38: 253-257.

Allan HH. 1961. Flora of New Zealand. Government Printer, Wellington, NZ.

Apse MP, Aharon GS, Snedden WA, Blumwald E. 1999. Salt tolerance conferred by overexpression of a vacuolar $\mathrm{Na}^{+} / \mathrm{H}^{+}$antiport in Arabidopsis. Science 285: 1256-1258.

Apse MP, Blumwald E. 2007. $\mathrm{Na}^{+}$transport in plants. FEBS Letters 581: 2247-2254.

Ayala F, O’Leary JW, Schumaker KS. 1996. Increased vacuolar and plasma membrane $\mathrm{H}^{+}$ATPase activities in Salicornia bigelovii Torr. in response to $\mathrm{NaCl}$. Journal of Experimental Botany 47: 25-32.

Azeredo HMC. 2009. Betalains: properties, sources, applications, and stability - a review. International Journal of Food Science \& Technology 44: 2365-2376.

Baker M, De Salas M. 2013. A census of the vascular plants of Tasmania. Tasmanian Herbarium, Tasmania, Australia.

Barkla BJ, Vera-Estrella R, Camacho-Emiterio J, Pantoja O. 2002. $\mathrm{Na}^{+} / \mathrm{H}^{+}$exchange in the halophyte Mesembryanthemum crystallinum is associated with cellular sites of $\mathrm{Na}^{+}$storage. Functional Plant Biology 29: 1017-1024.

Barragan V, Leidi EO, Andres Z, Rubio L, De Luca A, Fernandez JA, Cubero B, Pardo JM. 2012. Ion exchangers NHX1 and NHX2 mediate active potassium uptake into vacuoles to regulate cell turgor and stomatal function in Arabidopsis. The Plant Cell 24: 1127-1142. 
Bartels D, Sunkar R. 2005. Drought and salt tolerance in plants. Critical Reviews in Plant Sciences 24: 23-58.

Bates LS, Waldren RP, Teare ID. 1973. Rapid determination of free proline for water-stress studies. Plant and Soil 39: 205-207.

Bieleski R. 1994. Pinitol is a major carbohydrate in leaves of some coastal plants indigenous to New Zealand. New Zealand Journal of Botany 32: 37-41.

Boldt JK, Meyer MH, Erwin JE. 2014. Foliar anthocyanins: a horticultural review. Horticultural Reviews 42: 209-251.

Bose J, Rodrigo-Moreno A, Shabala S. 2014. ROS homeostasis in halophytes in the context of salinity stress tolerance. Journal of Experimental Botany 65: 1241-1257.

Bothe H. 1976. Salzresistenz bei pflanzen. Biologie in Unsere Zeit 6: 3-9.

Bradford MM. 1976. A rapid and sensitive method for the quantitation of microgram quantities of protein utilizing the principle of protein-dye binding. Analytical Biochemistry 72: 248-254.

Britto DT, Kronzucker HJ. 2006. Futile cycling at the plasma membrane: a hallmark of lowaffinity nutrient transport. Trends in Plant Science 11: 529-534.

Brockington SF, Walker RH, Glover BJ, Soltis PS, Soltis DE. 2011. Complex pigment evolution in the Caryophyllales. New Phytologist 190: 854-864.

Cai Y, Corke H. 1999. Amaranthus betacyanin pigments applied in model food systems. Journal of Food Science 64: 869-873.

Calcott KE. 2014. The localisation, intracellular transport, and biosynthetic regulation of betalain plant pigments.

Chauhan S, Forsthoefel N, Ran Y, Quigley F, Nelson DE, Bohnert HJ. 2000. $\mathrm{Na}^{+} / \mathrm{myo}^{-}$ inositol symporters and $\mathrm{Na}^{+} / \mathrm{H}^{+}$-antiport in Mesembryanthemum crystallinum. The Plant Journal : for Cell and Molecular Biology 24: 511-22.

Chaves MM, Flexas J, Pinheiro C. 2009. Photosynthesis under drought and salt stress: regulation mechanisms from whole plant to cell. Annals of Botany 103: 551-560.

Chinnock R. 1971. Studies in Disphyma - a genus related to Mesembryanthemum. 1. a revision of Disphyma australe (Ait.) JM Black. New Zealand Journal of Botany 9: 331-344.

Chinnock R. 1972. Natural hybrids between Disphyma and Carpobrotus (Aizoaceae) in New Zealand. New Zealand journal of botany 10: 37-41. 
Close D, Beadle C. 2003. The ecophysiology of foliar anthocyanin. The Botanical Review 69 : 149-161.

Colmenero-Flores JM, Martínez G, Gamba G, Vázquez N, Iglesias DJ, Brumós J, Talón M. 2007. Identification and functional characterization of cation-chloride cotransporters in plants. The Plant Journal 50: 278-292.

Conn S, Gilliham M. 2010. Comparative physiology of elemental distributions in plants. Annals of Botany 105: 1081-102.

Demidchik V, Maathuis FJM. 2007. Physiological roles of nonselective cation channels in plants: from salt stress to signalling and development. New Phytologist 175: 387-404.

Demmig B, Winter K, Krüger A, Czygan FC. 1987. Photoinhibition and zeaxanthin formation in intact leaves : a possible role of the xanthophyll cycle in the dissipation of excess light energy. Plant Physiology 84: 218-24.

Demmig-Adams B, Adams W. 1992. Photoprotection and other responses of plants to high light stress. Annual Review of Plant Molecular Biology 43: 599-626.

Duarte B, Santos D, Marques JC, Caçador I. 2013. Ecophysiological adaptations of two halophytes to salt stress: photosynthesis, PS II photochemistry and anti-oxidant feedback implications for resilience in climate change. Plant Physiology and Biochemistry 67C: 178-188.

Ehrendorfer F. 1976. Closing remarks: systematics and evolution of centrospermous families. Plant Systematics and Evolution 126: 99-106.

English JP, Colmer TD. 2013. Tolerance of extreme salinity in two stem-succulent halophytes (Tecticornia species). Functional Plant Biology 40: 897-912.

Flexas J, Bota J, Loreto F, Cornic G, Sharkey TD. 2004. Diffusive and metabolic limitations to photosynthesis under drought and salinity in C3 plants. Plant Biology 6: 269-279.

Flowers TJ. 1974. Salt tolerance in Suaeda maritima (L.) Dum A comparison of mitochondria isoltaed from green tissues of Suaeda and Pisum. Journal of Experimental Botany 25: 101-110.

Flowers TJ. 1985. Physiology of halophytes. Plant and Soil 89: 41-56.

Flowers TJ, Colmer TD. 2008. Salinity tolerance in halophytes. The New phytologist 179: 945963.

Flowers TJ, Colmer TD. 2015. Plant salt tolerance: adaptations in halophytes. Annals of Botany 115: $327-331$.

Flowers TJ, Munns R, Colmer TD. 2015. Sodium chloride toxicity and the cellular basis of salt tolerance in halophytes. Annals of Botany: 419-431. 
Fukuda A, Chiba K, Maeda M, Nakamura A, Maeshima M, Tanaka Y. 2004. Effect of salt and osmotic stresses on the expression of genes for the vacuolar $\mathrm{H}^{+}$-pyrophosphatase, $\mathrm{H}^{+}$ATPase subunit A, and $\mathrm{Na}^{+} / \mathrm{H}^{+}$antiporter from barley. Journal of Experimental Botany 55: 585594.

Gandía-Herrero F, Escribano J, García-Carmona F. 2010. Structural implications on color, fluorescence, and antiradical activity in betalains. Planta 232: 449-460.

Gandía-Herrero F, García-Carmona F. 2013. Biosynthesis of betalains: yellow and violet plant pigments. Trends in Plant Science 18: 334-343.

Gaxiola RA, Palmgren MG, Schumacher K. 2007. Plant proton pumps. FEBS Letters 581: 2204-2214.

George AS. 1984. Flora of Australia. Vol. 4, Phytolaccaceae to Chenopodiaceae. In: Prescott A, and Venning J, eds. Canberra: Australian Government Printing Service.

Giannakoula A, Moustakas M, Syros T, Yupsanis T. 2010. Aluminum stress induces upregulation of an efficient antioxidant system in the Al-tolerant maize line but not in the Alsensitive line. Environmental and Experimental Botany 67: 487-494.

Gierth M, Mäser P. 2007. Potassium transporters in plants - involvement in $\mathrm{K}^{+}$acquisition, redistribution and homeostasis. FEBS Letters 581: 2348-2356.

Glenn EP, Brown JJ, Blumwald E. 1999. Salt tolerance and crop potential of halophytes. Critical Reviews in Plant Sciences 18: 227-255.

Goss R, Lepetit B. 2015. Biodiversity of NPQ. Journal of Plant Physiology 172C: 13-32.

Gould KS. 2004. Nature's Swiss army knife: the diverse protective roles of anthocyanins in leaves. Journal of Biomedicine \& Biotechnology 2004: 314-320.

Gould KS, Dudle DA, Neufeld HS. 2010. Why some stems are red: cauline anthocyanins shield photosystem II against high light stress. Journal of Experimental Botany 61: 2707-17.

Gould KS, Vogelmann TC, Han T, Clearwater MJ. 2002. Profiles of photosynthesis within red and green leaves of Quintinia serrata. Physiologia Plantarum 116: 127-133.

Grattan SR, Grieve CM. 1998. Salinity-mineral nutrient relations in horticultural crops. Scientia Horticulturae 78: 127-157.

Greenway H, Munns R. 1980. Mechanisms of salt tolerance in nonhalophytes. Annual Review of Plant Physiology 31: 149-190.

Grotewold E. 2006. The genetics and biochemistry of floral pigments. Annual Review of Plant Biology 57: 761-780. 
Hall D, Evans AR, Newbury HJ, Pritchard J. 2006. Functional analysis of CHX21: a putative sodium transporter in Arabidopsis. Journal of Experimental Botany 57: 1201-1210.

Hamada A, Shono M, Xia T, Ohta M, Hayashi Y, Tanaka A, Hayakawa T. 2001. Isolation and characterization of a $\mathrm{Na}^{+} / \mathrm{H}^{+}$antiporter gene from the halophyte Atriplex gmelini. Plant Molecular Biology 46: 35-42.

Harris NN, Javellana J, Davies KM, Lewis DH, Jameson PE, Deroles SC, Calcott KE, Gould KS, Schwinn KE. 2012. Betalain production is possible in anthocyanin-producing plant species given the presence of DOPA-dioxygenase and L-DOPA. BMC Plant Biology 34: 1-12.

Hatier JB, Gould KS. 2009. Anthocyanin function in vegetative organs. In: Gould K, Davies K, Winefield C, eds. Anthocyanin. NY, USA: Springer, 1-19.

Hatlestad GJ, Sunnadeniya RM, Akhavan N a, Gonzalez A, Goldman IL, McGrath JM, Lloyd AM. 2012. The beet $\mathrm{R}$ locus encodes a new cytochrome P450 required for red betalain production. Nature Genetics 44: 816-820.

Hayakawa K, Agarie S. 2010. Physiological roles of betacyanin in a halophyte, Suaeda japonica Makino. Plant Production Science 13: 351-359.

Heenan PB, Sykes WR. 2010. Taxonomic notes on the New Zealand flora : $\times$ Carpophyma mutabilis and $\times$ Carpophyma pallida (Aizoaceae), new names for two wild intergeneric hybrids. New Zealand Journal of Botany 48: 225-230.

Hertwig B, Streb P, Feierabend J. 1992. Light dependence of catalase synthesis and degradation in leaves and the influence of interfering stress conditions. Plant Physiology 100: $1547-1553$.

Hilou A, Millogo-Rasolodimby J, Nacoulma OG. 2013. Betacyanins are the most relevant antioxidant molecules of Amaranthus spinosus and Boerhavia erecta. Journal of Medicinal Plants Research 7: 645-652.

Hortensteiner S, Lee DW. 2007. Chlorophyll catabolism and leaf coloration. In: Gan S, ed. Senescence Processes in Plants. Oxford, UK: Blackwell Publishing, 12-38.

Hu Y, Schmidhalter U. 2005. Drought and salinity: a comparison of their effects on mineral nutrition of plants. Journal of Plant Nutrition and Soil Science 168: 541-549.

Hughes NM, Reinhardt K, Feild TS, Gerardi AR, Smith WK. 2010. Association between winter anthocyanin production and drought stress in angiosperm evergreen species. Journal of Experimental Botany 61: 1699-1709.

Hussin S, Geissler N, Koyro HW. 2013. Effect of $\mathrm{NaCl}$ salinity on Atriplex nummularia (L.) with special emphasis on carbon and nitrogen metabolism. Acta Physiologiae Plantarum 35: $1025-1038$. 
Ibdah M, Krins A, Seidlitz H. 2002. Spectral dependence of flavonol and betacyanin accumulation in Mesembryanthemum crystallinum under enhanced ultraviolet radiation. Plant, Cell \& Environment 25: 1145-1154.

Jain G, Gould KS. 2015a. Are betalain pigments the functional homologues of anthocyanins in plants? Environmental and Experimental Botany (In press).

Jain G, Gould KS. 2015b. Functional significance of betalain biosynthesis in leaves of Disphyma australe under salinity stress. Environmental and Experimental Botany 109: 131-140.

Jain G, Schwinn KE, Gould KS. 2015. Betalain induction by L -DOPA application confers photoprotection to saline-exposed leaves of Disphyma australe. New Phytologist (In press).

Jou Y, Chiang C-P, Jauh G-Y, Yen HE. 2006. Functional characterization of ice plant SKD1, an AAA-type ATPase associated with the endoplasmic reticulum-golgi network, and its role in adaptation to salt stress. Plant Physiology 141: 135-146.

Joy R, Sugiyama M, Fukuda H, Komamine A. 1995. Cloning and characterization of polyphenol oxidase cDNAs of Phytolacca americana. Plant Physiology 107: 1083-1089.

Kader A. 2006. Salt Stress in Rice: adaptive mechanisms for cytosolic sodium homeostasis.

Kader MA, Lindberg S. 2005. Uptake of sodium in protoplasts of salt-sensitive and salttolerant cultivars of rice, Oryza sativa L. determined by the fluorescent dye SBFI. Journal of Experimental Botany 56: 3149-3158.

Khan MA, Ungar AI, Showalters MA. 2000. Effects of salinity on growth, water relations and ion accumulation of the subtropical perennial halophyte, Atriplex griffithii var . stocksii. Annals of Botany 85: 225-232.

Kimler L, Mears J, Mabry TJ, Rösler H. 1970. On the question of the mutual exclusiveness of betalains and anthocyanins. Taxon 19: 875-878.

Kishor P, Sangam S, Amrutha R, Laxmi P, Naidu K, Rao K, Rao S, Reddy K, Theriappan P, Sreenivasulu N. 2005. Regulation of proline biosynthesis, degradation, uptake and transport in higher plants: its implications in plant growth and abiotic stress. Current Science 34: 5-18.

Kugler F, Stintzing FC, Carle R. 2004. Identification of betalains from petioles of differently colored Swiss chard (Beta vulgaris L. ssp. cicla [L.] Alef. Cv. Bright Lights) by highperformance liquid chromatography-electrospray ionization mass spectrometry. Journal of Agricultural and Food Chemistry 52: 2975-2981.

Kugler F, Stintzing FC, Carle R. 2007. Characterisation of betalain patterns of differently coloured inflorescences from Gomphrena globosa L. and Bougainvillea sp. by HPLC-DAD-ESIMSn. Analytical and Bioanalytical Chemistry 387: 637-648. 
Kyparissis A, Grammatikopoulos G, Manetas Y. 2007. Leaf morphological and physiological adjustments to the spectrally selective shade imposed by anthocyanins in Prunus cerasifera. Tree Physiology 27: 849-857.

Landi M, Guidi L, Pardossi A, Tattini M, Gould KS. 2014. Photoprotection by foliar anthocyanins mitigates effects of boron toxicity in sweet basil (Ocimum basilicum). Planta 240: 941-953.

Lawrence W, Price J, Robinson G, Robinson R. 1939. The distribution of anthocyanins in flowers, fruits and leaves. Philosophical transactions of the Royal Society of London. Series B, Biological sciences 230: 149-178.

Lee DW, Collins TM. 2001. Phylogenetic and ontogenetic influences on the distribution of anthocyanins and betacyanins in leaves of tropical plants. International Journal of Plant Science 162: 1141-1153.

Lichtenthaler HK. 1987. Chlorophylls and carotenoids: pigments of photosynthetic biomembranes. Methods in Enzymology 148: 350-382.

Llanes A, Bertazza G, Palacio G, Luna V. 2013. Different sodium salts cause different solute accumulation in the halophyte Prosopis strombulifera. Plant Biology 15: 118-125.

Lokhande VH, Nikam TD, Patade VY, Ahire ML, Suprasanna P. 2011. Effects of optimal and supra-optimal salinity stress on antioxidative defence, osmolytes and in vitro growth responses in Sesuvium portulacastrum L. Plant Cell, Tissue and Organ Culture 104: 41-49.

Ma XL, Zhang Q, Shi HZ, Zhu JK, Zhao YX, Ma CL, Zhang H. 2004. Molecular cloning and different expression of a vacuolar $\mathrm{Na}^{+} / \mathrm{H}^{+}$antiporter gene in Suaeda salsa under salt stress. Biologia Plantarum 48: 219-225.

Maathuis FJM. 2007. Monovalent cation transporters: establishing a link between bioinformatics and physiology. Plant and Soil 301: 1-15.

Maathuis FJM. 2014. Sodium in plants: perception, signalling, and regulation of sodium fluxes. Journal of Experimental Botany 65: 849-858.

Mabry T, Dreiding A. 1968. The betalains. In: Mabry TJ, Alston R, Runeckles V, eds. Recent Advances in Phytochemistry. NY, USA: Appleton Century Crofts, 145-160.

Mabry TJ, Taylor A, Turner BL. 1963. The betacyanins and their distribution. Phytochemistry 2: 61-64.

Maxwell K, Johnson GN. 2000. Chlorophyll fluorescence--a practical guide. Journal of Experimental Botany 51: 659-668. 
Miller G, Suzuki N, Ciftci-Yilmaz S, Mittler R. 2010. Reactive oxygen species homeostasis and signalling during drought and salinity stresses. Plant, Cell \& Environment 33: 453-67.

Mittler R, Vanderauwera S, Gollery M, Van Breusegem F. 2004. Reactive oxygen gene network of plants. Trends in Plant Science 9: 490-498.

Mittova V, Guy M, Tal M, Volokita M. 2004. Salinity upregulates the antioxidative system in root mitochondria and peroxisomes of the wild salt tolerant tomato species Lycopersicon pennellii. Journal of Experimental Botany 55: 1105-1113.

Morris J, Tian H, Park S, Sreevidya CS, Ward JM, Hirschi KD. 2008. AtCCX3 is an Arabidopsis endomembrane $\mathrm{H}^{+}$-dependent $\mathrm{K}^{+}$transporter. Plant Physiology 148: 1474-1486.

Mosco A. 2012. Tissue localization of betacyanins in cactus stems. Revista Mexicana de Biodiversidad 83: 413-420.

Munns R. 2005. Genes and salt tolerance: bringing them together. New Phytologist 167: 645663.

Munns R, James RA, Läuchli A. 2006. Approaches to increasing the salt tolerance of wheat and other cereals. Journal of Experimental Botany 57: 1025-43.

Munns R, Tester M. 2008. Mechanisms of salinity tolerance. Annual Review of Plant Biology 59: $651-681$.

Nakashima T, Araki T, Ueno O. 2011. Photoprotective function of betacyanin in leaves of Amaranthus cruentus L. under water stress. Photosynthetica 49: 497-506.

Neill S, Gould KS. 1999. Optical properties of leaves in relation to anthocyanin concentration and distribution. Canadian Journal of Botany 77: 1777-1782.

Ort D. 2001. When there is too much light. Plant physiology 125: 29-32.

Parihar P, Singh S, Singh R, Singh VP, Prasad SM. 2015. Effect of salinity stress on plants and its tolerance strategies: a review. Environmental Science and Pollution Research International: In press.

Parks GE, Dietrich M a, Schumaker KS. 2002. Increased vacuolar $\mathrm{Na}^{+} / \mathrm{H}^{+}$exchange activity in Salicornia bigelovii Torr. in response to $\mathrm{NaCl}$. Journal of Experimental Botany 53: 10551065.

Pavoković D, Krsnik-Rasol M. 2011. Complex biochemistry and biotechnological production of betalains. Food Technology and Biotechnology 49: 145-155.

Percey WJ, Shabala L, Breadmore MC, Guijt RM, Bose J, Shabala S. 2014. Ion transport in broad bean leaf mesophyll under saline conditions. Planta 240: 729-743. 
Piattelli M. 1981. The betalains: structure, biosynthesis, and chemical taxonomy. The Biochemistry of Plants 7: 557-575.

Platten JD, Cotsaftis O, Berthomieu P, Bohnert H, Davenport RJ, Fairbairn DJ, Horie T, Leigh RA, Lin H-X, Luan S. 2006. Nomenclature for HKT transporters, key determinants of plant salinity tolerance. Trends in Plant Science 11: 372-374.

Plett DC, Møller IS. 2010. $\mathrm{Na}^{+}$transport in glycophytic plants: what we know and would like to know. Plant, Cell and Environment 33: 612-626.

Potvin C, Lechowicz M, Tardif S. 1990. The statistical analysis of ecophysiological response curves obtained from experiments involving repeated measures. Ecology 71: 1389-1400.

Qadir M, Schubert S. 2002. Degradation processes and nutrient constraints in sodic soils. Land Degradation and Development 13: 275-294.

Qiu N, Chen M, Guo J, Bao H, Ma X, Wang B. 2007. Coordinate up-regulation of $\mathrm{VH}^{+}$ATPase and vacuolar $\mathrm{Na}^{+} / \mathrm{H}^{+}$antiporter as a response to $\mathrm{NaCl}$ treatment in a $\mathrm{C} 3$ halophyte Suaeda salsa. Plant Science 172: 1218-1225.

Ramani B, Reeck T, Debez A, Stelzer R, Huchzermeyer B, Schmidt A, Papenbrock J. 2006. Aster tripolium L. and Sesuvium portulacastrum L.: two halophytes, two strategies to survive in saline habitats. Plant Physiology and Biochemistry 44: 395-408.

Ratajczak R, Richter J, Lüttge U. 1994. Adaptation of the tonoplast V-type $\mathrm{H}^{+}$-ATPase of Mesembryanthemum crystallinum to salt stress, C3-CAM transition and plant age. Plant, Cell \& Environment 17: 1101-1112.

Robb DA. 1984. Tyrosinase. In: Lontie R, ed. Copper Proteins and Copper Enzymes. Boca Raton, FL, USA: CRC Press, 207-240.

Rogers ME, Grieve CM, Shannon MC. 2003. Plant growth and ion relations in lucerne (Medicago sativa L.) in response to the combined effects of $\mathrm{NaCl}$ and $\mathrm{P}$. Plant and Soil 253: 187-194.

Rozema J, Flowers TJ. 2008. Crops for salinized world. Science 322: 1478-1480.

Ryan K, Drysdale J. 1988. X-ray analysis of copper, chromium and arsenic within the cell walls of treated hardwoods-New evidence against the microdistribution theory. Journal of Wood Science 11: 108-113.

Sairam R, Tyagi A. 2004. Physiology and molecular biology of salinity stress tolerance in plants. Current Science 86: 407-421.

Sakuta M. 2014. Diversity in plant red pigments: anthocyanins and betacyanins. Plant Biotechnology Reports 8: 37-48. 
Schreiner A, Rose C. 2012. Quantitative imaging of intracellular sodium. In: Mendez-Vilas A, ed. Current Microscopy Contributions to Advances in Science and Technology. Spain: Formatex, 119-129.

Sepúlveda-Jiménez G, Rueda-Benítez P, Porta H, Rocha-Sosa M. 2004. Betacyanin synthesis in red beet (Beta vulgaris) leaves induced by wounding and bacterial infiltration is preceded by an oxidative burst. Physiological and Molecular Plant Pathology 64: 125-133.

Shabala S. 2013. Learning from halophytes: physiological basis and strategies to improve abiotic stress tolerance in crops. Annals of Botany 112: 1209-1221.

Shabala S, Bose J, Hedrich R. 2014. Salt bladders: do they matter? Trends in Plant Science 19: 687-691.

Shabala S, Cuin TA. 2008. Potassium transport and plant salt tolerance. Physiologia Plantarum 133: $651-669$.

Shabala S, Mackay A. 2011. Ion transport in halophytes. Advances in Botanical Research 57: 151-199.

Sharma PK, Hall DO. 1991. Interaction of salt stress and photoinhibition on photosynthesis in Barley and Sorghum. Journal of Plant Physiology 138: 614-619.

Shen B, Jensen RG, Bohnert HJ. 1997. Mannitol protects against oxidation by hydroxyl radicals. Plant Physiology 115: 527-532.

Shi H, Quintero FJ, Pardo JM, Zhu J. 2002. The putative plasma membrane $\mathrm{Na}^{+} / \mathrm{H}^{+}$ antiporter SOS1 controls long-distance $\mathrm{Na}^{+}$transport in plants. The Plant Cell 14: 465-477.

Slama I, Abdelly C, Bouchereau A, Flowers T, Savoure A. 2015. Diversity, distribution and roles of osmoprotective compounds accumulated in halophytes under abiotic stress. Annals of Botany 115: 433-447.

Spencer JPE, Jenner A, Butler J, Aruoma OI, Dexter DT, Jenner P, Halliwell B. 1996. Evaluation of the pro-oxidant and antioxidant actions of L-DOPA and dopamine in vitro: implications for Parkinson's disease. Free Radical Research 24: 95-105.

Sperdouli I, Moustakas M. 2012. Interaction of proline, sugars, and anthocyanins during photosynthetic acclimation of Arabidopsis thaliana to drought stress. Journal of Plant Physiology 169: 577-585.

Stafford HA. 1994. Anthocyanins and betalains: evolution of the mutually exclusive pathways. Plant Science 101: 91-98.

Steglich W, Strack D. 1990. Betalains. The alkaloids: chemistry and pharmacology 39: 1-62. 
Steiner U, Schliemann W, Böhm H, Strack D. 1999. Tyrosinase involved in betalain biosynthesis of higher plants. Planta 49: 114-124.

Steyn WJ, Wand SJE, Holcroft DM, Jacobs G. 2002. Anthocyanins in vegetative tissues: a proposed unified function in photoprotection. New Phytologist 155: 349-361.

Stintzing FC, Carle R. 2004. Functional properties of anthocyanins and betalains in plants, food, and in human nutrition. Trends in Food Science \& Technology 15: 19-38.

Stintzing FC, Herbach KM, Mosshammer MR, Carle R, Yi W, Sellappan S, Akoh CC, Bunch R, Felker P. 2005. Color, betalain pattern, and antioxidant properties of cactus pear (Opuntia spp.) clones. Journal of Agricultural and Food Chemistry 53: 442-451.

Strack D, Vogt T, Schliemann W. 2003. Recent advances in betalain research. Phytochemistry 62: 247-269.

Su H, Balderas E, Vera-Estrella R, Golldack D, Quigley F, Zhao C, Pantoja O, Bohnert HJ. 2003. Expression of the cation transporter McHKT1 in a halophyte. Plant Molecular Biology 52: 967-980.

Sucre B, Suárez N. 2011. Effect of salinity and PEG-induced water stress on water status, gas exchange, solute accumulation, and leaf growth in Ipomoea pes-caprae. Environmental and Experimental Botany 70: 192-203.

Svenson J, Smallfield BM, Joyce NI, Sansom CE, Perry NB. 2008. Betalains in red and yellow varieties of the Andean tuber crop ulluco (Ullucus tuberosus). Journal of Agricultural and Food Chemistry 56: 7730-7737.

Szabados L, Kovacs H, Zilberstein A, Bouchereau A. 2011. Plants in extreme environments: importance of protective compounds in stress tolerance. Advances in Botanical Research 57: $105-150$.

Taira J, Tsuchida E, Katoh MC, Uehara M, Ogi T. 2015. Antioxidant capacity of betacyanins as radical scavengers for peroxyl radical and nitric oxide. Food chemistry 166: 531-536.

Taji T, Seki M, Satou M, Sakurai T, Kobayashi M, Ishiyama K. 2004. Comparative genomics in salt tolerance between Arabidopsis and Arabidopsis-related halophyte salt cress using Arabidopsis microarray. Plant Physiology 135: 1697-1709.

Takahashi S, Badger MR. 2011. Photoprotection in plants: a new light on photosystem II damage. Trends in Plant Science 16: 53-60.

Tanaka Y, Sasaki N, Ohmiya A. 2008. Biosynthesis of plant pigments: anthocyanins, betalains and carotenoids. The Plant Journal : for Cell and Molecular Biology 54: 733-749. 
Tang A, Kawamitsu Y, Kanechi M, Boyer JS. 2002. Photosynthetic oxygen evolution at low water potential in leaf discs lacking an epidermis. Annals of Botany 89: 861-870.

Tester M, Davenport R. 2003. $\mathrm{Na}^{+}$tolerance and $\mathrm{Na}^{+}$transport in higher plants. Annals of Botany 91: 503-527.

Tezara W, Martínez D, Rengifo E, Herrera A. 2003. Photosynthetic responses of the tropical spiny shrub Lycium nodosum (Solanaceae) to drought, soil salinity and saline spray. Annals of Botany 92: 757-765.

Tognetti J a, Pontis HG, Martínez-Noël GM a. 2013. Sucrose signaling in plants: a world yet to be explored. Plant Signaling \& Behavior 8: 1-10.

Ventura Y, Eshel A, Pasternak D, Sagi M. 2015. The development of halophyte-based agriculture: past and present. Annals of Botany: 529-540.

Vera-estrella R, Barkla BJ, Garcia-Ramirez L, Pantoja O. 2005. Salt stress in Thellungiella halophila activates $\mathrm{Na}^{+}$transport mechanisms required for salinity tolerance. Plant Physiology 139: $1507-1517$.

Véry A, Sentenac H. 2003. Molecular mechanisms and regulation of $\mathrm{K}^{+}$transport in higher plants. Annual Review of Plant Biology 54: 575-603.

Vogt T, Ibdah M, Schmidt J, Wray V, Nimtz M, Strack D. 1999. Light-induced betacyanin and flavonol accumulation in bladder cells of Mesembryanthemum crystallinum. Phytochemistry 52: 583-592.

Wang C-Q, Liu T. 2007. Involvement of betacyanin in chilling-induced photoinhibition in leaves of Suaeda salsa. Photosynthetica 45: 182-188.

Wang C-Q, Song H, Gong X-Z, Hu Q-G, Liu F, Wang B-S. 2007a. Correlation of tyrosinase activity and betacyanin biosynthesis induced by dark in C3 halophyte Suaeda salsa seedlings. Plant Science 173: 487-494.

Wang C-Q, Xu C, Wei J-G, Wang H-B, Wang S-H. 2007b. Enhanced tonoplast $\mathrm{H}^{+}$-ATPase activity and superoxide dismutase activity in the halophyte Suaeda salsa containing high level of betacyanin. Journal of Plant Growth Regulation 27: 58-67.

Wang C-Q, Zhao J-Q, Chen M, Wang B-S. 2006. Identification of betacyanin and effects of environmental factors on its accumulation in halophyte Suaeda salsa. Journal of Plant Physiology and Molecular Biology 32: 195-201.

Xue ZY, Zhi DY, Xue GP, Zhang H, Zhao YX, Xia GM. 2004. Enhanced salt tolerance of transgenic wheat (Tritivum aestivum L.) expressing a vacuolar $\mathrm{Na}^{+} / \mathrm{H}^{+}$antiporter gene with improved grain yields in saline soils in the field and a reduced level of leaf $\mathrm{Na}^{+}$. Plant Science 167: 849-859. 
Yancey PH. 2005. Organic osmolytes as compatible, metabolic and counteracting cytoprotectants in high osmolarity and other stresses. The Journal of Experimental Biology 208: 2819-2830.

Yang Q, Chen ZZ, Zhou XF, Yin HB, Li X, Xin XF, Hong XH, Zhu JK, Gong Z. 2009. Overexpression of SOS (salt overly sensitive) genes increases salt tolerance in transgenic Arabidopsis. Molecular Plant 2: 22-31.

Zhang H-X, Blumwald E. 2001. Transgenic salt-tolerant tomato plants accumulate salt in foliage but not in fruit. Nature Biotechnology 19: 765-768.

Zhang J-L, Flowers TJ, Wang S-M. 2009. Mechanisms of sodium uptake by roots of higher plants. Plant and Soil 326: 45-60.

Zhu J-K. 2001. Plant salt tolerance. Trends in Plant Science 6: 66-71.

Zhu JK. 2003. Regulation of ion homeostasis under salt stress. Current Opinion in Plant Biology 6: 441-445. 


\section{Appendix 1- Authored review paper}

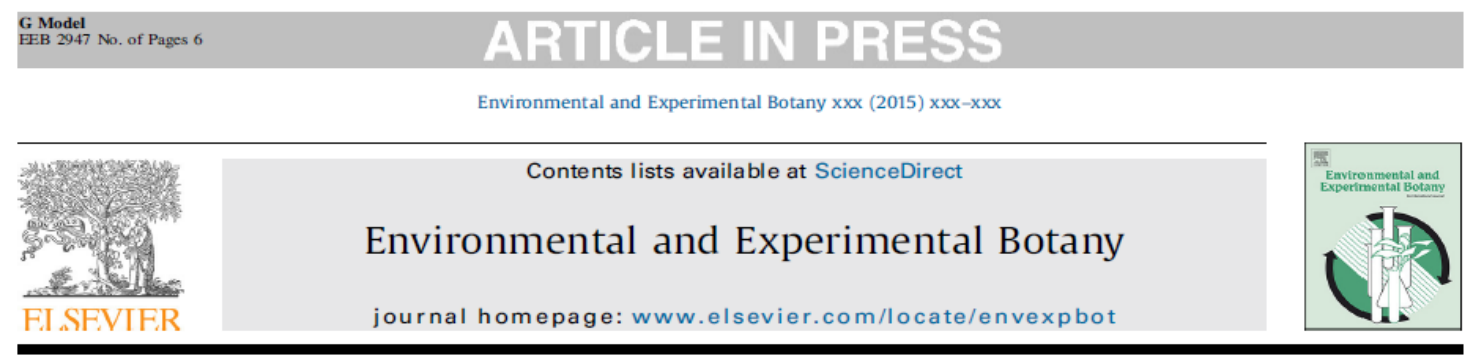

\section{Are betalain pigments the functional homologues of anthocyanins in plants?}

Gagandeep Jain, Kevin S Gould*

School of Biological Sciences, Victoria University of Wellington, P.O. Box 600, Wellington 6140, New Zealand

\begin{tabular}{l} 
A R T I C L E I N F O \\
\hline Article history: \\
Received 28 February 2015 \\
Received in revised form 28 May 2015 \\
Accepted 1 June 2015 \\
Available online xxx \\
\hline Keywords: \\
Betalain \\
Anthocyanin \\
Photoprotection \\
Antioxidant
\end{tabular}

A B S T R A C T

Betalains, a small group of alkaloid pigments restricted to certain families of the Caryophyllales, have comparable optical properties and share similar histological locations in vegetative tissues with those of the more abundant anthocyanins. It has long been speculated that the two pigments are functional homologues in plant-environment interactions. Recent empirical evidence indicates that anthocyanins and betacyanins are both effective photoprotectants, are associated with increased tolerance to drought and salinity stress, and are efficient scavengers of reactive oxygen species in plants facing a variety of abiotic stressors. Nevertheless, the capacity of betalains to maintain a red colour irrespective of changes in vacuolar $\mathrm{pH}$, their enhanced absorptivity of visible wavelengths, and their strong association with vacuolar ATPase activity, suggest that they may confer adaptive benefits not found in those species that produce anthocyanins. There remains much to be learned about the functional significance of betalains.

\section{Introduction}

Among the biochemically diverse groups of secondary metabolites in plants, the anthocyanins have arguably attracted the most scientific attention over recent decades. This large and disparate class of pigments found in the root and shoot systems of most angiosperms and some gymnosperms is especially notable for the range of reds and purples it confers to plant organs. Accordingly, a wide variety of functional hypotheses has been posited to explain the extraordinary evolutionary success of these compounds. There exists, however, another, much smaller group of pigments with comparable colours that has received considerably less attention. These are betalains, tyrosine-derived alkaloids that are restricted to certain fungi and one order of vascular plants. Because betalains and anthocyanins do not naturally co-exist in any extant species, and because of their similar optical and chemical properties, it has been suggested that the two may be functional homologues, the betalains substituting for anthocyanins in anthocyanin-free plants. Here, we compare recent evidence for putative roles of anthocyanins and betalains in vegetative organs to assess the degree to which the two pigment types might be functional equivalents in plant-environment interactions.

- Corresponding author at: School of Biological Sciences, Victoria University of Wellington, P.O. Box 600, Wellington 6140, New Zealand. Tel.: +64 4 4636649; fax: +6444635331 .

E-mail address: kevin.gould@vuw.ac.nz (K.S. Gould).
Betalains were originally called 'nitrogenous anthocyanins', which incorrectly implied structural similarities between the two pigment classes (Lawrence et al., 1939); indeed, it was not until the mid 20th century that the structural detail of betalain compounds was elucidated (Steglich and Strack, 1990). Mabry and Dreiding (1968) coined the term 'betalain', a derivative of betalamic acid which was originally identified from red beet (Beta vulgaris). We now know that two structurally different types of betalains exist (Fig. 1): the yellow/orange betaxanthins $\left(\lambda_{\max }=\right.$ approximately $470 \mathrm{~nm}$ ) which are the condensation products of betalamic acid and assorted amino compounds, and the red betacyanins $\left(\lambda_{\max }=\right.$ approximately $536 \mathrm{~nm}$ ) which are formed by glycosylation and acylation of cyclo-DOPA (Stintzing and Carle, 2004). To date, far fewer betalain compounds have been isolated from plants than have anthocyanins (Stintzing and Carle, 2007).

Like the anthocyanins, betalain pigments occur in the seeds, fruits, flowers, leaves, stems, and/or roots of plants from a wide range of natural environments (Gandía-Herrero and GarcíaCarmona, 2013; Kugler et al., 2004; Strack et al., 2003; Svenson et al., 2008). The timing of betalain production varies across species; as with the anthocyanins, they may be present only in immature organs, only in senescing organs or else persist for the life of the organ (Fig. 2); (Hortensteiner and Lee, 2007; Lee and Collins, 2001); their synthesis may be restricted to reproductive organs, as in the flowers and fruit of many cacti (e.g., Kobayashi et al., 2000), or else occur in both vegetative and reproductive structures, such as the leaves and flowers of iceplants (Jain and Gould, 2015). Both betalains and anthocyanins are stored as 
(A)

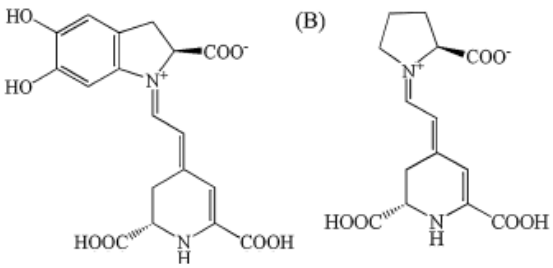

Fig. 1. Chemical structure of (A) betanidin, a common betacyanin and (B) indicaxanthin, a betaxanthin.
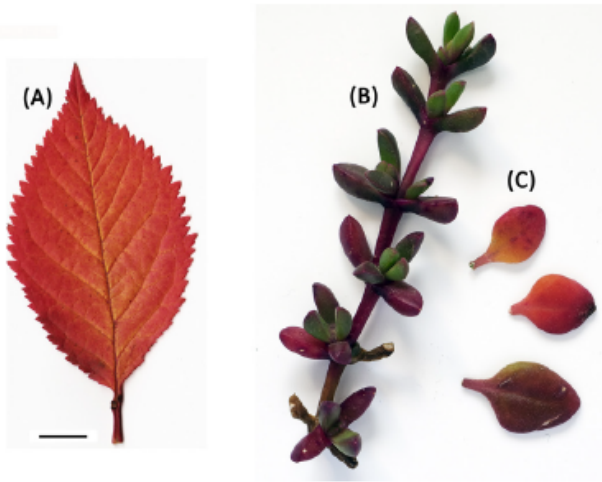

Fig. 2. Anthocyanins (A) and betacyanins (B,C) in vegetative shoots. (A) Prunus avium, (B) Disphyma australe, (C) Tetragonia implexicoma. Bar $=1 \mathrm{~cm}$.

glycosides in the cell vacuole, and they share similar histological locations in dermal, ground, and vascular tissues of vegetative organs (Gould and Quinn, 1999; Jain and Gould, 2015; Kytridis and Manetas, 2006; Lee and Collins, 2001; Mosco, 2012; Tattini et al, 2014).

Betacyanins and anthocyanins can produce a similar array of red colours (Lee and Collins, 2001; Tanaka et al., 2008). Both are also potent antioxidants, capable of scavenging a variety of reactive species (Hatier and Gould, 2009; Neill et al., 2002; Stintzing and Carle, 2004; Wang and Liu, 2007), and both have a relatively high osmotic potential, giving them the capacity to serve possible osmoregulatory roles (Chalker-Scott, 2002,1999; Stintzing and Carle, 2004). Although they are produced by very different biosynthetic pathways, the two pigment types are inducible by similar environmental cues, including light (Hatier and Gould, 2009; Hughes and Smith, 2007; Kishima et al., 1995; Vogt et al., 1999), UV radiation (Ibdah et al., 2002; Tsurunaga et al., 2013; Vogt et al., 1999; Wang et al., 2012), sucrose accumulation (Hughes et al. 2005; Oh et al., 2011; Solfanelli et al., 2006), and a host of abiotic stressors such as drought, low temperatures and salinity (Chaves et al., 2009; Duarte et al., 2013; Hayakawa and Agarie, 2010; Hughes, 2011; Jain and Gould, 2015; Nakashima et al., 2011; Pietrini et al., 2002; Sperdouli and Moustakas, 2012; Tahkokorpi et al., 2007; Wang and Liu, 2007). There are, therefore, compelling reasons to postulate that the two classes of pigments share common functional roles.

Notwithstanding these similarities, betalains are far less abundant than anthocyanins across the plant kingdom. The capacity to synthesise betalains has only been observed within one order of plants, the Caryophyllales, and even that has two families, the Caryophyllaceae and Molluginaceae, containing members that produce anthocyanins instead of betalains (Gandía-Herrero and García-Carmona, 2013). Aside from plants, the only other organisms to synthesise betalains are certain genera of Basidiomycetes (Gill, 2003). No plant species studied to date has been found to accumulate both anthocyanins and betalains (Strack et al., 2003). This exclusivity remains unexplained, and is, perhaps, surprising given that gene homologues for a key enzyme in betalain biosynthesis are present in anthocyanic plants (Christinet et al., 2004) and that betanidin 6-O-glucosyltransferase, which catalyses the glucosylation of betacyanin, can also efficiently glucosylate the anthocyanidins (Vogt et al., 1997). There is, moreover, no apparent physiological barrier that prevents the two pigments from co-occurring; a recent study transferred part of the betalain biosynthetic pathway into cell cultures of potato, petals of Antirrhinum and shoots of Arabidopsis, and demonstrated that betalain production was possible in these normally anthocyanic plants when they were fed with a betalain intermediate, L-DOPA (Harris et al., 2012). Indeed, Clement and Mabry (1996) posited that the ancestor of the Caryophyllales could have held both types of pigments, but that one or the other was lost as species evolved. However, a recent phylogenetic analysis of the core Caryophyllales using $\mathrm{rbcL} / \mathrm{mat} K$ plastid gene markers has shown that the ancestral type was almost certainly anthocyanic (Brockington et al., 2011). Intriguingly, that study also indicated that the capacity to synthesise betalains may have arisen more than once, and that in the course of speciation, some lineages evidently switched from betalain production back to anthocyanin production. There seems, therefore, to be a 'cost' associated with betalain production, which preferentially drives the evolution of anthocyanic rather than betalainic plants. From a functional perspective, their mutual exclusivity indicates that betalains may substitute for, but do not complement the roles of anthocyanin pigments. There may also be unique properties of betalains that provide fitness benefits under certain environments.

of the two betalain groups, the betacyanins have received far greater scientific attention from a plant-environment functional perspective. Nonetheless, the betaxanthins have also been implicated in vital functions such as pollinator attraction, desiccation tolerance and free-radical scavenging (Cai et al. 2005; Gandía-Herrero et al., 2005; Stintzing and Carle, 2004). However, there are as yet insufficient empirical data to afford useful comparisons between betaxanthins and anthocyanins; this review therefore focuses on the betacyanins in relation to key functional hypotheses proposed for the anthocyanins.

\section{Photoprotection}

Prolonged exposures to light energy in excess of the requirements for photosynthesis can lead to oxidative stress, damage to the manganese cluster in the oxygen-evolving complex of photosystem II (PSII), and inhibition of the repair of damaged PSII proteins (Takahashi and Badger, 2011). Anthocyanins in leaves and stems have long been proposed to contribute to the suite of photoprotective mechanisms that serve to mitigate photoinhibitory damage (Gould, 2010). According to the light screening hypothesis', anthocyanins in epidermal and/or palisade mesophyll cells would intercept quanta that might otherwise strike chloroplasts, thereby reducing excitation pressure on PSII. Consistent with the hypothesis, numerous studies have reported that red leaves and stems maintain higher quantum yields and recover from photoinactivation faster than do their green counterparts when exposed to saturating light (Boldt et al., 2014). However, the extent to which the photosynthetic machinery is apparently protected by anthocyanins seems to vary across species.

Although fewer studies have appraised a potential photoprotective role of foliar betalains, all report smaller declines in the quantum efficiency of PSII ( $\Phi_{\mathrm{PSII}}$, as estimated by the ratio of variable to maximum chlorophyll fluorescence) in betacyanic than 
in green leaves following exposure to high light (Jain and Gould, 2015; Jain et al., 2015; Nakashima et al., 2011; Wang and Liu, 2007). The presence of betacyanins effectively reduces both the transmittance and reflectance of light between 500 and $600 \mathrm{~nm}$, but has no effect on the reflectance of red light (Jain and Gould, 2015; Nakashima et al., 2011); these are comparable to the effects of anthocyanins in leaves (Neill and Gould, 1999), and are consistent with a light-screening role. Moreover, exposure to high light has been shown many times to upregulate betalain production in plants (De Nicola et al., 1975; Ibdah et al., 2002; Kishima et al., 1995; Kochhar et al., 1981; Vogt et al., 1999). It seems likely, therefore, that the accumulation of betalains is an acclimatory response to high light, and functions primarily to limit photoinhibitory damage.

It is difficult, nonetheless, to disentangle the possible effects of photoabatement by betalains from those of other photoprotective mechanisms, such as energy dissipation via xanthophyll cycle pigments. To address this problem, in a recent study L-DOPA was supplied to the cut stems of Disphyma australe, a succulent halophyte from New Zealand (Jain et al., 2015). Within $48 \mathrm{~h}$, the treated shoots produced five betacyanins in the leaf epidermis and mesophyll, affording a comparison of the responses of red and green (untreated) leaves to high light without the possible confounding effects of differences in genotype, leaf age, or growth conditions. Under white or monochromatic green light, $\Phi_{\mathrm{PS} I I}$ was depressed substantially more in the green than in the betacyanic leaves. However, under monochromatic red light-which is not absorbed by betacyanins-the two leaves showed similarly large reductions in $\Phi_{\text {PSII- }}$. Interestingly, non-photochemical quenching (NPQ) via the xanthophyll cycle was greater in the green than in red leaves under white light, indicating that in the absence of betacyanin, there may be a greater need to invoke energy dissipation; a similar conclusion was reached recently in a comparison of anthocyanic and acyanic cultivars of coleus (Logan et al., 2015) Collectively, the data present strong evidence for a protective light-screening role of foliar betalains.

\subsection{Tolerance to drought and salinity stress}

Red-leafed plants are commonly associated with arid and/or saline environments. For many species, a soil moisture deficit or exposure to substrate salinity can induce or upregulate foliar anthocyanin biosynthesis (Chalker-Scott, 1999), and in some instances, the presence of anthocyanins correlates to an improved tolerance to these stressors. In Arabidopsis, for example, a moderate drought stress leads to substantial increases in anthocyanin levels (Giraud et al., 2008; Sperdouli and Moustakas, 2012) and the overexpression of anthocyanins, as in the pap1-D (production of anthocyanin pigment 1 - dominant) mutant, correlates with improved drought resistance (Nakabayashi et al., 2014). Similarly, pap 1-D plants survived for longer, and retained more chlorophyll, on an $\mathrm{NaCl}$-enriched medium than did wild type Arabidopsis (Oh et al., 2011). To explain the apparent contribution of anthocyanins, Chalker-Scott $(1999,2002)$ suggested that these pigments might function as compatible solutes, depressing a leaf's osmotic potential, and thereby maintaining cell turgor during drought stress. However, a recent analysis of the winter-reddened leaves of Galax urceolata and Gaultheria procumbens concluded that the contribution of anthocyanins to osmotic adjustment is very small relative to those from glucose, fructose and sucrose, and is, therefore, unlikely to explain water deficit tolerance (Hughes et al., 2013). An alternative explanation is that anthocyanin may serve to mitigate or prevent oxidative stress when plant tissues are subjected to osmotic imbalance. In pap1-D Arabidopsis, for example, drought tolerance correlated strongly to the antioxidant activity associated with anthocyanin overaccumulation (Nakabayashi et al., 2014).

Betalainic plants in the Portulacaceae, Aizoaceae and Phytolaccoideae commonly feature in arid and/or saline environments such as deserts, salt marshes and dunes, and betacyanin content has been reported to increase under both drought and salinity stress (Bothe, 1976; Hayakawa and Agarie, 2010; Jain and Gould, 2015; Jain et al., 2015; Nakashima et al., 2011; Wang et al., 2007b). As for the anthocyanins, it has been suggested that betalains may function as solutes to counter osmotic stress (Stintzing and Carle, 2004). However, Wang et al., (2007b) found no differences in cell sap osmolarity between betacyanic and acyanic cells either before or after a salinity treatment. The betacyanic and acyanic leaves of Amaranthus cruentus responded similarly to water stress in terms of relative water content, gas-exchange rates and chlorophyll content (Nakashima et al., 2011). By contrast, the water use efficiency of Disphyma australe, calculated as the ratio of maximum net $\mathrm{CO}_{2}$ assimilation rate to stomatal conductance, was greater in betacyanic than in green leaves following salinity stress (Jain and Gould, 2015).

An intriguing new possibility for the involvement of betalains in salt tolerance has been reported for Suaeda salsa, a C3 halophyte collected from the Yellow River Delta (Wang et al., 2007b). The authors of that study found substantially greater increases in vacuolar $\mathrm{H}^{+}$-ATPase (V-ATPase) activity in betacyanic than in green leaves when plants were subjected to $400 \mathrm{mM} \mathrm{NaCl}$. V-ATPases couple the energy of ATP hydrolysis to proton transport, establishing an electrochemical gradient that drives $\mathrm{Na}^{+}$into the cell vacuole against a concentration gradient. A greater ability to compartmentalise $\mathrm{Na}^{+}$explained why the red $S$. salsa plants accumulated more salt and grew faster than the green plants under these strongly saline conditions. To explain the apparent link between V-ATPase activity and pigment accumulation, it was suggested that plants employ a similar mechanism to transport betacyanin and $\mathrm{Na}^{+}$into the cell vacuole. Accordingly, the biosynthesis of betacyanin would stimulate V-ATPase activity, which then transports betacyanin through the tonoplast. The elevated V-ATPase activity would subsequently afford more efficient sequestration of $\mathrm{NaCl}$ into these betalainic vacuoles. The applicability of this system to other plant species remains unknown.

Betalains might also serve to photoprotect chloroplasts for which their capacity to process light energy is compromised by drought or salinity. Consistent with this, the extent of photoinhibition was greater in acyanic than betacyanic leaves of $A$. cruentus after a high light and water stress treatment (Nakashima et al., 2011). Similarly, light-screening by epidermal betacyanins permitted Disphyma australe to maintain higher $\Phi_{\mathrm{PSII}}$ values and produce less $\mathrm{H}_{2} \mathrm{O}_{2}$, a product of photo-oxidative stress, during salinity treatments under high light (Jain and Gould, 2015; Jain et al., 2015). Thus, betalains may afford protection both directly (e.g. through $\mathrm{Na}^{+}$compartmentation) or indirectly (via photoabatement).

\subsection{Antioxidant activity}

Reactive oxygen species (ROS) are integral components of plant responses to stress. At low levels, ROS function as early messengers in signal transduction pathways to initiate restorative processes (Miller et al., 2010). However, supernumerary ROS can place plants under oxidative stress, with the potential to destroy cell and organelle membranes, damage DNA and denature proteins. The balance between beneficial and harmful ROS is achieved through the activities of antioxidants-predominantly enzymes, but also a variety of low molecular weight compounds. Anthocyanins have long been considered part of the antioxidant complement. They 
may diminish the oxidative load in a leaf simply by filtering out yellow-green light, since the transfer of excitation energy to molecular oxygen in chloroplasts is a major source of ROS (Landi et al., 2014). Anthocyanins are, in addition, excellent scavengers of most types of ROS (Agati et al., 2012). Since most abiotic and biotic stressors lead to the generation of ROS, the antioxidant capacities of anthocyanins may explain the preponderance of red leafed plants in marginal environments (Gould, 2004).

A strong antioxidant capacity of betalains has also been well documented (Butera et al., 2002; Cai et al., 2003; Hayakawa and Agarie, 2010; Hilou et al., 2013; Kanner et al., 2001; SepúlvedaJiménez et al., 2004; Stintzing et al., 2005; Taira et al., 2015), and a growing body of experimental evidence indicates that this antioxidant potential is indeed utilized by the leaf cells. In Suaeda salsa, for example, watering roots with the strong oxidant $\mathrm{H}_{2} \mathrm{O}_{2}$ led to the development of betalains in the leaf (Wang et al. 2007a). When S. salsa plants were subjected to a combination of strong light and low temperatures, more $\mathrm{H}_{2} \mathrm{O}_{2}$ was produced in acyanic than in betacyanic leaves (Wang and Liu, 2007). Thylakoids isolated from green leaves of these plants generated less $\mathrm{H}_{2} \mathrm{O}_{2}$ if betacyanin were added to the suspension (Wang anc Liu, 2007). Similarly, $\mathrm{H}_{2} \mathrm{O}_{2}$ production was lower in betacyanic than in acyanic leaves of Amaranthus tricolor following a heat stress (Shu et al., 2010). $\mathrm{H}_{2} \mathrm{O}_{2}$-induced protein oxidation in leaf extracts of Suaeda japonica was abolished when betacyanin solution was added to the mixture (Hayakawa and Agarie, 2010) Interestingly, under conditions of oxidative stress, antioxidant enzyme activity was lower in red than in green $S$. japonica leaves, but oxidative damage, estimated as malondialdehyde production, was similar for both leaf types; this suggests that betacyanins might in part compensate for deficiencies in other antioxidants.

As a caveat to the ROS-scavenging hypothesis, it should be noted that the betacyanins-like the anthocyanins-accumulate predominantly inside the vacuoles of plant cells. Unlike the antioxidant enzymes, therefore, neither pigment is optimally located to scavenge organelle-derived ROS such as superoxide radicals, which have only limited permeability across membranes. However, superoxide rapidly dismutates to $\mathrm{H}_{2} \mathrm{O}_{2}$, a highly mobile and relatively stable ROS which can move both between cell compartments and across adjacent cells (Mittler et al., 2004). It seems highly likely, therefore, that betacyanins and anthocyanins have the potential to directly neutralise vacuolar $\mathrm{H}_{2} \mathrm{O}_{2}$.

\subsection{Concluding remarks}

Anthocyanins are known to supply more protective functions than those listed above; they can, for example, serve as visual cues to deter herbivores, and they are involved in metalloid and heavy metal tolerance. Betalains are also known to complex with metal ions such as $\mathrm{Cu}^{2+}$ and $\mathrm{Hg}^{2+}$ (Herbach et al., 2006), and betalain biosynthesis is upregulated in response to $\mathrm{Co}^{2+}, \mathrm{Mo}^{2+}, \mathrm{Fe}^{2+}$ and $\mathrm{Cu}^{2}$ +(León Morales et al., 2012; Perotti et al., 2010; Trejo-Tapia, 2001); however, the possibility of a functional role of betalains in meta stress tolerance has never been evaluated. Similarly, it is not known if foliar betalains are involved in herbivore deterrence. It is clear, however, that betacyanins in leaves and other vegetative organs are a good match for anthocyanins in terms of their roles in photoprotection, drought and salinity stress responses, and oxidative stress. But are betalains and anthocyanins true functional equivalents? Functional redundancy would go some way to explain why anthocyanins and betalains are mutually exclusive, why betalains have an extremely limited distribution, and why some derived lineages of the Caryophyllales have apparently reverted to their ancestral anthocyanic state. However, functional redundancy would not explain the evolutionary persistence of betalains among the core Caryophyllales (given that these plants synthesise flavonoids other than anthocyanin), nor the apparent prominence of betalainic plants in saline and arid environments.

Notwithstanding the functional similarities with anthocyanin pigments, there are also distinctive properties of betalains that might confer additional benefits to plants in certain environments. First, unlike the (free) anthocyanins, betalain colour is stable between $\mathrm{pH} 3$ and 7 (Strack et al., 2003). This may be advantageous for betalainic plants such as Mesembryanthemum crystallinum and Portulaca oleracea which, upon experiencing water stress, switch their mode of carbon assimilation from C4 and C3, respectively, to Crassulacean acid metabolism (CAM), (Winter and Holtum, 2014). These plants therefore incur a shift from a relatively stable vacuolar $\mathrm{pH}$ to large diurnal fluctuations in $\mathrm{pH}$. A stable red colour would ensure that for plants at locations prone to drought, photoprotection is maintained irrespective of vacuolar $\mathrm{pH}$.

Second, the molar extinction coefficient for a betacyanin such as betanin is approximately two-fold greater than that for a common foliar anthocyanin, such as cyanidin-3-O-glucoside. Betacyanins therefore represent an energetically effective means to achieve red colouration, and thus to confer photoprotection. However, as discussed by Clement and Mabry (1996), this economy needs to be weighed against the additional cost of nitrogen required for betalain synthesis; the two nitrogen atoms per betalain molecule could, all things being equal between the two classes of pigments, make betalains less "successful" than anthocyanins as defensive molecules.

Finally, the association between V-ATPase activity and betacyanin content (Wang et al., 2007b) presents the possibility of a novel and effective three-pronged defence against salinity stress; plants potentially benefit from $\mathrm{NaCl}$ sequestration via increased V-ATPase activity, improved photoprotection via light abatement, and enhanced ROS scavenging from betacyanins acting as antioxidants. Although the mechanistic detail of betalain transport through the tonoplast remains unknown (Sakuta, 2013), the possibility that $\mathrm{Na}^{+}$sequestration might be coupled to betacyanin storage represents an exciting area for future research. There remains much to be learned about the functional significance of betalain pigments.

\section{References}

Agati, G., Azzarello, E., Pollastri, S., Tattini, M., 2012. Flavonoids as antioxidants in plants: location and functional significance. Plant Sci. 196, 67-76, doi:http://dx. doi.org/10.1016/j.plantsci.2012.07.014.

Boldt, J.K., Meyer, M.H., Erwin, J.E., 2014. Foliar anthocyanins: a horticultural review. Hortic. Rev. (Am. Soc. Hortic. Sci.) 42, 209-251.

Bothe, H., 1976. Salzresistenz bei pflanzen. Biol. Unsere Zeit 6, 3-9.

Brockington, S.F., Walker, R.H. Glover, B.J., Soltis, P.S., Soltis, D.E, 2011. Complex pigment evolution in the Caryophyllales. New Phytol. 190, 854-864.

Butera, D., Tesoriere, L., Gaudio Di, F., Bongiomo, A., Allegra, M., Pintaudi Maria, A. Kohen, R., Livrea, M.A., 2002. Antioxidant activities of Sicilian prickly pear (Opuntia ficus indica) fruit extracts and reducing properties of its betalains: (Opuntia ficus indica) fruit extracts and reducing properties of its

Cai, Y., Sun, M., Corke, H, 2003. Antioxidant activity of betalains from plants of the Amaranthaceae. J. Agric. Food Chem. 51, 2288-2294. doi:http://dx.doi.org/ 10.1021 /jf030045u.

Cai, Y.-Z, Sun, M., Corke, H., 2005. Characterization and application of betalain pigments from plants of the Amaranthaceae. Trends Food Sci. Technol. 16, 370376. doi:http://dx.doi.org/10.1016/j.tifs.2005.03.020.

Chalker-Scott, L., 2002. Do anthocyanins function as osmoregulators in leaf tissue? Adv. Bot. Res. 37, 103-127.

Chalker-Scott, L, 1999. Environmental significance of anthocyanins in plant stress responses. Photochem. Photobiol. 70,1-9.

Chaves, M.M., Flexas, J., Pinheiro, C., 2009. Photosynthesis under drought and salt stress: regulation mechanisms from whole plant to cell. Ann. Bot. 103, 551-560. doi:http://dx.doi.org/10.1093/aob/mcn125.

Christinet, L., Burdet, F., Zaiko, M., 2004. Characterization and functional identification of a novel plant 4,5-extradiol dioxygenase involved in betalain pigment biosynthesis in Portulaca grandiflora. Plant Physiol. doi:http://dx.doi. org/10.1104/pp.103.031914. 
Clement, J.S., Mabry, T.J. 1996. Pigment evolution in the Caryophyllales: a systematic overview. Bot. Acta 109, 360-367.

De Nicola, M.G. . Amigo, V., Sciwo, S., Piattelli, M., 1975. Light control of amaranthin synthesis in isolated Amaranthus cotyledons. Phytochemistry 14, 479-481.

Duarte, B., Santos, D., Marques, J.C., Caçador, I., 2013. Ecophysiological adaptations of two halophytes to salt stress: photosynthesis, PS II photochemistry and antioxidant feedback - implications for resilience in dimate change. Plant Physiol. Biochem. 67C, 178-188. doi: http://dx.doi.org/10.1016/j.plaphy.2013.03.004.

Gandia-Herrero, F., Escribano, J., García-Carmona, F., 2005. Betaxanthins as pigments responsible for visible fluorescence in flowers. Planta 222, 586-593. doi:http://dx.doi.org/10.1007/s00425-005-0004-3.

Gandía-Herrero, F., García-Carmona, F., 2013. Biosynthes is of betalains: yellow and violet plant pigments. Trends Plant Sci. 18, 334-343. doi:http://dx.doi.org/ 10.1016/j.tplants.2013.01.003.

Gill, M., 2003. Pigments of fungi (Macromycetes). Nat. Prod. Rep. 20, 615-639. doi: http://dx,doi.org/10.1039/b202267m.

Giraud, E., Ho, L.H.M., Clifton, R., Carroll, A., Estavillo, G., Tan, Y.-F, Howell, K., a Ivanova, A., Pogson, B.J., Millar a, H., Whelan, J., 2008. The absence of ALTERNATIVE OXIDASE1 a in Arabidopsis results in acute sensitivity to combined light and drought stress. Plant Physiol. 147, 595-610. doi:http://dx.doi.org/ 10.1104/pp.107.115121.

Gould, K.S., 2004. Nature's Swiss army knife: the diverse protective roles of anthocyanins in leaves. J. Biomed. Biotechnol. 314-320. doi:http://dx.doi.org/ $10.1155 /$ S1110724304406147.

Gould, K.S., 2010. Muriel Wheldale Onslow and the rediscovery of anthocyanin function in plants. In: Santos-Buelga, C., Escribano-Bailon, M., Lattanzio, V. (Eds.), Recent advances in polyphenol research. Blackwell Publishing Ltd., USA, pp. 206-225.

Gould, K.S., Quinn, B.D., 1999. Do anthocyanins protect leaves of New Zealand native species from UV-B? New Zeal. J. Bot. 37, 175-178. doi:http://dx,doi.org/10,1080/ 0028825X.1999.10512176

Harris, N.N., Javellana, J., Davies, K.M., Lewis, D.H., Jameson, P.E, Deroles, S.C. Calcott, K.E., Gould, K.S., Schwinn, K.E., 2012. Betalain production is possible in anthocyanin-producing plant species given the presence of DOPA-dioxygenase and L-DOPA. BMC Plant Biol. 1, 2. doi:http://dx.doi.org/10.1186/1471-2229-1234.

Hatier,J.B., Gould, KS., 2009. Anthocyanin function in vegetative organs. In: Gould, K., Davies, K. Winefield, C. (Eds). Anthocyanin. Springer, New York, pp. 1-19.

Hayakawa, K.. Agarie, S., 2010. Physiological roles of betacyanin in a halophyte, Suaeda japonica Makino. Plant Prod. Sci. 13, 351-359.

Herbach, K., Stintzing. F., Carle, R., 2006. Betalain stability and degradation -structural and chromatic aspects. J. Food Sci. 71, 41-50. doi:http://dx.doi.org/ $10.1111 / \mathrm{j} 1750-3841.2006 .00022$, $x$

Hilou, A., Millogo-Rasolodimby, J., Nacoulma, O.G., 2013. Betacyanins are the most relevant antioxidant molecules of Amaranthus spinosus and Boerhavia erecta. J. Med. Plants Res. 7, 645-652. doi:http://dx,doi.org/10.5897/JMPR012.574.

Hortensteiner, S., Lee, D.W., 2007. Chlorophyll catabolism and leaf coloration. In: Gan, S. (Ed.), Senescence processes in plants. Blackwell Publishing, Oxford, UK, pp. 12-38.

Hughes, N., 2011. Winter leaf reddening in evergreenspecies. New Phytol. 190, 573581.

Hughes, N.M., Carpenter, K.L., Cannon, J.G., 2013. Estimating contribution of anthocyanin pigments to osmotic adjustment during winter leaf reddening. J. Plant Physiol. 170, 230-233. doi:http://dx.doi.org/10.1016/j.jplph.2012.09.006.

Hughes, N.M., Neufeld, H.S., Burkey, K.O, 2005. Functional role of anthocyanins in high-light winter leaves of the evergreen herb Galax urceolata. New Phytol.168, 575-587. doi:http://dx.doi.org/10.1111/j 1469-8137.2005.01546. x.

Hughes, N.M., Smith, W.K., 2007. Seasonal photosynthesis and anthocyanin production in 10 broadleaf evergreen species. Funct. Plant Biol. 34, 1072-1079. doi:http://dx,doi.org/10.1071/FP07205.

Ibdah, M., Krins, A, Seidlitz, H., 2002. Spectral dependence of flavonol and betacyanin accumulation in Mesembryanthemum crystallinum under enhanced ultraviolet radiation. Plant. Cell Environ. 25, 1145-1154.

Jain, G., Gould, KS., 2015. Functional significance of betalain biosynthesis in leaves of Disphyma australe under salinity stress. Environ. Exp. Bot. 109, 131-140. doi; http://dx.doi.org/10.1016/j.envexpbot.2014.09.002.

Jain, G., Sch winn, K.E., Gould, KS., 2015. Betalain induction by L -DOPA application confers photoprotection to saline-exposed leaves of Disphyma australe. New Phytol, doi:http://dx.doi.org/10.1111/nph.13409.

Kanner, J., Harel, S., Granit, R., 2001. Betalains a new class of dietary cationized antioxidants. J. Agric. Food Chem. 49, 5178-5185.

Kishima, Y., Shimaya, A., Adachi, T., 1995. Evidence that blue light induces betalain pigmentation in Portulaca callus. Plant Cell. Tissue Organ Cult. 43, 67-70.

Kobayashi, N., Schmidt, J., Nimtz, M., Wray, V., Schliemann, W., 2000. Betalains from Christmas cactus. Phytochem. 54, 419-426.

Kochhar, V.K., Kochhar, S., Mohr, H., 1981. An analysis of the action of light on betalain synthesis in the seedling of Amaranthus caudatus. Planta 151, 81-87.

Kugler, F., Stintzing, F.C., Carle, R. 2004. Identification of betalains from petioles of differently colored Swiss chard (Beta vulgaris L ssp. cicla [L.] Alef. Cv. Bright lights) by high-performance liquid chromatography-electrospray ionization mass spectrometry. J. Agric. Food Chem. 52, 2975-2981. doi:http://dx.doi.org/ $10.1021 /$ jf035491w.

Kytridis, V., Manetas, Y, 2006. Mesophyll versus epidermal anthocyanins as potential in vivo antioxidants: evidence linking the putative antioxidant role to the proximity of oxy-radical source.J. Exp. Bot. 57, 2203-2210. doi:http://dx.doi. org/10.1093/jxb/erj 185 .
Landi, M., Guidi, L., Pardossi, A., Tattini, M., Gould, KS., 2014. Photoprotection by foliar anthocyanins mitigates effects of boron toxicity in sweet basil (Ocimum basilicum). Planta 240, 941-953. doi:http://dx.doi.org/10.1007/s00425-014. 2087-1.

Lawrence, W., Price, J., Robinson, G., Robinson, R., 1939. The distribution of anthocyanins in flowers, fruits and leaves. Philos. Trans. R. Soc. Lond. B. Biol. Sci. 230, 149-178.

Lee, D.W., Collins, T.M., 2001. Phylogenetic and ontogenetic influences on the distribution of anthocyanins and betacyanins in leaves of tropical plants. Int. J. plant Sci. 162, 1141-1153.

León Morales, J.M., Rodríguez-Monroy, M., Sepúlveda-Jiménez, G., 2012, Betacyanin accumulation and guaiacol peroxidase activity in Beta vulgaris L., leaves following copper stress. Acta Soc. Bot. Pol. 81, 193-201. doi:http://dx.doi.org/ 10.5586/asbp.2012.019.

Logan, B.A., Stafstrom, W.C., Walsh, M.J.L., Reblin, JS, Gould, K.S., 2015. Examining the photoprotection hypothesis for adaxial foliar anthocyanin accumulation by revisiting comparisons of green-and red-leafed varieties of coleus (Solenostemon scutellarioides). Photosynth. Res. 1-8. doi:http://dx.doi.org/ 10.1007/s11120-015-0130-0,

Mabry, TJ., Dreiding,A.S., 1968. The Betalains. In: Mabry, TJ., Alston, R., Runeckles, V. (Eds.), Recent Advances in Phytochemistry. Appleton century crofts, New York, pp. $145-160$.

Miller, G., Suzuki, N. Ciftci-Yilmaz, S., Mittler, R., 2010. Reactive oxygen species homeostasis and signalling during drought and salinity stresses. Plant. Cell Environ. 453-467, doi:http://dx.doi.org/10.1111/j 1365-3040.2009.02041. x

Mittler, R., Vanderauwera, S., Gollery, M., Van Breusegem, F., 2004. Reactive oxygen gene network of plants. Trends Plant Sci. 9, 490-498. doi:http://dx.doi.org/ 10.1016/j.tplants.2004.08.009.

Mosco, A., 2012. Tissue localization of betacyanins in cactus stems. Rev. Mex Biodivers. 83, 413-420.

Nakabayashi, R., Yonekura-Sakakibara, K., Urano, K., Suzuki, M., Yamada, Y, Nishizawa, T., Matsuda, F., Kojima, M., Sakakibara, H., Shinozaki, K., Michael, A.J., Tohge, T., Yamazaki, M., Saito, K., 2014. Enhancement of oxidative and drought olerance in Arabidopsis by overaccumulation of antioxidant flavonoids. Plant $\mathrm{J}$. 77, 367-379. doi:http://dx.doi.org/10.1111/tpj.12388.

Nakashima, T., Araki, T., Ueno, O., 2011. Photoprotective function of betacyanin in leaves of Amaranthus cruentus L. under water stress. Photosynthetica 49, 497506. doi:http://dx.doi,org/10.1007/s11099-011-0062-7.

Neill, S., Gould, K.S., 1999. Optical properties of leaves in relation to anthocyan in concentration and distribution. Can.J. Bot. 77, 1777-1782. doi:http://dx.doi.org/ concentration and distributi

Neill, S.O., Gould, K.S., Kilmartin, P., Mitchell, K., Markham, K.R., 2002. Antioxidant activities of red versus green leaves in Elatostema rugosum. Plant, Cell Environ. 25, 539-547. doi:http://dx.doi.org/10.1046/j 1365-3040.2002.00837. x

Oh, J.E., Kim, Y., Kim, J., Kwon, Y., Lee, H., 2011. Enhanced level of anthocyanin leads to increased salt tolerance in Arabidopsis PAP1-D plants upon sucrose treatment. J. Korean Soc. Appl. Biol. Chem. 54, 79-88, doi:http://dx.doi.org/10.3839/ jksabc.2011.011.

Perotti, J., Rodrigues, I., Kleinowski, A., 2010. Betacyanin production in alligator weed, grown in vitro, with different concentrations of copper sulfate. Cienc, Rural 40, 1874-1880.

Pietrini, F., Iannelli, M., Massacci a, 2002. Anthocyanin accumulation in the illuminated surface of maize leaves enhances protection from photo-inhibitory risks at low temperature, without further limitation to photosynthesis. Plant, Cell Environ. 1251-1259. doi:http://dx.doi.org/10.1046/j 13653040.2002.00917. $x$

Sakuta, M., 2013. Diversity in plant red pigments: anthocyanins and betacyanins. Plant Biotechnol. Rep . 8, 37-48. doi:http://dx.doi.org/10.1007/s11816-0130294-z.

Sepúlveda-Jiménez, G., Rueda-Benítez, P., Porta, H., Rocha-Sosa, M., 2004. Betacyanin synthesis in red beet (Beta vulgaris) leaves induced by wounding and bacterial infiltration is preceded by an oxidative burst. Physiol Mol. Plant Pathol. 64, 125-133. doi:http://dx,doi.org/10.1016/j.pmpp.2004.08.003.

Shu, Z., Shao, L., Huang, H.-Y., Zeng, X.-Q., Lin, Z-F., Chen, G.-Y., Peng, C.-L., 2010. Comparison of thermostability of PSII between the chromatic and green leaf cultivars of Amaranthus tricolor L. Photosynthetica 47, 548-558. doi:http://dx. doi.org/10.1007/s11099-009-0080-x.

Solfanelli, C., Poggi, A., Loreti, E., Alpi, A., Perata, P., 2006. Sucrose-specific induction of the anthocyan in biosynthetic pathway in Arabidopsis. Plant Physiol. 140, 637646. doi:http://dx.doi.org/10.1104/pp.105.072579 the.

Sperdouli, I, Moustakas, M., 2012. Interaction of proline, sugars, and anthocyanins during photosynthetic acclimation of Arabidopsis thaliana to drought stress. J. Plant Physiol. 169, 577-585. doi:http://dx.doi.org/10.1016/j.jplph.2011.12.015.

Steglich, W., Strack, D., 1990. Betalains. alka loids Chem. Pharmacol. 39, 1-62.

Stintzing, F.C., Carle, R., 2004. Functional properties of anthocyanins and betalains in plants, food, and in human nutrition. Trends Food Sci. Technol. 15, 19-38. doi: http://dx,doi.org/10.1016/j.tifs.2003.07.004.

Stintzing, F.C., Carle, R., 2007. Betalains - emerging prospects for food scientists. Trends Food Sci. Technol. 18, 514-525. doi:http://dx,doi.org/10.1016/j. tifs.2007.04.012.

Stintzing, F.C., Herbach, K.M., Mosshammer, M.R., Carle, R., Yi, W., Sellappan, S., Akoh, C.C., Bunch, R., Felker, P., 2005. Color, betalain pattern, and antioxidant properties of cactus pear (Opuntia spp.) clones.J. Agric. Food Chem. 53, 442-451. doi:http://dx.doi,org/10,1021/jf048751y.

Strack, D., Vogt, T., Schliemann, W., 2003. Recent advances in betalain research. Phytochemistry 62, 247-269. 
Svenson, J., Smallfield, B.M., Joyce, N.I., Sansom, C.E., Perry, N.B., 2008. Betalains in red and yellow varieties of the Andean tuber crop ulluco (Ullucus tuberosus). J. Agric. Food Chem. 56, 7730-7737, doi:http://dx.doi.org/10.1021/jf8012053.

Tahkokorpi, M., Taulavuori, K., Laine, K., Taulavuori, E., 2007. After-effects of drought-related winter stress in previous and current year stems of Vaccinium myrtillus L. Environ. Exp. Bot. 61, 85-93. doi:http://dx.doi.org/10.1016/j. myrtillus L. Environ. Exp.

Taira, J., Tsuchida, E., Katoh, M.C., Uehara, M., Ogi, T., 2015. Antioxidant capacity of betacyanins as radical scavengers for peroxyl radical and nitric oxide. Food

Chem. 166, 531-536. doi:http://dx.doi.org/10.1016/j.foodchem.2014.05.102

pakahashi, S., Badger, M.R., 2011. Photoprotection in plants: a new light on
photosystem II damage. Trends Plant Sci. 16, 53-60. doi:http://dx.doi.org/ 10.1016/j.tplants.2010.10.001.

Tanaka, Y., Sasaki, N., Ohmiya, A., 2008. Biosynthesis of plant pigments: anthocyanins, betalains and carotenoids. Plant J. 03447. doi:http://dx.doi.org/ $10.1111 / \mathrm{j} .1365-313 \mathrm{X}$.

Tattini, M., Landi, M., Brunetti, C., Giordano, C., Remorini, D., Gould, K.S., Guidi, L., 2014. Epidermal coumaroyl anthocyanins protect sweet basil against excess light stress: multiple consequences of light attenuation. Physiol. Plant. 152. 585-598. doi:http://dx.doi.org/10.1111/ppl.12201.

Trejo-Tapia, G., 2001. Influence of cobalt and other microelements on the production of betalains and the growth of suspension cultures of Beta vulgaris. Plant cell tissue and organ cult. 67, 19-23.

Tsurunaga, Y, Takahashi, T., Katsube, T., Kudo, A., Kuramitsu, O., Ishiwata, M. Matsumoto, S., 2013. Effects of UV-B irradiation on the levels of anthocyanin, rutin and radical scavenging activity of buckwheat sprouts. Food Chem. 141, 552-556. doi:http://dx.doi.org/10.1016/j.foodchem.2013.03.032.
Vogt, T., Ibdah, M., Schmidt, J., Wray, V., Nimtz, M., Strack, D., 1999. Light-induced betacyanin and flavonol accumulation in bladder cells of Mesembryanthemum crystallinum. Phytochemistry 52, 583-592.

Vogt, T. Zimmermann, E. Grimm, R., Meyer, M. Strack, D., 1997. Are the characteristics of betanidin glucosyltransferases from cell-suspension cultures of Dorotheanthus bellidiformis indicative of their phylogenetic relationship with flavonoid glucosyltransferases? Planta 203,349-361

Wang, C.-Q., Chen, M., Wang, B.-S., 2007a. Betacyanin accumulation in the leaves of $\mathrm{C} 3$ halophyte Suaeda salsa L is induced by watering roots with $\mathrm{H} 2 \mathrm{O} 2$. Plant Sci. 172, 1-7. doi:http://dx.doi.org/10.1016/j.plantsci.2006.06.015.

Wang, C.-Q., Liu, T., 2007. Involvement of betacyanin in chilling-induced photoinhibition in leaves of Suaeda salsa. Photosyn thetica 45, 182-188. doi: http://dx.doi.org/10.1007/s 11099-007-0030-4

Wang, C.-Q., Xu, C., Wei, J-G., Wang, H.-B., Wang, S.-H., 2007b. Enhanced tonoplast H +- ATPase activity and superoxide dismutase activity in the halophyte Suaeda salsa containing high level of betacyanin. J. Plant Growth Regul. 27, 58-67. doi: http://dx.doi.org/10.1007/s00344-007-9031-6.

Wang, Y., Zhou, B., Sun, M., Li, Y., Kawabata, S., 2012. UV-A light induces anthocyanin biosynthesis in a manner distinct from synergistic blue + UV-B light and UV-A/ blue light responses in different parts of the hypocotyls in turnip seedlings. Plant Cell Physiol. 53, 1470-1480. doi: http://dx.doi.org/10.1093/pcp/pcs088.

Winter, K., Holtum a, J.M., 2014. Facultative crassulacean acid metabolism (CAM) plants: powerful tools for unravelling the functional elements of CAM photosynthesis. J. Exp. Bot. 65, 3425-3441. doi:http://dx.doi.org/10.1093/jxb/ eru063.

Please cite this article in press as: Jain, G., Gould, K.S., Are betalain pigments the functional homologues of anthocyanins in plants?. Environ. Exp. Bot. (2015), http://dx.doi.org/10.1016/j.envexpbot.2015.06.002 
125 